\title{
AN AUTOMATED HIGH-TEMPERATURE GUARDED-HOT-PLATE APPARATUS FOR MEASURING APPARENT THERMAL CONDUCTIVITY
}

Jerome G. Hust

B. James Filla

James A. Hurley

David R. Smith

National Bureau of Standards

U.S. Department of Commerce

Boulder, Colorado 80303-3328

May 1988

$-(\theta)$

100

456

\#88-3089

1988

C.2 2

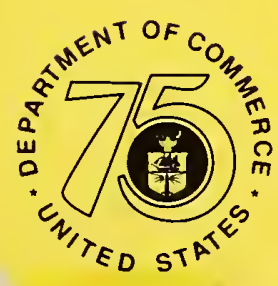





\section{AN AUTOMATED HIGH-TEMPERATURE GUARDED-HOT-PLATE APPARATUS FOR MEASURING APPARENT THERMAL CONDUCTIVITY}

Jerome G. Hust

B. James Filla James A. Hurley David R. Smith

Chemical Engineering Science Division Center for Chemical Engineering National Engineering Laboratory National Bureau of Standards Boulder, Colorado 80303-3328

May 1988

Funded in part by Department of Energy

Oak Ridge National Laboratory

Oak Ridge, Tennessee 37830

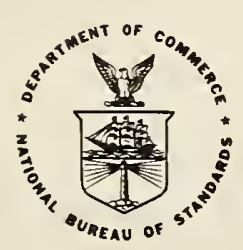

U.S. DEPARTMENT OF COMMERCE, C. William Verity, Secretary 



\section{CONTENTS}

Abbreviations and Symbols Used in This Report.......... iv

List of Figures..........................

List of Tables..............................

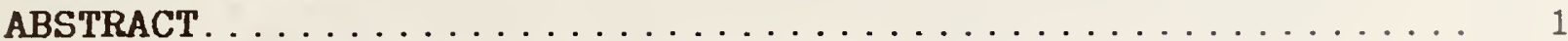

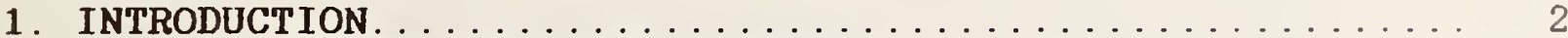

2. DESCRIPTION OF APPARATUS ELEMENTS ............... 3

2.1 Guarded-Hot-Plate Stack and

Environmental Control Elements............... 4

2.2 Mounting of Thermocouples and PRTs................ 6

2.3 System for Data Acquisition and Control........... 6

2.4 Specimen Thickness Spacers.................... 8

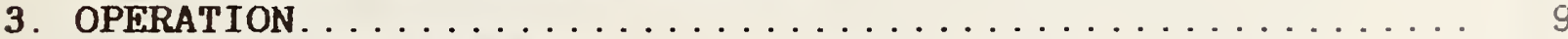

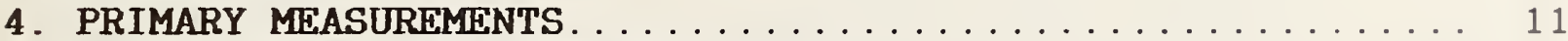

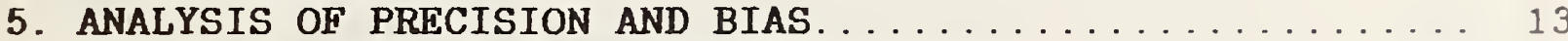

5.1 Analysis of Propagation of Errors................. 13

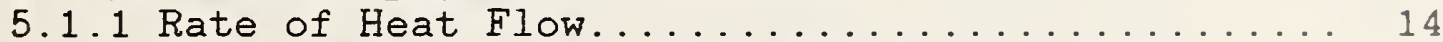

5.1.2 Thickness and Area of Specimen............. 16

5.1.3 Mean Temperature of, and Temperature

Difference Across the Specimen.......... 16

5.2 Error Analysis From Experimental Measurements....... 17

5.2.1 Experimental Reproducibility................ 17

5.2.2 Measurements on a Fibrous Glass Insulation

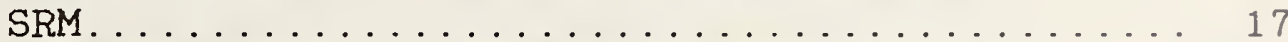

5.2.3 Experiments With Offsets in Temperature of

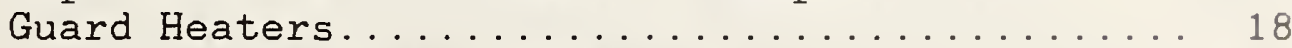

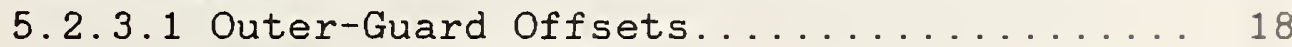

5.2.3.2 Inner-Guard Offsets................ 19

5.2.4 Zero Gradient Measurements................. 20

5.2 .5 Comparative Measurements................. 22

5.2.5.1 Comparison With Results From Round-

Robin Measurement Programs.

5.2.5.2 Comparison With Measurements at an

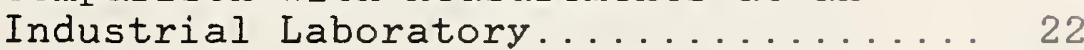

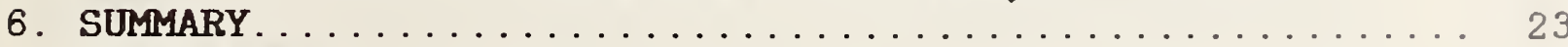

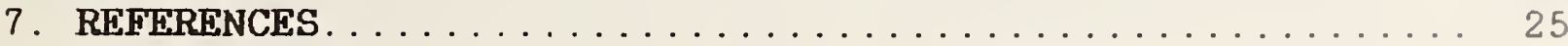

Appendix A: BASIC-Language Computer Program, "HT.GHP". for the High-Temperature Guarded-Hot-Plate Apparatus.

Appendix B: "A Thermocouple Device for Determination of Average Surface Temperature", J.G. Hust and David R. Smith; Journal of Thermal Insulation 11, 96-101 (Oct. 1988).

Appendix C: "A Modified Digital PID Temperature Controller for Thermal Properties Measurements", Jerome G. Hust, B. James Filla and David R. Smith; Journal of Thermal Insulation 11, 102-107 (Oct. 1988). 
Abbreviations and Symbols Used in This Report

$\begin{array}{ll}\text { A } & \text { Area of Metered Section } \\ \text { DTC } & \text { Differential Thermocouple } \\ \text { DVM } & \text { Digital Voltmeter } \\ \text { G } & \text { Gap between Main Heater and Inner Guard } \\ \text { GHP } & \text { Guarded Hot Flate } \\ \text { I } & \text { Electric Current } \\ \text { IG } & \text { Inner (Primary) Guard } \\ \text { K } & \text { Thermal Conductivity } \\ \text { K } & \text { PID Controller Gain } \\ \text { KP } & \text { Proportional Gain Function } \\ \text { KI } & \text { Integral Gain Function } \\ \text { KD } & \text { Derivative Gain Function } \\ \text { KP1, KP2 } & \text { Proportional Gain Parameters } \\ \text { MH } & \text { Main Heater } \\ \text { PRT } & \text { Platinum Resistance Thermometer } \\ \text { Q } & \text { Heater Power } \\ \text { R } & \text { Resistance } \\ \text { RTD } & \text { Resistive Temperature Detector (Thermometer) } \\ \text { S } & \text { Standard Deviation } \\ \text { SP1, Sp2 } & \text { Proportional Gain Bellwidths } \\ \text { SI } & \text { Integral Gain Bellwidth } \\ \text { SD } & \text { Derivative Gain Bellwidth } \\ \text { SRM } & \text { Standard Reference Material } \\ \text { te } & \text { Control-cycle time interval } \\ \text { TC } & \text { Thermocouple } \\ \text { TC } & \text { Temperature of Cold Surface of Specimen } \\ \text { TH } & \text { Temperature of Hot Surface of Specimen } \\ \Delta T 1, \Delta T 2 & \text { Temperature Difference Across Each Specimen } \\ \tau_{I} & \text { Integral Time Constant } \\ \tau_{D} & \text { Derivative Time Constant } \\ \text { V } & \text { Potential difference } \\ \Delta X & \text { Specimen Thickness } \\ \text { ZG } & \text { Zero Gradient } \\ & \end{array}$




\section{List of Figures}

Figure 1. Layout of thermal conductivity stack, guards, shroud and environmental chamber of the NBS high-temperature guarded-hot-plate apparatus...... 27

Figure 2. Block diagram of electronic system for control of temperature and acquisition of data..........2 28

Figure 3. Detailed block diagram of control and data acquisition within the "main apparatus" block

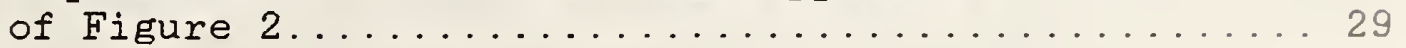

Figure 4. Output emf of gap thermocouple, between inner guard and main heater, vs. time: behavior during initial approach to set-point............... 30

Figure 5. Output emf of gap thermocouple, between inner guard and main heater, vs. time: behavior during stable operation at set-point............. 30

Figure 6. Temperature of outer guard, measured by resistance thermometer, vs. time: behavior during initial approach to set-point.............. 31

Figure 7. Temperature of outer guard, measured by resistance thermometer, vs. time: behavior during

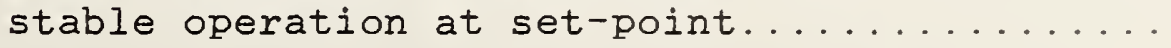

Figure 8. Temperature of top auxiliary heater plate, measured by resistance thermometer, vs. time: behavior during initial approach to set-point.

Figure 9. Temperature of top auxiliary heater plate, measured by resistance thermometer, vs. time: behavior during stable operation at set-point.

Figure 10. Temperature of bottom auxiliary heater plate, measured by resistance thermometer, vs. time: behavior during initial approach to set-point.

Figure 11. Temperature of bottom auxiliary heater plate. measured by resistance thermometer, vs. time: behavior during stable operation at set-point.

Figure 12. Temperature of main heater plate, measured by resistance thermometer, vs. time: behavior during initial approach to set-point. 
Figure 13. Temperature of main heater plate, measured by resistance thermometer, vs. time: behavior during stable operation at set-point........... 34

Figure 14. Main heater power vs. time: behavior during

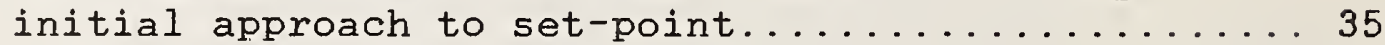

Figure 15. Main heater power vs. time: behavior during stable operation at set-point.

Figure 16. Experimental thermal conductivity, calculated from main heater power, specimen area and temperature gradient, vs. time: behavior during initial approach to set-point.................

Figure 17. Experimental thermal conductivity, calculated from main heater power, specimen area and temperature gradient, vs. time: behavior during stable operation at set-point............. 36

Figure 18. Temperature of thermocouple reference block, measured by resistance thermometer, vs. time.

Figure 19. Thermal conductivity of fibrous glass insulation SRM 1450b compared with certification function

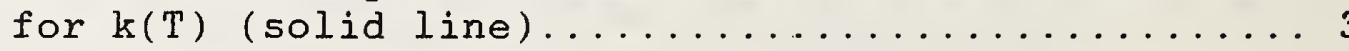

Figure 20. Relative deviations of thermal conductivity of fibrous glass insulation SRM $1450 \mathrm{~b}$, compared with certification function for $k(T) \ldots \ldots \ldots \ldots \ldots . \ldots . \ldots$

Figure 21. Main heater power supplied to specimens of fibrous alumina-silica insulation board, for outer-guard

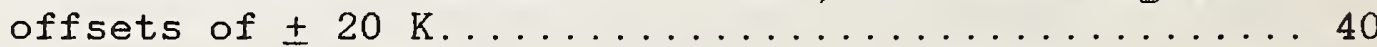

Figure 22. Main heater power supplied to specimens of fibrous glass insulation board for inner-guard offsets of

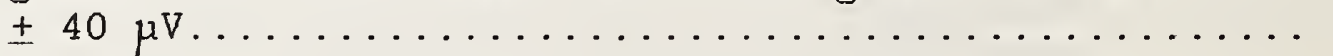

Figure 23. Zero-gradient heat vs. temperature, for fibrous glass insulation board.................. 42

Figure 24. Zero-gradient heat vs. temperature, for fibrous alumina-silica insulation board............. 43

Figure 25. Thermal conductivity round-robin test results for fibrous alumina-silica. The solid curve is calculated from $\mathrm{k}(\mathrm{T})=15.98+0.1003 \mathrm{~T}+3.053 \times 10^{-8} \mathrm{~T}^{3} \ldots$ 
Figure 26. Deviations of thermal conductivity round-robin test results from values calculated for fibrous aluminasilica, using the relation given in caption to

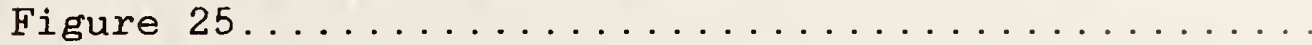

Figure 27. Thermal conductivity round-robin test results for calcium silicate. The solid curve is calculated from $k(T)=70.67+0.01878 T+5.796 \times 10^{-8} \mathrm{~T}^{3} \ldots \ldots 46$

Figure 28. Deviations of thermal conductivity round-robin test results from values calculated for calcium silicate, using the relation given in caption to Figure $27 \ldots 47$

Figure 29. Thermal conductivity of refractory fibrous aluminasilica insulation board (circles), compared to functional correlation of Mitchell [8]..........448

Figure 30. Relative deviation of thermal conductivity data from functional correlation of Mitchell.......449

\section{List of Tables}

Table 1. Typical data summary as printed at end of a measurement sequence................... 50

Table 2. Estimates of random variations and systematic uncertainties in measured quantities at room temperature. 



\title{
AN AUTOMATED HIGH-TEMPERATURE GUARDED-HOT-PLATE APPARATUS FOR MEASURING APPARENT THERMAL CONDUCTIVITY
}

\author{
Jerome G. Hust, B. James Filla, \\ James A. Hurley, and David R. Smith
Chemical Engineering Science Division
National Bureau of Standards
Boulder, Colorado 80303-3328

An automated guarded-hot-plate apparatus was designed and built to meet the requirements of ASTM Standard Test Method C-177 for measuring the thermal conductance of thermal insulation. Apparent thermal conductivity has been measured with this apparatus in the range from 40 to $100 \mathrm{~mW} /(\mathrm{m} . \mathrm{K})$ at mean temperatures from 300 to $750 \mathrm{~K}$, in environments of air and helium, at pressures ranging from atmospheric pressure to roughing-pump vacuum. The apparatus is controlled by a desk-top computer. A thermocouple device of novel design more accurately senses the average temperature over the surface of each heater plate. An improved algorithm for the control sequence leads to more stable heater powers and specimen temperatures. Initially it brings the system rapidly to a temperature setpoint with minimal overshoot. It also permits highly sensitive control of the plate temperatures in later phases of the measurement sequence when thermal stability of the specimen boundaries is very important in measuring the thermal conductivity with high precision. This algorithm has enhanced the performance of both the high-temperature and the low-temperature guarded-hotplate apparatus at this laboratory. The apparatus can be operated at either constant hot-plate temperature or constant heater power.

Overall uncertainties of apparent thermal conductivities at atmospheric pressure are $2 \%$ at $300 \mathrm{~K}$ and $5 \%$ at $750 \mathrm{~K}$ when measuring conductivities in the range from 40 to $100 \mathrm{~mW} /(\mathrm{m} . \mathrm{K})$. The apparatus will be valuable in development of new Standard Reference Materials of low conductivity and for higher temperature ranges, and is being used in comparative interlaboratory measurement programs.

Key words: automated control system; guarded-hot-plate apparatus; high temperature; mean-temperature sensor; thermal conductivity; thermal insulation; thermocouple device. 


\section{INTRODUCTION}

The U.S. National Bureau of Standards (NBS) establishes Standard Reference Materials (SRMs) needed to improve accuracy in measurement of physical properties. Within NBS the Center for Chemical Engineering (CCE) has helped to develop SRMs of thermal resistance for over twenty years. During the past ten years CCE helped establish SRMs for thermal insulation at temperatures from $100 \mathrm{~K}$ to $330 \mathrm{~K}$. As a result of this effort CCE established two insulation SRMs, fibrous glass board SRM 1450b [1-5], and fibrous glass blanket SRM 1451[6], in cooperation with the NBS Center for Building Technology. The low-temperature data for certifying these SRMs from CCE were obtained with a guarded-hot-plate apparatus designed to be used at ambient and low temperatures. This apparatus has been described by Smith, Hust, and Van Poolen [7].

Both industry and NBS have for several years recognized the need for thermal insulation SRMs for use at higher temperatures, but limited funds and manpower delayed the start of this effort until insulation SRMs for the building industry were completed. Several years ago CCE began to design and construct a guarded-hotplate apparatus capable of measuring materials having apparent thermal conductivities in the range of about 20 to $200 \mathrm{~mW} /(\mathrm{m} \cdot \mathrm{K})$ and for temperatures ranging from room temperature to about $750 \mathrm{~K}$.

This apparatus has been completed and tested to establish its precision and bias. The tests included determining the thermal conductivity $[\mathbf{8 , 9 ]}$ of SRM $1450 \mathrm{~b}$ fibrous glass insulation board at temperatures from 300 to $350 \mathrm{~K}$ and measurement of two candidate insulation SRMs for high temperatures. These measurements use double-sided heat flow as well as single-sided [10] heat flow; both small and large temperature gradients; runs with temperature offsets on the primary and secondary guards; environments of different gases such as ambient air, dry air, dry nitrogen, argon or helium; and investigations of the effect of drift of the specimen temperature. The results of these measurements, along with comparisons to previously published data, are used to assess the precision and bias of the new apparatus.

Ideally a guarded-hot-plate (GHP) apparatus should produce conditions of stable and straight-line flow of heat from a source of known power. The entire output of this source should flow through, and along a direction normal to, a known or "metered" area of the surface of a specimen. For practical reasons a matched pair of specimens is used, sandwiching the thermally guarded, main heater plate, and equally sharing the power. Stably controlled, cooled surfaces sink the heat energy. Measurement of the temperature gradient along the direction of heat flow and within the metered area of the specimen then allows one to compute the thermal conductivity as the ratio of heat flux (time rate of heat flow per unit area) to temperature gradient. Additional heater plates permit changing the mean temperature of the specimen independently of the temperature gradient, which is' established by the main heater plate. The collection of heater plates, specimens 
and cooling plates is called the "stack".

The major task of the designer of a GHP apparatus is to approach as closely as possible the ideal conditions described above. Measuring the true gradient within the specimen, ensuring straight-line flow of heat, and avoiding the loss of heat produced by the metered heater or the introduction of extraneous heat flow through the metered area of the specimen, can be particularly challenging. When measuring rate of heat flow through a material designed to be a good insulator, it is obviously difficult to insulate such a specimen to prevent loss of heat! Establishing within the specimen a mean temperature that is close to the ambient temperature will minimize errors in measuring the rate of heat flow through the specimen. However, contact resistance between the heater plates and the specimens is a source of error when measuring specimens of relatively high conductance. While we may consider avoiding this problem by mounting the thermocouples or other temperature sensors directly on the surface of the specimen, it is often desirable not to change the surface of the specimen by making grooves for the sensors or introducing adhesive material to hold the sensors.

The initial design of the high-temperature GHP apparatus was guided by the following criteria: (a) the size of the hot plate should be typical of those commonly in use, (b) the temperature range of the apparatus should be large enough to satisfy a significant need but not so large as to delay its timely completion, and (c) the apparatus should be totally automated both to control the measurement process and to acquire the data. A logical extension of item (c) was to construct the system for control and data acquisition in such a way that it could be used to operate the previously described low-temperature GHP system. The low-temperature apparatus was rewired to exploit the advantages of the automated control apparatus. It has been operated successfully to measure thermal insulation SRM 1450b [3], having a thermal conductivity of 40 to $60 \mathrm{~mW} /(\mathrm{m} \cdot \mathrm{K})$, while checking out the proper operation of the automatic control system.

\section{DESCRIPTION OF APPARATUS ELEMENTS}

This GHP apparatus is consistent with the specifications of ASTM Standard Test Method for "Steady-State Heat Flux Measurements and Thermal Transmission Properties by Means of the Guarded-HotPlate Apparatus" (C 177-85) [8]. It differs from the low-temperature apparatus [7] only in the materials used in its construction and in the diameter of its measurement stack. The stack elements of the GHP apparatus and the associated environmental control components are illustrated in figure 1. Figures 2 and 3 show block diagrams of the electronic system for control and data acquisition. For those who may wish to take advantage of the developed program, written in BASIC language, Appendix A contains a listing of the entire computer software package that completes the automation of the system. 


\subsection{Guarded-Hot-Plate Stack and Environmental Control Elements}

The stack, shown in figure 1, consists of the following elements from the bottom to the top: bottom cold plate, bottom heater offset insulation, bottom auxiliary heater plate, bottom specimen, main and inner guard heater plate assembly, top specimen, top auxiliary heater plate, top heater offset insulation, and top cold plate. The inner guard heater plate, surrounding the main heater plate, is also referred to as the primary guard. A cylindrical outer, or secondary, guard surrounds the stack. Alumina, with its high melting point and relatively high thermal conductivity for an insulating material, was chosen as the material for the outer guard and heater plates. The 25-mm thick sintered-alumina heater plates, having masses of $3.2 \mathrm{~kg}$, and the 6-mm thick copper cold plates, are circular disks $25.4 \mathrm{~cm}(10.0 \mathrm{in})$ in diameter. A $25-\mathrm{mm}$ thickness of calcium silicate heater-offset insulation permits the use of a wide range of specimen temperature differences within the limitations of the power supplies.

The heater plates and outer guard were fitted with the necessary sensors to measure and control their temperatures. NicrosilNisil* thermocouples, resistant to the effects of high temperatures, are used to sense the temperatures of the heater surfaces adjacent to the specimen surfaces and to control the temperature difference across the gap between the metered region and the primary guard. The sensitivity of this alloy increases from 28 to 38 $\mu V / K$ over the range from 300 to $800 \mathrm{~K}$. Sensitive control of each heater plate and each outer guard is achieved by mounting platinum resistance thermometers (PRTs), encased in a refractory material, on the heater assembly. Each of the wire leads for the heaters and temperature sensors was thermally anchored to its associated plate and was wrapped around and cemented to a thermal anchoring post in the midplane of the vertical outer surface of the heater plates. Each wire was then wrapped into a coil about $3 \mathrm{~mm}$ in diameter between the edge of the plate and the base plate of the stack. The base plate is water-cooled to keep it near room temperature.

*Trade name is given here purely for identification purposes and does not imply endorsement by NBS. Similar products of other manufacturers may work as well or better. 
Each cold plate comprises two copper disks soldered together. Machined next to each other in the inner surface of each disk are two symmetric spiral grooves, connected at the center. These form a counterflow heat exchanger for the entering and exiting streams of coolant, and minimize the temperature differences within the cold plates induced by the temperature difference between the two streams. The coolant lines were connected to the top and bottom cold plates in a parallel arrangement so that the rate of flow can be controlled by a separate valve for each plate. Water from the domestic supply is the coolant, but any other suitable coolant could be used, such as chilled alcohol from a refrigerated bath.

Each stack heater plate (top, main and bottom) was constructed from two alumina disks, one of which was grooved. The grooves were cast as two adjacent spirals connected at the center of the plate. This design is a convenient way to distribute the heating power uniformly over the heater area. It also minimizes the area enclosed between the two leads, which minimizes any inductive coupling to nearby sensor circuits in case it is desired to power the heater with ac power. Platinum heater wire was held within the grooves with refractory cement, which also holds the two plates together. The thicknesses of the disks and depth of the grooves are such that the plane of the heater wire lies midway between the top and bottom surfaces of the assembled heater plate.

To make the main heater-inner guard plate, the centers of two plates identical to those used for the auxiliary heaters were cut out, with diameters half of that of the whole plate. The central core became the main heater, and the annulus, the inner guard.

The outer guard is a $4.6 \mathrm{~kg}$ circular, cylindrical shell of cast alumina $6 \mathrm{~mm}$ in thickness and $20 \mathrm{~cm}$ in length surrounding the stack from the level of the bottom auxiliary heater plate to that of the top auxiliary plate. Its inner diameter is $2.5 \mathrm{~cm}$ larger than the diameter of the stack plates. Platinum heater wire was wrapped non-inductively on the outside of this guard and cemented in place.

An aluminum shroud surrounds the stack and contains the loose-fill insulation which limits the loss of heat from the stack. The shroud is $46 \mathrm{~cm}$ high and $58 \mathrm{~cm}$ in diameter. Its position on the water-cooled base plate helps keep it near ambient temperature.

Surrounding the entire stack/shroud assembly is a stainlesssteel environmental-control chamber with an O-ring seal on its bottom edge. This chamber allows us to introduce different gases or to evacuate the space around the stack to a vacuum of about 7 $\mathrm{Pa}(50 \mu \mathrm{m})$. The type of loose-fill insulation (exfoliated mica) used around the stack has a large surface-to-volume ratio and is a good moisture adsorbent; this makes it difficult to achiovo pressures of less than $10 \mathrm{~Pa}$ in a short time. 


\subsection{Mounting of Thermocouples and PRTs}

To sense the absolute temperature needed to obtain the thermal conductivity, with minimum distortion of the isotherms and heat flux lines within the specimens, thermocouples are used at the centers of the heater plate surfaces. To control the desired plate temperatures, four-lead PRTs are used as sensors in the control circuits.

One PRT was cemented into a slot machined in the center of the outer edge of each auxiliary heater plate. Another PRT was similarly mounted on the metered (main) plate within the gap between it and the inner guard. The PRT for the outer guard was cemented to its outside surface.

A unique three-lead thermocouple combination was designed to measure accurately the average temperature over the surface of each heater plate. This three-lead device results in significantly more accurate measurements of the average temperature of a surface compared to those obtained with a single thermocouple. See Appendix B for a more detailed discussion of the theoretical basis, construction and comparative performance of this device.

The temperature difference across the gap between the metered plate and the primary guard is controlled with a twenty-element thermopile. Ten thermopile elements (the first half) lie on the top surface of the plate and the other ten (the second half) are on the bottom. Control is exercised using the whole thermopile but a third lead is connected to the junction between the two halves so that the top and bottom thermopiles can be monitored separately. The junctions of the thermopile are uniformly distributed along the circumference of the gap at locations alternating between its opposite sides, approximately $4 \mathrm{~mm}$ from the edges of the gap.

\subsection{System for Data Acquisition and Control}

The system for acquiring data and controlling temperature and power is composed of two principal parts: (a) the computer (with associated multiprogrammer, interface cards and software) and (b) power supplies and digital voltmeters (DVMs). The schematic arrangement of these components is shown in figures 2 and 3 .

The system contains five power supplies for the heaters in the five plates and guards, a single current supply for the five PRTs on the heater units, and six digital voltmeters. Three DVMs respectively read the potential differences across the PRTs sensing the temperatures of the main heater plate and two auxiliary heater plates. A fourth DVM monitors the emf from the gap thermopile used to maintain equality of temperature between the main heater and primary guard. The fifth DVM reads the emfs for the thermocouples sensing various plate temperatures, as well as the output from the PRT used to sense the temperature of the outer guard. 
Each thermocouple emf is selected for reading by the computer through the use of two switching-relay modules having low levels of parasitic thermal emfs. Each switching module has ten relays, i.e., ten double-pole switch positions. These relays are also used to determine the currents in the PRTs and main heater by allowing the fifth DVM also to read the potential drop across a standard resistor in each circuit. The power delivered to the main heater is calculated from values of the current in and the potential drop across the main heater resistance. This potential difference is measured with the sixth DVM.

Four of the five power supplies for the heater plates are capable of a maximum output of $55 \mathrm{~V}$ and $5 \mathrm{~A}(275 \mathrm{~W})$. For maximum power transfer the optimum heater resistance is therefore $11 \Omega$

The actual heater resistances, ignoring lead resistances, are:

(a) main heater, $3.7 \Omega$;

(b) top and bottom auxiliary heaters, $14.3 \Omega$;

(c) inner guard, $10.2 \Omega$; and

(d) outer guard, $11.9 \Omega$.

The outer guard requires a power supply of at least $75 \mathrm{~V}$ to supply the power needed at the highest temperatures of operation. The low resistance of the main heater is not a problem, because it is thermally well shielded against loss of heat and requires only a low power even at high temperatures.

The PRT current supply is manually set to the optimum current as calculated by the computer for each set of runs. The optimum current for the temperature range of this apparatus varies from 0.6 to $1.5 \mathrm{~mA}$. At room temperature the resistance of each PRT is $100 \Omega$.

Thermocouple emfs and the power to the main heater are measured by two DVMs having a precision of $61 / 2$ digits $(0.01 \mu \mathrm{V})$. The four DVMs used to measure the gap thermopile emf and the PRT voltages on the main heater and two auxiliary heaters have a precision of $5 \mathrm{l} / 2$ digits $(0.1 \mu \mathrm{V})$. The analog-to-digital conversion card used to measure the outer guard PRT voltage has a precision of $31 / 2$ digits. The heater control circuits for all but the main heater provide for changes in power supply voltage as small as $10 \mathrm{mV}$. The control circuit for the main heater can change its output by values as small as $1 \mathrm{mV}$. The low-thermal-emf relay modules are designed to provide selector switches free of spurious emfs down to levels of $20 \mathrm{nV}$. 
The core of the control system is a modified digital PID (Proportional, Integral and Derivative) controller of novel design and based in software residing in a scientific personal computer. Its algorithm for control of the power supplied to the heater plates provides for vigorous heating and rapid approach to the desired temperature when the controlled temperature is far from the set point, yet gives very sensitive control when the controlled temperature is near the set point. These features are a result of variable controller gains. The control algorithm is described in detail in Appendix C.

\subsection{Specimen Thickness Spacers}

Some specimens to be measured compress under the weight of the overlying plates, the thickness of the specimens then varying with time due to creep. To slightly compress these specimens, and thereby assure good thermal contact between them and the adjacent heater plates, the plates are held apart with rigid spacers cut from stainless steel tubes. These spacers have walls $0.25 \mathrm{~mm}$ thick and are shorter than the specimen thickness by about $0.2 \mathrm{~mm}$. Three equally-spaced notches are cut into the outer periphery of each specimen to hold the spacers between the outer edges of the inner guard and the auxiliary heaters. Each spacer is cut to the desired length within a tolerance of $0.025 \mathrm{~mm}$. The tubes are filled with refractory fibrous insulation, to reduce the possibility of radiative and convective heat transfer within their interiors. These modes of heat transfer would shunt the conductive heat transfer through the specimens.

Although the tubes thermally connect the outer edges of the inner guard and auxiliary heaters, their presence is necessary to preserve constancy of the thickness of compressible specimens. The shunting effect of the spacer tubes is minimized by their thin walls, fibrous inner packing and poor (point) contact with the ceramic plate surfaces. Their position at the outer margins of the stack minimizes the effect of their shunting on the direction of flow lines of the metered heat through the specimens. 


\section{OPERATION}

After the specimens have been prepared and installed, flow of coolant to the cold plates is initiated. The power supplies, DVMs, multiprogrammer and electronic relay modules are turned on and the computer program started. During the initial part of the run the computer prompts the operator for the time and date, identification and characteristics (mass and thickness) of the specimen, the environmental gas, and run information. This last item includes the values of temperatures to be maintained at the surfaces of the specimens, and whether flow of heat is desired to be single-sided (through either specimen, as selected) or double-sided (through both specimens). The operator may choose whether the system should be controlled at constant temperature or at constant power. Up to nine runs can be programmed at one time, each with unique conditions of operation.

After the operator has keyed in the information, the computer begins automatically controlling the experimental conditions and acquiring data. During this automated sequence, the operator may view on the computer monitor various plots showing the behavior of any of the controlled circuits as a function of time. In addition, the operator may change setpoint temperatures and other control parameters during the run.

Each measurement sequence is divided into three phases. During phase I, the desired temperatures are established at the surfaces of the heater plates facing the specimens, using for temperature control the temperatures sensed by the PRTs. These temperatures are compared to the thermocouple temperatures of the main and auxiliary heater plates during Phase I. If a difference of more than $10 \mathrm{mK}$ exists, the control setpoints are adjusted so that the desired temperatures are obtained as sensed by the thermocouples on the plate surfaces. When these temperatures and the main heater power have stabilized within preset limits, the sequence enters Phase II.

During this second phase thermal conductivity is computed every three minutes. After the first thirty minutes of Phase II the main heater power and the calculated thermal conductivity are examined for stability within specified limits, allowing entry into the third phase if the stability criteria are met.

In Phase III the operator is allowed to plot on a dot-matrix printer a permanent record of the history of the various plate temperatures, the power to the metered heater, or the thermal conductivity calculated as successive 3-minute time averages. Then, if the operator does not intervene the computer automatically averages the last 30 minutes of data for storage on disk. Data from any longer interval may be averaged if the operator so chooses. All of the data from Phase II is saved to disk for lator re-analysis as desired. 
Table 1 shows the data printed out at the end of a typical experimental sequence, using a specimen of microporous fumed silica insulation board. A summary of the conditions of the experiment is given. Also included are final values of measured temperatures and temperature differences, heater power, and thermal conductivity for the experiment. Statistical measures of the random variations of these quantities, averaged over the interval of stability at the end of the run, are listed. Corrected data for sample thickness and main plate area result from considering thermal expansion of these elements resulting from heating them from room temperature to the temperature of measurement; the main plate area is also adjusted to include half the sap area.

Both Phase I and Phase II have predetermined maximum time limits. The maximum time limit for Phase $I$ is 5 hours and that for Phase II is 10 hours. The combined maximum time limit for the whole experiment is 11 hours. These limits force the run to be completed after a definite time interval in cases where the stability requirements are too stringent in the control software.

Typical graphical outputs that may be viewed during the measurement sequence and printed at the end of the run are given in figures 4 through 18. They illustrate conditions during measurement of (arbitrarily chosen) microporous fumed silica insulation board and correspond to the information given in Table 1. The even-numbered figures 4 through 16 show the behavior of the system during the initial approach to the respective setpoints of the various heater plates. The odd-numbered figures 5 through 17 depict the behavior of the system during final stable operation at the respective setpoints. Figure 18 gives the temperature history of the thermocouple reference block.

The even-numbered figures 4 through 16 illustrate several noteworthy aspects of the operation of the control system using the PID algorithm described in Appendix C. For example, figure 12 shows that the temperature of the main heater was raised by about $110 \mathrm{~K}$ in less than $30 \mathrm{~min}$ without overshooting the setpoint. Figure 4 shows that during the same interval the output emf of the gap thermocouple went to zero in about $35 \mathrm{~min}$, also without overshoot. (As the emf of this differential thermocouple went to zero, the inner guard temperature caught up with that of the main heater.) The temperatures of the top and bottom auxiliary heater plates took a little longer to reach their setpoints, about $55 \mathrm{~min}$ (figs. 8 and 10).

Figure 7 reveals that a less-sensitive level of control was used for the outer guard: the fluctuations in its temperature are about $\pm 0.3 \mathrm{~K}$. This is quite acceptable since the temperature of the outer guard is only relatively loosely coupled to that of the measurement stack. 
Figure 14 shows that the power to the main heater plate initially called for by the control algorithm was about $60 \mathrm{~W}$ for the first $25 \mathrm{~min}$, and then dropped rapidly down to about $4 W$. Thereafter the power decreased gradually to the final stable value of $2.4 \mathrm{~W}$ (fig. 15). This represents a range of about one and a half orders of magnitude of power. In about $60 \mathrm{~min}$ a value of heater power very near the final stable value is reached (a considerably longer time is of course needed for the whole experimental stack to come to its stable state). It is also noteworthy that the power fluctuation amplitude gradually decayed to relatively small values $( \pm 0.2 \mathrm{~W}$ ) near the end of the trace in figure 15. This behavior is a direct result of the PID control algorithm, when operating in the constant-temperature mode.

Figure 13 depicts typical behavior of the final temperature of the main heater plate during stable operation at the setpoint. The amplitude of the temperature fluctuations is about $\pm 5 \mathrm{mK}$.

According to figure 16, the experimental thermal conductivity is determinable to within about $\pm 10 \%$ after about $35 \mathrm{~min}$. This is cited not to claim any ability to determine thermal conductivity accurately within this short an interval of time, but rather to illustrate how rapidly the control algorithm brings the system to the setpoints desired.

The data illustrated in figure 17, averaged every three minutes over the last sixty minutes of the run, gave a value for thermal conductivity of $22.07 \mathrm{~mW} /(\mathrm{m} . \mathrm{K})$, with a standard deviation of $0.028 \mathrm{~mW} /(\mathrm{m} . \mathrm{K})$. This represents a relative deviation of $0.12 \%$, which is typical behavior for most temperatures of operation.

\section{PRIMARY MEASUREMENTS}

The measurements required for the computation of average thermal conductivity $k$ at a temperature $T$ are governed by the defining equation,

$$
k(T)=Q \Delta X /(A \Delta T),
$$

where $Q$ is the rate of flow of heat through the metered portion of a single specimen, $\Delta X$ is the average thickness of the specimen. A is the metered area and $\Delta T$ is the mean temperature difference across the specimen. The value of $T$ associated with the computed value of $k$ must be carefully defined, as will be discussed below.

The normal mode of operation of the GHP apparatus involves flow of heat through two sides of the main heater plate through two matched specimens. This is referred to as the double-sided mode and results in an average value of $k$ for the two specimens We can also adjust the temperature of one of the auxiliary heaters to match closely that of the main heater, thus minimizing the flow of heat through the specimen in that direction. This is referred 
to as the one-sided mode [10] of operation and results in the $k$ value for the other specimen, through which most of the heat flows. To accommodate both modes of operation, the following equation is used to calculate thermal conductivity:

$$
k=Q \Delta X /\left(A\left(\Delta T_{1}+\Delta T_{2}\right)\right) \text {, }
$$

where $Q$ is the total power generated by the metered heater, flowing through both specimens, and $\Delta \mathrm{T} 1$ and $\Delta \mathrm{T} 2$ are respectively the temperature differences across the two specimens. In the special case where either $\Delta \mathrm{T}_{\mathrm{i}}$ is zero, this reduces to eq(1). When both $\Delta T^{\prime}$ s are equal we obtain the same expression as that for the case of one specimen of area $2 \mathrm{~A}$, conducting a power $\mathrm{Q}$.

For the one-sided mode either $\Delta \mathrm{T} 1$ or $\Delta \mathrm{T} 2$ is small but this small value can be either positive or negative. The specimen with the smaller $\Delta T$ is sometimes referred to as the "back" specimen because its purpose is to minimize the flow of heat from the main heater plate in the "back" direction, away from the specimen being measured.

The term "average thermal conductivity" has been used here to denote two types of averaging. First, in the double-sided mode the arithmetic average value of $k$ for the two specimens is obtained. No information on either specimen individually can be calculated from measurements in this mode. Second, the value of $k$ averaged with respect to temperature from the cold-face temperature, Tc, to the hot-face temperature, $\mathrm{TH}$, is obtained in either the single- or double-sided mode. As a rule of thumb, if this temperature difference $\Delta T$ between the two faces is less than $10 \%$ of the absolute mean temperature of the specimen, ( $\mathrm{Tc}+\mathrm{TH}) / 2$, the value of $k$ can be assigned to the mean temperature with an error of less than 0.1\%. This is immeasurable, given the current state of the art in measuring thermal conductivity. If $\Delta \mathrm{T}$ is significantly larger, the $k$ value obtained may be measurably different from the true $k$ value corresponding to that mean temperature. In such cases, the integral method of analysis as described by Hust and Lankford [11] is used to obtain $k$ as a function of temperature.

There is also a third type of averaging involved in the calculation of $\mathrm{k}$ using this apparatus, $i . e$. , an average over $t i m e$. This is done to reduce the effect of the imprecision of the individual readings. The minimum time interval for this averaging process, occurring in Phase II, has been set to $30 \mathrm{~min}$. During this period values of temperature are obtained every 3 min; thus the time-averaged value of $T$ involves a minimum of 10 readings. The values of potential difference and current needed to obtain the power, $Q$, are read every $5 \mathrm{~s}$, so the time-averaged value of power involves a minimum of 360 readings. 


\section{ANALYSIS OF PRECISION AND BIAS}

The apparatus is designed to determine heat flow through the specimens under a prescribed set of boundary conditions; from the heat flow one can subsequently calculate the apparent thermal conductivity, $k$, when applicable. The analysis of errors (uncertainties) will be directed toward determining the imprecision and systematic uncertainty (bias) of $\mathrm{k}$. Errors due to the inapplicability of the definition of $k$ for a particular material and to inhomogeneity within the material will be ignored. Only uncertainties in experimental control and measurement will be considered.

The imprecision and bias of this apparatus were analyzed by two methods: (a) from a propagation-of-error analysis of the imprecision and bias inherent in the measurement of each primary variable, and (b) from the measurement of standard reference specimens. The propagation-of-error analysis requires detailed knowledge of the potential errors of each measuring instrument as well as knowledge of any existing deviations from unidirectional heat flow and from stability over time. It requires a vast amount of experimental effort to produce estimates of imprecision and bias that are reliable. The measurement of standard reference specimens for estimating imprecision and bias is easier, but for temperatures above $350 \mathrm{~K}$, no standard reference specimens of thermal insulation exist at the present time.

\subsection{Analysis of Propagation of Errors}

The error-propagation formula for the defining equation takes the form

$$
S_{k}{ }^{2}=\left(\frac{\partial K}{\partial T_{M}} S T_{M}\right)^{2}+\left(\frac{\partial k}{\partial Q} S Q\right)^{2}+\left(\frac{\partial K}{\partial A} S_{A}\right)^{2}+\left(\frac{\partial k}{\partial D X} S D X\right)^{2}+\left(\frac{\partial k}{\partial D T} S D T\right)^{2} .
$$

In this relation, $S$ is a standard deviation, the subscript $k$ represents thermal conductivity, TM is mean specimen temperature, $Q$ is heater power, $A$ is area of the metered (main) heater, DX is the specimen thickness, and DT is the temperature difference through the specimen. The heater power $Q$ is obtained from the product of potential difference and current through the main heater. Strictly speaking only normally distributed errors (including imprecisions) propagate according to this formula but the errors due to biases will be propagated using the same formula for simplicity. That is, each term of the form of $\mathrm{S}^{2}$ in eq(3) will represent either S2IMP or S2BIAS. The imprecisions and biases of the primary variables are estimated using $95 \%$ confidence intervals (two standard deviations) in the sections below. These estimates and the resulting estimated imprecision and bias for $k$ are summarized in Table 2. 


\subsubsection{Rate of Heat Flow}

The heat power $Q$ through the specimen(s) is equal under conditions of stable and unidirectional flow to the power $P=V_{H} I_{H}$ supplied by the heater to the metered area. The potential difference across the main heater is $V H$ and the main heater current is IH. The uncertainty in $Q$ is the most difficult uncertainty to estimate of all those for factors determining $k$. This difficulty arises not so much through inaccurate measurement of $V H$ and $I H$ as through establishing a flow of heat through the specimens that is both stable and unidirectional along the longitudinal axis of the stack.

The value of $V_{H}$ is measured directly but IH is obtained from a measured potential difference VSTD across a standard resistance RSTD in series with, and carrying the same current as, the main heater resistance: $\quad$ IH $=$ VSTD/RSTD. Thus the uncertainty in $Q$ depends on the uncertainty in the values of $V H$, VSTD and RSTD.

The uncertainty in the value RSTD of the standard resistance is stated in its certificate of calibration and is of the order of parts per million. The two values $V H$ and VsTD have negligible instrumental bias because the DVM's used to measure them are calibrated. The instrumental imprecision of these potential differences is estimated as $10^{-5}$, or $0.001 \%$, when measuring power, values of potential typically ranging from 0.1 to $6 \mathrm{~V}$. For thermocouple emfs of $10 \mu \mathrm{V}$ the imprecision is $0.2 \%$.

One possible systematic error in $V H$ depends on where the potential leads are attached to the main heater resistance; for the corresponding potential difference to be correct the heat flowing through the metered area must be precisely the energy dissipated in that portion of the heater resistance wire between the potential taps. If for example the potential leads were attached too close to the center of the metered resistance wire then more heat would be dissipated within the metered area than would be calculated from the measured potential difference between the leads. This error (bias) is estimated to be less than $0.13 \%$.

In practice a far more serious error in determining $Q$ lies in the assumption of unidirectional heat flow from the main heater through the metered areas of the specimens. If the metered area were surrounded by a guard area at exactly the same temperature then no heat would be lost from the metered area to the guarded area, along the radial direction. The flow of heat would be unidirectional, and along the direction of the symmetry axis of the stack (axial).

Obtaining this condition is attempted by controlling the heater power for the metered area with the output of the differential thermocouple (DTC) bridging the gap between the metered area and the primary guard, as described earlier in sect. 2.1. This DTC contains twenty pairs of junctions to increase its sensitivity to temperature imbalances. The control circuitry 
attempts to regulate the guard heater power so that the output of the DTC is zero. In practice this output randomly deviates from zero with an imprecision of about $\pm 2 \mathrm{mK}$.

An estimate of the effective thermal conductance across the gap yields a value of $85 \mathrm{~mW} / \mathrm{K}$ of imbalance due to conduction through air in the gap. An estimate of the effective radiant heat transfer gives a value of about $40 \mathrm{~mW} / \mathrm{K}$ of imbalance at room temperature, and a worst-case value of about $600 \mathrm{~mW} / \mathrm{K}$ due to radiation (at a mean temperature of $750 \mathrm{~K}$, the highest temperature usable in this apparatus). Convection is made negligible by the use of mineral fiber insulation in the gap. Conduction through the thermocouple wires bridging the gap is also negligible due to their resistivity and small diameter.

For a total value of about $125 \mathrm{~mW} / \mathrm{K}$ of imbalance at room temperature, and a value of $690 \mathrm{~mW} / \mathrm{K}$ at $750 \mathrm{~K}$, the random temperature fluctuation of $\pm 2 \mathrm{mK}$ is found to lead to random heat power fluctuations across the gap of $1.4 \mathrm{~mW}$ at $750 \mathrm{~K}$. For these worst-case conditions of high temperatures and high radiative transfer across the gap as assumed here, powers are at least $2.5 \mathrm{~W}$ even for very good insulators, so these random fluctuations are less than $0.1 \%$ of the heater power. This represents an imprecision of $0.1 \%$ in the apparent thermal conductivity.

There is some evidence for a systematic unbalance of temperature between different points on the main heater, based on information (Table 1) on the emfs from the "top" and "bottom" halves of the control thermopile, each half containing ten elements. These emfs often differ by about $1.0 \mu \mathrm{V}(0.004 \mathrm{~K})$ when operating at temperatures near $300 \mathrm{~K}$ and by about $25 \mu \mathrm{V}(0.07 \mathrm{~K})$ when operating at $750 \mathrm{~K}$. The temperature differences across the gap can be assumed to be nearly equal to these temperature differences, $0.004 \mathrm{~K}$ and $0.07 \mathrm{~K}$. These would indicate, from the sensitivities of $125 \mathrm{~mW} / \mathrm{K}$ at $300 \mathrm{~K}$ and of $690 \mathrm{~mW} / \mathrm{K}$ at $750 \mathrm{~K}$, imbalances in the heater power of $500 \mathrm{~mW}$ at room temperature, and $50 \mathrm{~mW}$ at $750 \mathrm{~K}$, due to loss across the gap.

Typical metered powers are at least $1 \mathrm{~W}$ at room temperature and $2.5 \mathrm{~W}$ at $750 \mathrm{~K}$; the estimated systematic error in power could then be $0.05 \%$ at room temperature and $2 \%$ under worst-case conditions at $750 \mathrm{~K}$. The typical systematic error in power at 750 $\mathrm{K}$ is estimated to be $1.5 \%$.

From data such as those shown in Table 1, under dynamic control the imprecision in power $Q$ is found to be typically $0.2 \%$, and seldom worse than 0.5\%, at room temperature. At $750 \mathrm{~K}$ the imprecision in power rises to typically about $0.5 \%$ and is seldom worse than $0.7 \%$. 


\subsubsection{Thickness and Area of Specimen}

For a given assembly of the stack, the thickness and metered area of the specimen do not vary with time except as they are affected by thermal expansion. Compression of the specimen is limited by the use of spacers. For the conditions of thermal stability under which data are obtained, any thermal expansion taking place within the stack is negligible. Thus the imprecisions of the thickness and of the area are taken to be negligible.

The bias, however, is affected by length measurements performed at room temperature and by the degree of validity of the thermal expansion corrections. Changes in spacer lengths and in the diameter of the metered area are allowed for as the stack is heated to the temperature of measurement. The specimen thickness is estimated to be correct to within $0.08 \mathrm{~mm}$ as determined by the spacer thicknesses, whose lengths are nominally $25 \mathrm{~mm}$. This yields a relative error (bias) of $0.3 \%$. The area of the specimen, including the gap correction, is estimated to be correct to within $1 \mathrm{~cm}^{2}$. For a total metered area of $128.9 \mathrm{~cm}^{2}$ this represents a relative error of $0.8 \%$.

\subsubsection{Mean Temperature of, and Temperature Difference Across the Specimen}

The precision and bias of the temperature difference across each specimen is affected somewhat by instrumentation read-out errors and calibration errors, but primarily by effectiveness of thermal anchoring of the thermocouples, uncertainty in the location and orientation of the effective plane containing the thermocouple beads, and deviations from planarity of the isotherms within the specimen, or equivalently, deviations from rectilinearity of the heat flux lines. Dynamically the imprecision in temperature is affected by the quality of control maintained by the control system.

The domestic water supply is varies by about $0.7 \mathrm{~K}$ during the course of a given experiment, and causes fluctuations of about $\pm 10 \mathrm{mK}$ at the surface of the specimen. This is acceptable.

The instrumentation bias is negligible due to calibration of the instruments. It is estimated to be less than $0.01 \%$ of the temperature. Since the thermocouple calibration is based on an equation the calibration imprecision is negligible. Calibration bias is estimated to be less than $0.04 \%$. Errors in the temperature difference caused by inadequate thermal anchoring of the thermocouples are difficult to assess analytically. This bias is difficult to separate from errors caused by heat loss as described in the next section. The bias caused by uncertainty of the thermocouple measurement plane is estimated to be $0.6 \%$ of the temperature difference. Thus the total bias in mean temperature, and also of the temperature difference through the specimen, 
summed in quadrature, is estimated to be $0.85 \%$. From data such as that shown in Table 1, summarizing the experimentally observed data and their statistical variation under dynamic control over the time used to calculate the thermal conductivity, the imprecisions due to dynamic variations in $T$ and in $\Delta T$ are found to be $0.02 \%$. Combined with the imprecision in reading the TC emfs, this yields $0.1 \%$.

Combining in quadrature the dynamic imprecisions in temperature, power, thickness, area (the last two having negligible imprecision) and temperature difference, we find the imprecision in thermal conductivity to be $1 \%$ at $300 \mathrm{~K}$ and $5 \%$ at $750 \mathrm{~K}$.

\subsection{Error Analysis from Experimental Measurements}

Several different experimental comparisons have been made to assess the experimental imprecision and bias of this hightemperature GHP apparatus.

\subsubsection{Experimental Reproducibility}

Thermal conductivities were repeatedly measured for a claybonded fibrous alumina-silica thermal insulation board under consideration for adoption as a high-temperature SRM. The imprecision of these results with removal and re-installation of the specimens in new orientations is $0.5 \%$ at $300 \mathrm{~K}$.

\subsubsection{Measurements on a Fibrous Glass Insulation SRM}

One series of comparison measurements of thermal conductivity was made on a pair of specimens of SRM $1450 \mathrm{~b}$ fibrous glass insulation board from a lot certified in 1982 [3]. This thermal resistance SRM has a nominal thickness of $2.54 \mathrm{~cm}$ and a density of $137 \mathrm{~kg} / \mathrm{m}^{3}$. This SRM was established on the basis of measurements made here in 1980 using the earlier low-temperature guarded-hot-plate apparatus as well as those made at ambient temperature by NBS in Gaithersburg [1,2,4,5]. The experimental data obtained for thermal conductivity as a function of temperature was compared with values obtained from the polynomial published in the SRM certification document [3].

Figure 19 shows thermal conductivity data obtained with the high-temperature guarded-hot-plate apparatus and at temperatures from 300 to $345 \mathrm{~K}$, compared with the functional dependence from the fibrous glass SRM certificate. The deviation plot for these data, shown in figure 20, reveals a slight systematic bias between the data points and the thermal conductivity function, but the agreement between data and function is better than $1.8 \%$, about the same as the imprecision projected from the above error-propagation analysis. 


\subsubsection{Experiments with Offsets in Temperature of Guard Heaters}

Experiments were performed in which the temperature of either the outer guard or the inner guard was deliberately controlled at a setpoint different from the normal one. This condition of operation is called a guard offset. It allows us to assess the effects on measured thermal conductivity of small random or systematic deviations of a guard from its setpoint, which may occur during a normal experiment.

\subsubsection{Outer-Guard Offsets}

In the course of experiments on fibrous alumina-silica insulation board, the outer guard was controlled at offsets of $\pm 20 \mathrm{~K}$ while operating at a mean specimen temperature of $573 \mathrm{~K}$. The power supplied to the main heater, which is proportional to the thermal conductivity, is plotted in figure 21 for each outerguard offset.

When the outer guard is lower in temperature than the mean specimen temperature ( $-20 \mathrm{~K}$ offset), under stable control the main heater is required to supply slightly more power in response to the resulting loss from the stack, and conversely. For this effect the sensitivity coefficient is $-0.02 \mathrm{~mW} / \mathrm{K}$. Thus if the outer guard temperature were not equal to the mean specimen temperature, the error in metered power passing through the specimens would be $0.02 \mathrm{~mW} / \mathrm{K}$ of offset. This offset would produce an error of $0.05 \%$ in the value of $k$ for a $1 \mathrm{~K}$ offset when measuring a low-conductivity insulation having a (typical) k-value of $40 \mathrm{~mW}$.

For insulation materials of higher conductivity, requiring higher heating power to maintain the desired gradient, the error due to such an outer guard offset would be less at the same mean temperature. In this case the temperature distribution within the elements of the stack would still be the same, and so conductive losses from the stack to the surroundings would be unchanged, while being a smaller fraction of the required increased power.

Figure 7 shows that the random fluctuations in temperature of the outer guard under stable control are $\pm 0.4 \mathrm{~K}$. If the main heater could follow the outer guard temperature as rapidly as the fluctuations occur, the resulting power fluctuation would be $\pm 0.01 \mathrm{~mW}$. The heat capacity of the heater plate however does not allow it to fluctuate at the frequency observed in figure 7 .

We believe that any outer-guard offsets occurring during normal operation at temperatures near room temperature are much less than the deliberately produced offsets. However, at temperatures near the upper end of the range of operation of this apparatus, it is possible that there could be offsets in the temperature of the outer guard of about $10 \mathrm{~K}$. This is based on the observation of differences between the temperature of the 
controlling PRT and the measuring thermocouple of the top and bottom auxiliary heater plates, when operating at $750 \mathrm{~K}$.

\subsubsection{Inner-Guard Offsets}

During experiments on fibrous alumina-silica, and at a mean specimen temperature of $573 \mathrm{~K}$, offsets were made to occur in the output emf of the gap thermocouple between the main heater plate and the inner-guard heater (inner-guard offset). This was done by altering the control software so as to shift the inner-guard setpoint from its usual value of $0 \mu \mathrm{V}$. The power supplied to the main heater for each of the two inner-guard offsets is plotted in figure 22 , along with the zero-offset value.

Consider the case when the inner guard has a lower temperature than the main heater $(-40 \mu \mathrm{V}$ offset). Then under stable control the main, metered heater is required to supply slightly more power in response to its loss to the guard. Conversely, if the inner guard is higher in temperature than the main heater, the main heater will consume less power as it gains power from the guard. The sensitivity coefficient for this effect is $-0.6 \mathrm{~mW} / \mu \mathrm{V}$, for the twenty-junction differential thermocouple used, having a twenty-fold amplified sensitivity. Thus the sensitivity per junction is $-0.03 \mathrm{~mW} / \mu \mathrm{V}$, equivalent to $0.9 \mathrm{~mW} / \mathrm{K}$. If the inner guard tempera-ture were not equal to the temperature of the main heater, the error in metered power passing through the specimens would be $0.9 \mathrm{~mW} / \mathrm{K}$ of offset in the differential control thermocouple. This offset would produce an error of $2 \%$ in the value of $\mathrm{k}$ for a one kelvin offset, but only $0.1 \%$ in the value of $k$ for a one microvolt offset in the emf of the control thermocouple, when measuring a low-conductivity insulation having a (typical) $k$-value of $40 \mathrm{~mW}$.

From figure 5 it is noted that the random fluctuations in temperature of the inner guard under stable control are $\pm 1.5 \mu \mathrm{V}$. If the main heater could follow the inner guard temperature as rapidly as the fluctuations occur, the resulting power fluctuation would be $\pm 0.05 \mathrm{~mW}$. This fluctuation amplitude, if realized, would be equivalent to a fluctuation of $\pm 0.1 \%$ in the value of the thermal conductivity. The heat capacity of the main heater plate, however, does not allow it to fluctuate at the frequency observed in Figure 6.

We think that any inner-guard offsets occurring during normal operation at temperatures near room temperature are much less than the above deliberately produced offsets.

No information on the acually existing offsets is available at present. The temperature difference in greater than or equal to $10 \%$ of the absolute other instrumental errors. Thus the effect the specimen must bo temperature to avoid power due to biases in controlling the inner guard is believed to be negligible, for operation at room temperature, and of the order of $1 \%$ at $750 \mathrm{~K}$. 


\subsubsection{Zero-Gradient Measurements}

Inspection of the defining equation (1) for thermal conductivity shows that $\mathrm{k}$ is determined from the ratio of $\mathrm{Q}$ to $\Delta \mathrm{T}$. A $1 \%$ error in either $Q$ or $\Delta T$ would propagate a $1 \%$ error into $k$. Using only one kind of specimen (fixed thermal conductivity), it is impossible to separate experimental errors in measuring $Q$ from errors in measuring $\Delta \mathrm{T}$ by examining the experimental thermal conductivity. In order to judge whether the present apparatus suffers predominantly from experimental errors in $Q$, or in $\Delta T$, or in both, "zero-gradient" measurements on different pairs of specimens of widely different thermal conductivity can however be very informative.

These zero-gradient measurements are made with the control system programmed to keep the two opposite surfaces of the specimens at the same temperature. Under dynamic control the thermal gradient in the specimen under these operating conditions is not exactly zero, so the system may call for a small amount of power to the main heater. From conventional measurements performed separately, the thermal conductivity of the specimen is known as a function of temperature. This knowledge allows us to compute the amount of heat required to flow by thermal conduction from the main heater through the specimens at the given gradient and mean temperature for the conditions of operation.

We could then assume that any difference between this heat and that actually supplied by the main heater is due to errors in determining the true temperature difference in the specimens. On the other hand, we can assume that any difference between this heat and that supplied by the main heater is a measure of the heat loss from the main heater due to experimental error in meeting the conditions of stable, unidirectional flow of heat along the longitudinal axis. It could possibly be due to conduction of heat from the metered heater out of the stack along thermocouple or heater leads, for example. This difference is called the zerogradient heat.

Figure 23 shows the zero-gradient heat for specimens of fibrous glass SRM insulation board at temperatures from $293 \mathrm{~K}$ to $343 \mathrm{~K}$. The line was fitted to the points by a linear least-squares routine.

The intersection of the line with the abscissa at $\mathrm{T}=290 \mathrm{~K}$ was forced, for the following reason. The electrical leads into the thermal conductivity stack lie near a large baseplate which is water-cooled to about $290 \mathrm{~K}$ and cools the leads. Thus $290 \mathrm{~K}$ is a "best estimate" of the temperature of the leads, and is consistent with the behavior shown by the data points. At the conditions of zero gradient, there should be no exchange of heat between the stack and the surroundings for a stack temperature of about $290 \mathrm{~K}$. For higher stack temperatures it should be necessary to supply 
heat to the stack.

This is illustrated by figure 23.

The slope

of the fitted line is found to be $b=97 \mathrm{~mW} / \mathrm{K}$.

Figure 24 shows the zero-gradient heat for specimens of fibrous alumina-silica insulation board, having approximately the same thermal conductivity as the previously mentioned fibrous glass board. The intersection of the fitted line with the temperature axis at $\mathrm{T}=290 \mathrm{~K}$ was also forced, as explained above. The slope of this fitted line is found to be $b=87 \mathrm{~mW} / \mathrm{K}$, in good agreement with that of the data for the fibrous glass board. Thus both materials have approximately the same sensitivity to rise in mean temperature above $\mathrm{T}=290 \mathrm{~K}$.

Both figures consistently indicate the presence of a small but measurable loss of heat from the stack, or apparatus error, increasing in direct proportion to the difference between the mean temperature of the stack and the surroundings.

Additional light is shed by measurements in which the temperature difference $\Delta T$ is varied, holding the mean temperature constant. Such data were obtained on a pair of specimens of microporous fumed silica insulation board. At a mean specimen temperature of $673 \mathrm{~K}$ consistent values for the thermal conductivity could be obtained only for $\Delta T \geq 80 \mathrm{~K}$. For $\Delta T$ less than this value, the experimental thermal conductivity increased roughly hyperbolically as $\Delta \mathrm{T}$ was reduced. Similar behavior was observed for a mean temperature of $523 \mathrm{~K}$.

The asymptotic value of thermal conductivity at a given mean temperature for large $\Delta T$ is independent of $\Delta T$ and is therefore the more reliable estimate of the true value. We can calculate the difference between the experimental value of $\mathrm{k}$ at low $\Delta \mathrm{T}$ and the constant value at large $\Delta T$. This is an error in measurement of $\mathrm{k}$ for that mean temperature. If we assume that this error is due entirely to error in measuring $Q$, we can then calculate this value of power corresponding to the error in k, from knowledge of $\mathrm{T}$ and $\Delta \mathrm{T}$, for each $\Delta \mathrm{T}$.

In so doing, for all values of $\Delta T$ used we found a roughly constant value of $Q=29 \pm 4 \mathrm{~mW}$ for $\mathrm{T}=673 \mathrm{~K}$, and a roughly constant value of $Q=6 \pm 2 \mathrm{~mW}$ for $\mathrm{T}=523 \mathrm{~K}$. Under the assumption that this error in $Q$ is the sole contributor to error in measuring $k$, we can compare it to the values of zero-gradient heat (QZG) from figure 24. This was assumed to be due to loss of heat from the stack by conduction along leads, and therefore independent of specimen conductivity.

Figure 24 shows that at $T=523 \mathrm{~K}, Q \mathrm{~g}$ is $20 \mathrm{~mW}$, with an uncertainty from the figure of $\pm 10 \mathrm{~mW}$; extrapolating to $\mathrm{T}=673$. QzG is $33 \pm 10 \mathrm{~mW}$. These values lie in rough agreement, within experimental error, with the values found above from the experiments with decreasing $\Delta T$. Thus both experiments aro consistent with the assumption that there is a small heat leak from the stack to the surroundings, that is greater as the mean 
stack temperature is increased, and that contributes to error in determining $\mathrm{k}$ accurately. Experimentally it was determined that values of $T$ of at least $10 \%$ of the absolute mean temperature must be used to minimize the error due to this heat leak.

\subsubsection{Comparative Measurements}

\subsubsection{Comparison With Results From Round-Robin Measurement Programs}

During the summer of 1987 an interlaboratory comparative measurement program was organized which involved participation by NBS-Boulder and six industrial laboratories [12]. Thermal conductivity was measured for specimens of fibrous alumina-silica insulation board, and for specimens of calcium silicate insulation board, both types having a nominal thickness of $2.5 \mathrm{~cm}$.

For the fibrous alumina-silica insulation the standard deviation of 58 test results from the seven labs was $9.3 \%$. The data from the apparatus described in this report (X's) lay within $7 \%$ of the group mean over a range of temperature from $300 \mathrm{~K}$ to 770 $K$ (figures 25 and 26). Since the specimens were different, no great weight should be placed on the $7 \%$ difference.

For the calcium silicate insulation board the standard deviation of 48 test results from the seven labs was $9.1 \%$. The data from this apparatus lay within $5 \%$ of the group mean over the same range of temperature, $300 \mathrm{~K}$ to $770 \mathrm{~K}$ (figures 27 and 28). Little weight should be given to the $9 \%$ difference, for different specimens.

\subsubsection{Comparison With Measurements at an Industrial Laboratory}

In an in-house calibration and standardization program at an industrial research and development laboratory, measurements of thermal conductivity were made on refractory alumina-silica fibrous insulation board similar to that used in the round robin measurement program described above. Data over a range of temperature from $300 \mathrm{~K}$ to $1150 \mathrm{~K}$ were found to fit the following correlation by Mitchel1 [13], to within $\pm 3.5 \%$ :

$$
\mathrm{ka}=0.0142+9.167 \mathrm{~T} \times 10^{-5}+2.776 \mathrm{~T}^{3} \times 10^{-11} \mathrm{~W} /(\mathrm{m} . \mathrm{K})
$$

Figure 29 shows measurements on this apparatus (circles) compared with the above correlation relation (solid line). Figure 30 gives the relative deviation between the experimental data for this apparatus and the correlation equation. There is a systematic difference between the two of approximately $4 \%$. 


\section{SUMMARY}

This report describes the design and performance of an automated guarded-hot-plate apparatus built to meet the requirements of ASTM standard test method C-177 for measuring the thermal conductance of thermal insulation. The apparatus is capable of measuring thermal conductivity over a range of temperatures from ambient up to $750 \mathrm{~K}$.

Important features of the design and construction of this apparatus are the following:

(1) An improved algorithm for the control sequence leading to stable heater powers and specimen temperatures was developed. Initially it rapidly approaches the temperature setpoint with minimal overshoot. It also permits very sensitive control of the plate temperatures in later phases of the measurement sequence when thermal stability of the specimen boundaries is very important in measuring the thermal conductivity with high precision. This high precision of control in turn leads to very good reproducibility of measurements under the same nominal conditions, as has been verified experimentally.

(2) A novel thermocouple design is used which more accurately senses the average temperature over the surface of each heater plate in the apparatus. This design leads to greater accuracy because more points of the surface are sampled. This in turn leads to more accurate control of the absolute temperature of the plate surfaces and of the adjoining surfaces of the specimens. Consequently the measurement of thermal conductivity with this instrument is also more accurate. The arrangement also leads to greater precision in measuring temperature because the design incorporates a thermopile arrangement which multiplies the effect of any temperature differences across the area sampled by the sensor.

Measurements are described which help to assess the precision and bias of the apparatus. These measurements involve the use of standard reference materials and participation in round-robin measurement programs. Data from this apparatus are compared with measurements on similar materials reported in the literature. 


Error-propagation analysis suggests the estimated imprecision
in measurement of thermal conductivity is $0.6 \%$. The
experimentally observed imprecision under dynamic control of the
automated system is $1 \%$ near room temperature, rising to $5 \%$ at the
upper end of the temperature range. The reproducibility of the
apparatus is found experimentally to be about $1.2 \%$. Participation
in a round-robin measurement program on fibrous board insulations
showed results from this apparatus to lie within 5\% and $7 \%$ of the
means of all participating laboratories for two different
materials. No great weight should be given to this deviation
since specimens measured by the round-robin participants were
different from the ones we measured. Measurement by an industrial
laboratory on one similar material agreed within $4 \%$ of the
results from this apparatus.




\section{REFERENCES}

[1] Siu, M.C.I., "Fibrous Glass Board as a Standard Reference Material for Thermal Resistance Measurement Systems", Symposium on Thermal Insulation Performance, ASTM STP 718, pp. 343360 (ASTM, 1980).

[2] Smith, D.R. and Hust, J.G., "Effective Thermal Conductivity of a Glass Fiber-Board Standard Reference Material", NBSIR 81-1639, (U.S. National Bureau of Standards, 1981).

[3] Siu, M.C.I. and Hust, J.G., "Standard Reference Material $1450 \mathrm{~b}$, Thermal Resistance-Fibrous Glass Board", National Bureau of Standards Certificate (Office of Standard Reference Materials, NBS, Gaithersburg, MD, 1982).

[4] Smith D.R. and Hust, J.G., "Effective Thermal Conductivity of Glass-Fiber Board and Blanket Standard Reference Materials", Thermal Conductivity 17: Proceedings of the 17th International Conference on Thermal Conductivity, Hust, J.G., Ed., pp. 408-410 (Plenum, NY, 1983).

[5] Hust, J.G., "Standard Reference Materials: Glass Fiberboard SRM for Thermal Resistance", NBS Special Publication 260-98 (U.S. National Bureau of Standards, Aug. 1985).

[6] Hust, J.G., "Standard Reference Materials: Glass Fiberblanket SRM for Thermal Resistance", NBS Special Publication 260-103 (U.S. National Bureau of Standards, Sep. 1985).

[7] Smith, D.R., Hust J.G. and Van Poolen, L.J., "A Guarded-hotPlate Apparatus for Measuring Effective Thermal Conductivity of Insulations Between $80 \mathrm{~K}$ and $360 \mathrm{K"}$, NBSIR 81-1657 (U.S. National Bureau of Standards, 1982).

[8] Standard Test Method C 177 for "Steady-State Heat Flux Measurements and Thermal Transmission Properties by Means of the Guarded-Hot-Plate Apparatus", 1986 ANNUAL BOOK OF ASTM STANDARDS, Vol. 04.06, pp. 21-36, (ASTM, Philadelphia, 1986).

[9] Standard Practice C 1045-85 for "Calculating Thermal Transmission Properties from Steady-State Heat Flux Measurements", 1986 ANNUAL BOOK OF ASTM STANDARDS, Vol. 4.06, pp. 689-696, (ASTM, Philadelphia, 1986).

[10] Standard Practice C 1044-85 for "Using the Guarded-Hot-Plate Apparatus in the One-Sided Mode to Measure Steady-State Heat Flux and Thermal Transmission Properties", 1986 ANNUAL BOOK OF ASTM STANDARDS, Vol. 4.06, pp. 685-688 (ASTM, Philadelphia, 1986). 
[11] Hust, J.G. and Lankford, A.B., "Comments on the Measurement of Thermal Conductivity and Presentation of a Thermal Conductivity Integral Method", Int. J. of Thermophysics $3 / 1,67-77$ $(1982)$.

[12] Hust, J.G. and Smith, D.R., "Round-Robin Measurements of the Apparent Thermal Conductivity of Two Refractory Insulation Materials Using High-Temperature Guarded-Hot-Plate Apparatus" NBSIR 88-3087, (U.S. National Bureau of Standards, May 1988)

[13] Mitchell, H., "The Development of a Refractory Fiber Insulation for Use As a High Temperature Thermal Transmission Calibration Sample". In press: Proceedings of the 19th International Conference on Thermal Conductivity, Yarbrough, D., Ed. (Plenum, N.Y., 1988). 


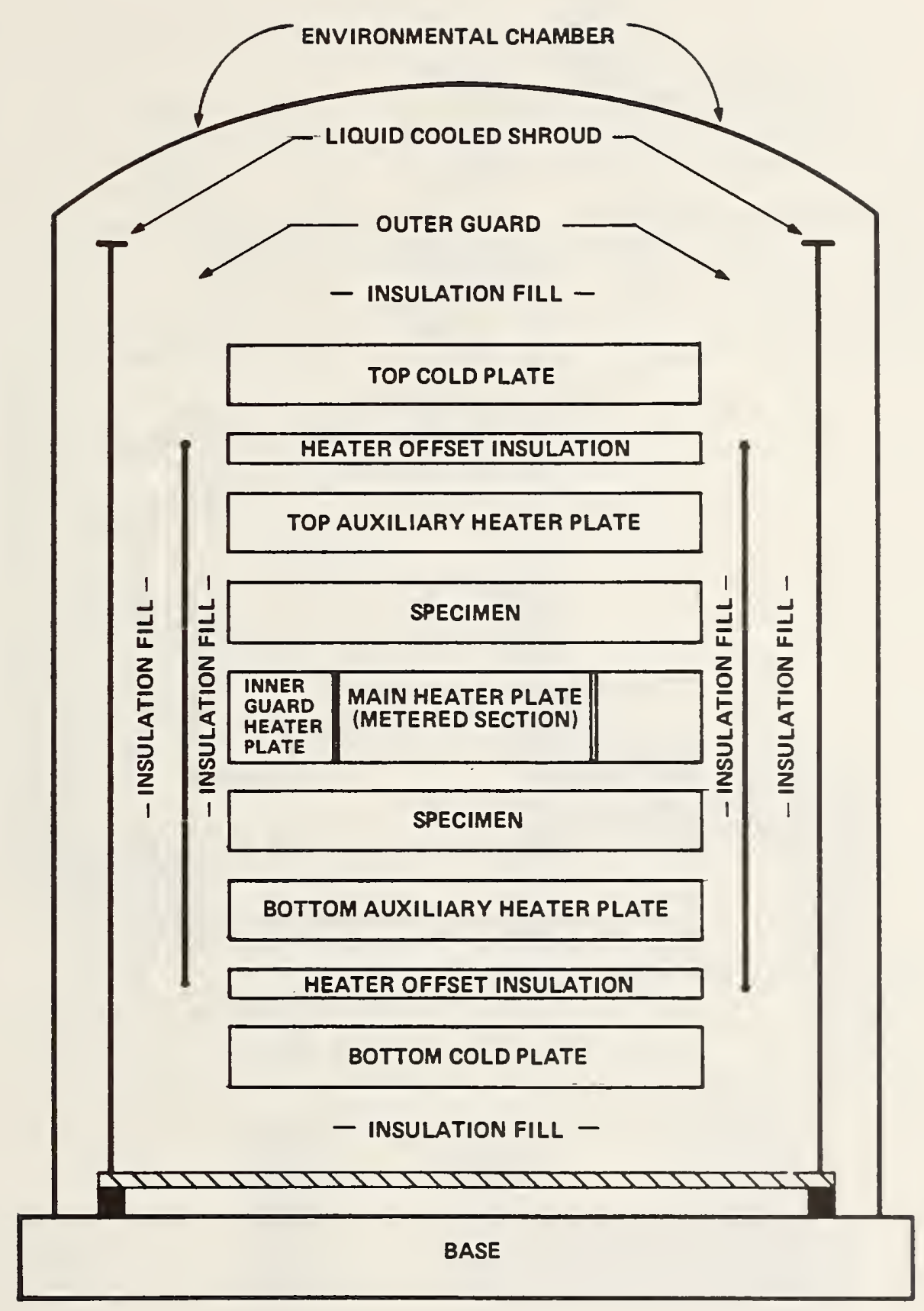

Figure 1. Layout of thermal conductivity stack, guards, shroud and environmental chamber of the NBS high-temperature guarded-hot-plate apparatus 


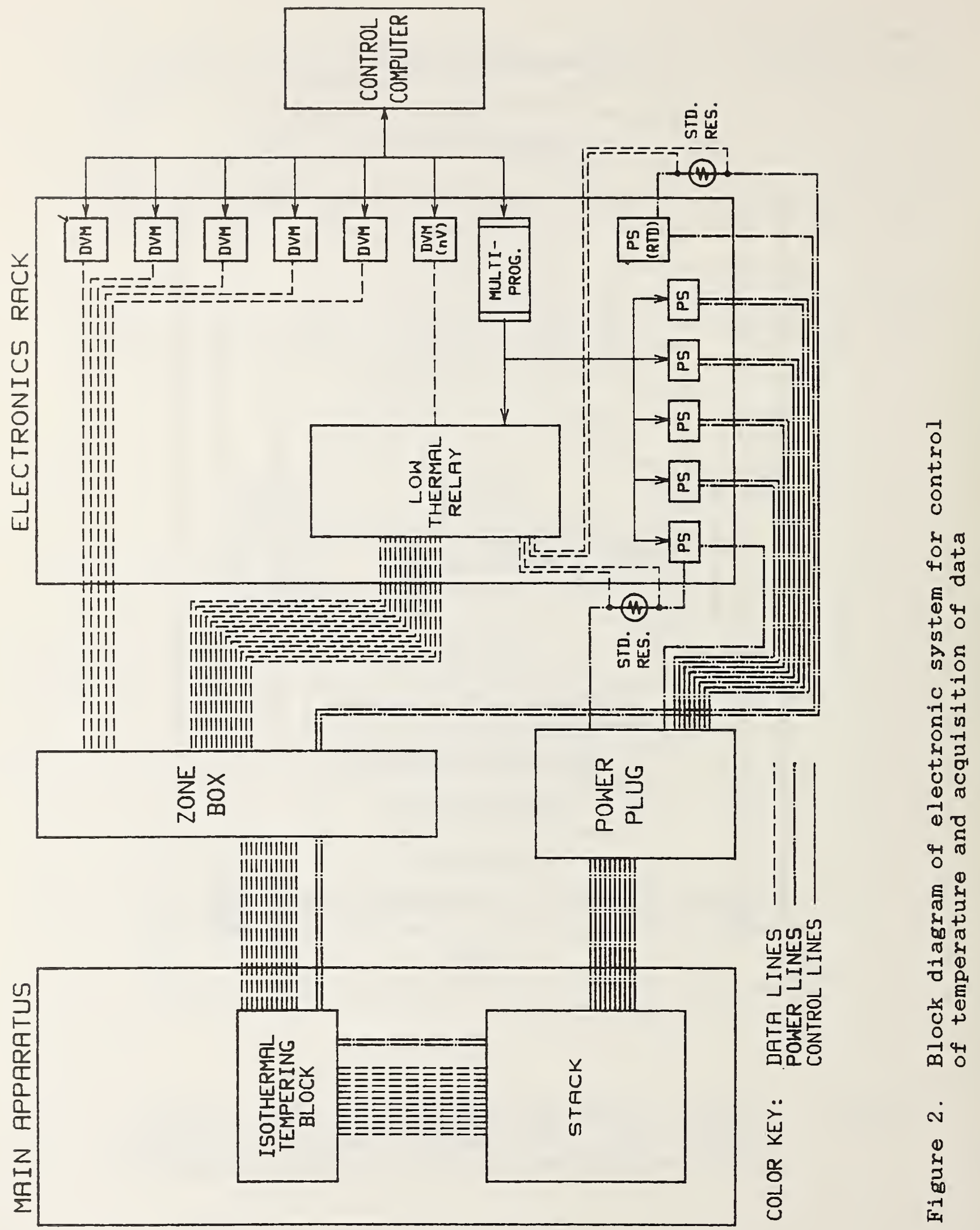




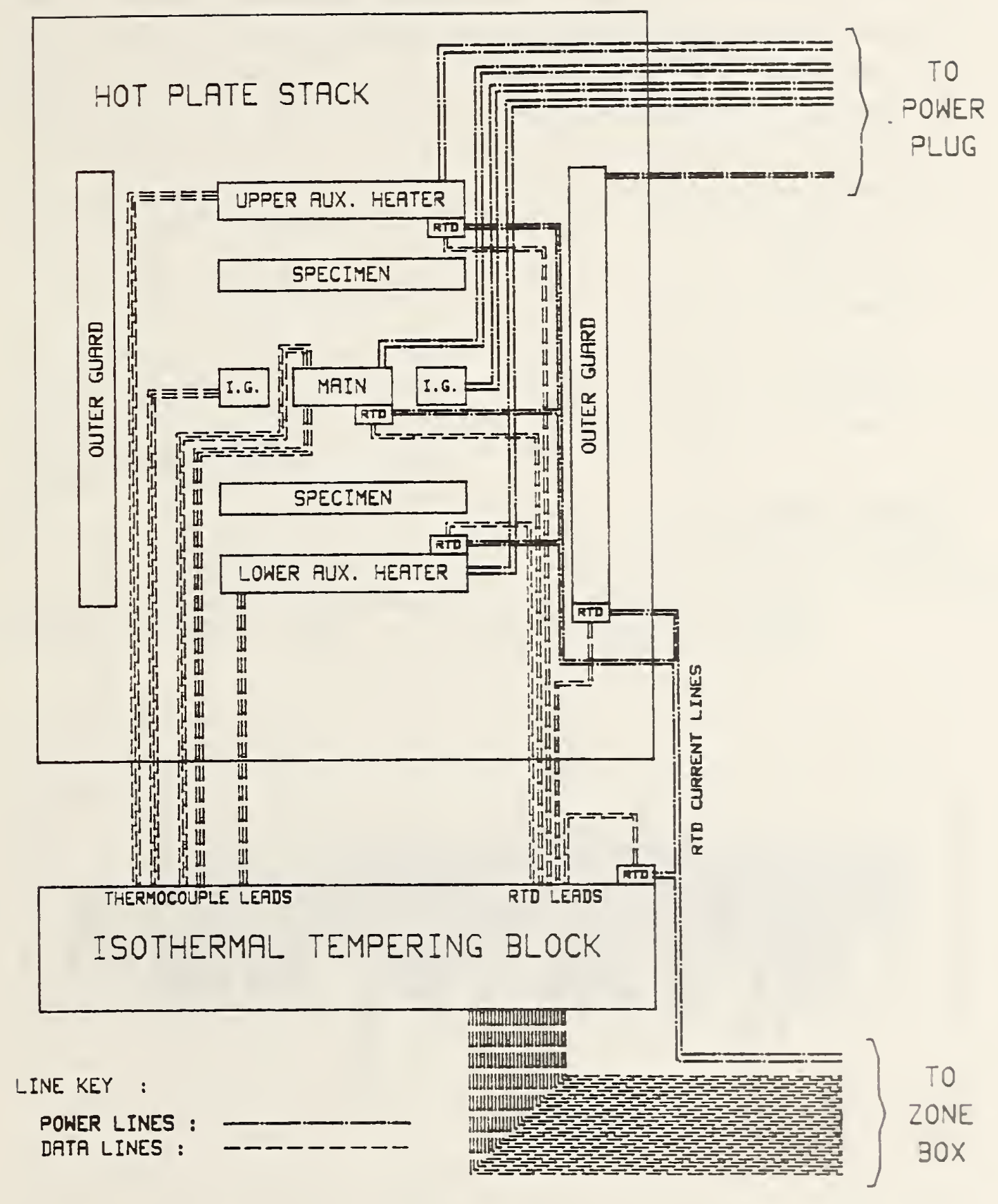

Figure 3. Detailed block diagram of control and data acquisition within the "main apparatus" block of Figure 2 


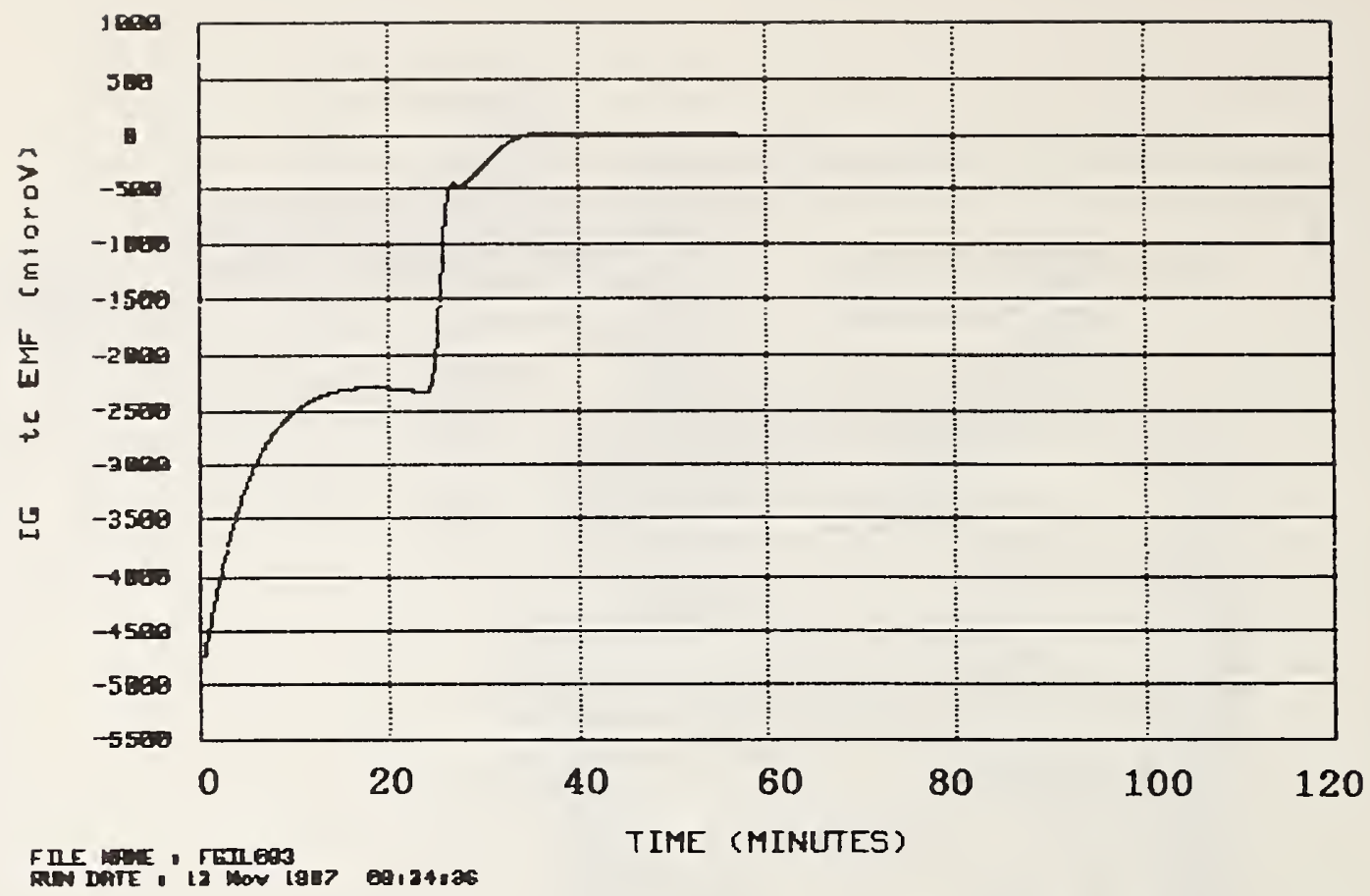

Figure 4. Output emf of gap thermocouple, between inner guard and main heater, vs. time: behavior during initial approach to set-point

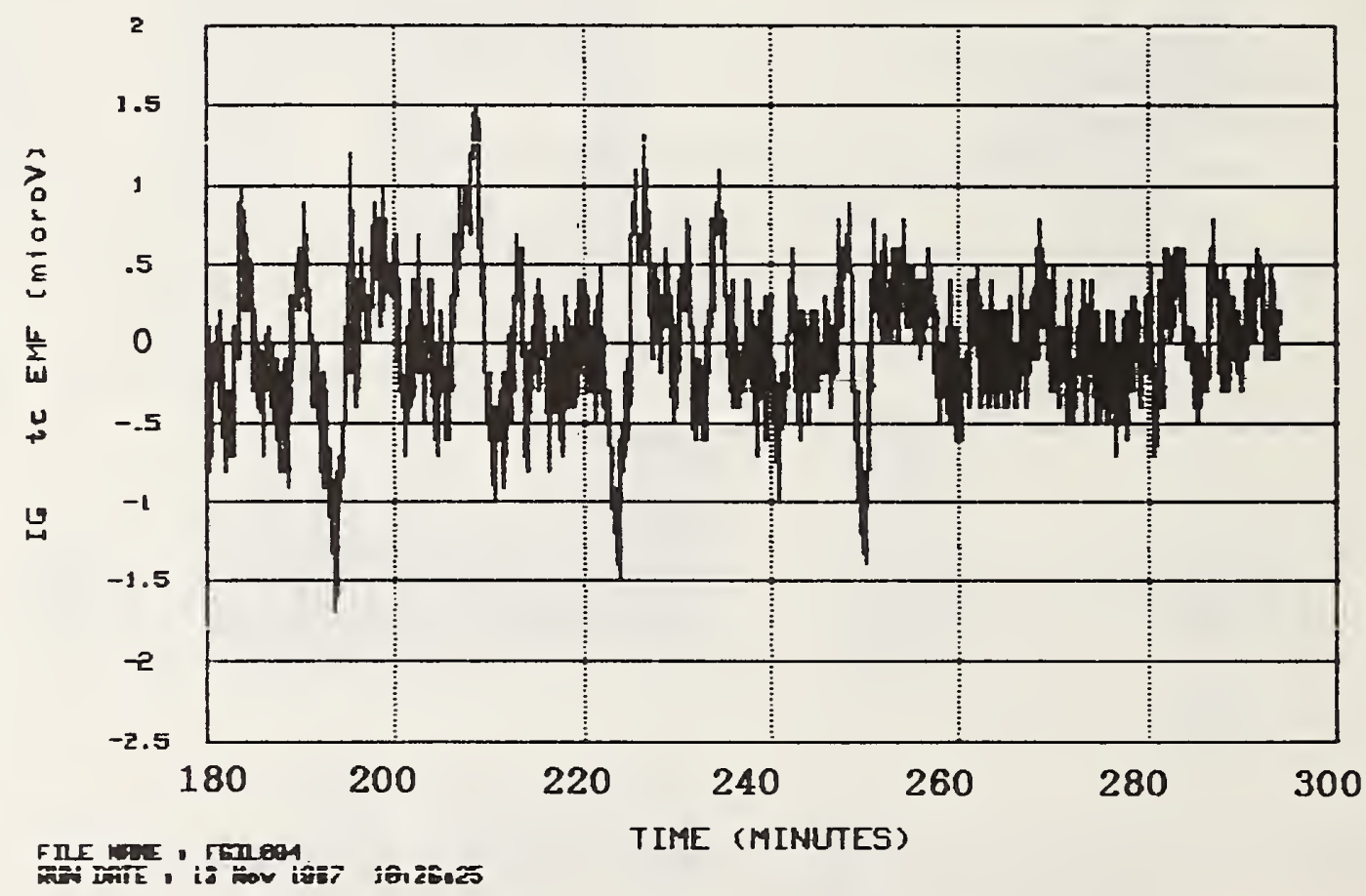

Figure 5. Output emf of gap thermocouple, between inner guard and main heater, vs. time: behavior during stable operation at set-point 


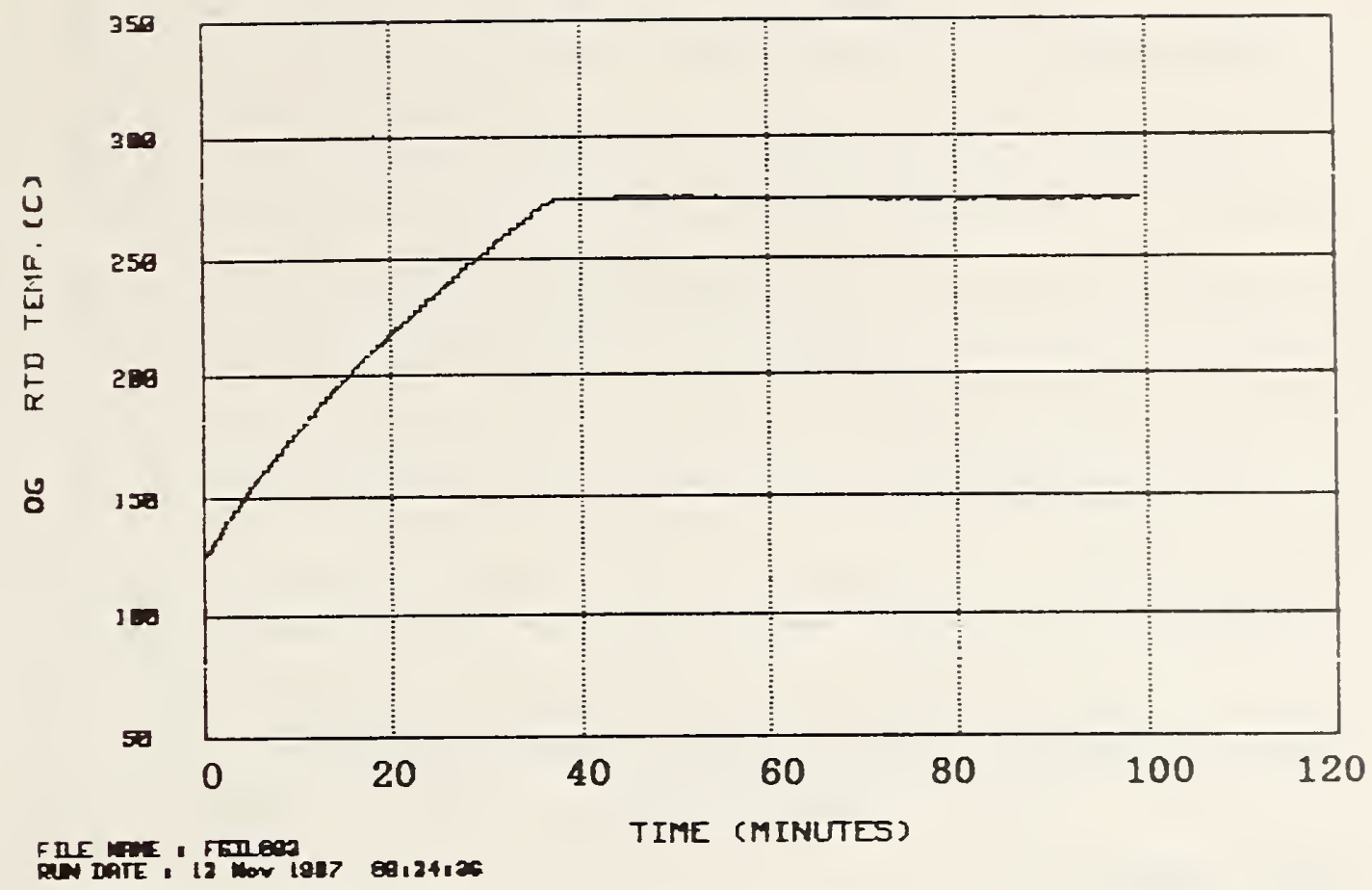

Figure 6. Temperature of outer guard, measured by resistance thermometer, vs. time: behavior during initial approach to set-point

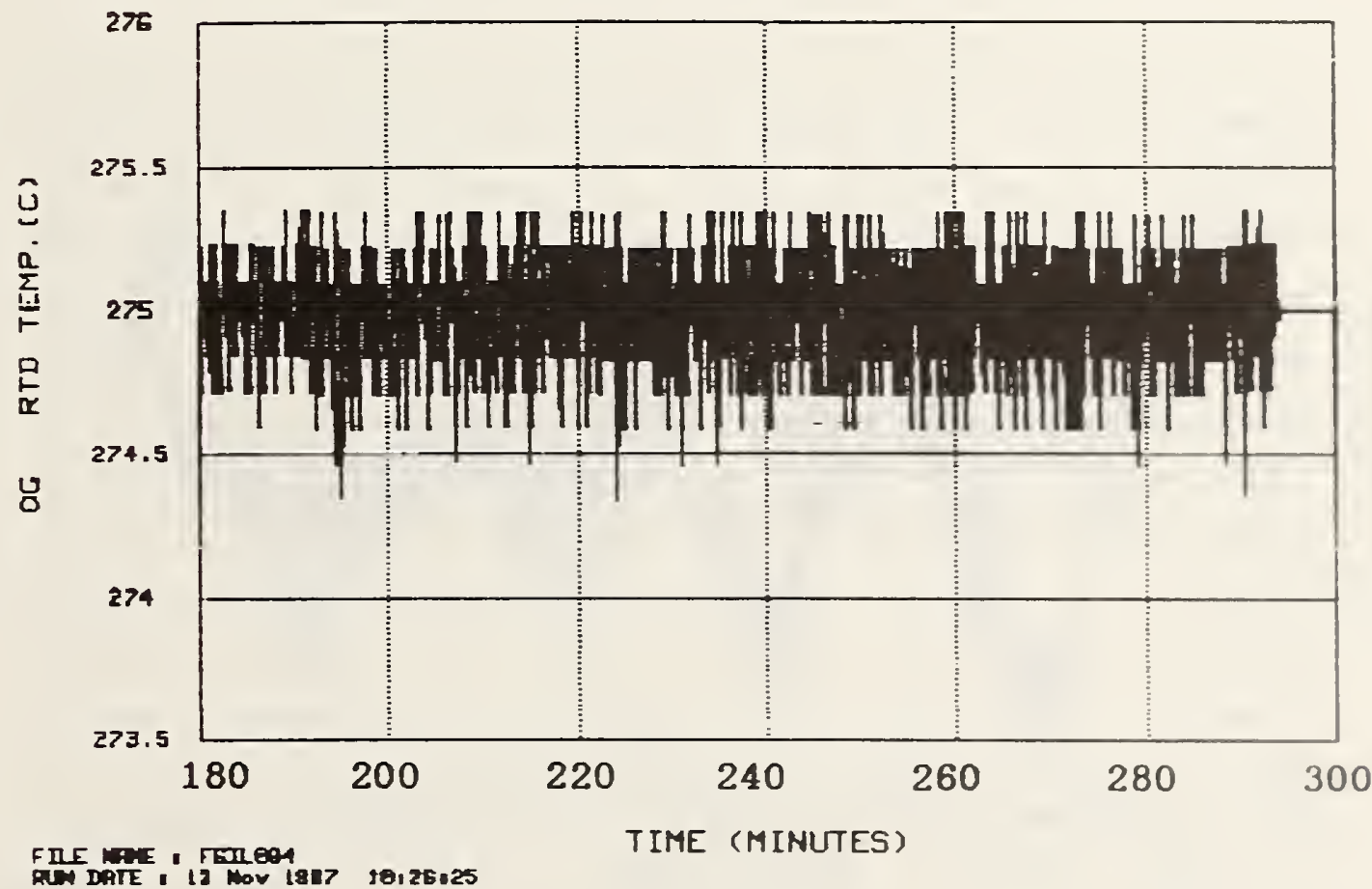

Figure 7. Temperature of outer guard, measured by resistance thermometer, vs. time: behavior during stable operation at set-point 


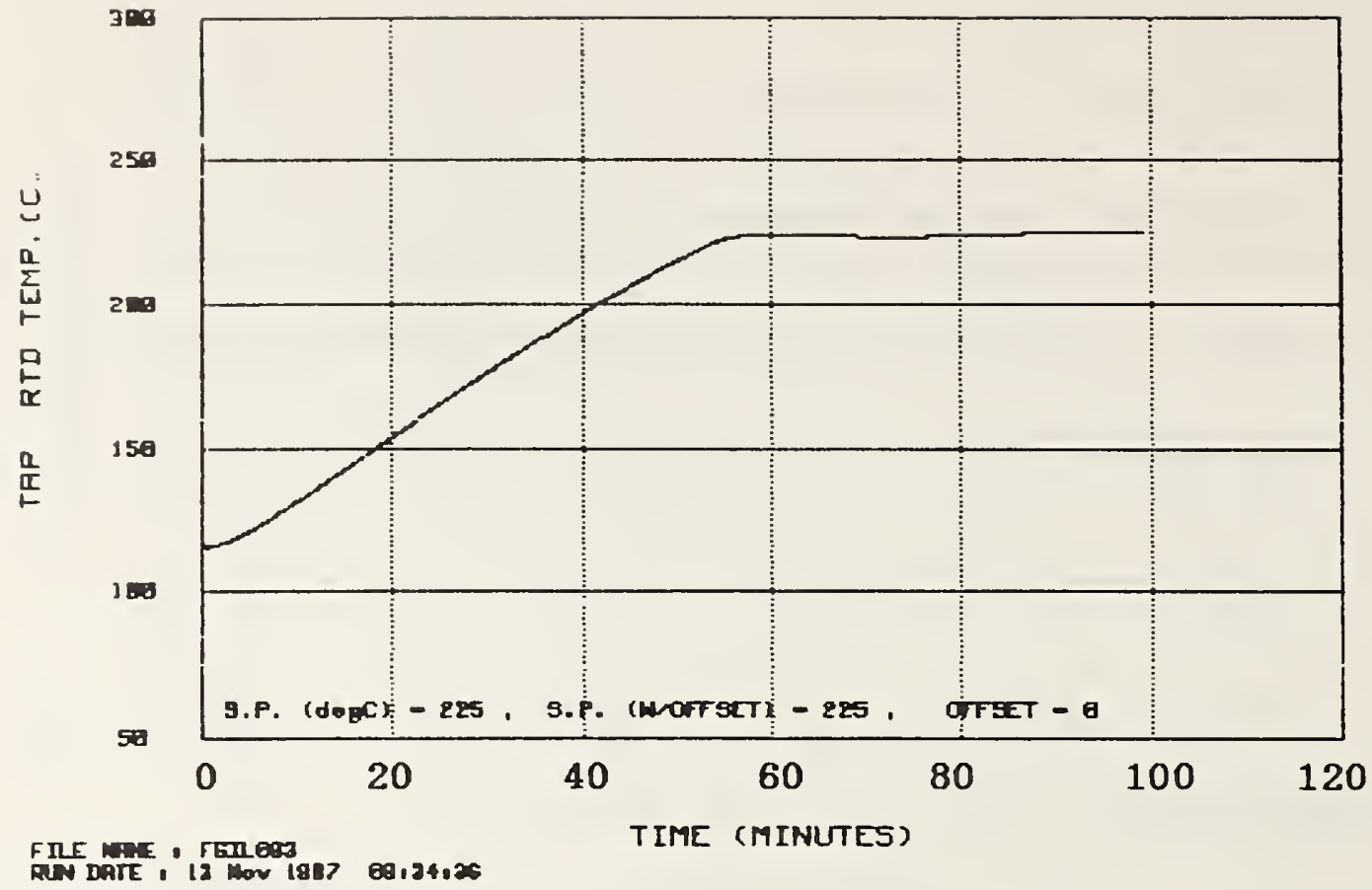

Figure 8. Temperature of top auxiliary heater plate, measured by resistance thermometer, vs. time: behavior during initial approach to set-point

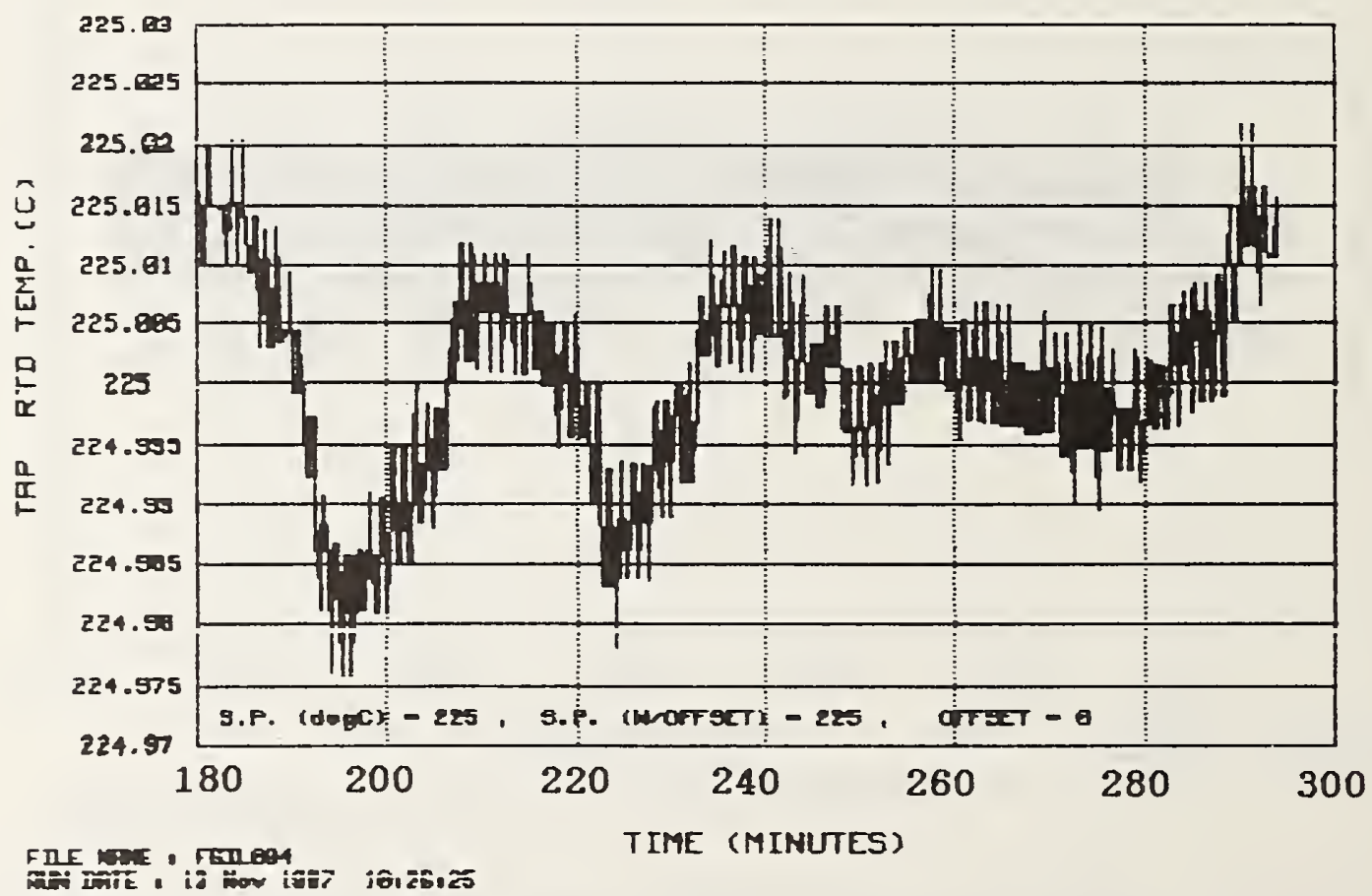

Figure 9. Temperature of top auxiliary heater plate, measured by resistance thermometer, vs. time: behavior during stable operation at set-point 


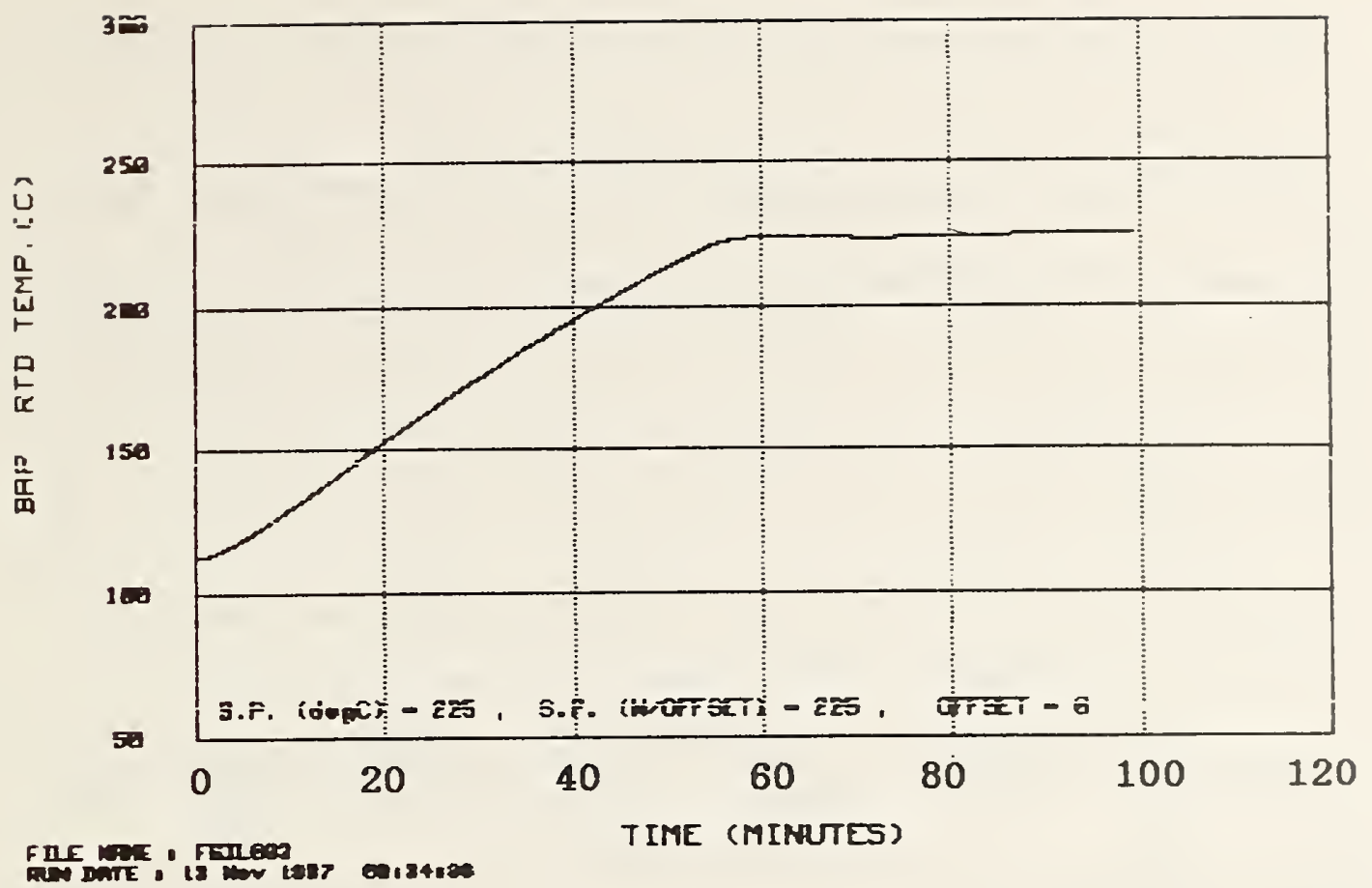

Figure 10. Temperature of bottom auxiliary heater plate, measured by resistance thermometer, vs. time: behavior during initial approach to set-point

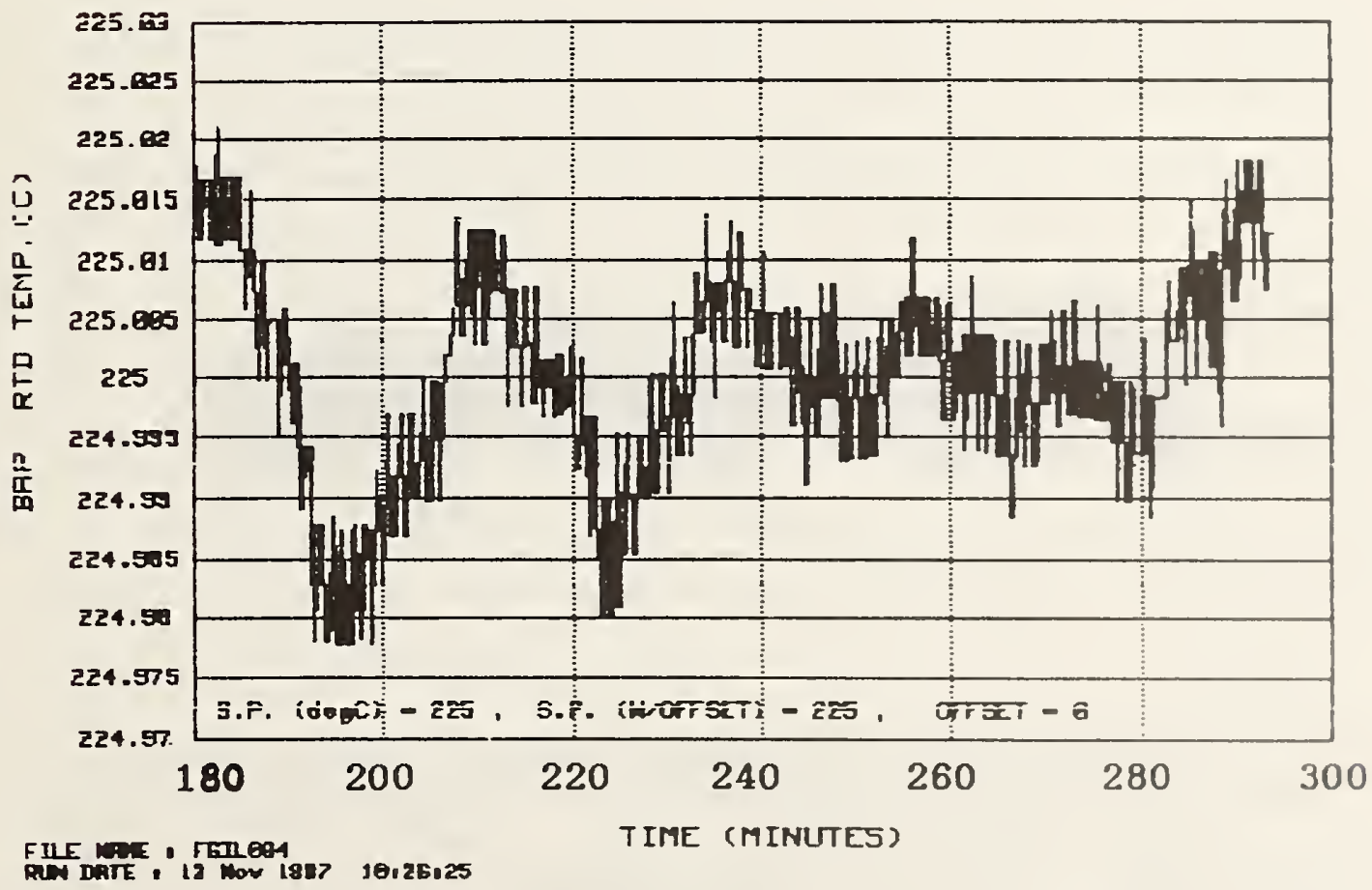

Figure 11. Temperature of bottom auxiliary heater plate, measured by resistance thermometer, vs. time: behavior during stable operation at set-point 


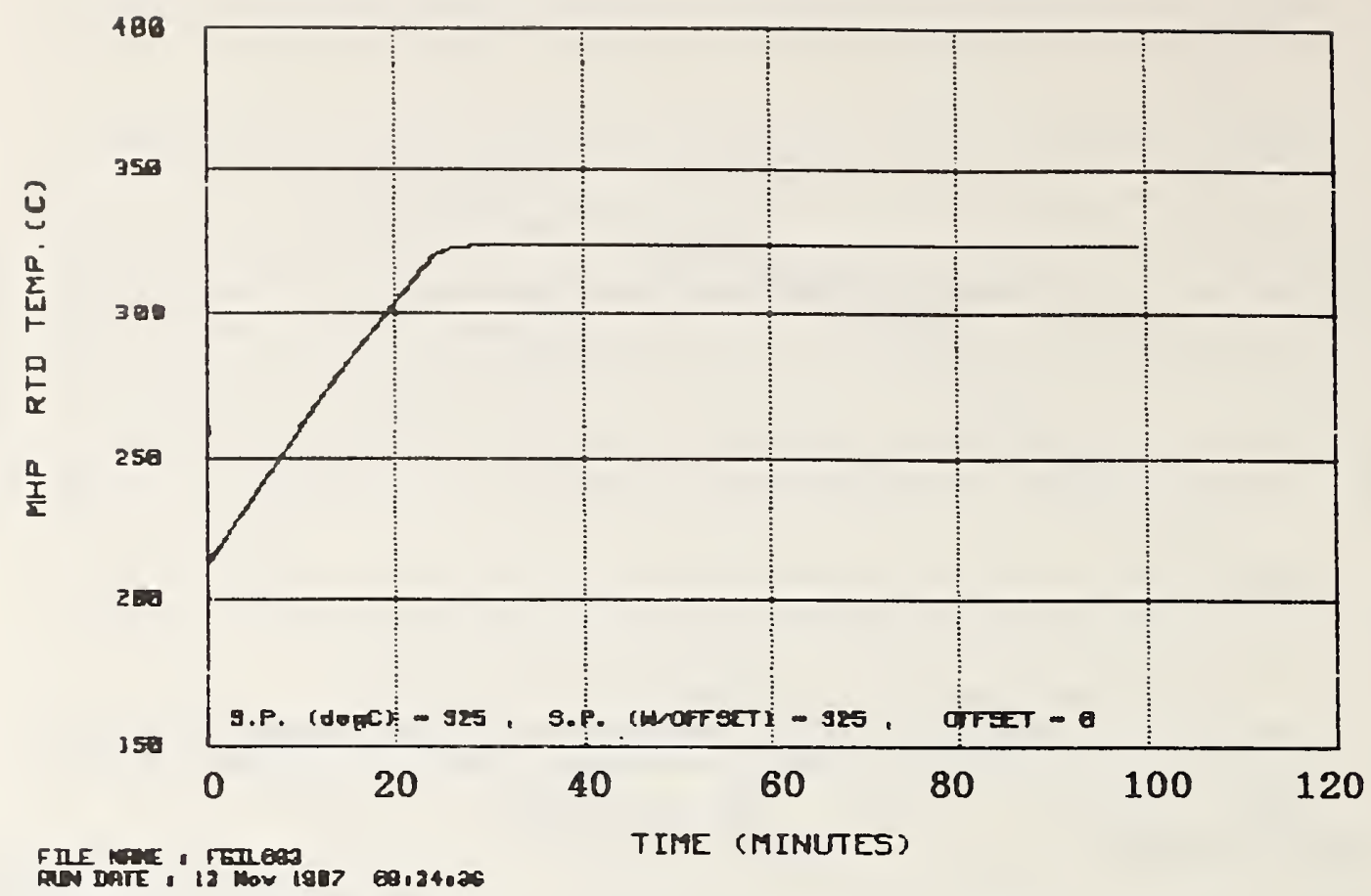

Figure 12. Temperature of main heater plate, measured by resistance thermometer, vs. time: behavior during initial approach to set-point

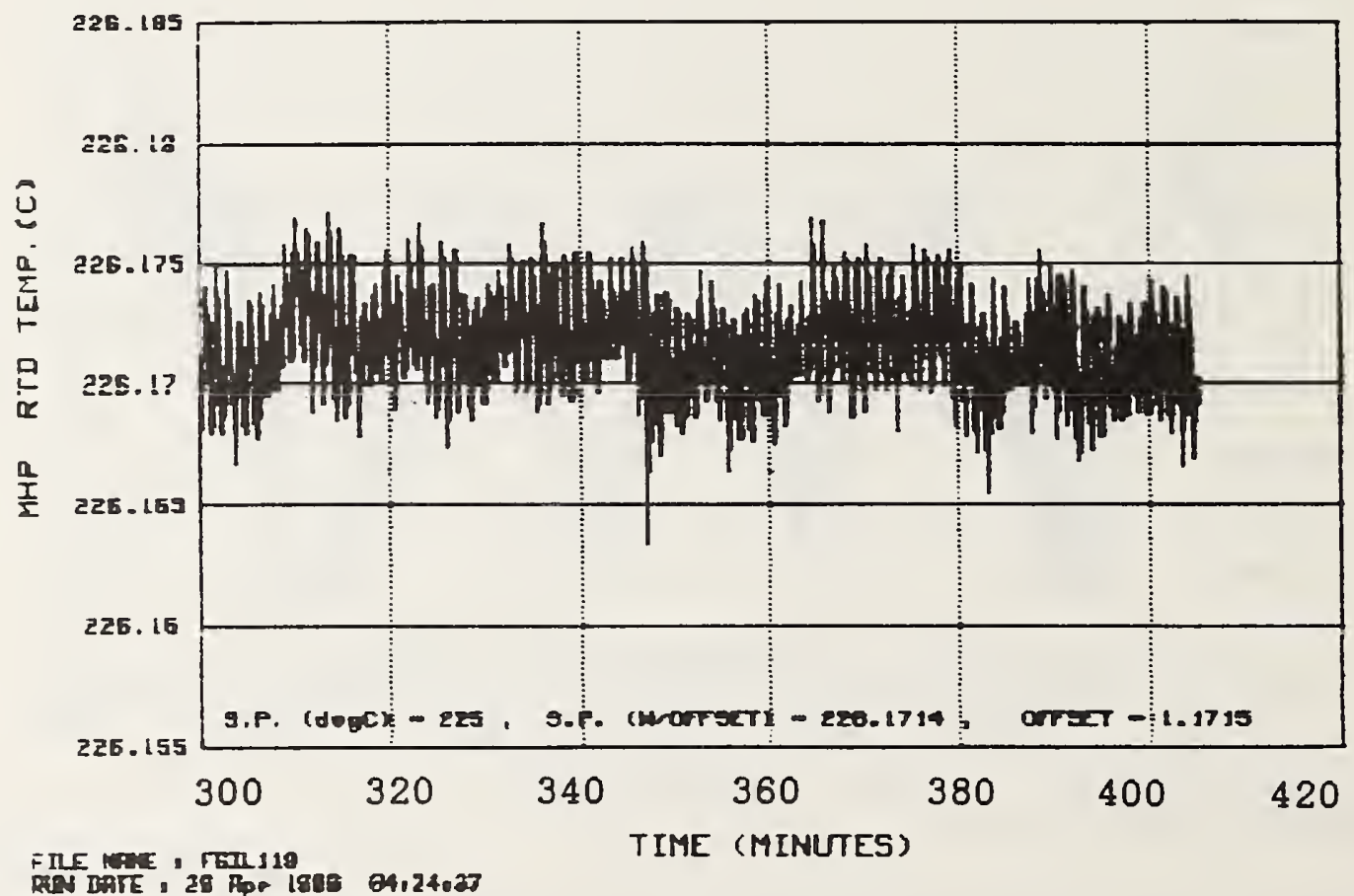

Figure 13. Temperature of main heater plate, measured by resistance thermometer, vs. time: behavior during stable operation at set-point 


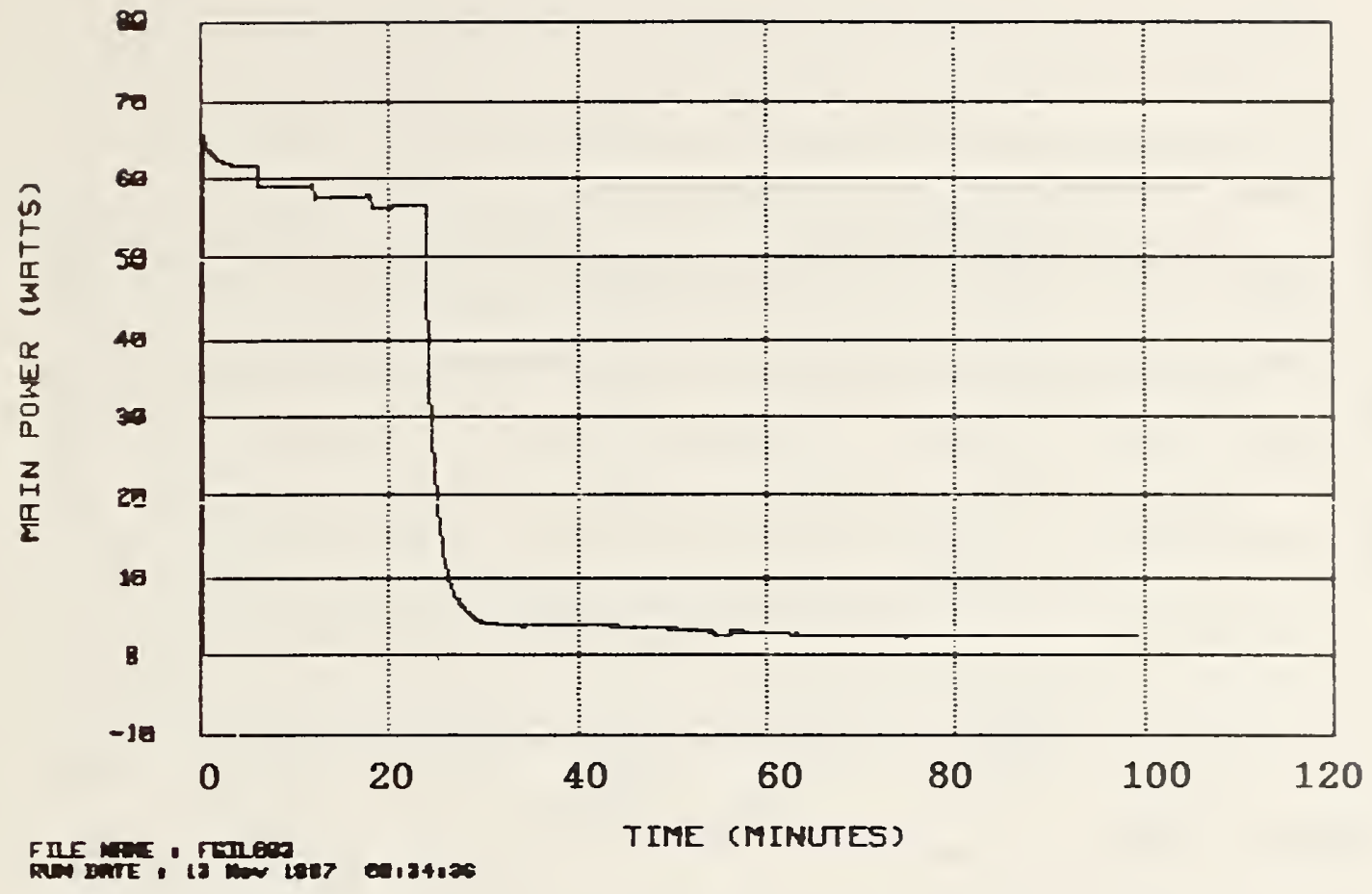

Figure 14. Main heater power vs. time: behavior during initial approach to set-point

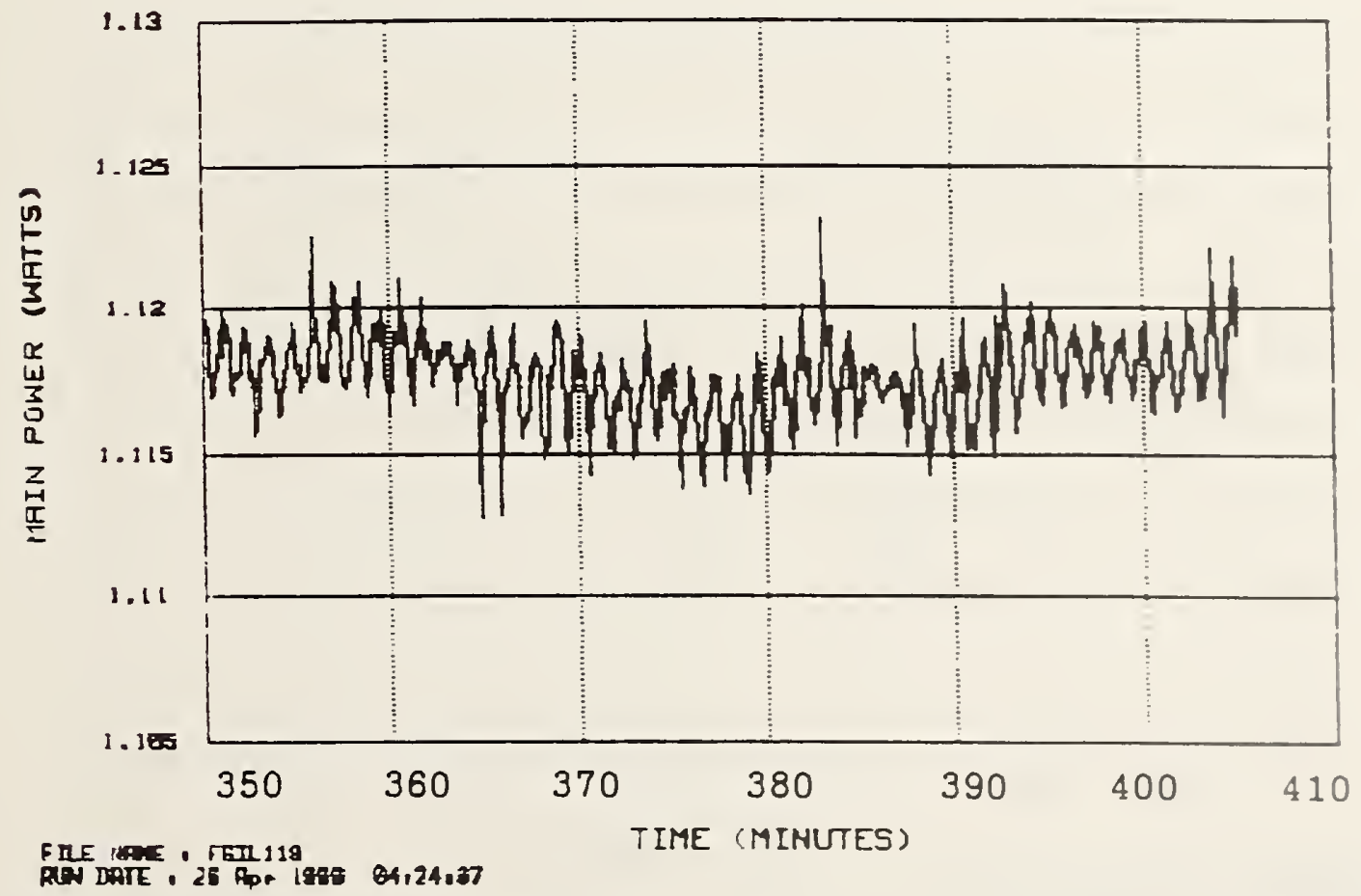

Figure 15. Main heater power vs. time: behavior during stable operation at set-point 


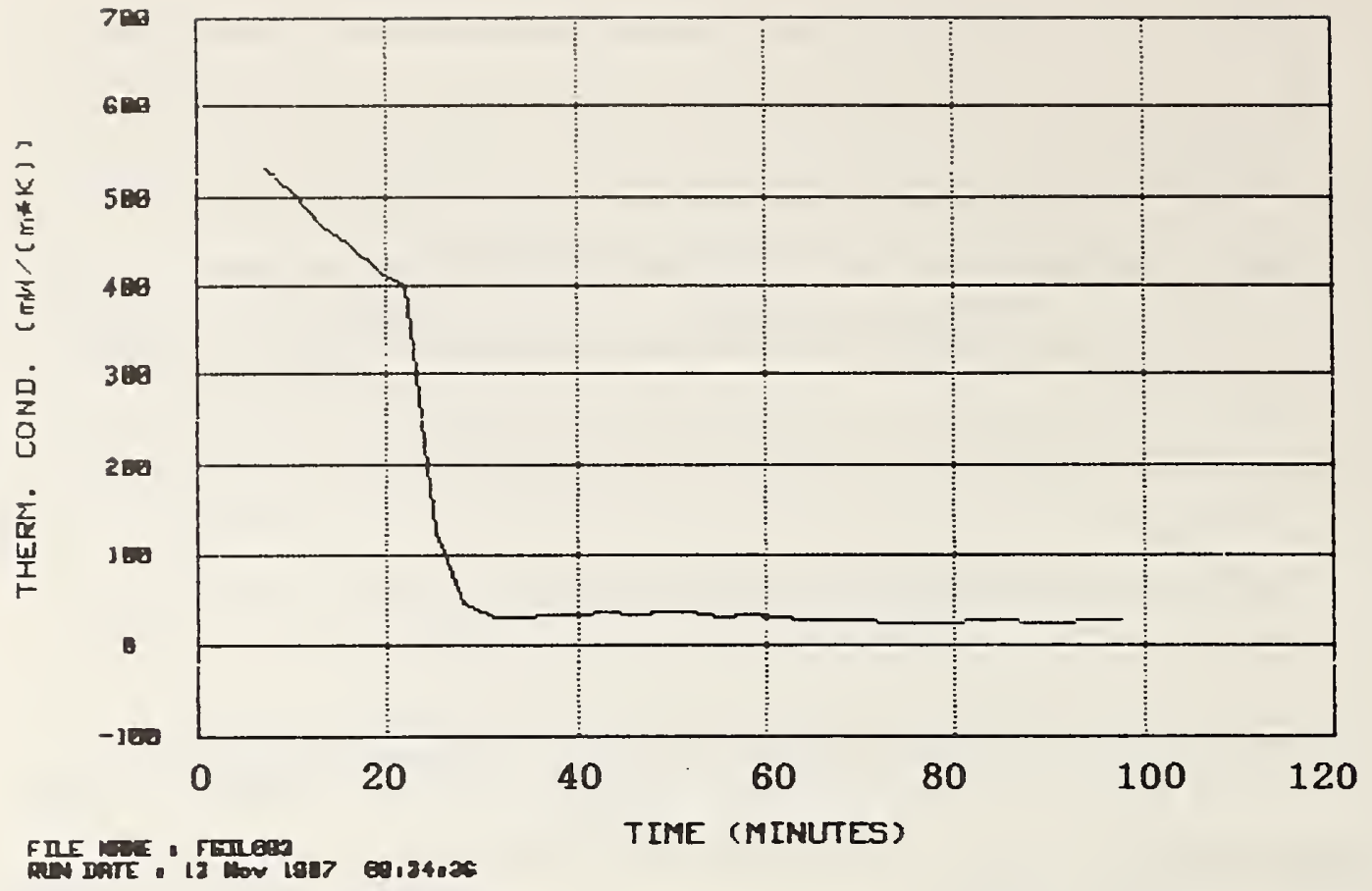

Figure 16. Experimental thermal conductivity, calculated from main heater power, specimen area and temperature gradient, vs. time: behavior during initial approach to set-point

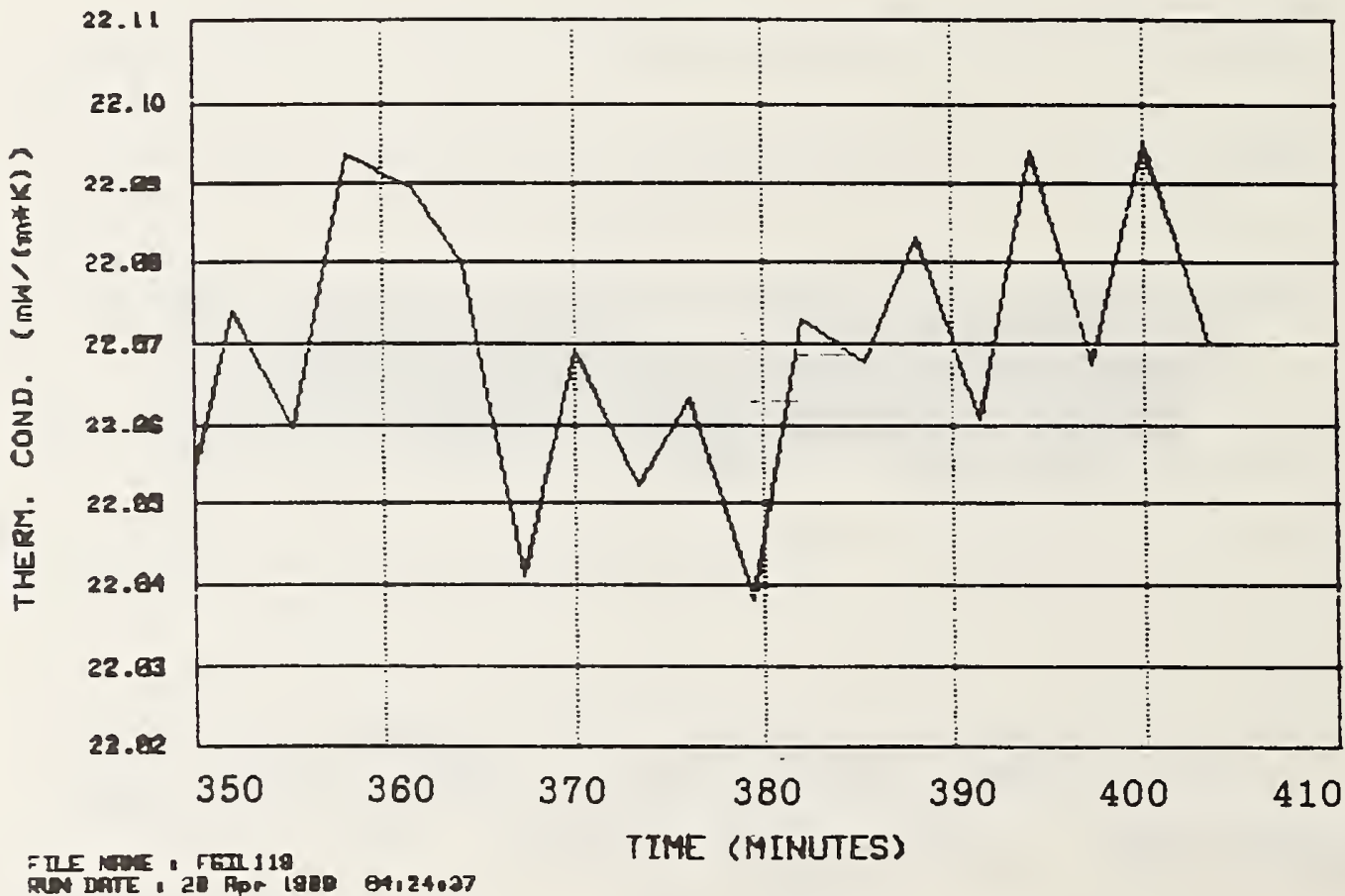

Figure 17. Experimental thermal conductivity, calculated from main heater power, specimen area and temperature gradient, vs. time: behavior during stable operation at set-point 


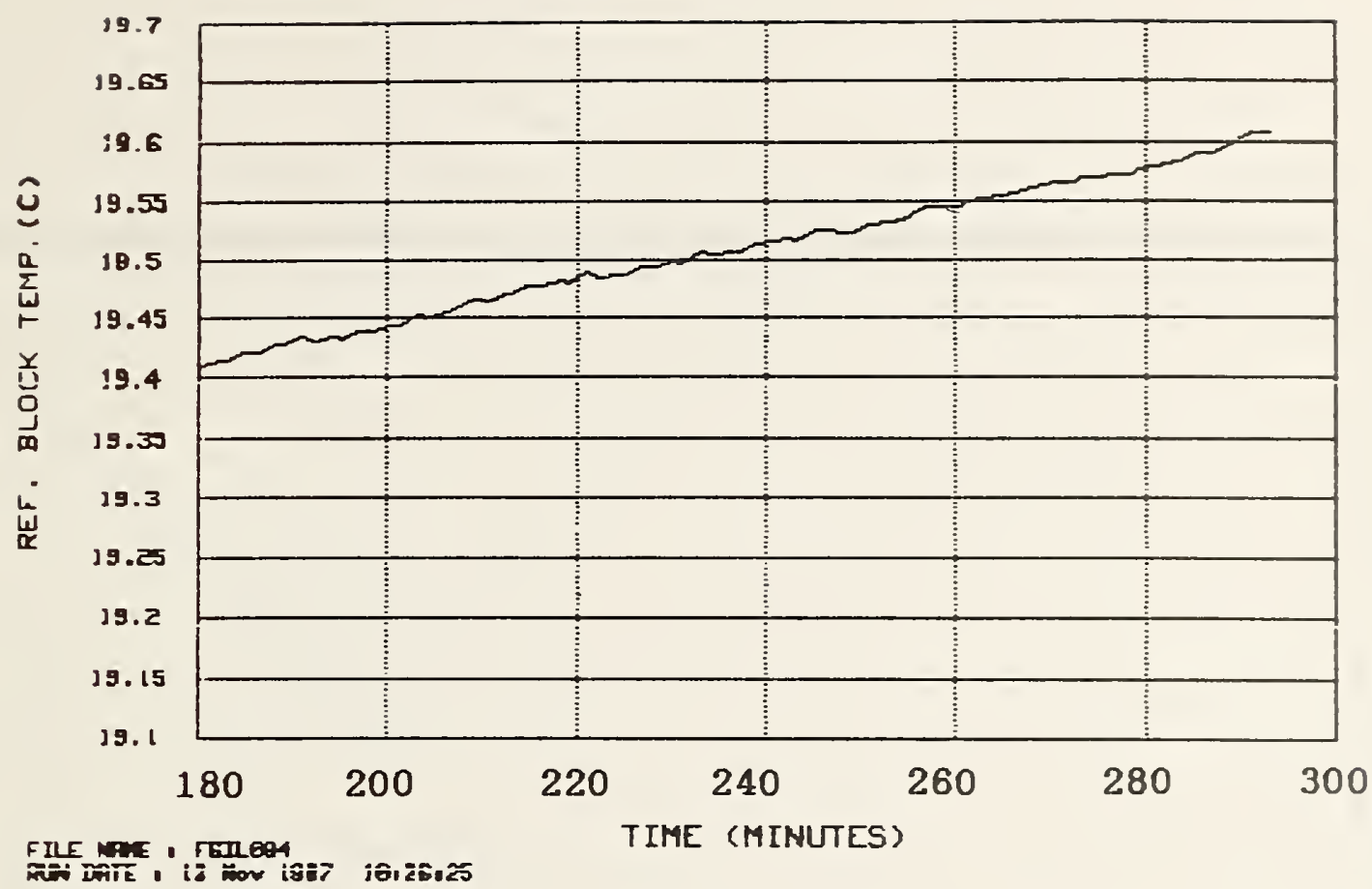

Figure 18. Temperature of thermocouple reference block, measured by resistance thermometer, vs. time 


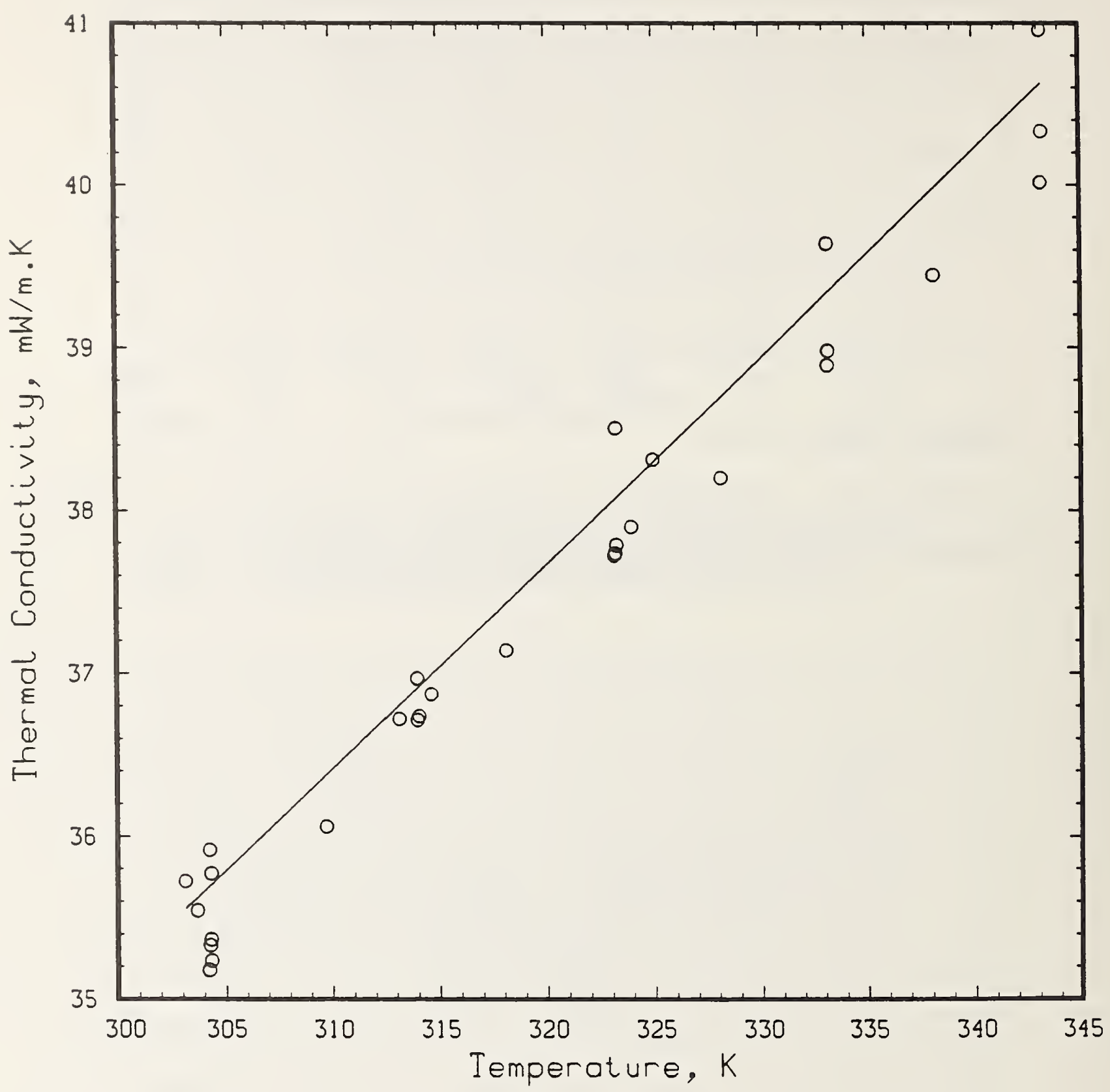

Figure 19. Thermal conductivity of fibrous glass insulation SRM $1450 \mathrm{~b}$ compared with certification function for $k(T)$ (solid line) 


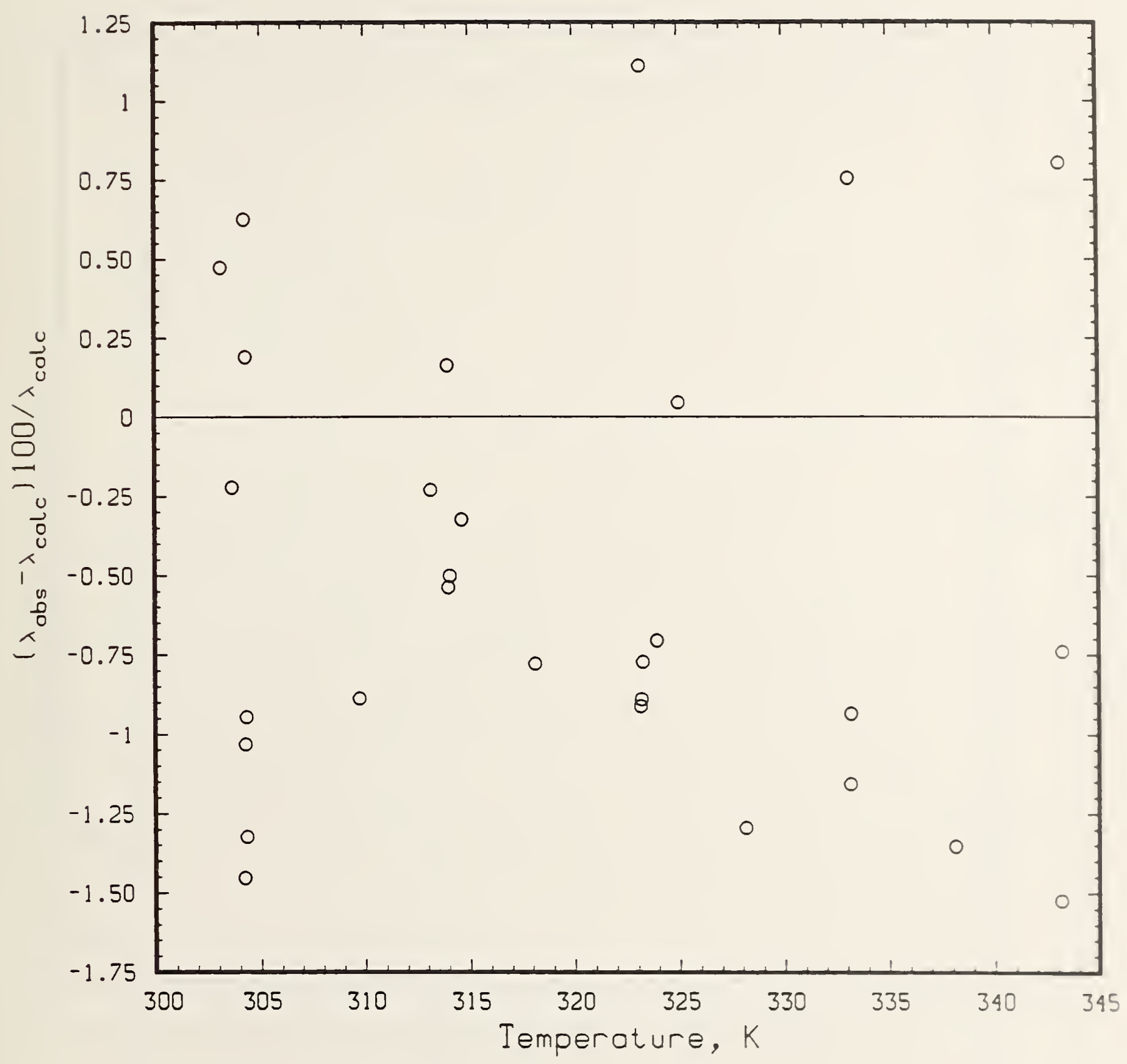

Figure 20. Relative deviations of thermal conductivity of fibrous glass insulation SRM 1450b, compared with certification function for $\mathrm{k}(\mathrm{T})$ 


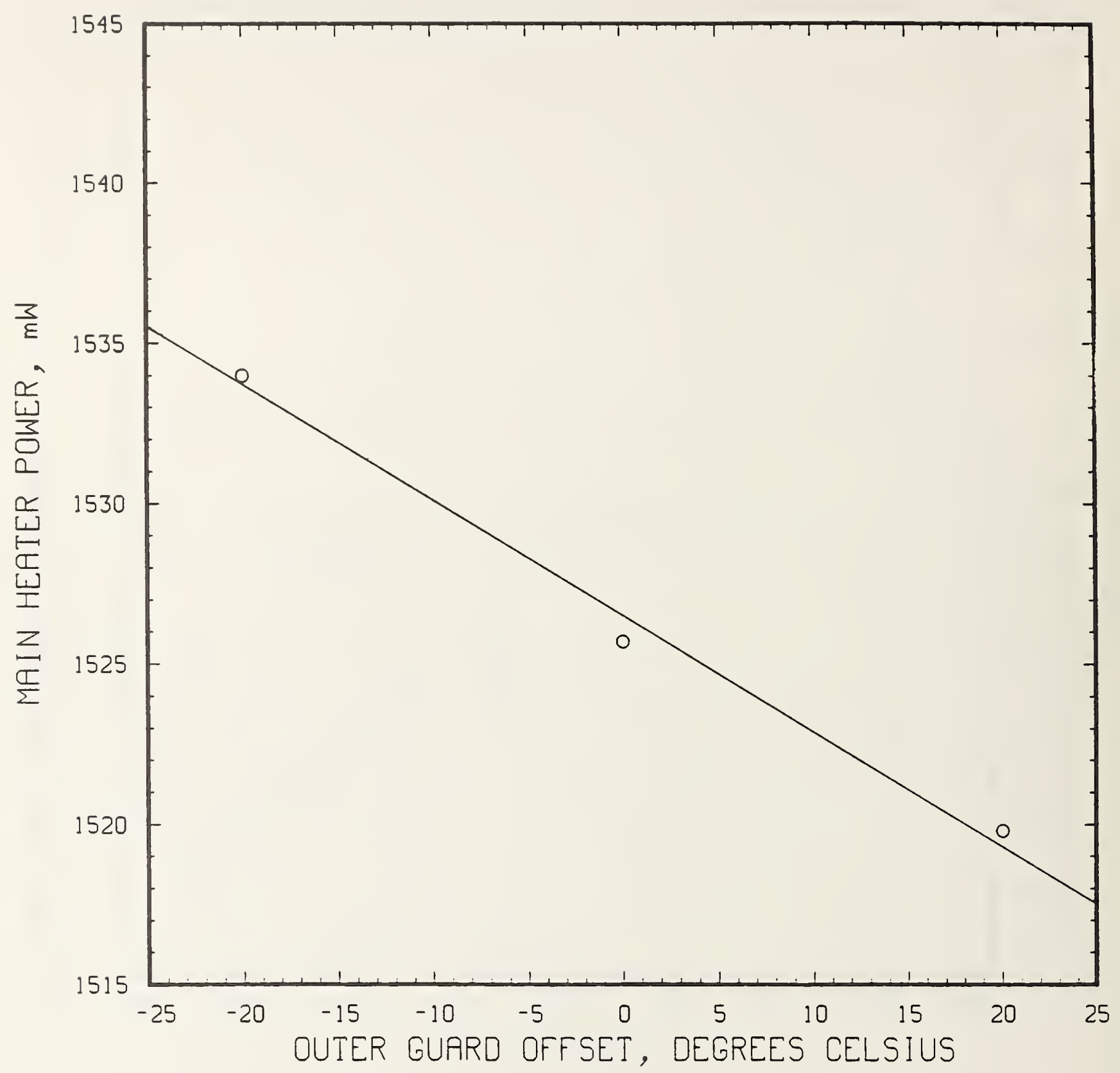

Figure 21. Main heater power supplied to specimens of fibrous alumina-silica insulation board, for outer-guard offsets of $\pm 20 \mathrm{~K}$ 


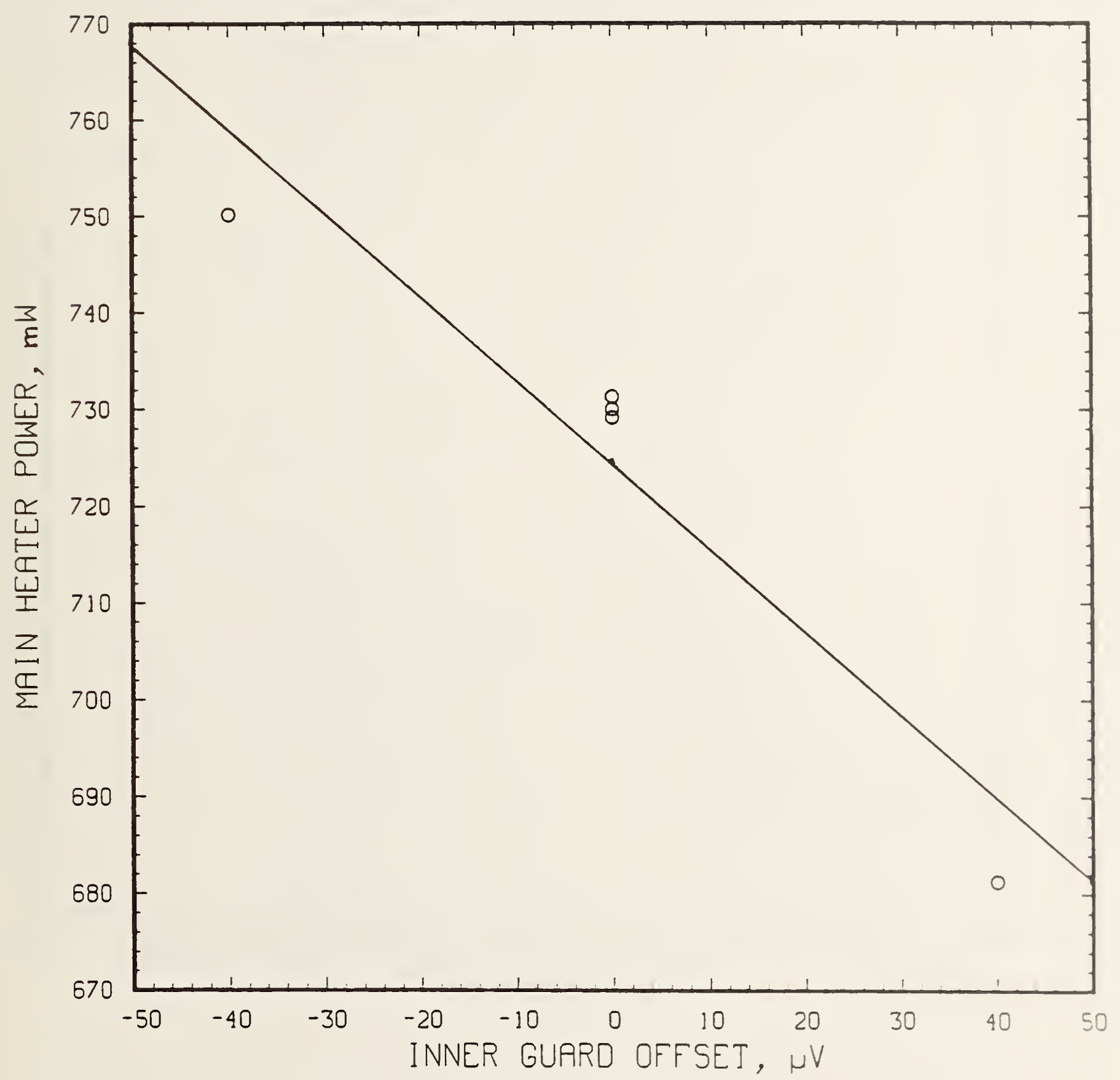

Figure 22. Main heater power supplied to specimens of fibrous glass insulation board for inner-guard offsets of $\pm 40 \mathrm{uV}$ 


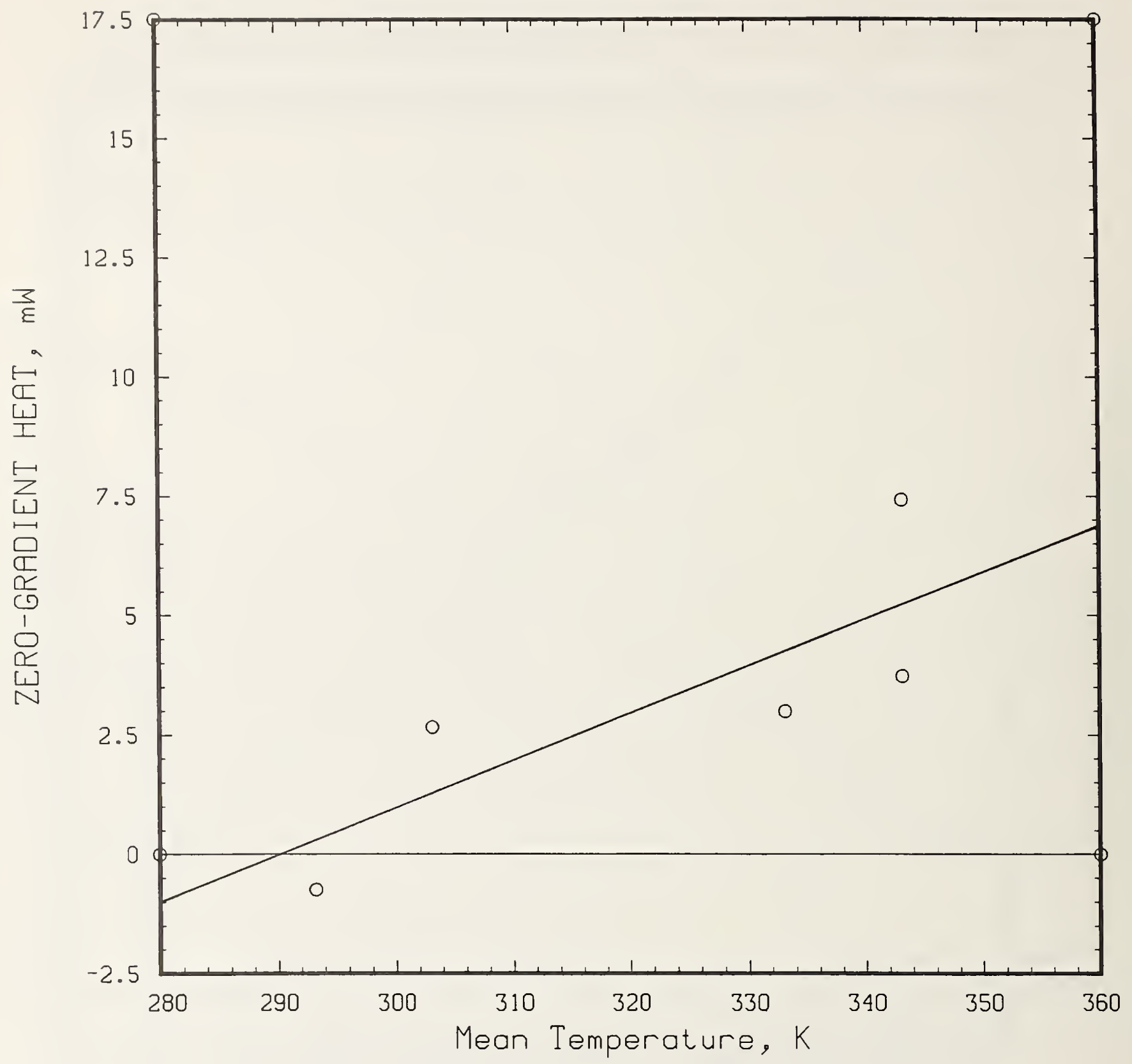

Figure 23. Zero-gradient heat vs. temperature, for fibrous glass insulation board 


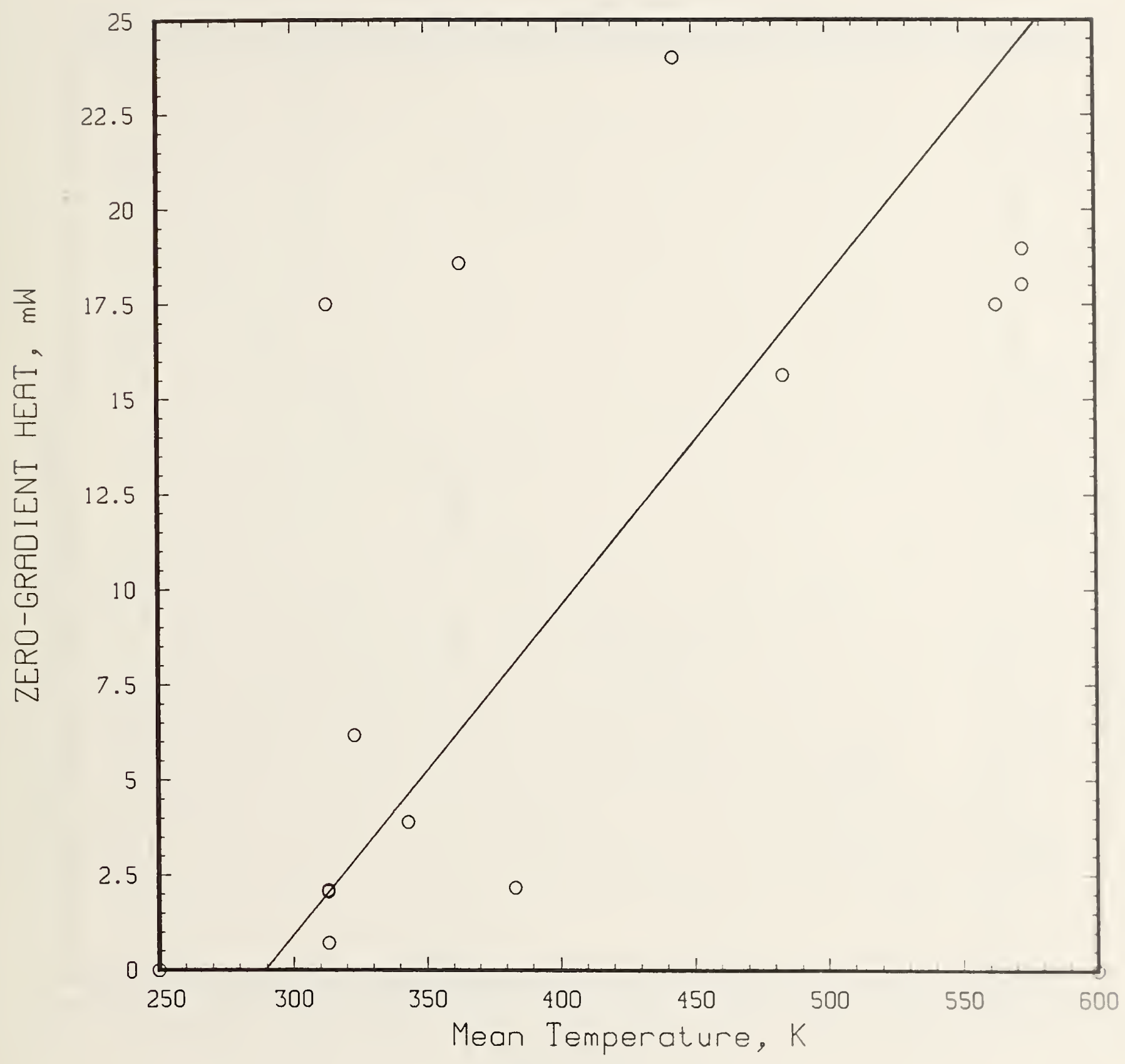

Figure 24. Zero-gradient heat vs. temperature, for fibrous alumina-silica insulation board 


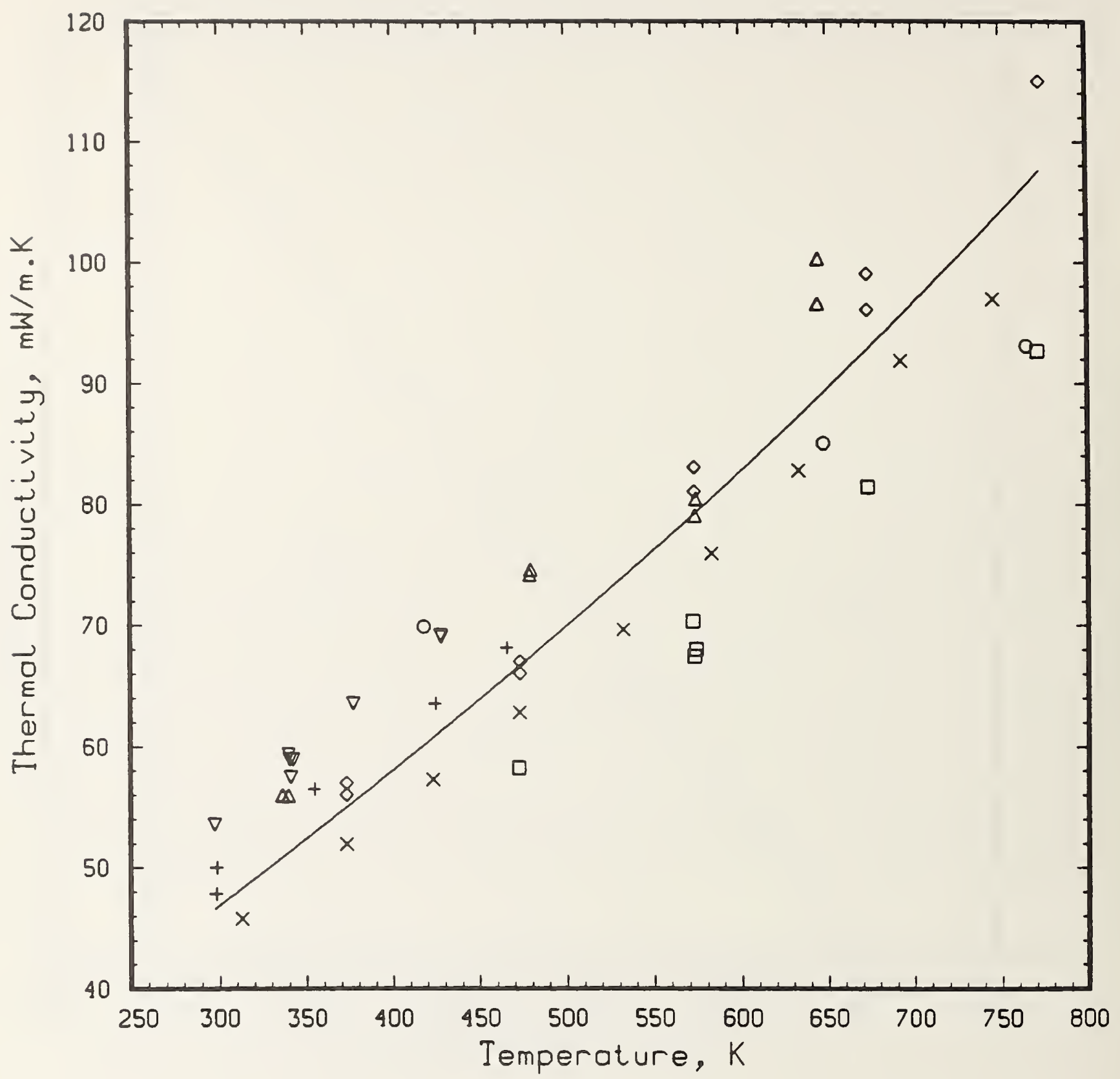

Figure 25. Thermal conductivity round-robin test results for fibrous alumina-silica. The solid curve is calculated from $k(T)=15.98+0.1003 T+3.053 \times 10-8 T^{3}$ 


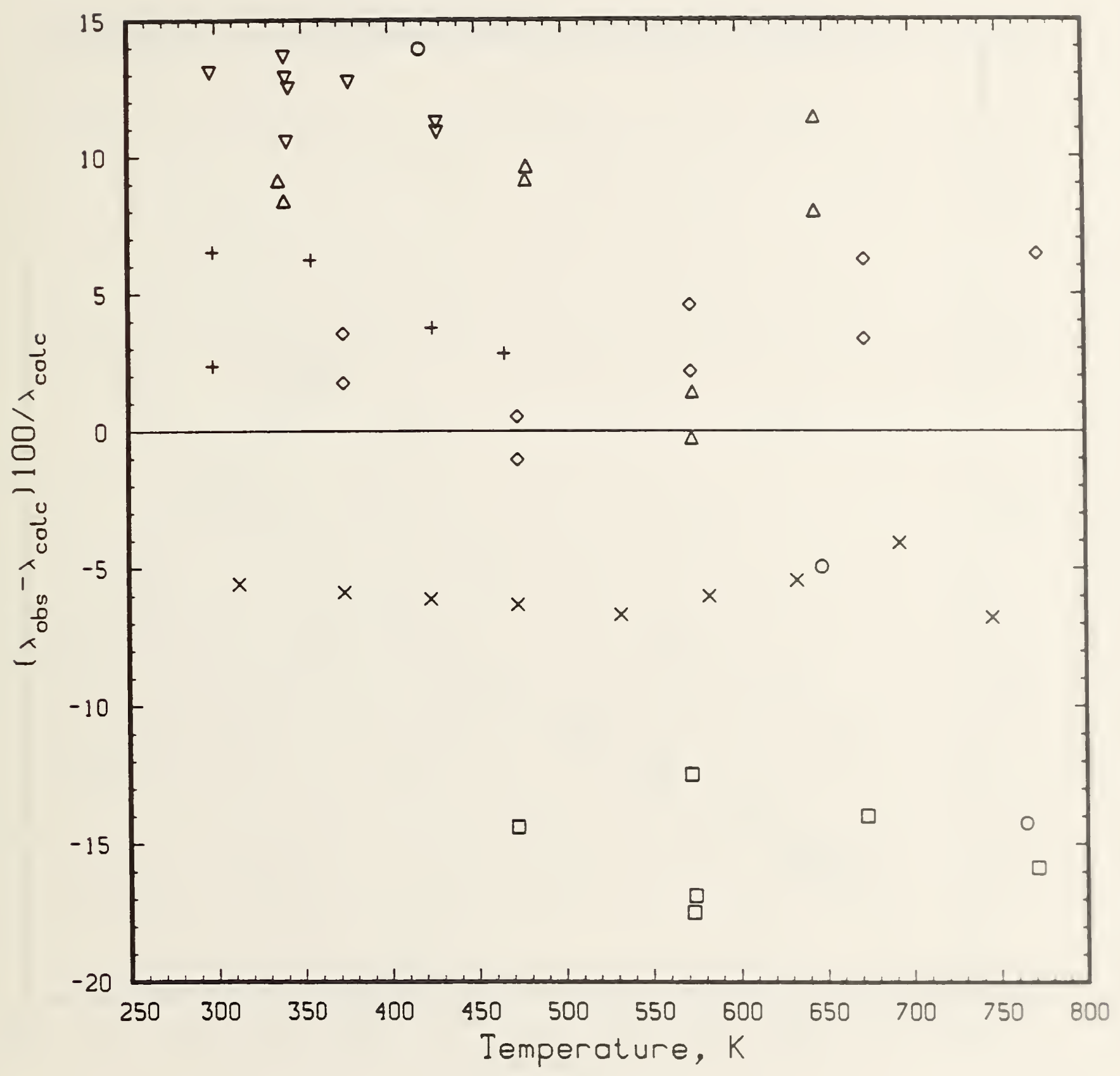

Figure 26. Deviations of thermal conductivity round-robin test results from values calculated for fibrous alumina-silica, using the relation given in caption to Figure 25 


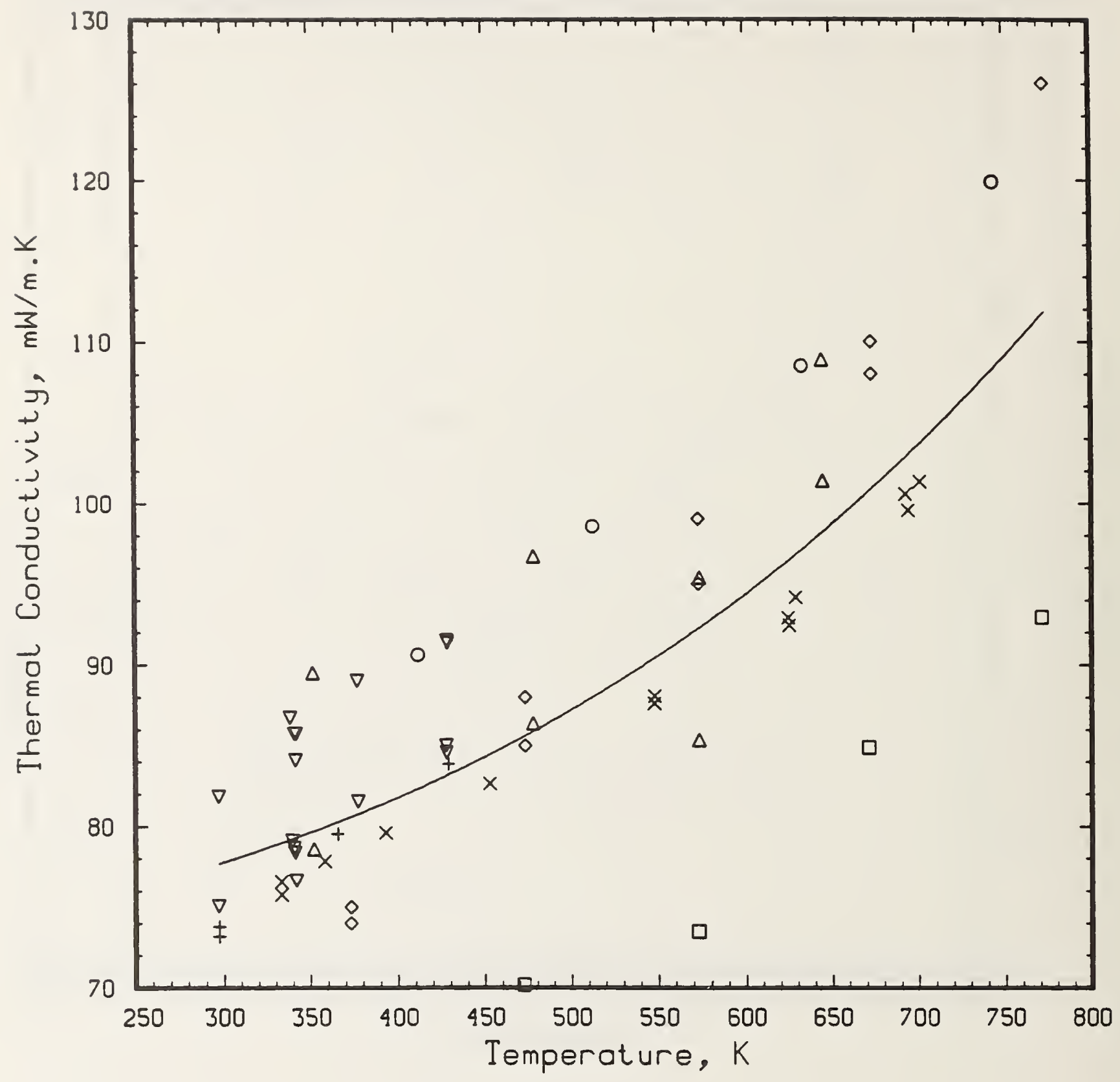

Figure 27. Thermal conductivity round-robin test results for calcium silicate. The solid curve is calculated from $k(T)=70.67+0.01878 T+5.796 \times 10^{-8} T^{3}$ 


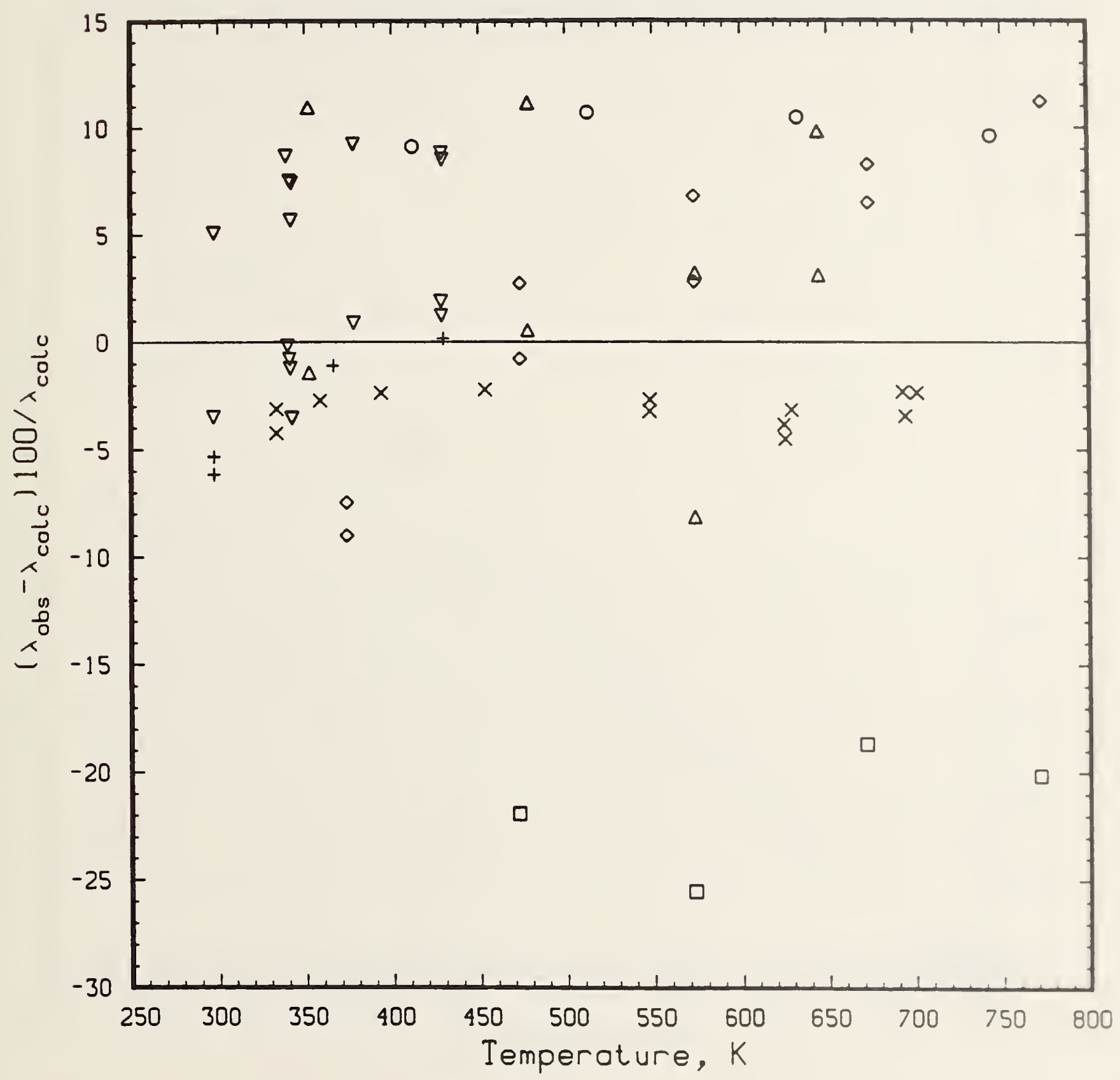

Figure 28. Deviations of thermal conductivity round-robin test results from values calculated for calcium silicate, using the relation given in caption to Figure 27 


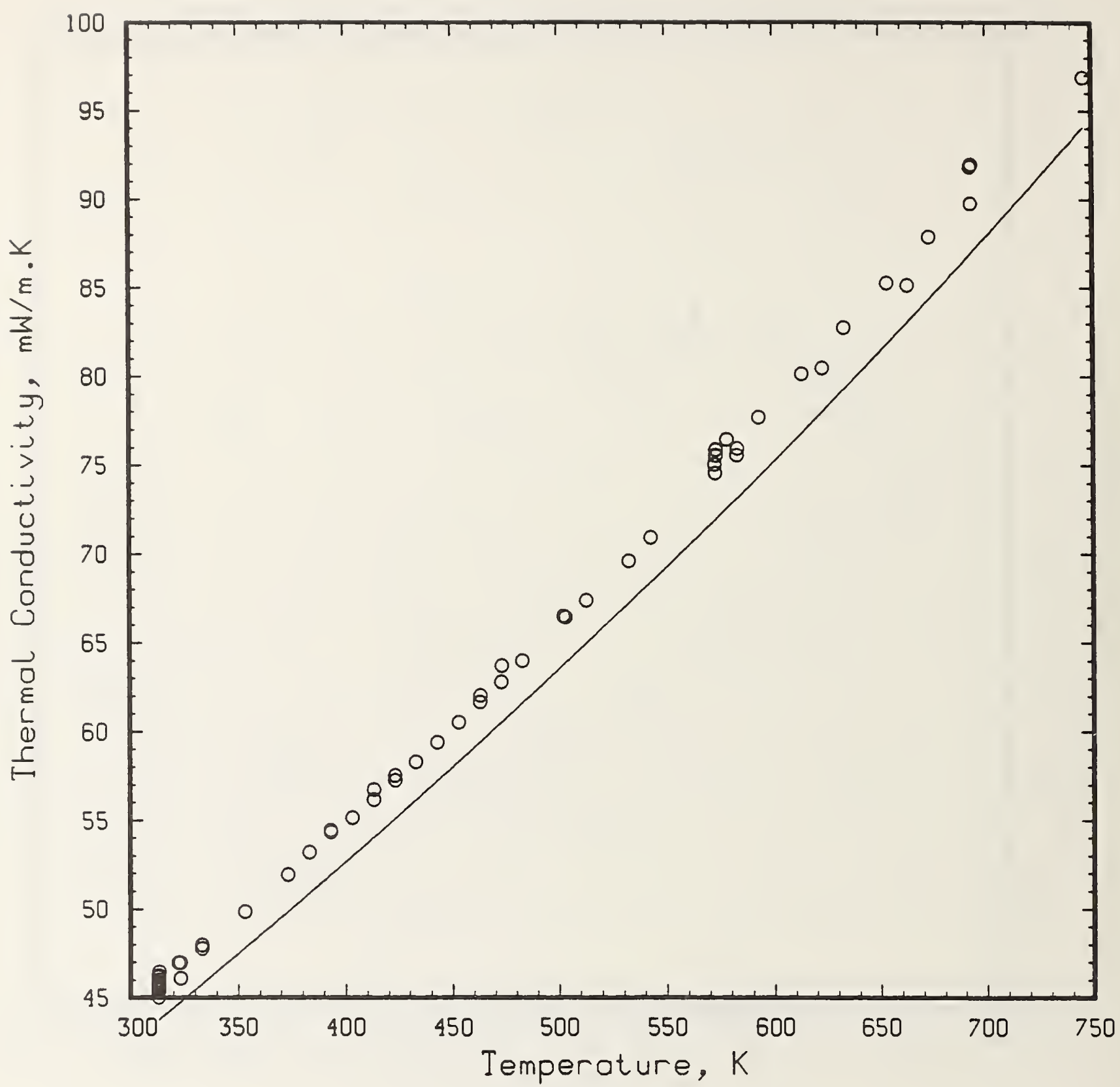

Figure 29. Thermal conductivity of refractory fibrous aluminasilica insulation board (circles) compared to functional correlation of Mitchell [8] 


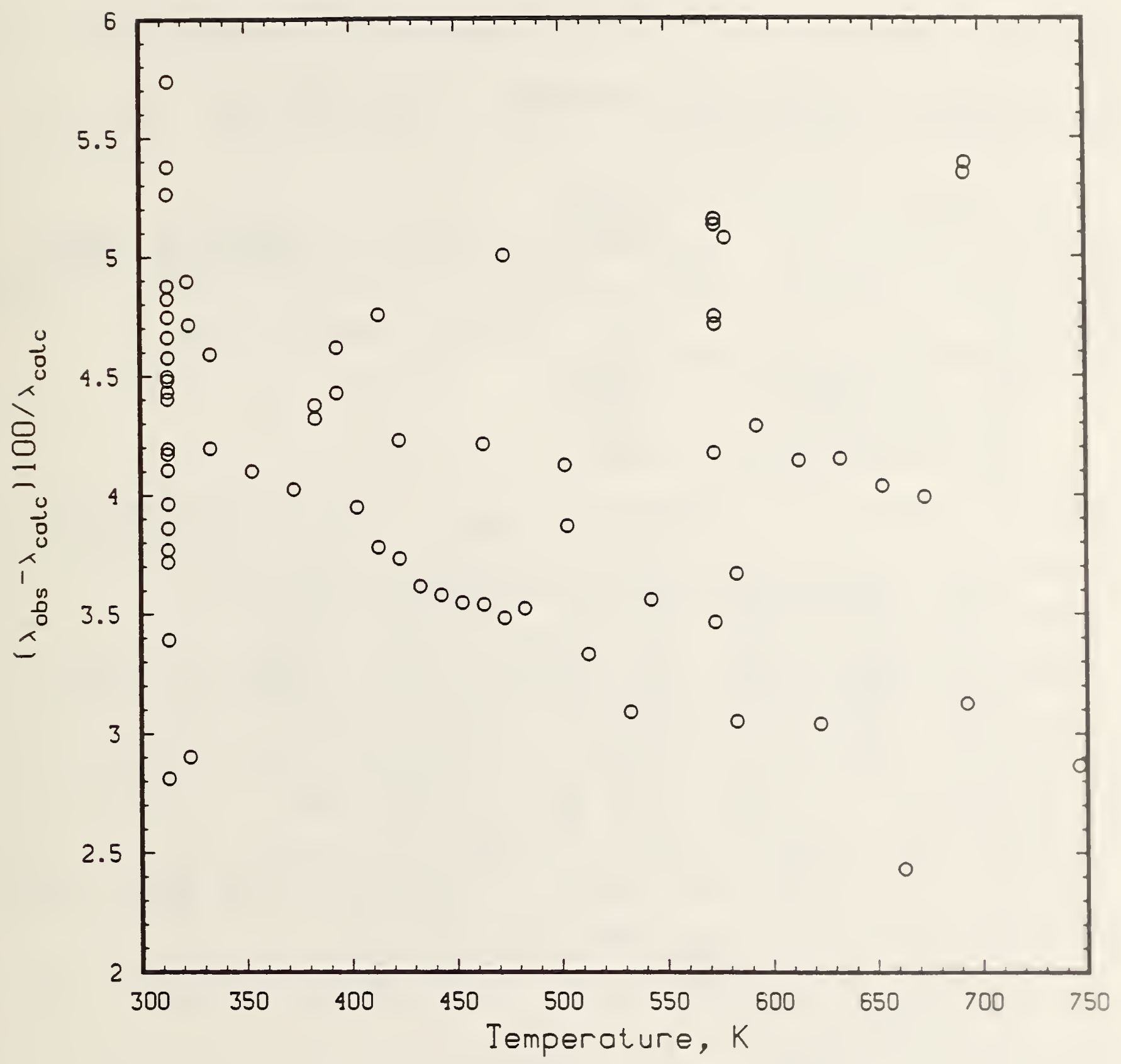

Figure 30. Relative deviation of thermal conductivity data from functional correlation of Mitchell 
Table 1. Typical data summary as printed at end of a measurement sequence

\section{FILE NAME : FSIL094}

13 Nov 1987 10:26:25 OPERATING MODE : DOUBLE SIDED

USER DETERMINED STABILITY AT : $1.3 \mathrm{~min}$. ; TOTAL RUN TIME : $293 \mathrm{~min}$. SRM CANDIDATE: FUMED SILICA

\section{GENERAL FILE SPECIFICATIONS:}

SAMPLE THICKNESS $(\mathrm{cm})$; UNCORRECTED $=2.523, \quad$ CORRECTED $=2.533$

MAIN PLATE AREA $\left(\mathrm{cm}^{\wedge} 2\right) ;$ UNCORRECTED $=123.505 ; \quad$ CORRECTED $=128.909$ AREA DENSITY $\left(\mathrm{kg} / \mathrm{m}^{\wedge} 2\right)=7.704$, CORRECTED BULK DENSITY $\left(\mathrm{kg} / \mathrm{m}^{\wedge} 3\right)=304.064$ PLATE SPACER MATERIAL : STAINLESS STEEL

FILL GAS : AIR

SPECIMEN AND SPECIMEN GUARD CODES :

$\begin{array}{ll}\text { TOP SPECIMEN CODE } & : \text { FUSIL-1 } \\ \text { TOP GUARD CODE } & \text { NONE } \\ \text { BOTTOM SPECIMEN CODE } & \text { FUSIL-2 } \\ \text { BOTTOM GUARD CODE } & \text { : NONE }\end{array}$

CORRECTED AVERAGE PLATE TEMPERATURES (degC) AND TEMP. CORRECTIONS:

UPPER AUX. PLATE TEMP.$=226.983$, STD.DEV $=.007$

TEMP. CORRECTION $=-.0979, \mathrm{dT} / \mathrm{dt}(\mathrm{deg} / \mathrm{hr})=.0326$

UPPER MAIN PLATE TEMP. $=324.5048$, STD.DEV $=.0056$

TEMP . CORRECTION $=-.1753, \mathrm{dT} / \mathrm{dt}(\mathrm{deg} / \mathrm{hr})=.0318$

LOWER MAIN PLATE TEMP.$=324.3238$, STD.DEV.$=.0058$

TEMP. CORRECTION $=-.0876, \mathrm{dT} / \mathrm{dt}(\mathrm{deg} / \mathrm{hr})=.0339$

LOWER AUX. PLATE TEMP. $=226.587$, STD.DEV. $=.0045$

TEMP. CORRECTION $=-1.2749, \mathrm{dT} / \mathrm{dt}(\mathrm{deg} / \mathrm{hr})=.0016$

UPPER del ta $T=97.5217$, STD. DEV. OF MEAN $=.0027$

LOWER delta $T=97.7368$, STD. DEV. OF MEAN $=.0022$

TOTAL delta T $(T 2-T 1+T 3-T 4)=195.2586$

STD. DEV. OF DelT =.0117, \% STD.DEV. OF DeIT $=0$

STD. DEV. OF THE MEAN $=.0035, \%$ STD.DEV. OF THE MEAN $=.0018$

AVG. MAIN HEATER PLATE POHER $(\mathrm{mW})=2398.518$

STD.DEV. OF $Q=13.354, \%$ STD.DEV. OF $Q=.55$

STD.DEV. OF THE MEAN $=.702, \%$ STD.DEV. OF THE MEAN $=.029$ $\mathrm{dP} / \mathrm{dt}(\mathrm{mW} / \mathrm{hr})=-6.977$

DATA AVERAGING INTERVAL : 30 MINUTES

START POINT OF INTERVAL : 262.1 MINUTES

FINAL HEATER RESISTANCE : 5.1361 OHMS

IG THERMOPILE FINAL READINGS :

UPPER PILE : $1 \uparrow .5$ microvolts

LOWER PILE : -9 microvolts

TOTAL PILE : 2.1 microvolts

Thi $($ degC $)=324.4143$, Tlo $(\operatorname{deg} C)=226.785$, de $1 T=97.6293$ AVG. TEMP. (C) IS: 275.600 , THERMAL COND. ( $k)=24.14 \mathrm{mH} /(\mathrm{m} * \mathrm{~K}$ STD.DEV. OF $k=.134, \%$ STD.DEV. OF $k=.55$ 
Table 2. Estimates of random variations and systematic uncertainties in measured quantities at room temperature.

A. Measurements at $325 \mathrm{~K}(52 \circ \mathrm{C})$

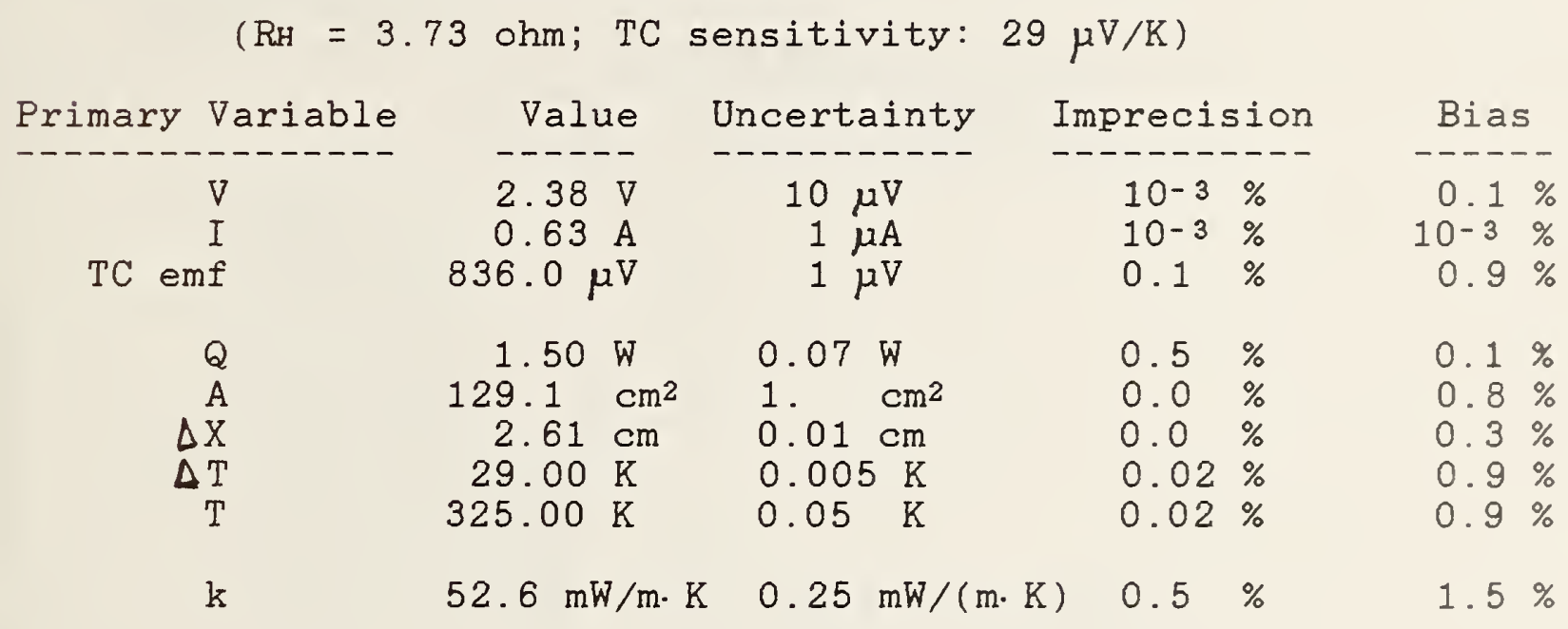

B. Measurements at $750 \mathrm{~K}(4770 \mathrm{C})$

$(\mathrm{RH}=5.71 \mathrm{ohm} ; \mathrm{TC}$ sensitivity: $38.4 \mu \mathrm{V} / \mathrm{K})$

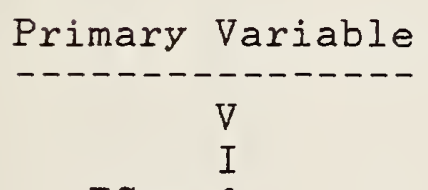

TC emf

$Q$
$A$
$\Delta X$
$\Delta T$
$T$

$\mathrm{k}$

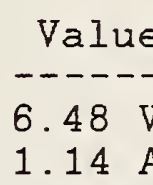

$15.9 \mathrm{mV}$

$\begin{array}{rl}7.40 & \mathrm{~W} \\ 129.1 & \mathrm{~cm}^{2} \\ 2.61 & \mathrm{~cm} \\ 75.00 \mathrm{~K} \\ 750.00 \mathrm{~K}\end{array}$

$100.0 \mathrm{~mW} / \mathrm{m} \cdot \mathrm{K}$

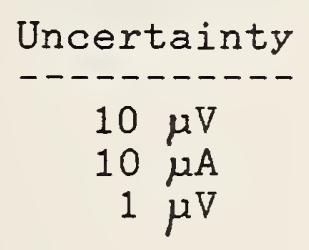

$0.05 \mathrm{~W}$

1. $\mathrm{cm}^{2}$

$0.01 \mathrm{~cm}$

$0.015 \mathrm{~K}$

$0.15 \mathrm{~K}$

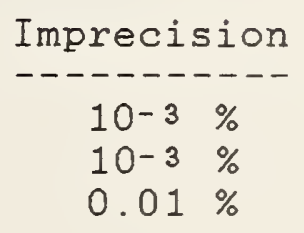

$0.7 \%$

$0.0 \%$

$0.0 \%$

$0.02 \%$

$0.02 \%$
Bias

-----

$0.1 \%$

10-3\%

$0.02 \%$

$2 \%$

$0.8 \%$

$0.3 \%$

$0.9 \%$

$0.9 \%$

$2.5 \%$ 

Appendix A: BASIC-Language Computer Program, "HT_GHP", for the High-Temperature Guarded-Hot-Plate Apparatus.

I PROGRAM 'HT_GHP' LAST REVISION DATE : 8-12-87

1 THIS PROGRAM OPERATES THE HIGH TEMPERATURE GUARDED HOT

PLATE THERMAL CONDUCTIVITY APPARATUS.

TEMPERATURES OF VARIOUS PARTS OF THE APPARATUS WILL

I BE PRINTED OUT ON THE THERMAL PRINTER DURING THE SYSTEM'S

1 EQUILIBRATION PROCESS. TC TEMPERATURE DATA WILL BE PRINTED OUT

AFTER THE DATA ACQUISITION PHASE IS COMPLETE AND WILL THEN BE

STORED ON FLOPPY DISK.

ABBREVIATIONS USED: tc $=$ thermocouple

RTD = platinum resistance the rmometer

$M H=$ MAIN (METERED) HEATER PLATE

$I G=$ INNER GUARD HEATER PLATE

$O G=$ OUTER GUARD HEATER PLATE

HPIB ADDRESS LIST:

$T / B A H=$ TOP $/$ BOTTOM HEATER PLATES

$\begin{array}{lr}\text { PRINTER } & : 701 \\ \text { DVM } 195 \text { (IG) } & : 706 \\ \text { DVM } 195 \text { (OG) } & : 707 \\ \text { DVM } 195 \text { (TAHP) } & : 708 \\ \text { DVM } 195 \text { (BAHP) } & : 709 \\ \text { DVM } 181 \text { (MEAS. SENSORS) } & : 710 \\ \text { DVM } 181 \text { (MHP) } & : 712 \\ \text { MULT IPROGRAMMER } & : 723 \\ \text { PPROGRAMMER CARD ADDRESSES: }\end{array}$

MULTIPROGRAMMER CARD ADDRESSES:

DIGITAL OUTPUT CARD : 00

DIGITAL INPUT CARD : 01

HI SPEED A/D CARD : 02

RELAY OUTPUT CARD : 05

VOLTAGE D/A CARDS : 07

07 (METERED AREA HEATER )

Q8 (OUTER GUARD HEATER )

09 (TOP AUXILIARY HEATER )

10 (BOTTOM AUXILIARY HEATER )

165

170

SCAN CONTROL CARD $: 11$ (INNER GUARD HEATER )

FET SCAN $16: 15$

! PROGRAM SUBROUTINE LIST :

GOTO 1105

GOTO 10360

GOTO 16915

GOTO 15280

GOTO 17085

GOTO 18505

GOTO 7865

GOTO 12620

GOTO 9020

GOTO 12525

GOTO 7275

GOTO 7445

GOTO 13115

GOTO 6740

GOTO 17870

GOTO 13745

GOTO 14480

GOTO 14690

GOTO 14395

GOTO 10115

GOTO 12215

GOTO 11070

GOTO 15660

GOTO 11760

GOTO 10275

GOTO 10245

GOTO 13255

GOTO 15410

GOTO 9155

GOTO 7690

GOTO 12740

GOTO 18110

GOTO 18075

GOTO 14090

GOTO 5375

GOTO 5235
(SKIP FOLLOWING Adjust

* Atod_io

Chan_switch

Data_read

Err_record

Finol_averages

FNChon_sig

FNEmf_tc

FNOhms_rtd

FNT emP_rtd

FNT emp_tc

G_label

Init_run_vars

K_stor

K_ghp

Linear

Manua!

Outseven

Pock_queue

Pblank

Pid

Plot_prep

Plot_switch

Poweroff

Poweron

- Read_io

Reod_old_dato

Record_data

Ref_rtd

Rescole_plot

Rtd_tune

Run_abort

Set_pnt_colc

- Sys_init

Sys_shutdown
LIST TO BEGIN AT MAIN PROGRAM) (GOTO'S HERE ENABLE AUTOMATIC

RENUMBER ING) 


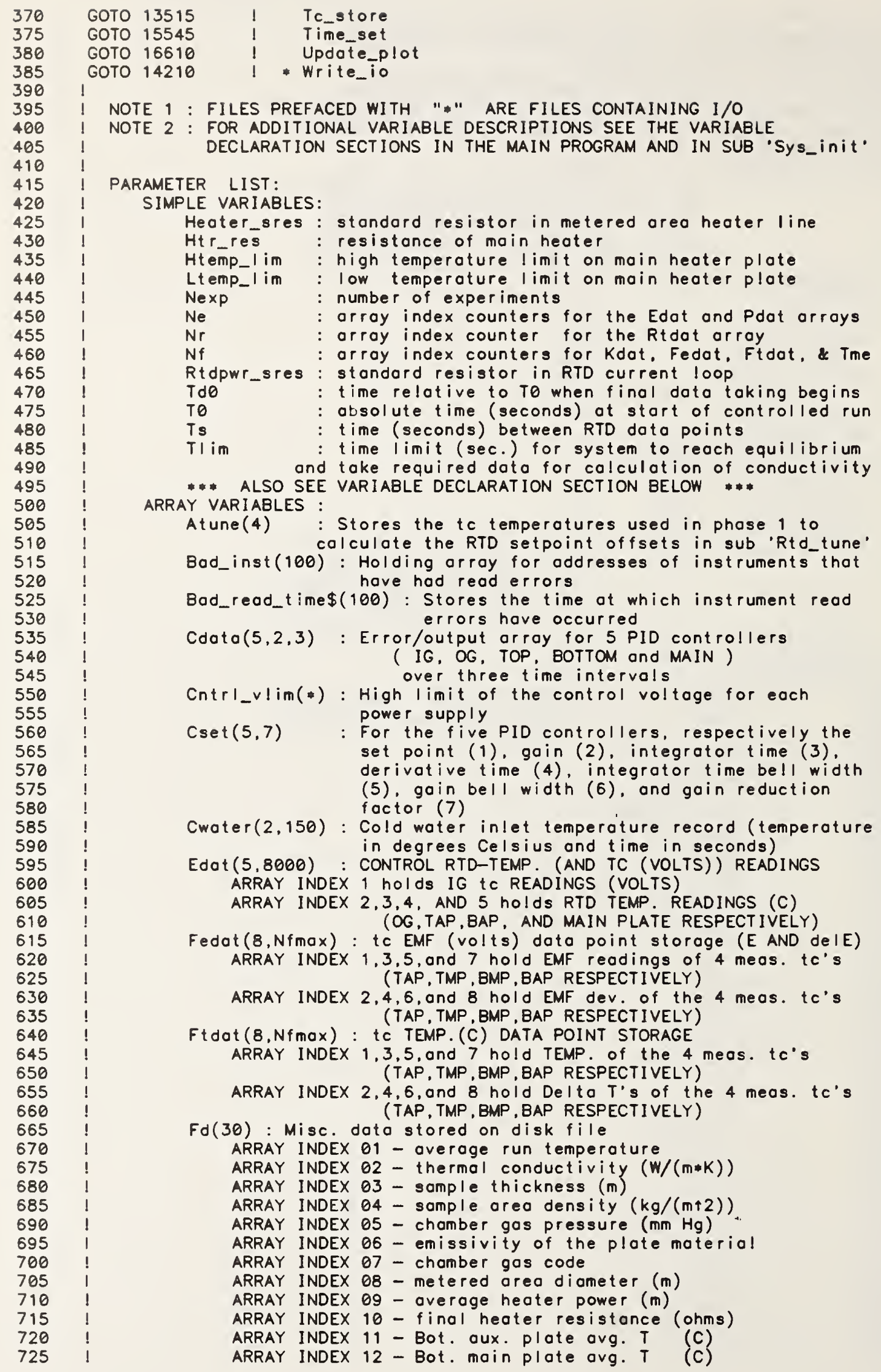


ARRAY INDEX 13 - TOP moin plote ovg. T (C)
ARRAY INDEX 14 - TOP auX. plate ovg. T

ARRAY INDEX $15-R C=$ code for run mode $(1$ = double sided:

2 = single sided: top; $3=$ single sided: bottom)

ARRAY INDEX 16 - Thi : avg. high temp. meosured (C)

ARRAY INDEX 17 - TIO : ovg. Iow temp. meosured (C)

ARRAY INDEX 18 - IG bottom (volts)

ARRAY INDEX 19 - IG combined (volts)

ARRAY INDEX 20 - IG tOP (volts)

ARRAY INDEX 21 - Dr : IG gop width (m)

ARRAY INDEX 22 - Sc : Plate spocer code

( 1 = quartz, 2 = stainless steel)

ARRAY INDEX 23 - DXc : Corrected somple thickness (m)

ARRAY INDEX 24 - Ts : Controller cycle time (seconds)

ARRAY INDEX 25 - Acor: Corrected moin plote oreo (m†2)

ARRAY INDEX 27 - TdO : Start time of dota oquisition (sec)

ARRAY INDEX 28 - Finol overoging interval for dato (sec)

ARRAY INDEX 29 - Starting point for final overoging intervol

ARRAY INDEX 30 - Type of run code : $\theta=$ normol or zero.

ARRAY INDEX 26 - spare orray spoce

File_num(Nexp) : file number for eoch experimental run

File_specs\$(5)[80]: string orroy stored on disk file

ARRAY INDEX 1 HOLDS THE FILENAME, RUN DATE, AND OPER. MODE

ARRAY INDEX 2 HOLDS HI AND LO TEMP. SETPOINTS AND THE

MAIN HEATER OPERATING MODE

ARRAY INDEX 3 HOLDS THE TIME TO EQUILIBRATION AND HOW IT WAS DETERMINED, AND TOTAL RUN TIME

ARRAY INDEX 4 CHAMBER GAS, SPECIMEN CODE (TOP AND BOTTOM). GUARD CODE (TOP AND BOTTOM)

ARRAY INDEX 5 MATERIAL DESCRIPTION/USER COMMENTS ON THE RUN Htemp(Nexp) : High temp. for eoch experiment

$\mathrm{Ht}$ mode(Nexp) : Moin heoter plote control mode indicotor 1 = constant temperature mode

2 = constant power mode

$\operatorname{Kdat}(\mathrm{Nfmax})$

- Data point store for 'run time' calc. of $k$

Lost_reoding(Indx) : Records last $V$ on JRL chonnel 'Indx'

Ltemp(Nexp) : Low temperoture for eoch experiment

Mode\$(4)[34] : string vector for operoting modes

Ok_flog(4) : stability flag for RTD setpoint offsets

Op_mode(Nexp) : Operotion mode for eoch of the experiments $0=$ double sided operotion

1 = single sided operotion (top)

2 = single sided operation (bottom)

Pdat (2,8000) : Heater power data storage orray (these dato ore sampled every Ts seconds)

ARRAY INDEX 1 Moin heoter current (omps)

ARRAY INDEX 2 Moin heoter voltoge (volts)

Queve $(\mathrm{Nq})$ : Holds scanner relay \#'s (to be sconned in sequence)

Qseq1(Nqs1): Holds the sconner sequence (s.c.) for the tc's

Qseq2(Nqs2): Holds the s.c. for the iso-block temp. reoding

Qseq3(Nas3) : Holds the s.c. for the three IG parts

Qseq4(Nas4) : Holds the s.c. for the moin htr. current reoding

Qseq5(Nqs5) : Holds the s.c. for the DVM zero reoding updotes

Qseq6(Nas6): Holds the s.c. for phose 1 tc meosurements

Rtdot (2,Nrmox) : TEMP. (C) AND TIME (seconds) doto point storage for the isothermol reference block RTD

ARRAY INDEX 1 Holds the temperoture doto

ARRAY INDEX 2 Holds the time doto

Run_errors $\$(E r r$ mox) : Record of errors occurring during o run

Sdlim(5) : 2 std.dev. I imit for phose 1 RTD temp. stobility

Sp_corr(5) : RTD temp. setpoint corrections for phase 1 control

Sp_errlim(5): Temp. deviotion from setpoint; limit for phose? stability.

Splast $(5,2)$ : holds the previous ond current RTD temp. setpoint corrections.

Tme (Nfmax) : TIME (sec) orroy for the doto in Fedot. Ftdat. AND Kdat (one to one arroy index correspondence)

Zhistory $(3,2)$ : this holds the dvm zero values ot the beginning and end of phase 2 


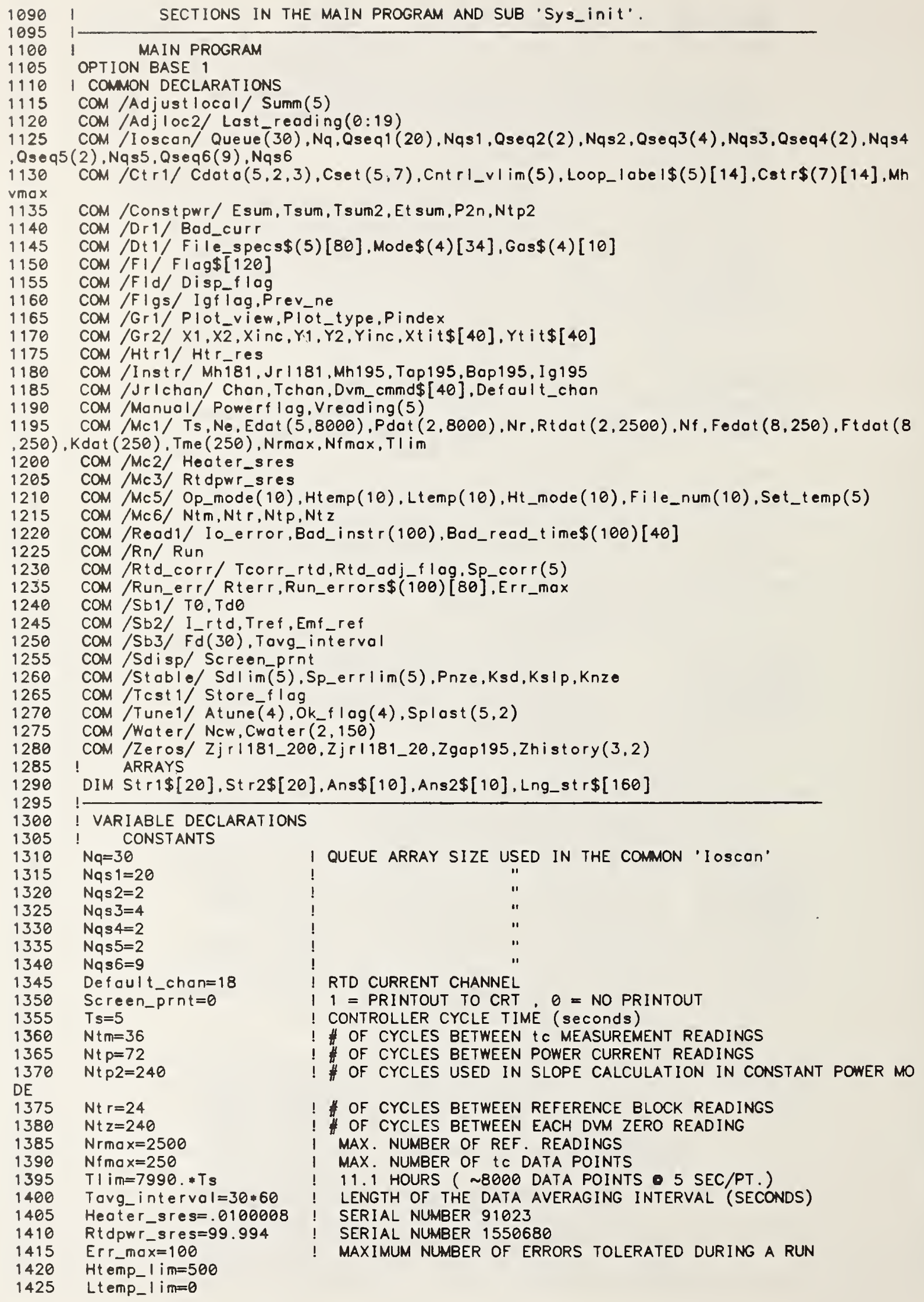




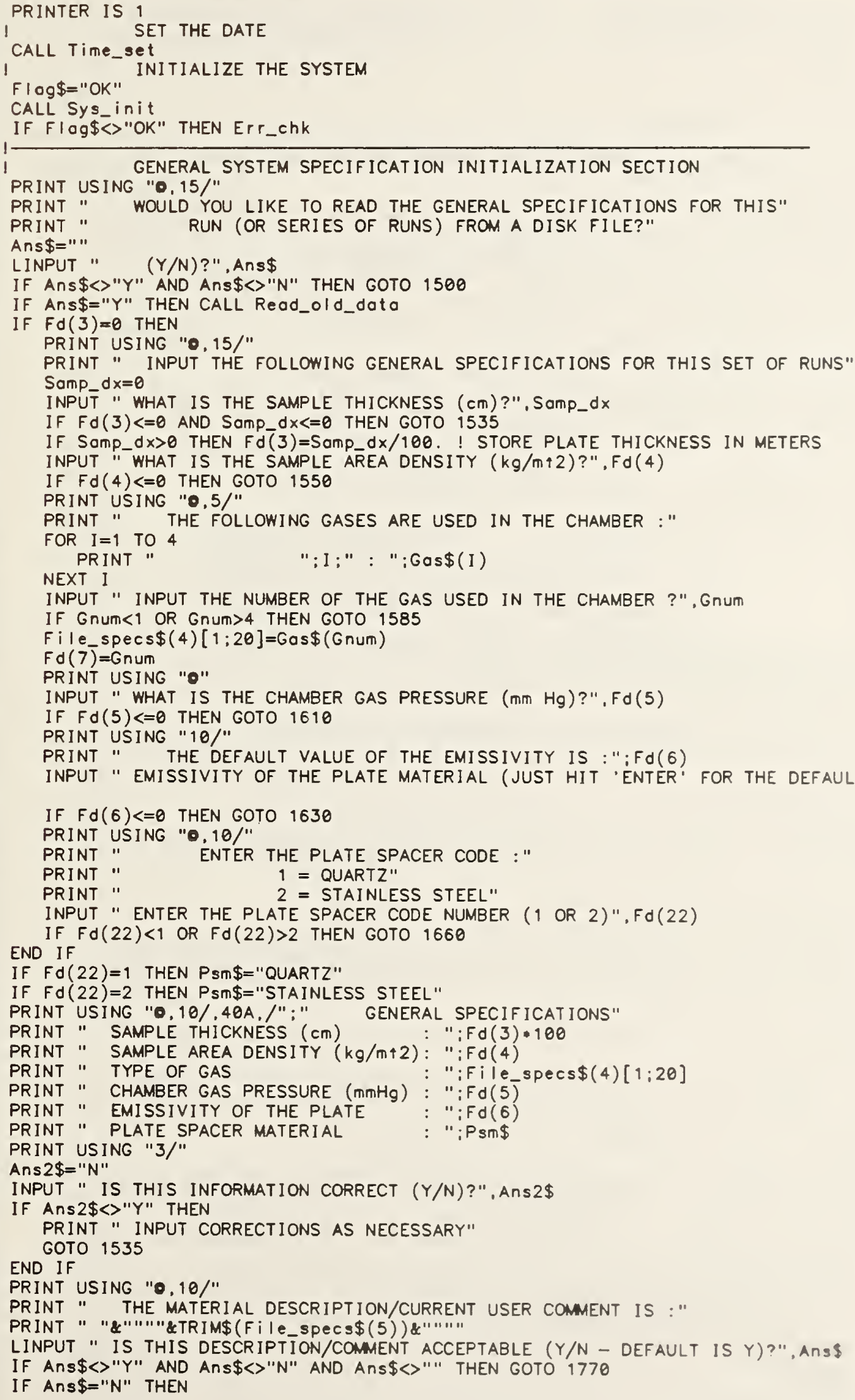


LINPUT " ENTER YOUR MATERIAL DESCRIPTION/COMMENT (80 CHARACTER MAX.)", Lng_str\$ IF LEN(Lng_str\$)>80 THEN DISP " YOU ARE TOO WORDY ... BE CONCISE (LESS THEN 80 CHARACTERS!)" WAIT 2

END IF GOTO 1785

END IF

File_specs $\$(5)=$ Lng_st $\$$

File_specs $\$(4)[1]=F i \mid e_{-} \operatorname{specs} \$(4) \& R P T \$("$ ", 80-LEN(File_specs\$(4)))

IF LEN(TRIM\$(File_specs\$(4))) <21 THEN

PRINT USING "ه"

LINPUT " ENTER THE TOP SPECIMEN CODE ( 10 CHAR. MAX. ) :",Lng_str\$

IF LEN(Lng_str\$)>10 THEN GOTO 1840

IF LEN(Lng_st $r \$)>0$ THEN File_specs $\$(4)[21,30]=\operatorname{Lng} s t r \$$

LINPUT " ENTER THE TOP GUARD CODE ( 10 CHAR. MAX. ) :", Lng_st $\$$

IF LEN(Lng_st $\$$ ) $>10$ THEN GOTO 1855

IF LEN(Lng_str $\$$ ) >0 THEN Fi le_specs $\$(4)[41,50]=$ Lng_st $r \$$

LINPUT "ENTER THE BOTTOM SPECIMEN CODE ( 10 CHAR. MAX. ) : ", Lng_str\$

If LEN(Lng_st $r \$$ ) $>10$ THEN GOTO 1870

IF LEN(Lng_str $\$$ ) >0 THEN File_specs $\$(4)[31,40]=$ Lng_str $\$$

LINPUT " ENTER THE BOTTOM GUARD CODE ( 10 CHAR. MAXX. ) :", Lng_str\$

IF LEN(Lng_st $r \$)>10$ THEN GOTO 1885

If LEN(Lng_str $\$$ ) >0 THEN File_specs $\$(4)[51,60]=$ Lng_st $\$$

END IF

PRINT USING "०, 5/"

PRINT " SPECIMEN AND SPECIMEN GUARD CODES :"

PRINT USING " 3 /"

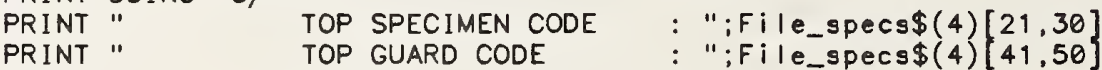

PRINT

PRINT " BOTTOM SPECIMEN CODE : ";File_specs\$(4) $[31,40]$

PRINT" BOTTOM GUARD CODE : "; File_specs $\$(4)[51,60]$

Ans $\$=" "$

INPUT " ARE THESE CODES CORRECT ( $/ N / N)$ ?", Ans\$

If Ans\$<>"Y" AND Ans\$<>"N" THEN GOTO 1950

IF Ans $\$=" N "$ THEN GOTO 1835

PRINT USING "0,10/"

INPUT "HOW MANY RUNS DO YOU WANT TO PERFORM $(<=10)$ ?" Ne NP

IF Nexp>10 OR Nexp<1 THEN 1970

PRINT USING "0,7/"

File_specs $\$(1)[1]="$

INPUT " WHAT IS THE FILE NAME PREFIX (FOUR CHARACTERS)?",An $\$$

IF LEN(Ang\$)>4 THEN PRINT USING "2/,50A,2/";" ILLEGAL FILE NAME : IT IS TOOO LONG!!" ELSE GOTO 1985

IF LEN(Ans\$)<1 THEN GOTO 1985

IF NUM(Ans\$)<65 OR NUM(Ans\$)>90 THEN

PRINT USING " $2 /$ "

PRINT " THE FIRST CHARACTER OF THE FILE SPECIFIER MUST BE A LETTER!" END IF GOTO 1985

File_specs $\$(1)[1, \operatorname{LEN}($ Ans $\$)]=A n s \$$

END IF

PRINT USING "4/"

PRINT " THE FILE NAME PREFIX FOR THIS SERIES OF RUNS WILL BE : ";File_specs\$(1) Ans $\$=" \cdot "$

INPUT "IS THIS PREFIX CORRECT ( $Y / N)$ ?",Ans $\$$

IF Ans\$<>"Y" THEN GOTO 1980

Ans $2 \$=" N "$

I IF THE RUN NUMBERS ARE SEQUENTIAL, INITIALIZE THE ENTIRE FILE NUM VECTOR

IF Nexp>1 THEN

Ans $2 \$="$ "

INPUT " WILL THE FILE RUN NUMBERS BE SEQUENTIAL $(Y / N)$ ?", Ans $2 \$$

IF Ans $2 \$=" Y "$ THEN

INPUT " WHAT IS THE RUN NUMBER OF THE FIRST RUN (0 TO 990)?",File_num(1)

IF File_num(1)<0 OR File_num(1)>990 THEN DISP " ILLEGAL RUN NUMBER - TRY AGAIN "

WAIT 3

END IF GOTO 2110

FOR $I=1$ TO Nexp-1 
IF Ht_mode(Isis) $>1$ AND Ht_mode(Isis) $<2$ THEN GOTO 2395

PRINT USING "๑,/////,36A,D,6A";" THE FINAL PARAMETERS FOR RUN NUMBER "; is is;" A

PRINT "

(FILE NUMBER";File_num(Isis);" )"

PRINT

PRINT " SYSTEM";Mode\$(4);Mode\$(OP_mode(Is is))

PRINT USING "27A,DDDD.DD";" HIGH TEMPERATURE IS: ";Htemp(Isis)

PRINT USING "27A,DDDD.DD";" LOW TEMPERATURE IS : "; Ltemp(Isis)

SELECT Ht_mode(Isis)

CASE 1

PRINT " MAIN HEATER PLATE CONTROL MODE : CONSTANT TEMPERATURE"

CASE 2

PRINT " MAIN HEATER PLATE CONTROL MODE : CONSTANT POWER"

END SELECT

An $\$ \$=" N "$

INPUT " ARE THESE VALUES ACCEPTABLE ( $Y / N)$ ?",An $\$$

IF Ans\$<>"Y" THEN GOTO 2245

NEXT Is is 


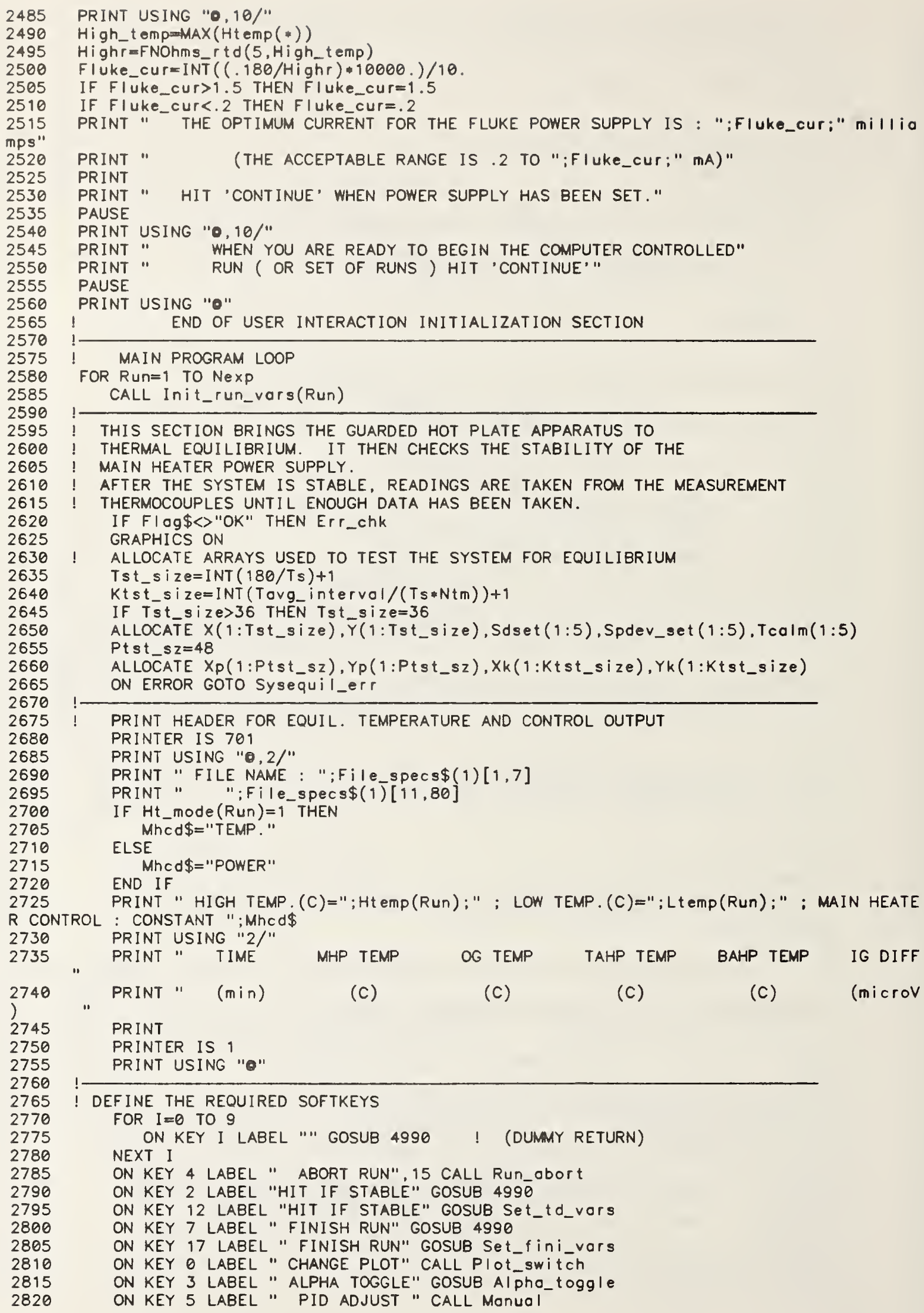


ON" GOSUB 4990

OFF" GOSUB 4990

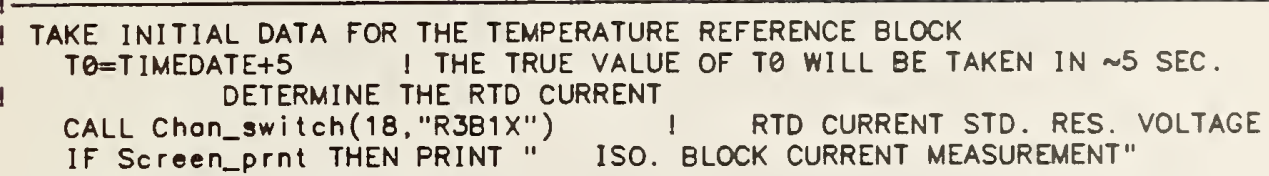




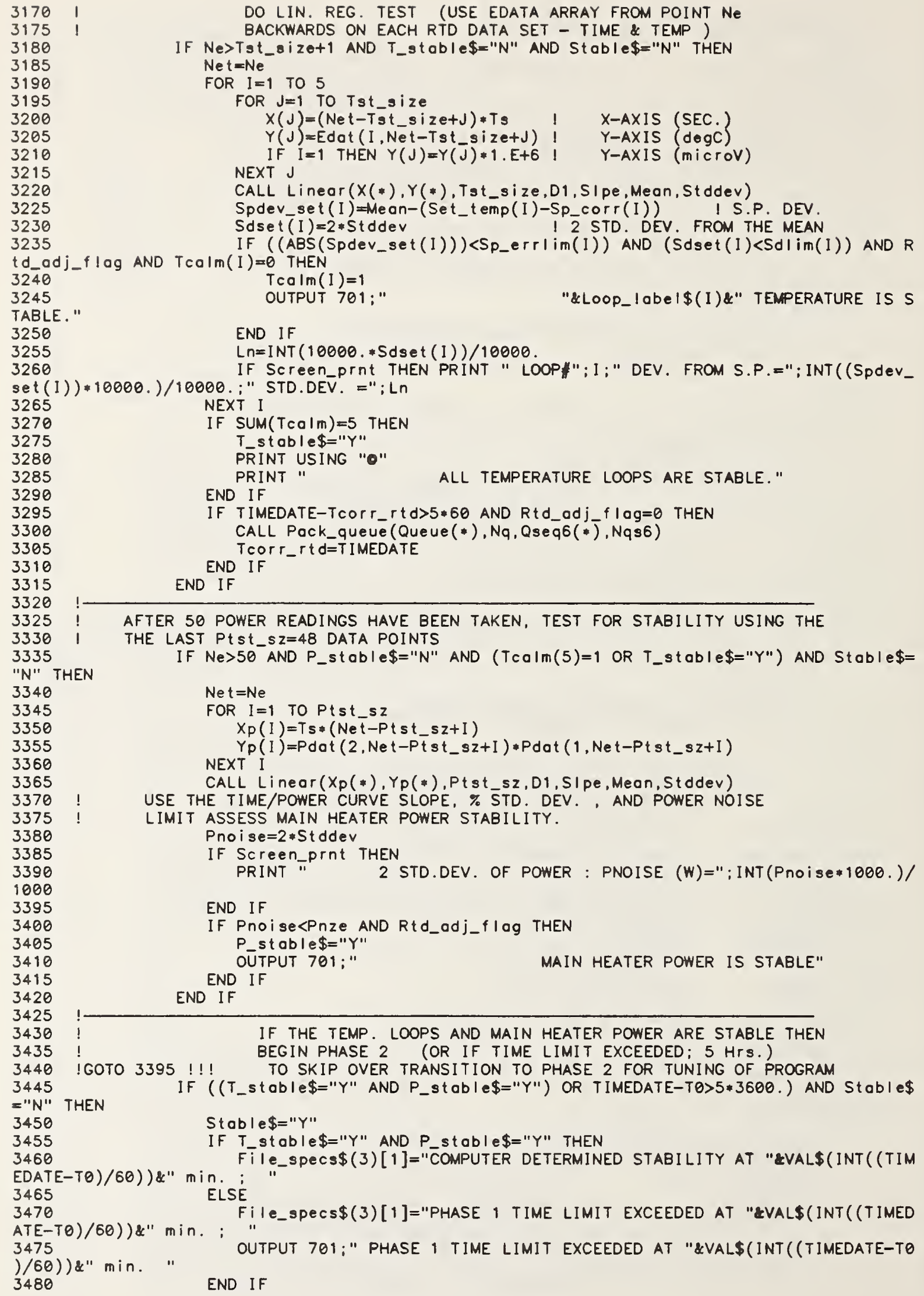




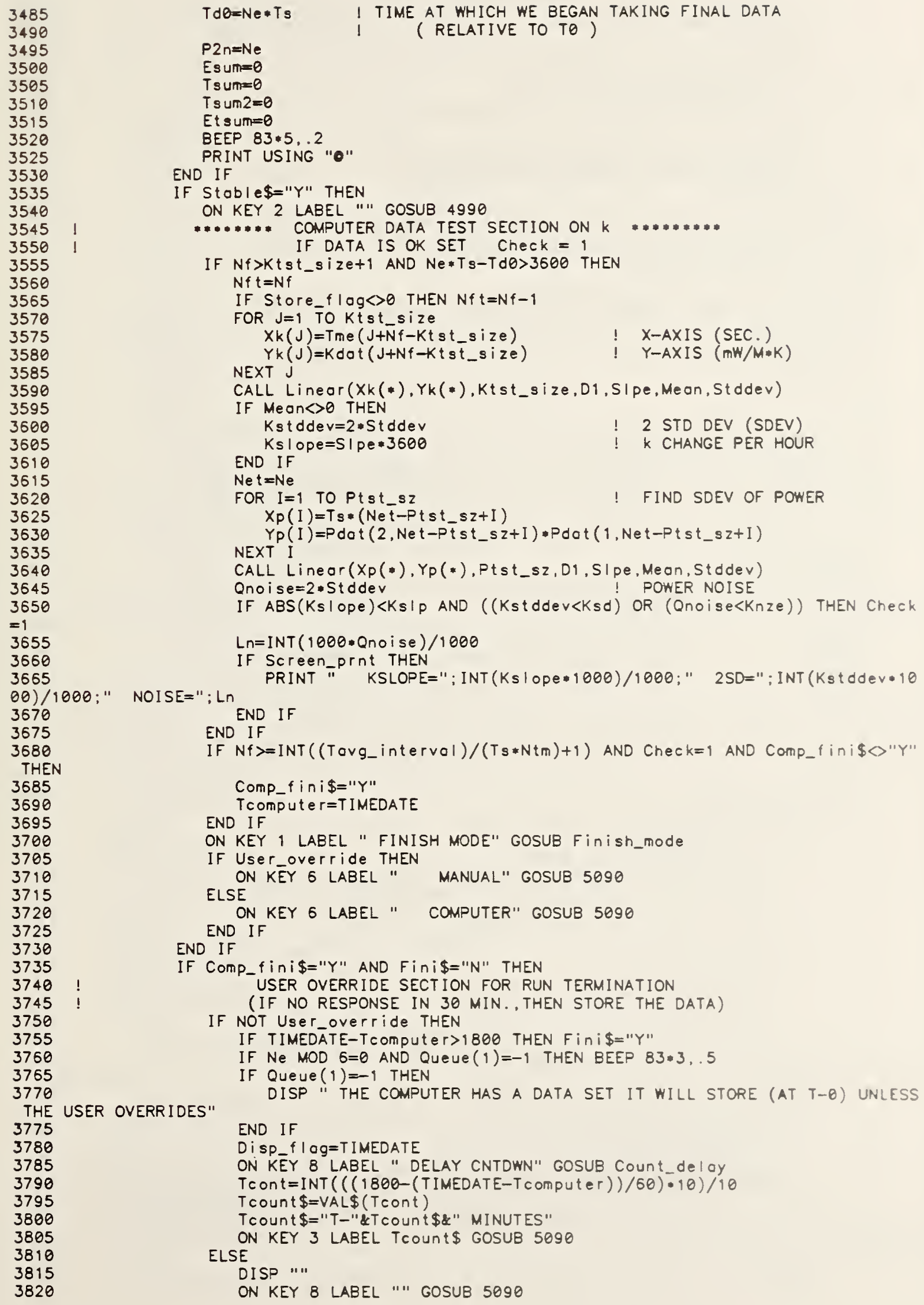




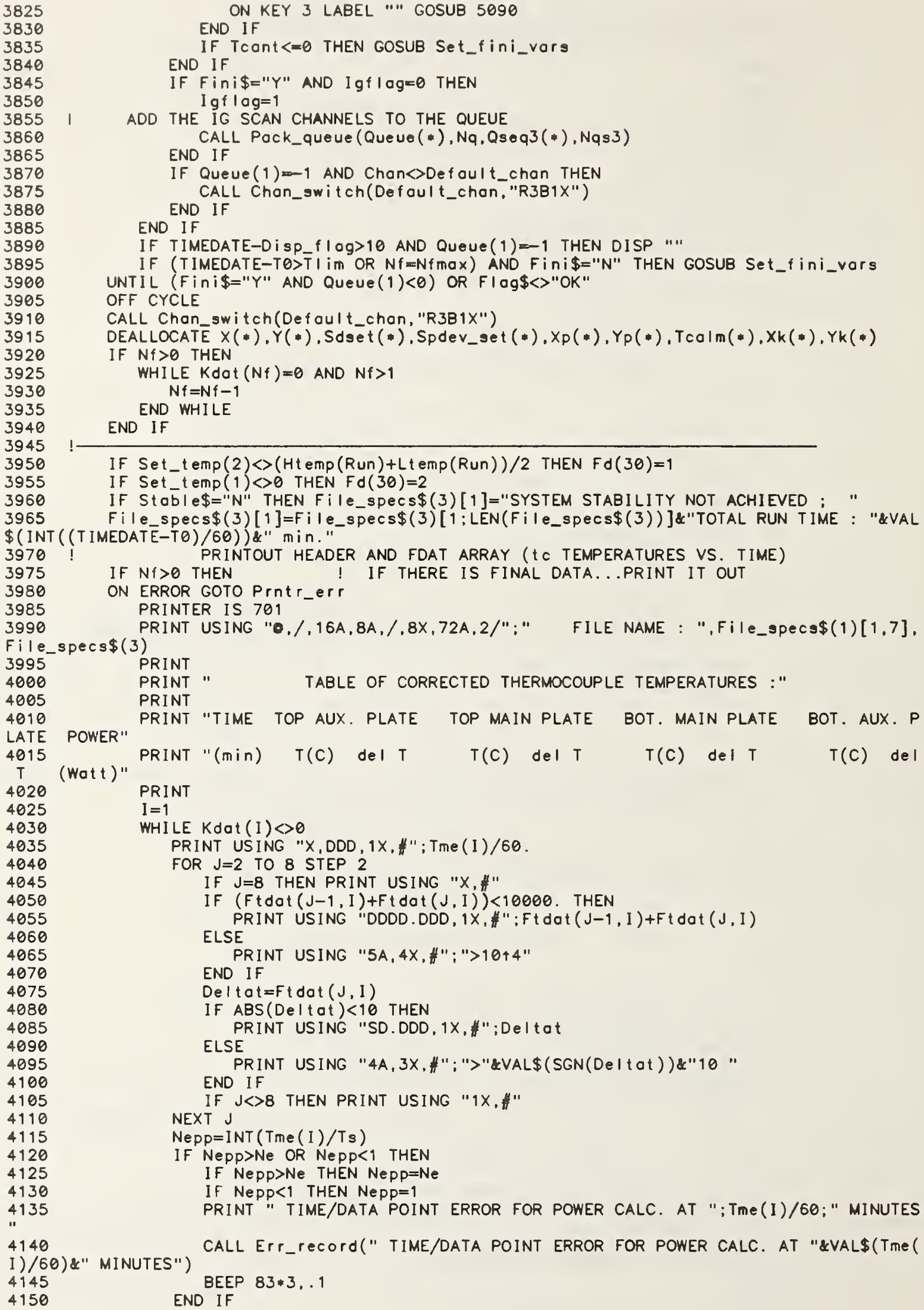




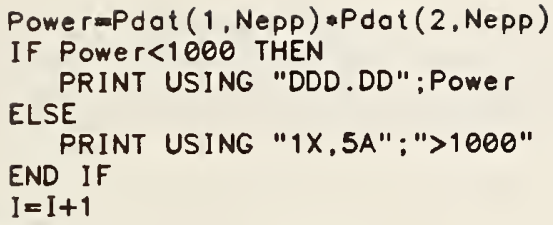




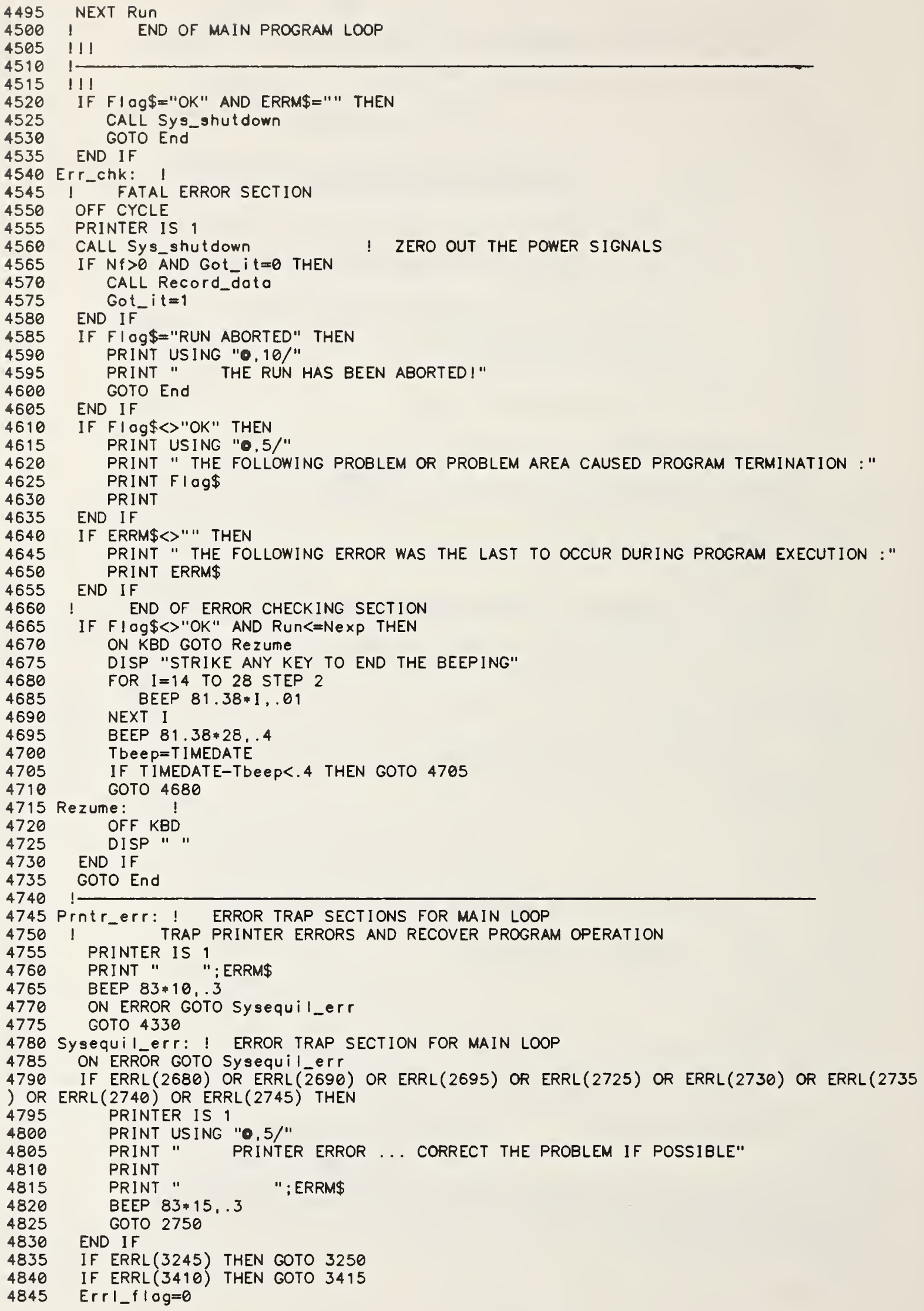


min. :

4960

4965

4970

4975

4980

4985

4990

4995

5000

5005

5010

5015

5020

5025

5030

5035

5040

5045

5050

5055

5060

DATA"

5065

5070

5075

5080

5085

5090

5095

5100

5105

5110

5115

5120

5125

5130

5135

5140

5145

5150

5155

5160

5165

5170

5175

5180

5185

5190

5195

IF ERRL(3475) THEN GOTO 3480

1 IF THE ERROR IS NOT A PLOTTER ERROR THEN SET 'FLAG\$' AND STOP EXECUTION IF FIOg\$="OK" THEN FIOg\$=" MAIN LOOP ERROR "\&ERRM\$

PRINTER IS 1

GOTO Err_chk

Alpho_toggle: I

IF Screen_prnt=1 THEN

Screen_prnt $=0$

PRINT USING "Q"

ELSE

ON KEY 8 LABEL " OFF" GOSUB 4990

Screen_prnt=1

ON KEY 8 LABEL " ON" GOSUB 4990

END IF

RETURN 1

Set td vars:

Stable $\$=" Y "$

P_stoble $\$=" Y "$

T_stable $\$=" Y "$

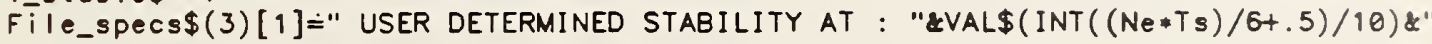

$\mathrm{Td} \theta=\mathrm{Ne} * \mathrm{Ts}$

$\mathrm{P} 2 \mathrm{n}=\mathrm{Ne}$

Es um $=0$

Ts um $=0$

T sum2 $=0$

Et sum $=0$

RETURN

et_fini_vors:

COLLECT DATA FOR AT LEAST 'Tovg_intervol' SECONDS BEFORE STORAGE

IF (Nf>INT ( (Tavg_interval)/(Ntm*Ts) +1)) OR (TIMEDATE-TO>TIim) OR (Nf=Nfmax) THEN Fini\$="Y"

DISP " THE TERMINATION SEQUENCE HAS BEGUN ... DO NOT HIT ANY OTHER KEYS!!"

ON KEY 7 LABEL "FINISHING RUN!" GOSUB 5090

CALL Pock_queue(Queue(*),Nq.Qseq3(*),Nqs3)

ELSE I $g$ $\mathrm{log}=1$

IF $T d \theta>\theta$ THEN

T_to_woit $=$ INT ( $($ Tavg_interval- $($ IIMEDATE-TO $)+T d \theta+3 * T s * N \mathrm{tm}) / 6) / 1 \theta$

IF T to wo it $\bar{F} .1$ THEN T to woi $t=.1$

DISP" "YOU DON'T HAVE ENOUGH DATA! YOU NEED ";T_to_woit;" MORE MINUTES OF

ELSE

END IF

DISP " YOU DON'T HAVE ANY DATA YET"

END IF

DisP_f I ag=TIMEDATE

RETURN

Count_delay: !

Tcomput e $r=$ TIMEDATE

RETURN

Finish_mode: !

If User_override=1 THEN

User_override=0

ELSE

Tcomputer=TIMEDATE

END IF

RETURN

End:

END OF THE MAIN PROGRAM

PRINT USING " $2 / .50 A ": "$ END OF THE PROGRAM"

IF Io_error>0 THEN

PRINT

PRINT "IO ERRORS OCCURED DURING PROGRAM EXECUTION THEY"

PRINT " ARE LISTED IN THE ARRAYS : BAD_INSTR( ()$\left.^{\prime}\right) "$

PRINT" AND BAD_READ_TIME\$(*)" 


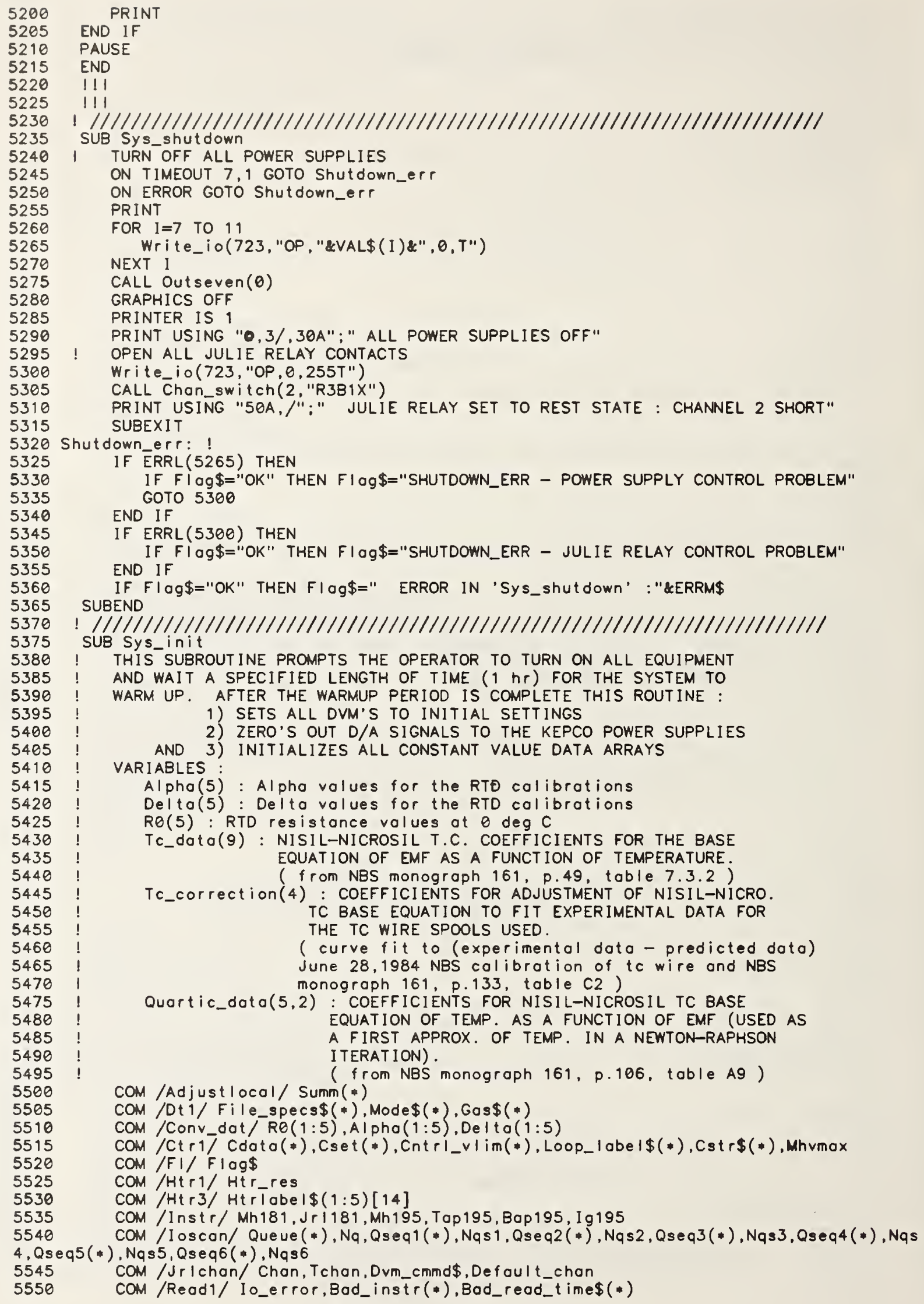


5680

5685

5690

5695

5700

5705

5710

5715

5720

COM /Rtd_corr/ Tcorr_rtd,Rtd_odj_flog.Sp_corr (*)

$\mathrm{COM} / \mathrm{Sb} 3 / \mathrm{Fd}($ ) , Tovg_scon

Com /Stoble/ Sdiim(*). Sp_errlim(*), Pnze,Ksd,KsIp,Knze

com/Tcdat/ Tc_dato( $1: 9)$. Tc_correction ( $1: 4)$, Quortic_doto( $1: 5,1: 2)$

com /Zeros/Zjrl181_200,Zjrl181_20,Zgop195, Zhistory(*)

ALLOCATE Heoter_res $(1: 5)$

SCUZ $=-1$ ZERO OUT THE PID SUMM ARRAY

MAT SUMm $=(\theta)$ ZERO OUT PART OF THE SPECIFICATIONS STRING ARRAY

File_specs\$(1)=RPT $\$("$ " 80$)$

File_specs $\$(2)=$ RPT $\$("$ ".80)

File_specs\$(3)=RPT\$(" ".80)

DISPLAY SYSTEM POWER UP EQUIPMENT LIST AND TIME LIMIT

TO_WO IMUP $=$ TIMEDATE

PRINT USING "0,/"

PRINT CHR\$(129)

PRINT "

PRINT"

PRINT "

PRINT" "

PRINT"

PRINT "

PRINT "

PRINT "

PRINT "

PRINT "

PRINT " "

PRINT "

PRINT"

PRINT "

PRINT "

TURN ON THE FOLLOWING PIECES OF EQUIPMENT :
A) THE PRINTER
B) THE MULTIPROGRAMMER
C) THE SIX KEITHLEY DVM'S (4-195'S AND $2181^{\prime} \mathrm{S}$ )
D) THE FIVE KEPCO POWER SUPPLIES
E) BOTH JULIE RELAYS
F) THE FLUKE POWER SUPPLY ( BETWEEN 1.5mA AND 0.5mA)
G) THE WATER SUPPLY !!

PRINT CHR\$(128)

PRINT USING "9X,1A,46A";CHR\$(131)," WHEN THE SYSTEM IS READY, HIT ' CONTINUE

PRINT CHR\$(128)

PAUSE

PRINT USING " $\bullet, 5 / "$ GOTO 5800 !!! REMOVABLE SKIP !!!

IF (TIMEDATE-TO_warmUP) $<3600$ THEN INPUT " HAS IT REALLY BEEN ON FOR ONE HOUR (Y/N)??",ANS\$

If AnS\$="Y" THEN PRINT " OK ... I WAS JUST CHECKING!"

SET THE RANGE AND DISPLAY VALUES OF ALL THE DVM'S PRINT USING " $0,5 /$ "

PRINT" DVM'S ARE NOW BEING SET"

ON TIMEOUT $7,1.0$ GOTO In it_err

FOR $J=1$ TO 2 ! SEND OUT THE DVM SET COMMANDS TWICE

Scu $z=0$

FOR $I=706$ TO 709

OUTPUT I;"ROX" ! SET THE 195's TO THE AUTO RANGING MODE

WAIT .2

ENTER I;DUT

NEXT I

NAIT .2

Scuz=1

OUTPUT MH181;"R3B1X" ! MAIN RTD 


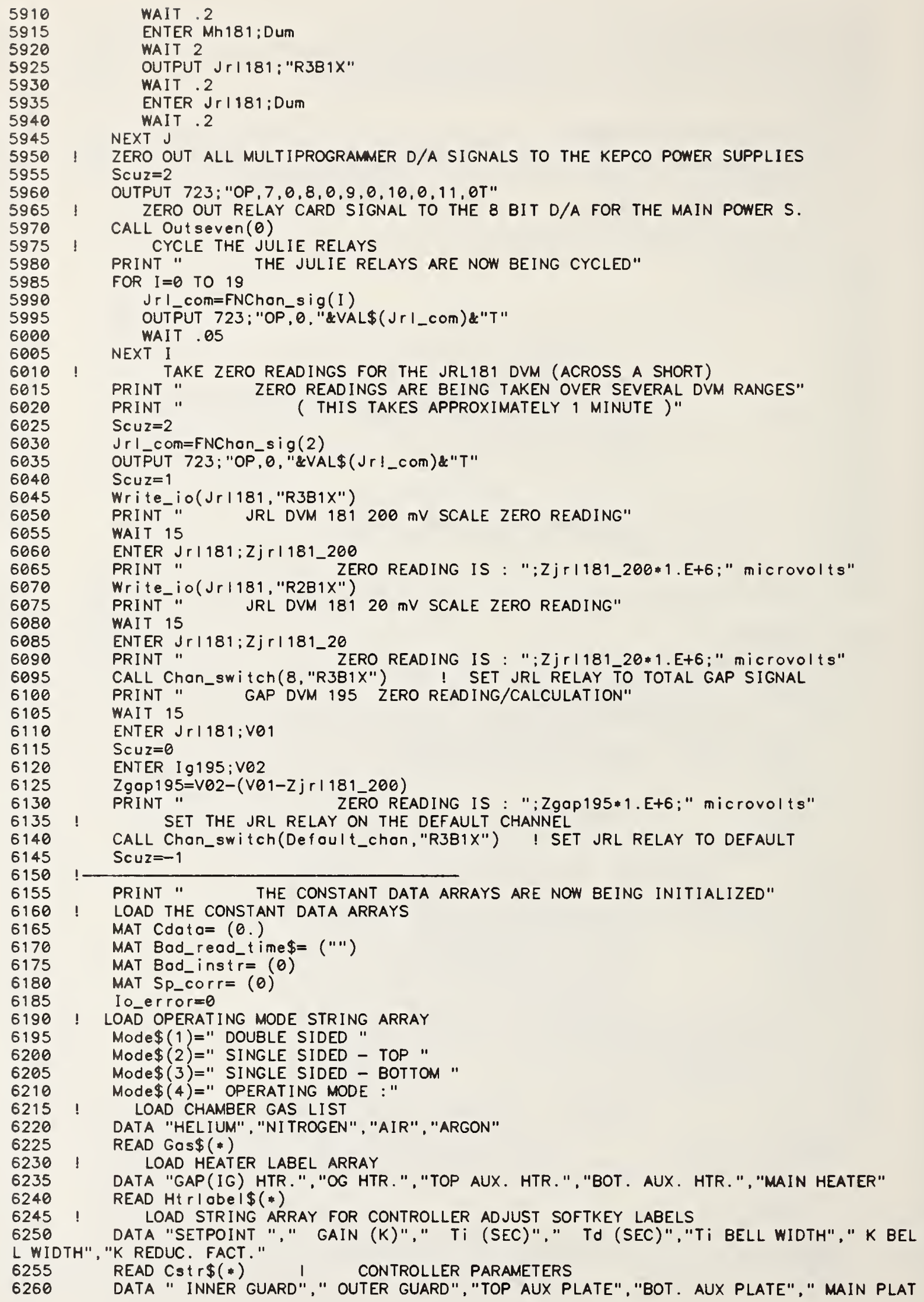


READ LOOP_I abeI\$(*)

I ADD CONSTANT DATA TO THE FD(*) ARRAY AND CANCEL PORTIONS OF IT

$\mathrm{Fd}(1)=0$.

$\mathrm{Fd}(2)=0$.

FOR $I=9$ TO 20

$\mathrm{Fd}(\mathrm{I})=0$.

NEXT I

FOR $I=23$ TO 30

NEXT I

$$
\mathrm{Fd}(\mathrm{I})=0 \text {. }
$$

$\mathrm{Fd}(24)=\mathrm{Ts}$

$\mathrm{Fd}(6)=.85$

$\mathrm{Fd}(8)=.1254$

$\mathrm{Fd}(21)=.0024$

! CONTROL CYCLE TIME

PLATE EMISSIVITY

1 METERED AREA DIAMETER (m)

I GAP WIDTH (m)

I RESISTANCE VALUES OF THE PLATE HEATERS (USED TO CALC. CntrI_vI im) NOTE: IF THE TOTAL RESISTANCE IS >11 THE CONTROL V-LIM. WILL BE 10V Heater_res $(1)=10.2+.9$ ! INNER GUARD HEATER RESISTANCE + LEAD RES.

Heater_res $(2)=11.9$ ! OUTER GUARD HEATER RESISTANCE

Heater_res $(3)=14.3$ ! TOP AUX. PLATE HEATER RESISTANCE

Heater-res $(4)=14.3$ ! BOTTOM AUX. PLATE HEATER RESISTANCE

Heater_res $(5)=3.7+.9$ ! MAIN PLATE HEATER RESISTANCE + LEAD RES.

Htr_res=Heater_res(5) ! MAIN PLATE HTR. RES. (RE-MEASURED DURING RUN) CALCULLATE THE CONTROL VOLTAGE HIGH LIMITS FROM THE HEATER PLATE RES. ( BASED ON 5A - 55V MAX. OUTPUT FOR POWER SUPPLY AND A 0 TO 10 VOLT CONTROLLER SIGNAL)

FOR $I=1$ TO 5

Cntrl_vlim(1)=Heater_res (1) $45 . /\left(55 . / 10_{\text {. }}\right)$

IF CntrI_vi im(I)>10. THEN CntrI_vIim(I)=10.

IF I $=5$ THEN Mhvmax $=$ Heoter_res $(I) * 5$. ! M.H. $\vee \operatorname{MAX}$. (BASED ON 5A) NEXT I ASSIGN VALUES OF STD. DEV. LIMIT AND SET POINT DEV. LIMIT FOR ! STABILITY CRITERIA ON ALL PLATES (TEMP. CONTROLLED LOOPS). DATA $1.0,1.0$

DATA $2.0,0.2$

DATA $.01, .005$

DATA .01,.005

DATA .002,.001

FOR $I=1$ TO 5 READ Sdlim(I), Sp_errlim(I)

NEXT I

I INNER GUARD

(MICROVOLTS; LINE 3145)

1 OUTER GUARD

1 TOP AUX. PLATE

! BOTTOM AUX. PLATE

! MAIN PLATE ASSIGN VALUES OF SLOPE AND 2 STD. DEV. FOR POWER AND 2 STD.DEV. AND SLOPE FOR $k$, AND 2 STD. DEV. FOR POWER THE MAIN PLATE POWER AND THERMAL CONDUCTIVITY

DATA .003

READ Pnze

DATA $0.3,0.08, .0020$ ! THERMAL CONDUCTIVITY $(k)$

READ Ksd,KsIP, Knze

! DATA FOR THE RTD SERIAL NUMBERS Z603,J57,Z597,Z602, AND J52,RESPECTIVELY 1=REF. BLOCK, 2=OG, 3=TOP PLATE, 4=BOTTOM PLATE, 5=MAIN PLATE

DATA $100.059,99.63,100.269,100.049,99.977$

READ RO (*)

$R O(3)=R \theta(3)-.86$ !!! SYSTEM DEPENDENT 'TUNING' FACTOR (TAHP)

$R \theta(4)=R \theta(4)+.052$ !!! SYSTEM DEPENDENT 'TUNING' FACTOR (BAHP)

$R O(5)=R \theta(5)-.31$ !!! SYSTEM DEPENDENT 'TUNING' FACTOR (MAIN PLATE)

DATA .00389613,.00390382,.00390608,.00390002,.00390316

READ Alpha(*)

DATA $1.310780,1.501776,1.456476,1.398146,1.510977$

READ Delta (*)

! DATA FOR NIS. -NICRO. T.C. TEMP. NOLT CONVERSION EQUATION NBS MONOGRAPH 161, PAGE 49. TABLE 7.3.2 FOR AWG 14 WIRE

DATA $25.897798582,1.6656127713 \mathrm{E}-2,3.1234962101 \mathrm{E}-5,-1.7248130773 \mathrm{E}-7$

DATA $3.6526665920 E-10 .-4.4390833504 E-13.3 .1553382729 E-16$

DATA $-1.2150879468 E-19,1.9557197559 E-23$

READ TC_dato(*)

DATA $2.73134350 E 2,2.94724845 E 2,3.87205729 E-2,3.21321378 E-2$

DATA $-1.09710024 \mathrm{E}-6,-2.89538382 \mathrm{E}-7,5.25218480 \mathrm{E}-11.5 .02114728 \mathrm{E}-12$

DATA $-1.14636136 \mathrm{E}-15,-2.61445196 \mathrm{E}-17$

READ Quartic_data(*)

DATA $-4.0694 \overline{3} 153 E-1,3.14764457 E-1,-1.07467859 E-3,1.29379614 E-6$

READ TC_correction (*)

! LOAD THE SCANNER QUEUES 


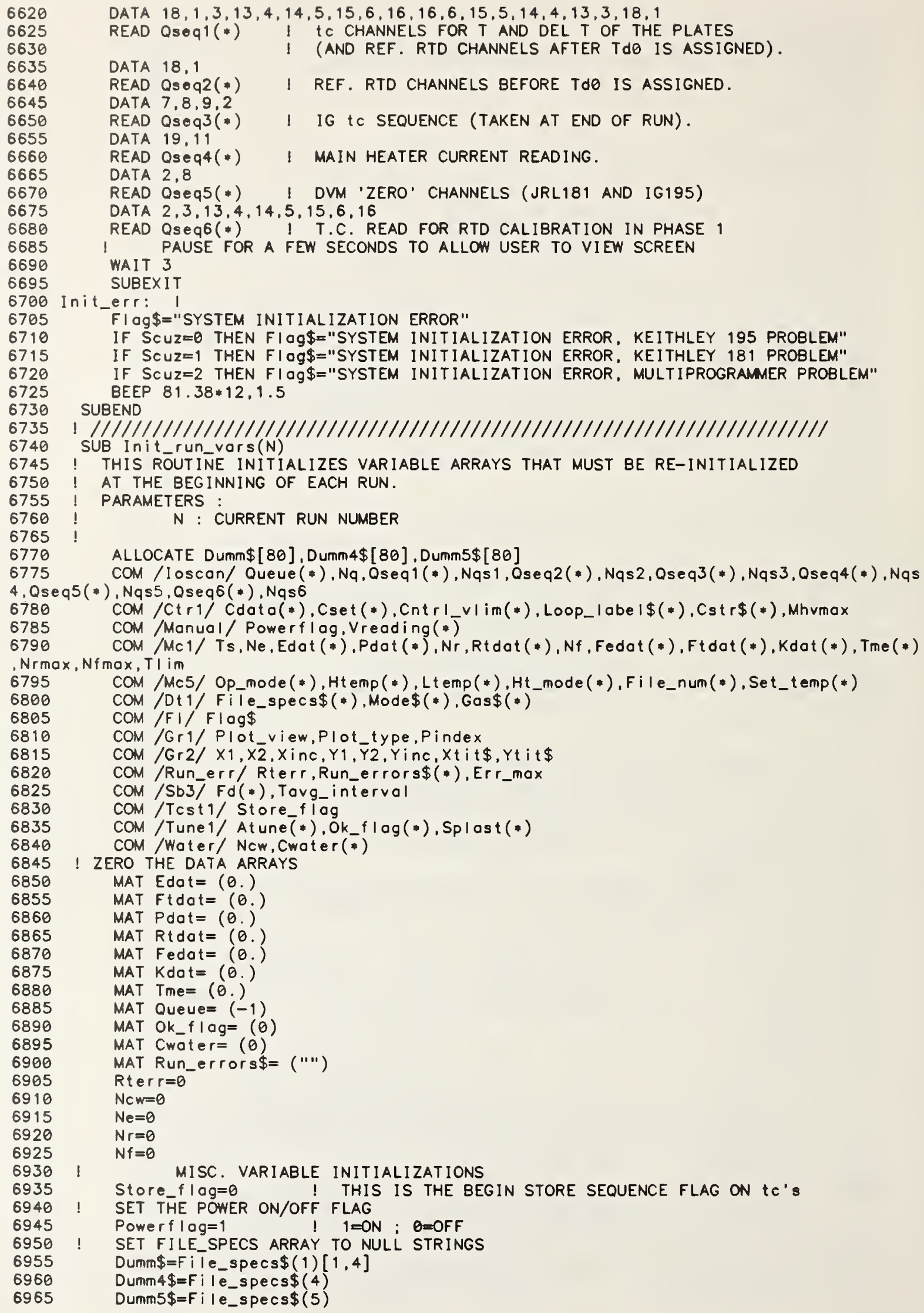

6790

- Nrmax

6795

6800

6805

6810

6815

6820

6825

6830

6835

6840

6845

6850

6855

6860

6865

6870

6875

6880

6885

6890

6895

6900

6905

6910

6915

6920

6925

6930

6935

6940

6945

6950

6955

6960

6965

DATA $18,1,3,13,4,14,5,15,6,16,16,6,15,5,14,4,13,3,18,1$

READ Qseq1(*) I tc CHANNELS FOR T AND DEL T OF THE PLATES

DATA 18,1

READ Os०q2(*) I REF. RTD CHANNELS BEFORE TdO IS ASSIGNED.

DATA $7,8,9,2$

READ Qseq3(*) I IG tc SEQUENCE (TAKEN AT END OF RUN).

DATA 19,11

READ Oseq4(*) I MAIN HEATER CURRENT READING.

DATA 2.8

READ Qseq5 (*) I DVM 'ZERO' CHANNELS (JRL181 AND IG195)

DATA $2,3,13,4,14,5,15,6,16$

READ QSEG6(*) ! T.C. READ FOR RTD CALIBRATION IN PHASE 1

PAUSE FOR A FEW SECONDS TO ALLOW USER TO VIEW SCREEN

WAIT 3

SUBEXIT

Init_err:

FI $\circ g \$=" S Y S T E M$ INITIALIZATION ERROR"

IF SCUZ=0 THEN FI $99 \$=$ "SYSTEM INITIALIZATION ERROR, KEITHLEY 195 PROBLEM"

IF $S c u z=1$ THEN FIOg $\$=" S Y S T E M$ INITIALIZATION ERROR, KEITHLEY 181 PROBLEM"

IF ScuZ=2 THEN FIag $\$="$ "SYSTEM INITIALIZATION ERROR, MULTIPROGRAMMER PROBLEM"

BEEP $81.38 * 12,1.5$ SUBEND

! $/ 1 / 1 / 1 / 1 / 1 / 1 / 1 / 1 / 1 / 1 / 1 / 1 / 1 / 1 / 1 / 1 / 1 / 1 / 1 / 1 / 1 / 1 / 1 / 1 / 1 / 1 / 1 / 1 / 1 / 1 / 1$

SUB In it_run_vars(N)

! THIS ROUTINEE INITIALIZES VARIABLE ARRAYS THAT MUST BE RE-INITIALIZED

! AT THE BEGINNING OF EACH RUN.

PARAMETERS :

N : CURRENT RUN NUMBER

ALLOCATE Dumm $\$[80]$, Dumm4\$[80], Dumm5 $\$[80]$

COM /Ioscan/ Queue (*), Nq, Oseq1(*),Nqs1, Qseq2(*), Nqs2, Qseq3(*),Nas3, Oseq4(*), Nqs

95 (*), Nas5, Qseq6 (*), Nqs6

CaM /Ctr1/Cdata(*), Cset (*),CntrI_vlim(*),Loop_labe $1 \$(*), C s t r \$(*)$, Mhvmax

COM /Manual/Powerflag, Vreading(*)

$\operatorname{CoM} / \mathrm{Mc} 1 / \mathrm{Ts}, \operatorname{Ne}, \operatorname{Edat}(*), \operatorname{Pdat}(*), \mathrm{Nr}, \operatorname{Rtdat}(*), N f, F e d a t(*), F t \operatorname{dat}(*), \operatorname{Kdat}(*), T m e(*)$ , Nfmax, TI im

COM /Mc5/Op_mode (*), Htemp (*),Ltemp (*),Ht_mode (*),File_num (*), Set_temp (*)

COM /Dt1/File_specs\$(*), Mode\$(*), Gas\$(*)

$\operatorname{COM} / \mathrm{Fl} / \mathrm{Flag} \$$

COM /Gr1/Plot_view,Plot_type,Pindex

COM /Gr2/ X1, X2 2 Xinc, Y1, Y2, Yinc, Xtit $\$, Y t$ it $\$$

COM /Run_err/Rterr, Run_errors $\$(*)$, Err_max

$\mathrm{COM} / \mathrm{Sb} 3 / \mathrm{Fd}(*)$, Tovg_interval

COM /Tcst1/ Store_fiag

COM /Tune 1/ Atune(*), Ok_flog(*), Splast (*)

COM /Woter/ Ncw, Cwater(*)

! ZERO THE DATA ARRAYS

MAT Edot $=(0$.

MAT Ftdat $=(\theta$.

MAT Pdat $=(\theta$.

MAT Rtdat $=(0$.

MAT Fedat $=(0$.

MAT $K$ dat $=\left(\theta_{.}\right)$

MAT Tme $=(\theta$.

MAT Queve $=(-1)$

MAT OK_flag=(O)

MAT Cwoter= (0)

MAT Run_errors $\$=$ ("'")

Rter $r=0$

Ncw $=0$

$\mathrm{Ne}=0$

$\mathrm{Nr}=0$

$\mathrm{Nf}=\mathrm{O}$

1 MISC. VARIABLE INITIALIZATIONS

Store_flag=0 IHIS IS THE BEGIN STORE SEQUENCE FLAG ON $t c^{\prime} s$ SET THE POWER ON/OFF FLAG

Powe $\mathrm{I} f \mathrm{I} O \mathrm{~g}=1 \quad 1=\mathrm{ON}$ : $0=O F F$

SET FILE_SPECS ARRAY TO NULL STRINGS

Dumm $\$=F i$ le_specs $\$(1)[1,4]$

Dumm $4 \$=F$ i le_specs $\$(4)$

Dumm5 $\$=F$ i le_specs $\$(5)$ 


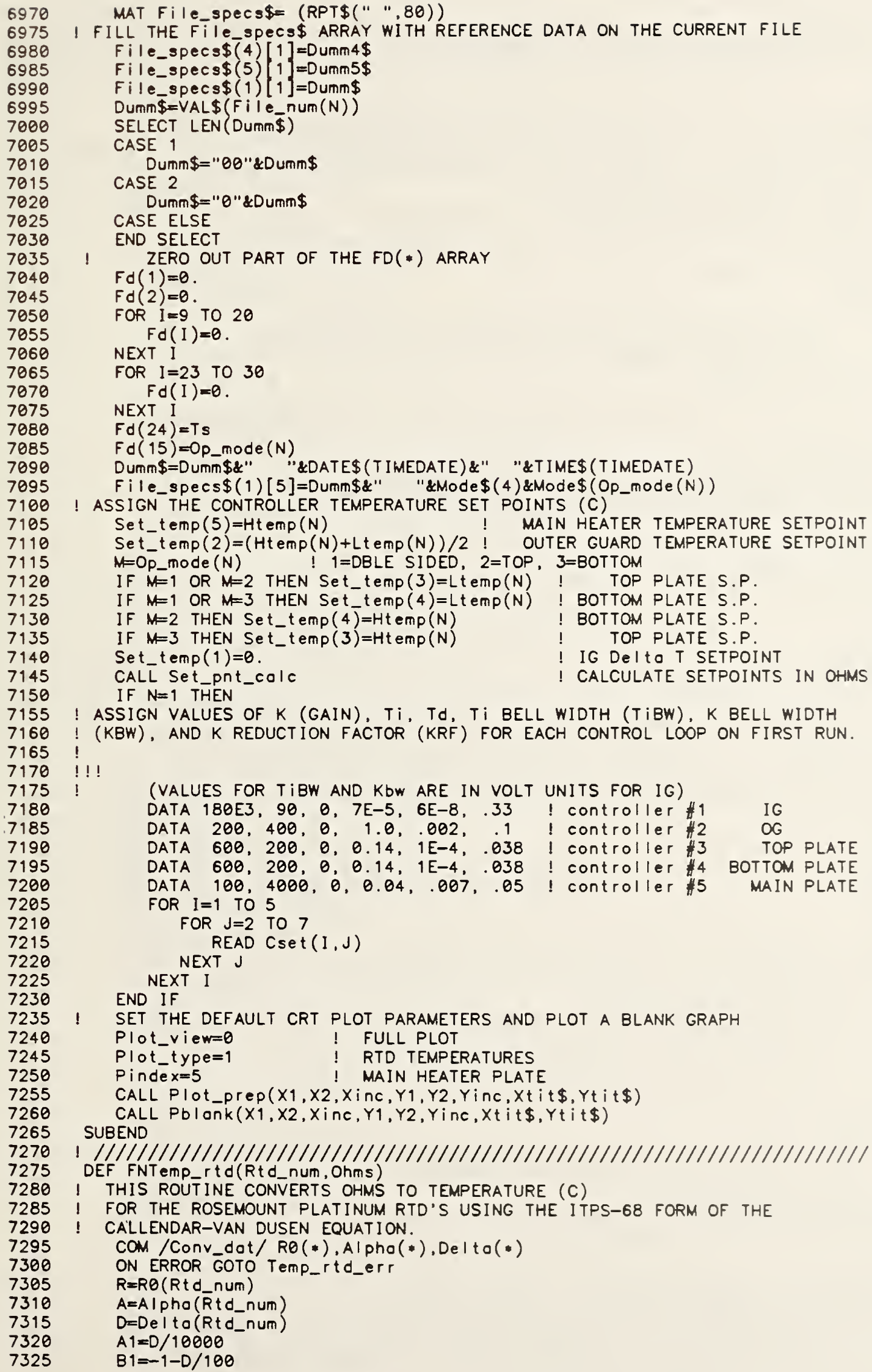




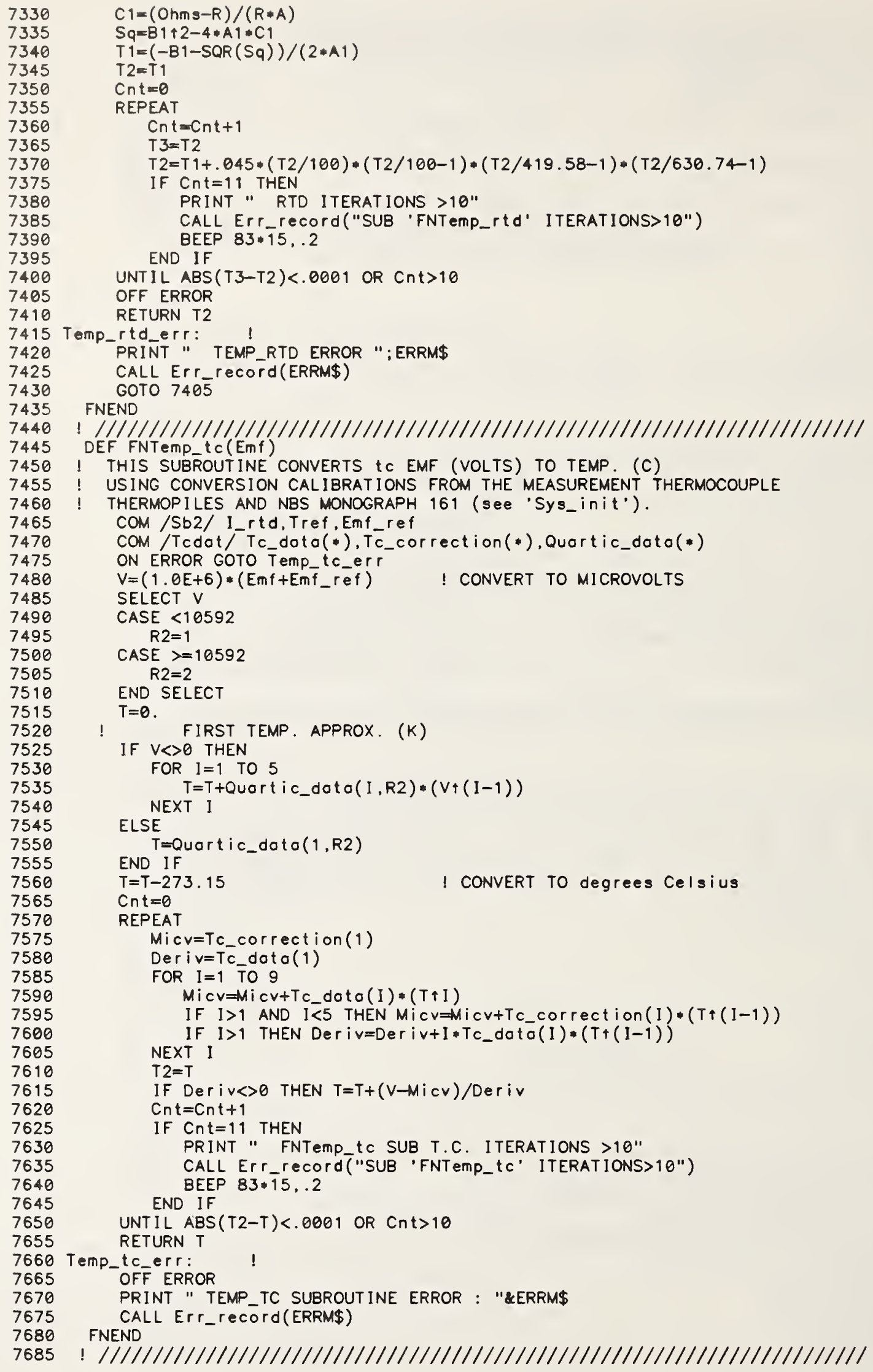


SUB Ref_rtd(V.Tmr)

I THIS SUBROUTINE TAKES THE REF. BLOCK DVM VOLTAGE READING ( $V$ ) CONVERTS

I THE VALUE TO TEMPERATURE, AND THEN STORES IT IN THE Rtdat ARRAY.

$\mathrm{COM} / \mathrm{FI} / \mathrm{Flag} \$$

$\operatorname{COM} / \mathrm{Sb} 1 / \mathrm{TO}$. Td 0

COM/Sb2/ I_rtd, Tref, Emf ref

$\mathrm{COM} / \mathrm{Mc} 1 / \mathrm{Ts}, \mathrm{Ne}, \mathrm{Edat}(*), \overline{\mathrm{P} d a t}(*), \mathrm{Nr}, \mathrm{Rt} \operatorname{dat}(*), \mathrm{Nf}, \mathrm{Fedat}(*), \mathrm{Ftdat}(*), \mathrm{Kdat}(*), \mathrm{Tme}(*)$

ax, Nfmax, TI Im

7730

7735

7740

7745

7750

7755

7760

7765

7770

7775

7780

7785

7790

7795

7800

7805

7810

7815

7820

7825

7830

7835

7840

7845

7850

7855

7860

7865

7870

7875

7880

7885

7890

Nrmax

ON ERROR GOTO Ref_rtd_err

Ohms=ABS (V/I_rtd)

$\mathrm{Nr}=\mathrm{Nr}+1$

Rtd_num=1

Tref2=FNTemp_rtd(Rtd_num, Ohms)

IF ABS(Tref-Tref2) $<1 \bar{\theta}$. OR Tref=0. THEN

Tref $=$ Tref2

ELSE Emf_ref $=$ FNEmf_tc $($ Tref, 1$)$

PRINT " BAD READING FOR THE REFERENCE BLOCK TEMPERATURE !!"

CALL Err_record("BAD READING FOR REFERENCE BLOCK TEMPERATURE") BEEP $83 \cdot \overline{5}, .3$

END IF

If $\mathrm{Nr}<=\mathrm{Nrmax}$ THEN

Rtdat $(2, N r)=T m r$

ELSE

Rtdat $(1, N r)=$ Tref

PRINT " ISO. BLOCK STORAGE ARRAY IS FULL"

CALL Err_record("ISO. BLOCK DATA STORAGE ARRAY IS FULL")

END IF

BEEP $83 * \overline{5}, .1$

SUBEXIT

Ref_rtder $r$ :

OFF ERROR

PRINT " REF_RTD SUBROUTINE ERROR : "\&ERRM\$

CALL Err_recard(ERRM\$)

\section{SUBEND}

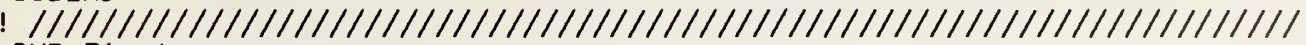

SUB Final_overages

$! \quad$ THIS SUB CALCULATES THE AVERAGED VALUES FOR PLATE TEMPERATURES,

! POWER. AND THERMAL CONDUCTIVITY. THESE VALUES ARE THEN ASSIGNED

TO THEIR CORRESPONDING DISK STORAGE ARRAY ELEMENTS.

COM /Dt1/File_specs $\$(*), \operatorname{Mode} \$(*), \operatorname{Gos} \$(*)$

$\operatorname{CoM} / \mathrm{Mc} 1 / \mathrm{Ts}, \mathrm{Ne}, \mathrm{Edat}(*), \operatorname{Pdat}(*), \mathrm{Nr}, \operatorname{Rt} \operatorname{dot}(*), N f, F \operatorname{dat}(*), \mathrm{Ft} \operatorname{dot}(*), \operatorname{Kdat}(*), T m e(*)$

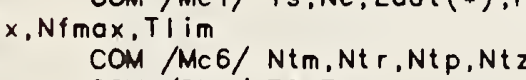

COM /Sb1/ To, Td

COM /Sb2/I_rtd,Tref, Emf_ref

$\mathrm{COM} / \mathrm{Sb3} / \mathrm{F} \bar{d}(\cdot)$. Tovg_scan

IF $N F<1$ THEN SUBEXIT

ON ERROR GOTO Calc_err

ALLOCATE TI ImS $(1: 2)$

TCOIC=TIMEDATE I RECORD WHEN THE SUB WAS ENTERED (TO TIME EXIT)

WHILE Tme (Nf) $=0$

$$
N f=N f-1
$$

END WHILE

Tlast $=$ Tme $(N f)$

Tend $=1$

Tstep=1 ! TIME TOGGLE SIZE (MIN.)

I INDEX FOR TLIMS(*) , BEGINNING \& END OF AVG. SECTION

TI ims (2) $=\operatorname{Tme}(\mathrm{Nf})$

TI ims (1)=Tlims(2)-Tavg_scon

IF TI ims (1) $<0$ THEN TI ims (1) $=0$

IF Tlims(2)-Tlims(1) $=0$ THEN SUBEXIT

PRINT USING " $0,10 / "$

BEEP $83 * 11, .3$

DISP " SELECT THE TIME ENDPOINTS FOR THE FINAL DATA AVERAGING INTERVAL (BEFORE

REDEF I

ON KEY I LABEL " " GOSUB 8970

NEXT I

ON KEY 9 LABEL "PERFORM AVGS. " GOTO Take_avg

ON KEY 1 LABEL " CHANGE PLOT " GOTO 8055

ON KEY O LABEL " SELECT TLIM. " GOTO 8070 


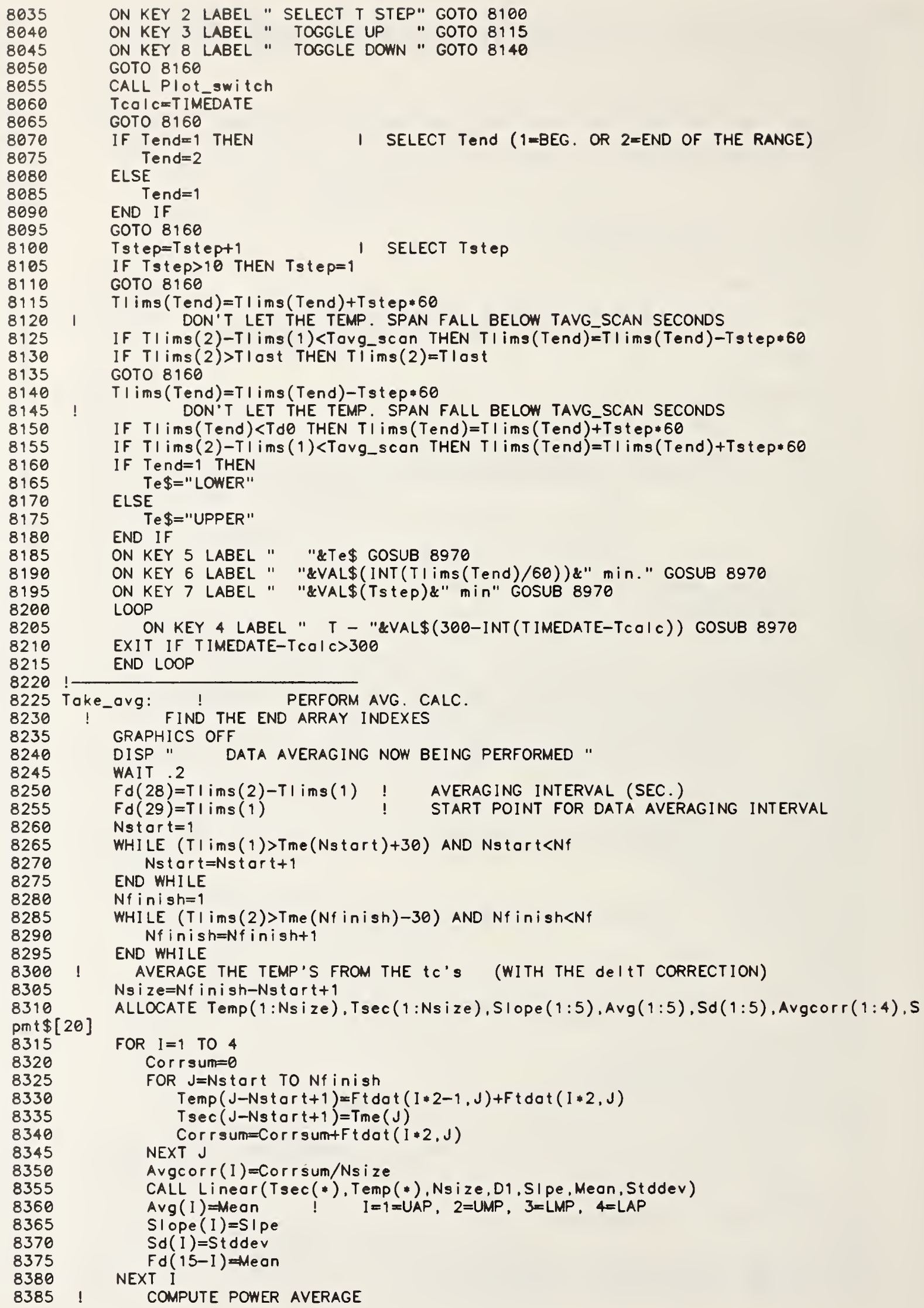

ON KEY 2 LABEL " SELECT T STEP" GOTO 8100

ON KEY 3 LABEL " TOGGLE UP " GOTO 8115 ON KEY 8 LABEL " TOGGLE DOWN " GOTO 8140

GOTO 8160

CALL Plot_switch

TCOIC=TIMEDATE

GOTO 8160

IF Tend=1 THEN

I SELECT Tend ( $1=B E G$. OR 2=END OF THE RANGE)

ELSE Tend $=2$

Tend $=1$

END IF

GOTO 8160

Ts tep $=$ Ts t ep +1

IF Ts tep $>10$ THEN Ts te $p=1$

GOTO 8160

TI ims (Tend) $=$ T I ims (Tend) + Ts tep*60 DON'T LET THE TEMP. SPAN FALL BELOW TAVG_SCAN SECONDS

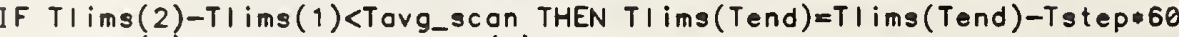

IF TI ims (2) >Tlast THEN Tlims(2)=Tlast

GOTO 8160

Tl ims ( Tend) $=$ T I ims (Tend) - Ts t ep $* 60$

DON'T LET THE TEMP. SPAN FALL BELOW TAVG_SCAN SECONDS

IF $T$ I ims (Tend) $\angle T d \theta$ THEN $T$ I ims (Tend) $=T$ I ims ( Tend) +Ts tep $* 60$

IF TI ims(2)-TI ims(1)<Tovg_scon THEN TI ims (Tend) $=T$ I ims (Tend) + Ts tep*60

If Tend=1 THEN

Te $\$=" L O W E R "$

ELSE

Te $\$=" U P P E R "$

END IF

ON KEY 5 LABEL " "\&Te\$ GOSUB 8970

ON KEY 6 LABEL " "\&VAL\$(INT(TIims(Tend)/60)) \&" min." GOSUB 8970

ON KEY 7 LABEL " "\&VAL $\$$ (Ts tep)\&" min" GOSUB 8970

LOOP

ON KEY 4 LABEL "T - "\&VAL\$(300-INT(TIMEDATE-TCOIC)) GOSUB 8970

EXIT IF TIMEDATE-TCOI $C>300$ END LOOP 
8735 PRINT" $\quad$ UPPER AUX. PLATE TEMP. $=" ; \operatorname{INT}(\operatorname{Avg}(1) * 10000) / 10000 . ; "$, STD.DEV. =" . INT (Sd (1)*10000.) /10000.

8740 PRINT " TEMP. CORRECTION="; INT(Avgcorr(1)*10000.)/10000.;", dT/dt(de $g / h r)="$; INT $(3600$ *SI Ope (1)*10000.)/10000.

8745 PRINT" UPPER MAIN PLATE TEMP. $="$; INT (Avg(2)*10000.)/10000.;", STD.DEV. $="$; INT (Sd (2) *10000.) $/ 10000$.

8750 PRINT" TEMP. CORRECTION="; INT(Avgcorr(2)*10000.)/10000.;", dT/dt(de $g / h r)="$; INT $(3600 *$ SIOpe (2)*10000.)/10000.

8755 PRINT" LOWER MAIN PLATE TEMP. ="; INT(Avg(3)*10000.)/10000.;", STD.DEV.="; INT $(\operatorname{Sd}(3) * 10000) /$.10000 .

8760 PRINT" TEMP. CORRECTION="; INT (Avgcorr (3)*10000.)/10000.:", dT/dt (de $g / h r)=" ; \operatorname{INT}(3600$. SI Ope (3)*10000.)/10000.

8765 PRINT " LOWER AUX. PLATE TEMP. $=" ; \operatorname{INT}($ Avg (4)*10000.)/10000.;", STD.DEV.="; INT(Sd(4)*10000.)/10000.

8770 PRINT " TEMP. CORRECTION="; INT (Avgcorr (4)*10000.)/10000.:", dT/dt(de $g / h r)=" ; \operatorname{INT}(3600$. SI ope (4)*10000.)/10000.

$8775 \quad \operatorname{Sdm} t=(\operatorname{SQR}(\operatorname{Sd}(1)+2+\operatorname{Sd}(2)+2)) / \operatorname{SQR}($ Ns ize $)$

8780 PRINT" UPPER delta T="; INT((Avg(2)-Avg(1))*10000.)/10000.;", STD. DEV. O F MEAN="; INT (Sdmt*10000.) $/ 10000$

$8785 \quad \operatorname{Sdmb}=(\operatorname{SQR}(\operatorname{Sd}(3) \uparrow 2+\operatorname{Sd}(4) \uparrow 2)) / \operatorname{SOR}($ Ns ize $)$

8790 PRINT" LOWER del ta T="; INT((Avg(3)-Avg(4))*10000.)/10000.;", STD. DEV. O

F MEAN $="$; INT (Sdmb*10000.) $/ 10000$.

$8795 \quad$ Sdmtot $=\operatorname{SQR}(S d m t \uparrow 2+S d m b+2)$

$8800 \quad$ Psdmt ot $=100 . \quad \mathrm{SQR}(\mathrm{Sdm} t+2+\mathrm{Sdmb} \uparrow 2) /(\mathrm{T} 2-\mathrm{T} 1+\mathrm{T} 3-\mathrm{T} 4)$

8805 Sddel $t=I N T$ (Delt_frac* $(T 2-T 1+T 3-T 4) * 10000$.) $/ 10000$.

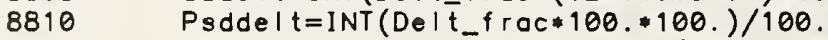

8815 PRINT" TOTAL del to T (T2-T1+T3-T4)="; INT ( (T2-T1+T3-T4)*10000.)/10000.

8820 PRINT" STD. DEV. OF DeIT =";Sddelt;", \% STD.DEV. OF DeIT =";PSddeI

8825 PRINT" STD. DEV. OF THE MEAN=": INT (Sdmtot*10000.)/10000.;", \% STD.D EV. OF THE MEAN $="$; INT (Psdmt ot $* 10000.) / 10000$.

8830 PRINT

8835 PRINT" AVG. MAIN HEATER PLATE POWER (mW) $=" ;$ INT $(1 . E+6 * A \vee g(5)) / 1000$.

8840 PRINT" STD.DEV. OF $Q=" ; I N T(1 . E+6 * S d(5)) / 1000 . ; "$ \% STD.DEV. OF $Q$

$="$; INT (Q_frac 10000.) $/ 100$.

$8845 \quad$ Sdqmean $=\operatorname{INT}((1 . E+6 * \operatorname{Sd}(5)) / \operatorname{SQR}($ Npw $r)) / 1000$.

$8850 \quad$ Psdqmean=INT ( $1 . E+8 * \operatorname{Sd}(5)) / \operatorname{SQR}($ Npwr $) /(1 . E+3 * A v g(5))) / 1000$.

8855 PRINT" STD.DEV. OF THE MEAN =";Sdqmean;" \% STD.DEV. OF THE MEAN =

"; Psdqmean

8860 PRINT"

8865 PRINT" DATA AVERAGING INTERVAL:":INT (Fd (28).100./60.)/100.

START POINT OF INTERVAL : ":INT(Fd(29)*100./60.)/100.:" MINUTES "

8875 PRINT

8880 PRINT" FINAL HEATER RESISTANCE : "; INT(Fd(10)*10000.)/10000.; "OHMS"

8885 PRINT

8890 PRINT "

8895 PRINT"

8900 PRINT"

8905 PRINT"

8910 PRINT

8915 Dtovg=INT $((\mathrm{Fd}(16)-\mathrm{Fd}(17)) * 10000) / 10000$.

8920 PRINT" Thi $(\mathrm{degC})=$ ": INT (Fd (16)*10000.)/10000.:" TI0 (degC) = ";INT(Fd( 17)*10000.)/10000.;", de IT="; Dtavg

8925 IF Fd(2)<10 AND Fd(2)>1 THEN

8930 PRINT USING "23A,4D.DDD,25A,4D.DD,8A";" AVG. TEMP. (C) IS :",Fd(1)," , TH ERMAL COND. $(k)=", F d(2) * 1000 ., " m W /(m * K) "$ 8935 ELSE

8940 PRJNT USING "23A,4D.DDD,40A";" AVG. TEMP. (C) IS :",Fd(1),", THERMAL CON D. $(k)=9999.99 \mathrm{~mW} /(\mathrm{m} * \mathrm{~K}) "$

8945 END IF

8950 PRINT" STD.DEV. OF $k=":$ INT (Kstd_deV*1000.)/1000.;", $\%$ STD.DEV. OF

$k="$ : INT $\left(K_{-}\right.$froc*100.*100.) $/ 100$.

8955 PRINTER IS 1

8960 OFF ERROR

8965 SUBEXIT

$8970 \quad$ TCaI $c=$ TIMEDATE

8975 RETURN

8980 Calc_er

8985 PRINTER IS 1

8990 PRINT "SUB 'FINAL AVERAGES" ERROR : "\&ERRM\$

8995 CALL Err_record(ERRM\$)

$9000 \quad$ BEEP $83 * \overline{5}, .3$ 


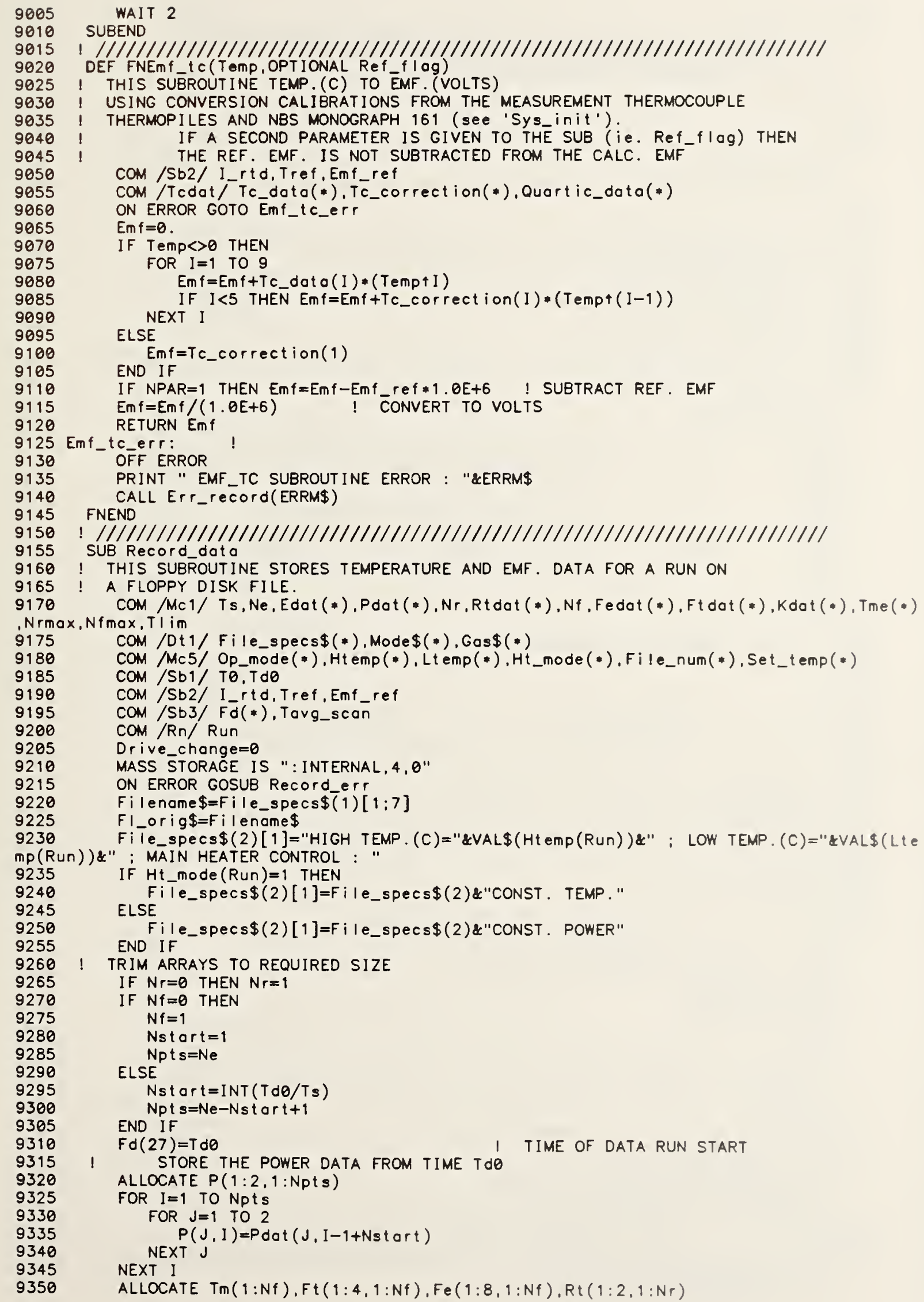


FOR $I=1$ TO $N f$

FOR $J=1$ TO 8 


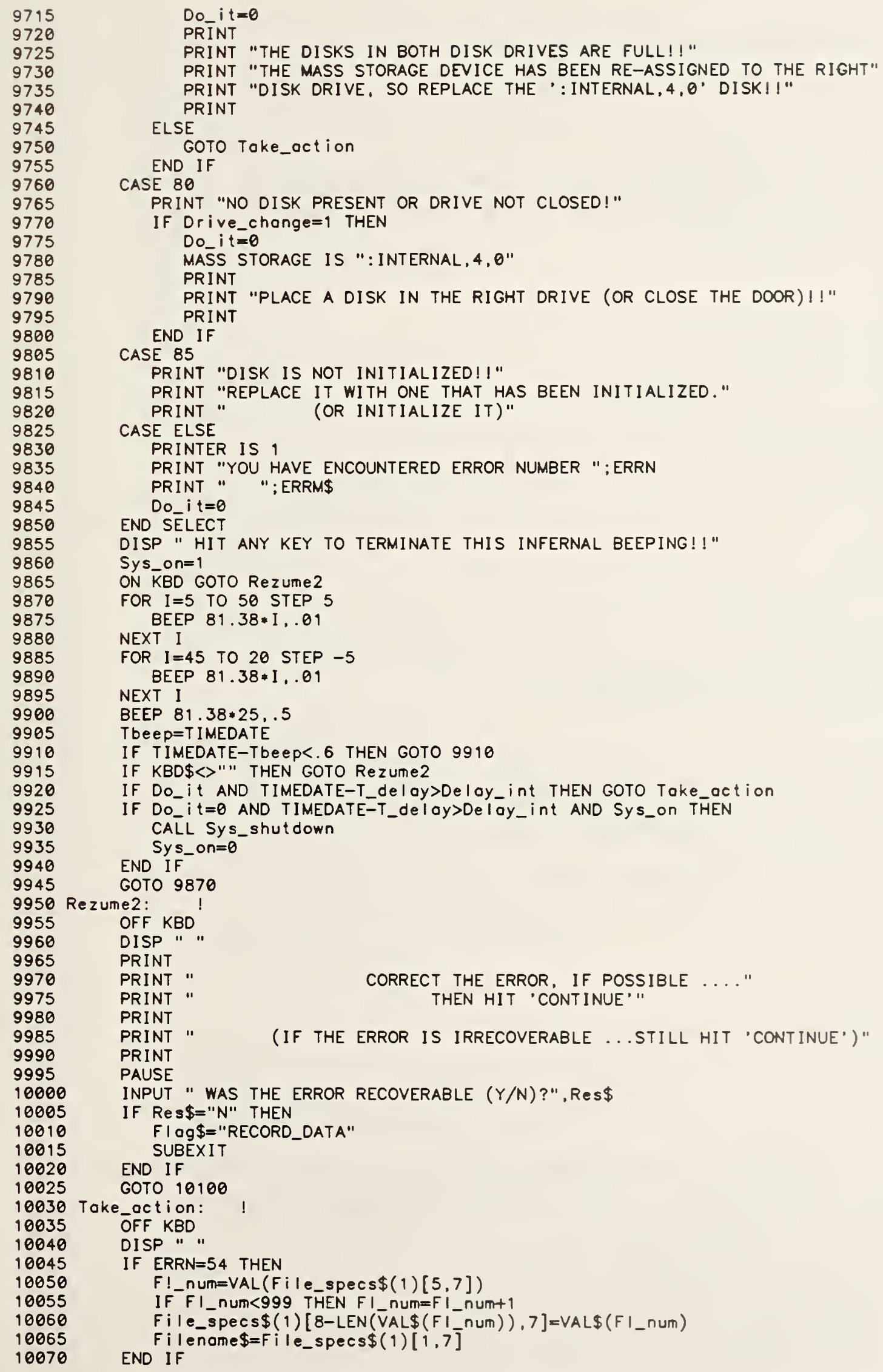




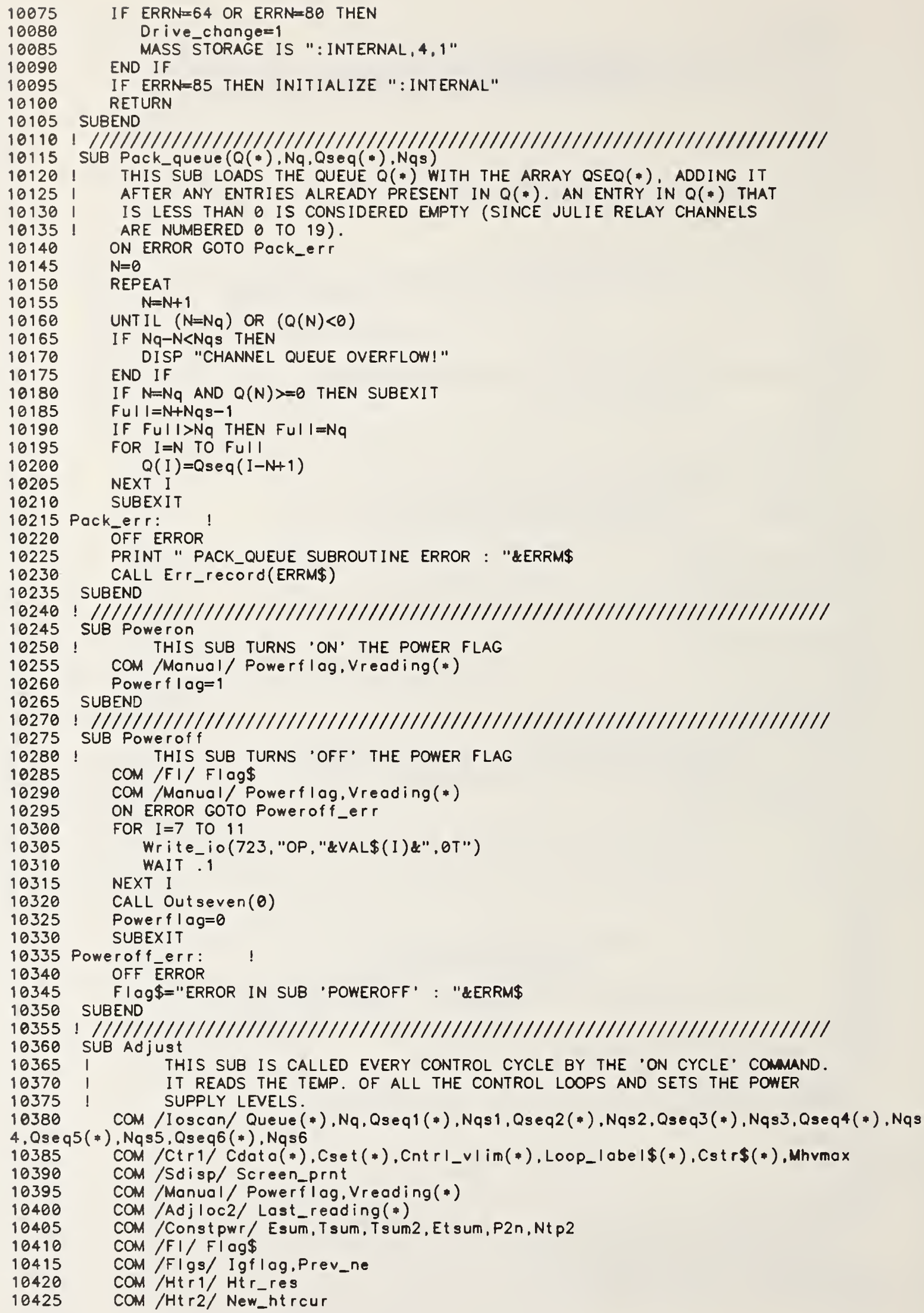


10430 CoM /Instr/ Mh181,Jr1181, Mh195, Top195, Bop195, Ig195

10435

Nrmax, Nfmax.Ti im

10440 COM / Mc2/ Heater_sres

10445

10450

10455

10460

10465

10470

10475

10480

10485

10490

10495

10500

10505

10510

10515

10520

10525

10530

10535

10540

10545

res) \&"

com /Mc5/Op_mode (*),Htemp (*),Ltemp (*),Ht_mode (*), File_num (*), Set_temp (*)

com / Mc6/ Ntm,Ntr, Ntp, Ntz

COM/Rn/ Run

$\operatorname{COM} / \mathrm{Sb} 1 / \mathrm{TO}, \mathrm{Td} \theta$

Com /Sb2/ I_rtd, Tref, Emf_ref

$\mathrm{COM} / \mathrm{Sb} 3 / \mathrm{Fd}($ ) , Tavg_scan

DIM Power_prob(1:5)

ON KBD GOSUB Nothing

ON KEY 8 LABEL "" GOSUB Nothing

ON KEY 5 LABEL " " GOSUB Nothing

ON ERROR GOTO Adj_error

Tod $j=$ T IMEDATE

$\mathrm{Ne}=\mathrm{Ne}+1$

If Ne>1 THEN Ov=Pdot (2, $\mathrm{Ne}-1)$

CALL Reod_io(Vpwr, Treod, Mh195, "R0X",Ov)

Pdat $(2, N e)=V$ pwr

If New_ht reur THEN

New_ht rcur $=0$

IF $\overline{P d a t}(1, \mathrm{Ne}-1)<>0$ THEN Fo $(10)=V$ pwr $/ \mathrm{Pdat}(1, \mathrm{Ne}-1)$

IF ABS (Fd $\left.(10)-H t r_{-} r e s\right)>.5 * H t r_{-}$res THEN

CALL Err_recorō" "HEATER RESISTANCE VARIATION TOO GREAT : OLD="\&VAL\$(Ht NEW (IGNORED) = "\&VAL\$(F $\$(10))$

10550 PRINT "HEATER RESISTANCE VARIATION TOO GREAT: OLD="\&VAL\$(Htr_res)\&", N

EW (IGNORED) = "\&VAL\$(Fd (10))

$10555 \quad \mathrm{Fo}(10)=\mathrm{Ht} r_{-}$res

10560

10565

10570

10575

10580

10585

10590

10595

10600

10605

10610

10615

10620

10625

10630

10635

10640

10645

10650

10655

10660

10665

10670

10675

10680

10685

10690

10695

10700

10705

10710

END IF

BEEP $83 * 28, .1$

IF Screen_prnt THEN PRINT"

HEATER RESISTANCE CALC. $=" ; F \sigma(10) ; "$ OHMS" END I $F$ Ht r-res $=\bar{F} \bar{d}(10)$

$\operatorname{Pdat}(1, \mathrm{Ne})=\mathrm{Vpwr} / \mathrm{Htr}$ _res

! FOR EACH PAIR OF IDENTICAL CURRENTS ( $\mathrm{Ne}$

MAT Power_prob $=(0$.

FOR $I=1$ TO 5

Vin=Vreoding (I)

IF I=1 THEN CALL Reod_io(Vout, T, I g195, "ROX",Vin)

IF $I=2$ THEN CALL Atod_io(Vout, T,Vin) ! A/D CARD OUTPUT (FOR $O G$ )

IF I =3 THEN CALL Read_io(Vout, T, Tap195, "ROX", Vin)

IF I=4 THEN CALL Reod_io(Vout, T, Bop195, "ROX",Vin)

IF I=5 THEN CALL Reod_io(Vout. T, MH181, "R3B1X",Vin)

Vreoding (I)=Vout NEXT

If (I>1) AND (Vreading(I)<(100..0001)) THEN Power_prob(I)=1

IF SUM(Power_Prob) $=4$ THEN FIOG $\$=" R T D$ POWER SUPPLY MALFUNCTION"

IF POWe $f$ log=1 THEN ! ADJUST HEATERS

Pid (1, Vreoding (1), Ot)

FOR $I=2$ TO 5

NEXT I

Pid(I.Vreoding (I)/I_rtd,Ot)

IF ( $(\mathrm{Ne}-\mathrm{P} 2 n)$ MOD Ntp2=0) AND (TdO<>0) AND (Ht_mode(Run)=2) THEN

$P 2 n=N e$

Ets lope $=($ Etsum $* N t p 2-E s u m * T s u m) /(T s u m 2 * N t p 2-T$ sum 2$) \quad ! \quad K / S E C$

Esum=0

T sum $=0$

Tsum $2=0$

Etsum=0

Slope_cor $=-(110 *(.8+.006 * \operatorname{Edat}(5, \mathrm{Ne}))+.5) * E t \mathrm{slope} / \mathrm{Cdoto}(5,2,2)$

IF ABS(SIope_cor/Cdata $(5,2,2))>.05$ THEN

PRINT "SLOPE CORRECTION OVER 5\%; CHANGE RESTRICTED TO 5\%"

Slope_cor $=S G N\left(S I O P C_{-}\right.$cor $) * .05 * \operatorname{Cdoto}(5,2,2)$

END IF

END IF

Cdata $(5,2,2)=\operatorname{Cdata}(5,2,2)+$ Slope_cor

10740

10745

10750

10755

10760

10765

IF (Ht_mode(Run) $=2$ ) AND $(T d \theta<>\theta)$ THEN Cdoto $(5,2,1)=\operatorname{Cdoto}(5,2,2)$

CALL Write_io(723, "OP, "\&VAL $\$(11) \& "$ "\&VAL $\$($ Cooto $(1,2,1)) \&$ "T")

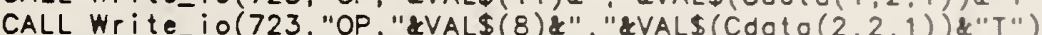

CALL Write_io(723, "OP,"\&VAL\$(9)\&" "\&VAL\$(Cdoto $(3,2,1)$ ) "T")

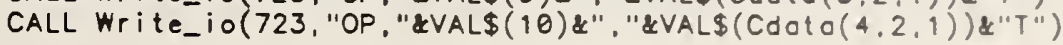




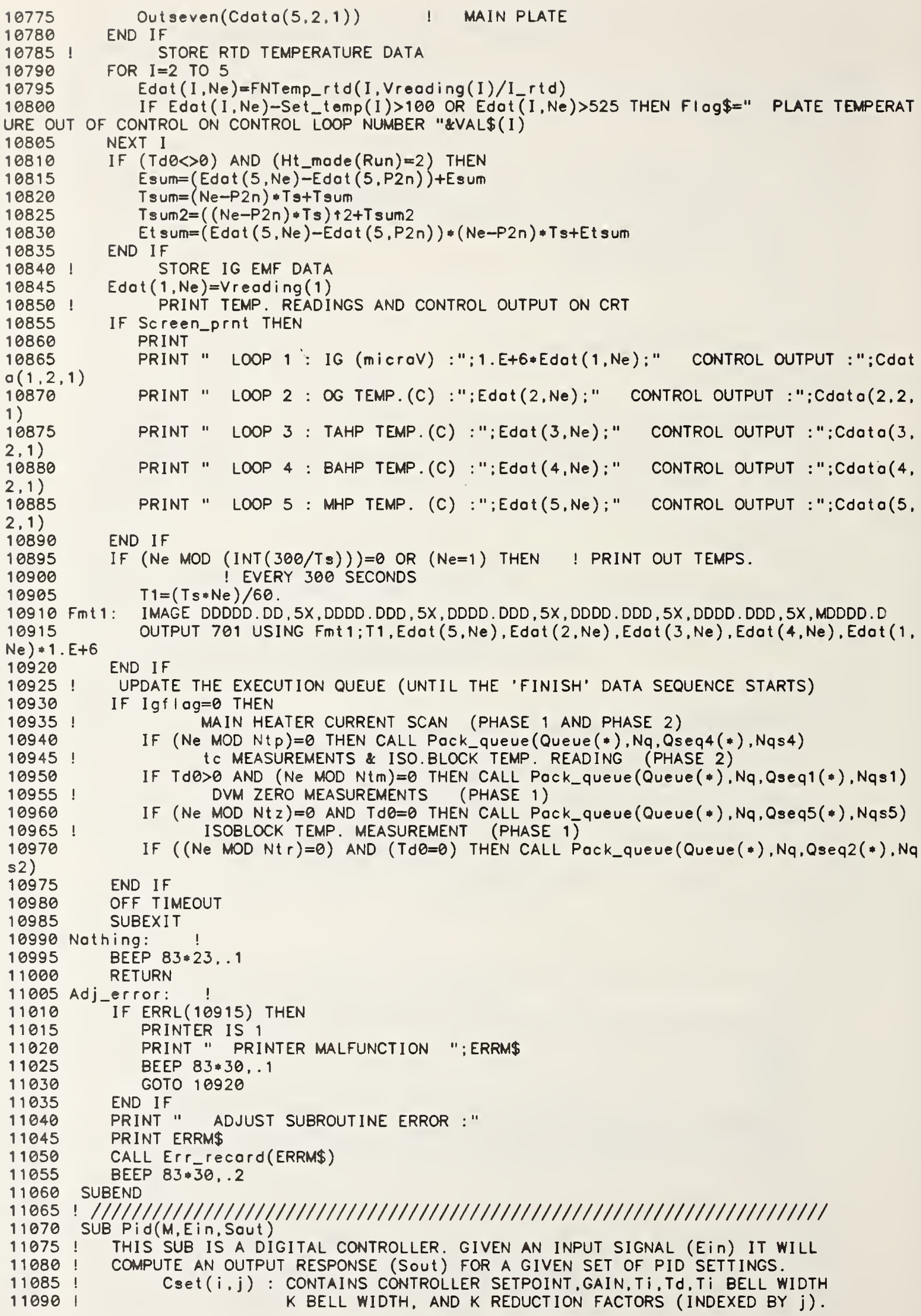

11015 END IF 
THE INDEX i REFERS TO DIFFERENT CONTROL LOOPS. 


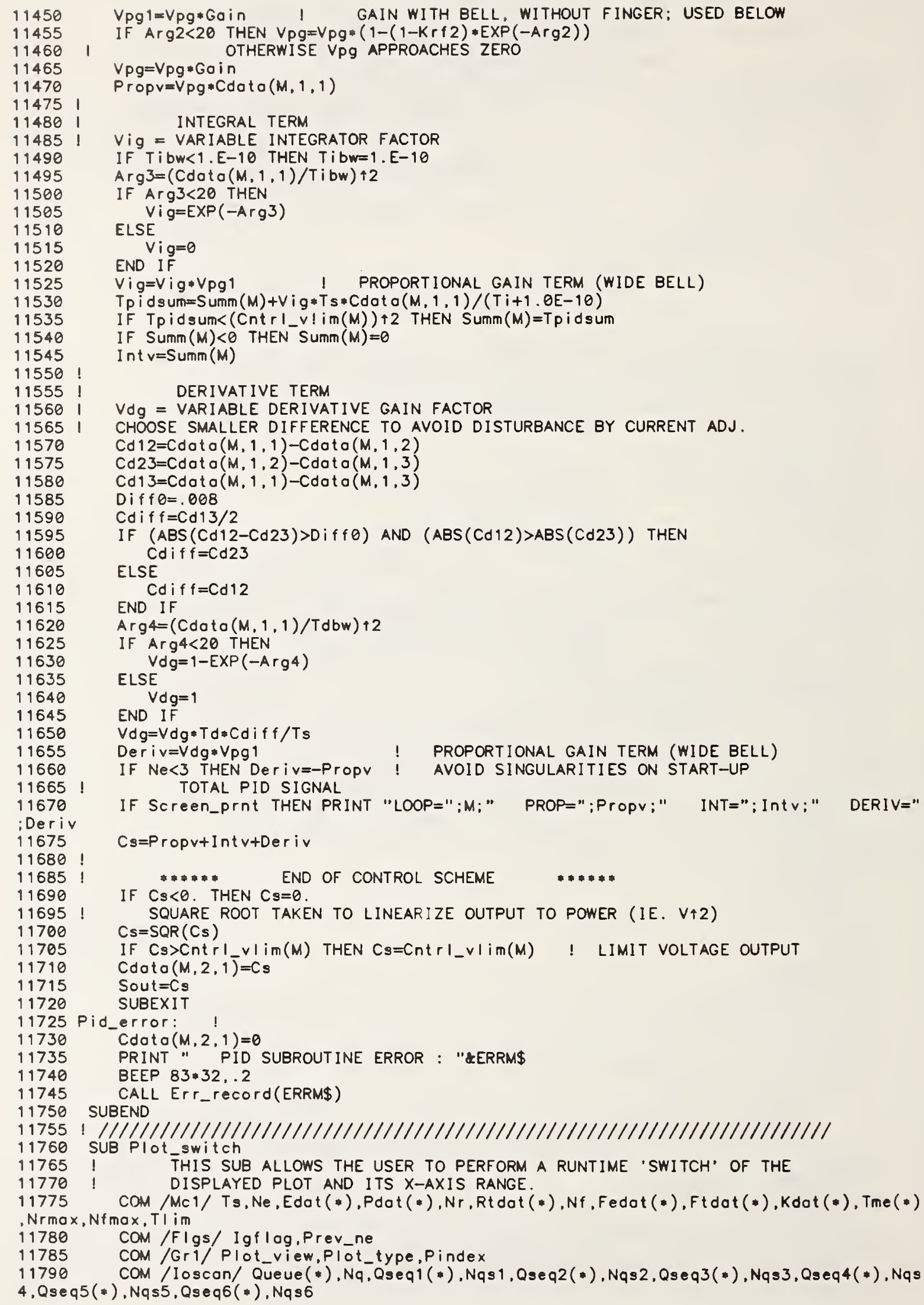


com/Gr2/ X1, X2, Xinc, Y1, Y2, Yinc, Xt it\$, Ytit\$

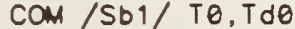

SYSTEM PRIORITY $\theta$

ON ERROR GOTO PIOt_sw_error

If Quevo(1)>1 THEN

BEEP $83 * 23, .1$

SUBEXIT

END IF

DISP " "

Beot_it $=0$

Tpinde $x=P$ inde $x$

Tplot_type=Plot_type

Tplot_view=Plot_view

FOR $I=0$ TO 9

ON KEY I LABEL " "GOTO 12135

NEXT I

ON KEY 8 LABEL "SELECT DATA" GOTO 11945

ON KEY 2 LABEL "SELECT VIEW" GOTO 12850

ON KEY 8 LABEL " PLOT IT " GOTO 11910

ON KEY 9 LABEL " MAIN MENU " GOTO 11900

GOTO 12835

Beot_it $i$

GOTO 11925

Plot_type=Tplot_type

$P$ inde $x=T p$ index

Plot_view=Tplot_view

CALL Plot_prep $(\bar{X} 1, X 2, X i n c, Y 1, Y 2, Y i n c, X t i t \$, Y t i t \$)$

CALL Rescole_plot $\left(X_{1}+\left(X_{2}-X_{1}\right) / 2, Y_{1}+\left(Y_{2}-Y_{1}\right) / 2\right)$

IF Beot_it THEN SUBEXIT

GOTO $12 \overline{8} 35$

$I d=I d+1$

If Id $>12$ THEN Id $=1$

If $T$ me $(1)=0$ AND ( $(I d>5$ AND Id<18) OR Id=12) THEN GOTO 11945

Tp index=1

SELECT Id

CASE 1 TO 5

Tplot_type=1

Tpinde $x=I d$

CASE 6 TO 9

Tplot_type=2

$T p$ inde $x=I d-5$

CASE 10

Tplot_type=3

CASE 11

Tplot_type=4

CASE 12

Tplot_type=5

END SELECT

CALL G_lobel (Glab\$, Tplot_type, Tpindex)

ON KEY 5 LABEL GIOB\$ GOTO 12135

GOTO $1206 \theta$

Tplot_view=Tplot_view+1

If Tplot_view>5 THEN Tplot_view=0

SELECT Tplot_view

CASE 1

PV\$="LAST 30 MIN."

CASE 0

PV\$=" FULL VIEW"

CASE 2

PV\$ $\$=$ "LAST 60 MIN."

CASE 3

PV\$="LAST 120 MIN."

CASE 4

PV\$="LAST 240 MIN."

CASE 5

PV\$="LAST 480 MIN."

END SELECT

ON KEY 7 LABEL PV\$ GOTO 12135

$T p=T$ IMEDATE

LOOP

If Ne<>Prev_ne THEN CALL Updote_plot ("N")

EXIT IF TIMEDATE-T $P>120$ 


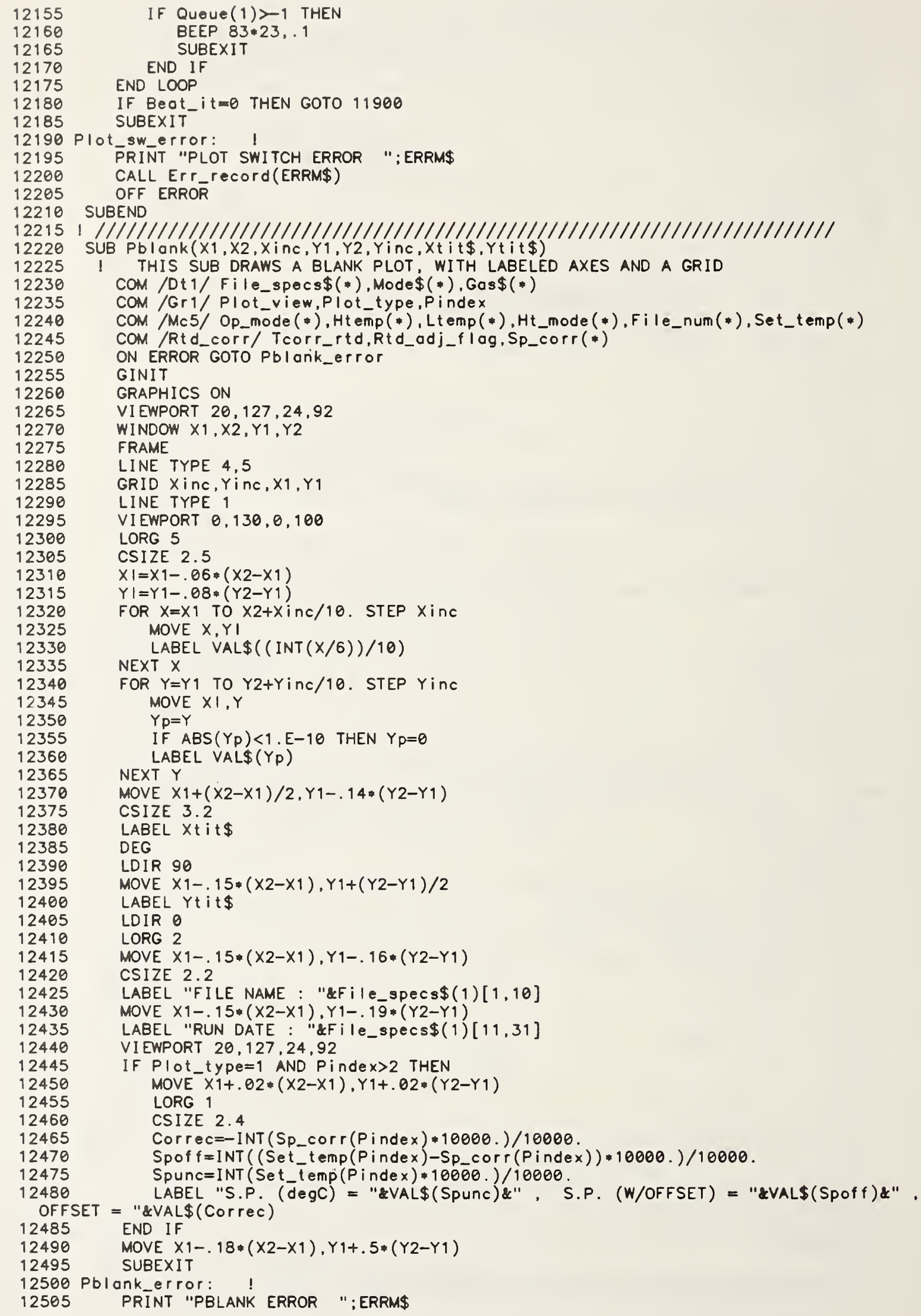


CALL Err_record(ERRM\$)

I THIS ROUT INE CONVERTS TEMPERATURE (C) TO OHMS

12535 I FOR THE ROSEMOUNT PLATINUM RTD'S USING THE ITPS-68 FORM OF THE

12540 I CALLENDAR-VAN DUSEN EQUATION.

12545 COM/Canv_dat/RO (*), Alpha(*), Delto(*)

12550

12555

12560

12565

12570

12575

12580

12585

12590

12595

12600

12605

12610

12615

12620

12625

12630

12635

12640

12645

12650

12655

12660

12665

12670

12675

12680

12685

12690

12695

12700

12705

12710

12715

12720

12725

12730

12735

12740

12745

12750

12755

12760

, Nrmax

ON ERROR GOTO Ohms_rtd_errar

$R=R O$ (Rtd_num)

$A=A l$ pho (Rtd_num)

$D=D$ I I o (Rtd_num)

CONVERT TEMP. (C) TO RESISTANCE (OHMS)

$T 2=T-.045 *(T / 100) *(T / 100-1) *(T / 419.58-1) *(T / 630.74-1)$

Resistance=R*(1+A*(T2-D*(T2/100)*(T2/100-1)))

OFF ERROR

RETURN Resistance

Ohms rtd_ertar: I

PRINT" "RTD CONVERSION ERROR : ";ERRM\$

FNEND

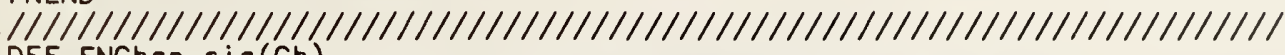

DEF FNChan_sig(Ch)

THIS SUB CALCULATES AN INTEGER COMMAND FOR THE DIGITAL

OUTPUT CARD IN THE H.P. MULTIPROGRAMMER THAT WILL SET

THE JULIE RELAY TO THE CHANNEL 'Ch'.

ON ERROR GOTO Chan_sig_err

IF $\mathrm{Ch}<10$ THEN

$\mathrm{N}=240+\mathrm{Ch}$

ELSE

$\mathrm{N}=15+16 *(\mathrm{Ch}-10)$

END IF

IF $N<\theta$ THEN

$\mathrm{N}=0$

PRINT " REQUESTED JULIE RELAY CHANNEL IS OUT OF RANGE!!"

END IF

IF $N>255$ THEN

$N=255$

PRINT " REQUESTED JULIE RELAY CHANNEL IS OUT OF RANGE!!"

END IF

RETURN N

Chan_sig_ert:

PRINT " ERROR IN SUB 'CHAN_SIG".

FNEND

CALL Err_record(ERRM\$)

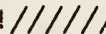

SUB Rescole_plot $(X, Y)$

THIS SUB RESCALES PLOTS THAT HAVE GONE OFFSCALE

COM /Gr1/Plot_view,Plot_type,Pindex

$\operatorname{com} / G, 2 / X 1, X \overline{2}, X i n c, Y 1, \bar{Y} 2, Y i n c, X t i t \$, Y t i t \$$

$\mathrm{COM} / \mathrm{Mc} 1 / \mathrm{Ts}, \mathrm{Ne}, \mathrm{Edat}(*), \operatorname{Pdat}(*), \mathrm{Nr}, \mathrm{Rt} \operatorname{dat}(*), N f, F e d a t(*), F t \operatorname{dat}(*), \operatorname{Kdat}(*), T m e(\cdot)$

12765

12770

12775

12780

12785

12790

12795

12800

12805

12810

12815

12820

12825

12830

12835

12840

12845

12850

12855

12860

max, T I im

ON ERROR GOTO Rescale_errar

IF $Y<Y 1$ THEN $Y 1=Y 1-Y$ inc

IF $Y>Y 2$ THEN $Y 2=Y 2+Y$ inc

If (Y2-Y1)/Yinc>10 THEN CALL Plat_Prep(X1,X2,Xinc,Y1,Y2,Yinc,Xtit\$,Ytit\$)

IF $X>\left(X_{1}+.9 \cdot\left(X_{2}-X_{1}\right)\right)$ THEN

$X$ range $=x 2-X 1$

IF Plat_view>=1 THEN

$x 2=x \overline{2}+x$ inc

ELSE $x 1=x 2-x$ range

$x 2=x 2+x$ range

END IF

$x$ inc $=x$ inc $* 2$

CALL Pblank $(X 1, X 2, X i n c, Y 1, Y 2, Y i n c, X t i t \$, Y t i t \$)$

SELECT Plot_type

CASE 1,3

IF Plot_view>=1 THEN Nstart=INT( $\times 1 / T s)$

IF Nstart=0 THEN Nstart $=1$

$\mathrm{Nend}=\mathrm{Ne}$ 


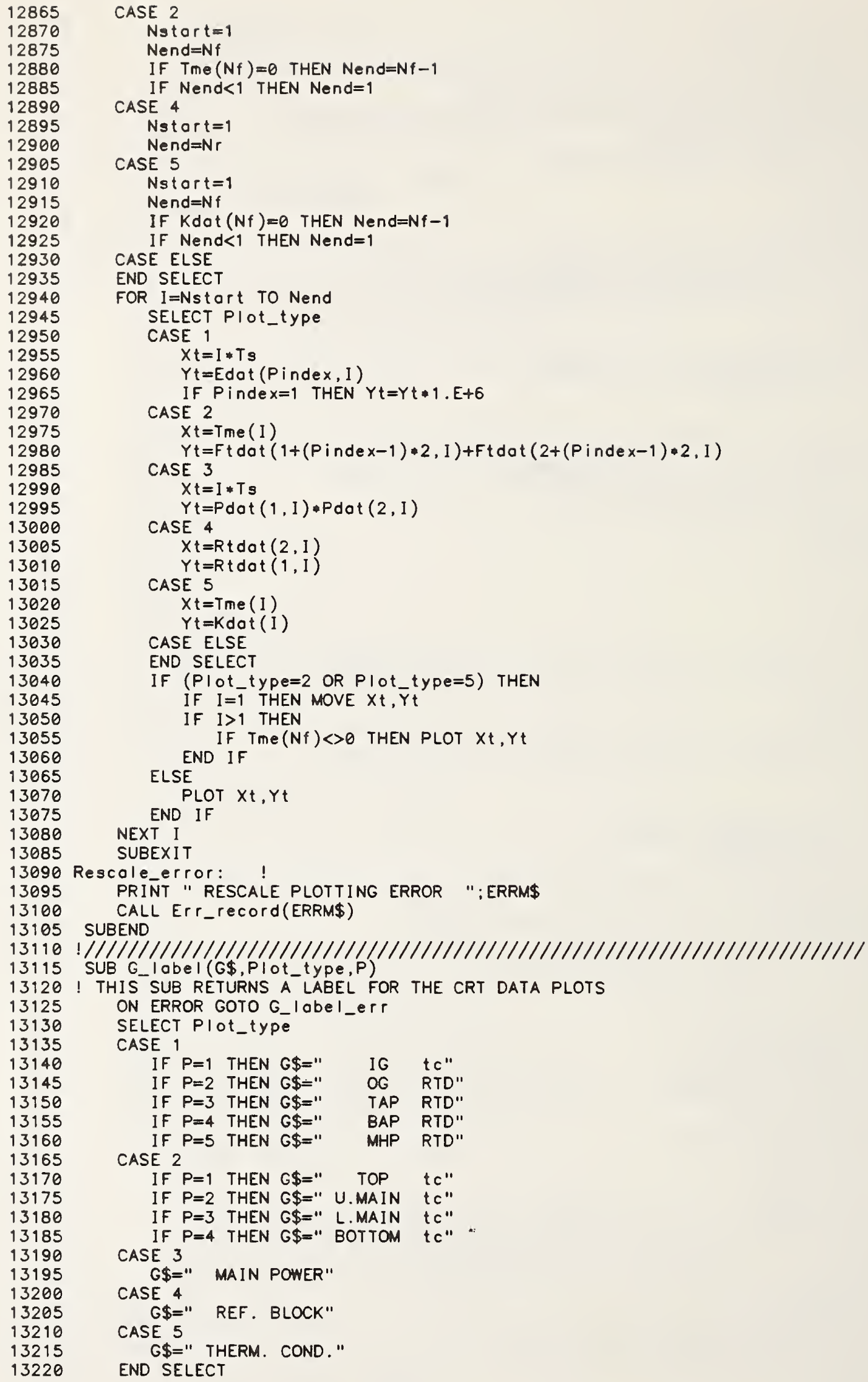


G_label_err:

PRINTT" ERROR IN SUB 'G_LABEL" "

13240

13255 SUB Read io(V.Tread Inst rument DVm cmo $\$$ Oldvolt $)$

13260 I THIS SUB TAKES AN INSTRUMENT READING \& TRAPS INSTRUMENT READ

13265 I ERRORS

13270

13275

13280

13285

13290

13295

13300

13305

13310

13315

13320

13325

13330

13335

13340

13345

13350

13355

13360

13365

13370

COM/Instr/ Mh181, J I I 181, Mh195, Tap195, Bap195, I g195

CoM /Read1/ Io_error,Bad_instr (*), Bad_read_time\$(*)

$\operatorname{COM} / \mathrm{Sb} 1 / \mathrm{TO}, \mathrm{T} d \theta$

$\operatorname{COM} / \mathrm{Fl} / \mathrm{Flag} \$$

COM /Zeros/Zjrl181_200,Zjrl181_20,Zgap195,Zhistory(*)

Error $=0$

ON TIMEOUT 7,1. GOTO Read_it_error

ON ERROR GOTO Read_io_err

Zero=0

If Instrument=I g195 THEN Zero=Zgap 195

If Instrument $=J P \mid 181$ THEN

Zero=Zjrl181_200

IF POS(Dvm_cm \$. "R2") $<>$ THEN Zero=ZjrI181_20

END IF

$T t=T$ IMEDATE

ENTER Instrument; $V$

$V=V-Z$ ero

Treod=TIMEDATE-TO

OFF TIMEOUT

SUBEXIT

Read_it_error: I

ON TIMEOUT 7,1. GOTO Reod_it_error

Error=Errort1

Io_error=Io_errort

Bad_instr (Io_error) =Instrument

Bod_read_time $\$$ (Io_error)=DATE\$(TIMEDATE)\&" "\&TIME\$(TIMEDATE)

PRINT " IO ERROR IN SUB 'READ_IO"

BEEP $83 * 35, .1$

IF Io_error $=100$ THEN

FI $\bar{a} \$ \$=" M A X I M U M$ NUMBER OF IO ERRORS EXCEEDED !!"

SUBEXIT

END IF

IF Error=1 THEN

CLEAR Instrument

WAIT .2

BEEP $83, .1$

OUTPUT Instrument:Dvm_cmd\$

WAIT .2

ELSE

GOTO 13300

13460

13465

13470

13475

13480

13485

13490

13495

13500

13505

13510

13515

13520

13525

Nrmax,

$V=01 d v 01$ it

Treod=TIMEDATE-TO

END IF

SUBEXIT
REadiIo_erT: ।

PRINT " ERROR IN SUB 'READ_IO" "\&ERRM\$

SUBEND

CALL Err_record(ERRM\$)

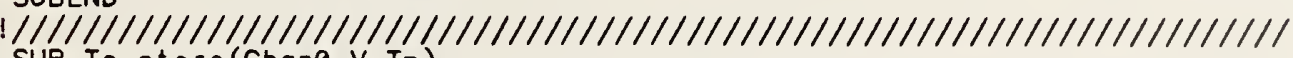

SUB Tc_store (Chano,V.Tm)

THIS SUB STORES T.C. VOLTAGE DATA (PHASE 2)

CoM /Mc1/ Ts, Ne,Edat (*),Pdat (*),Nr,Rtdat (*),Nf, Fedat (*), Ftdat (*), Kdat (*), Tme (*)

ax, Nfmax, Tl im

13535

13540

13545

13550

13555

13560

13565

13570

13575

$\operatorname{COM} / \mathrm{Sb} 2 / I_{-}$rtd, Tref, Emf_ref

$\operatorname{com} / \mathrm{Sb}_{3} / \mathrm{F} \bar{d}(*)$, Tavg_interval

COM /Tcst1/Store_flag

ON ERROR GOTO TC_store_epror

If Store_fl $a g=0$ THEN

$N f=N f+1$

If $\mathrm{Nf}>\mathrm{Nfmax}$ THEN

$N f=N f \max$

PRINT " DATA STORAGE ARRAYS ARE FULL!"

BEEP $83 * 5, .1$ 


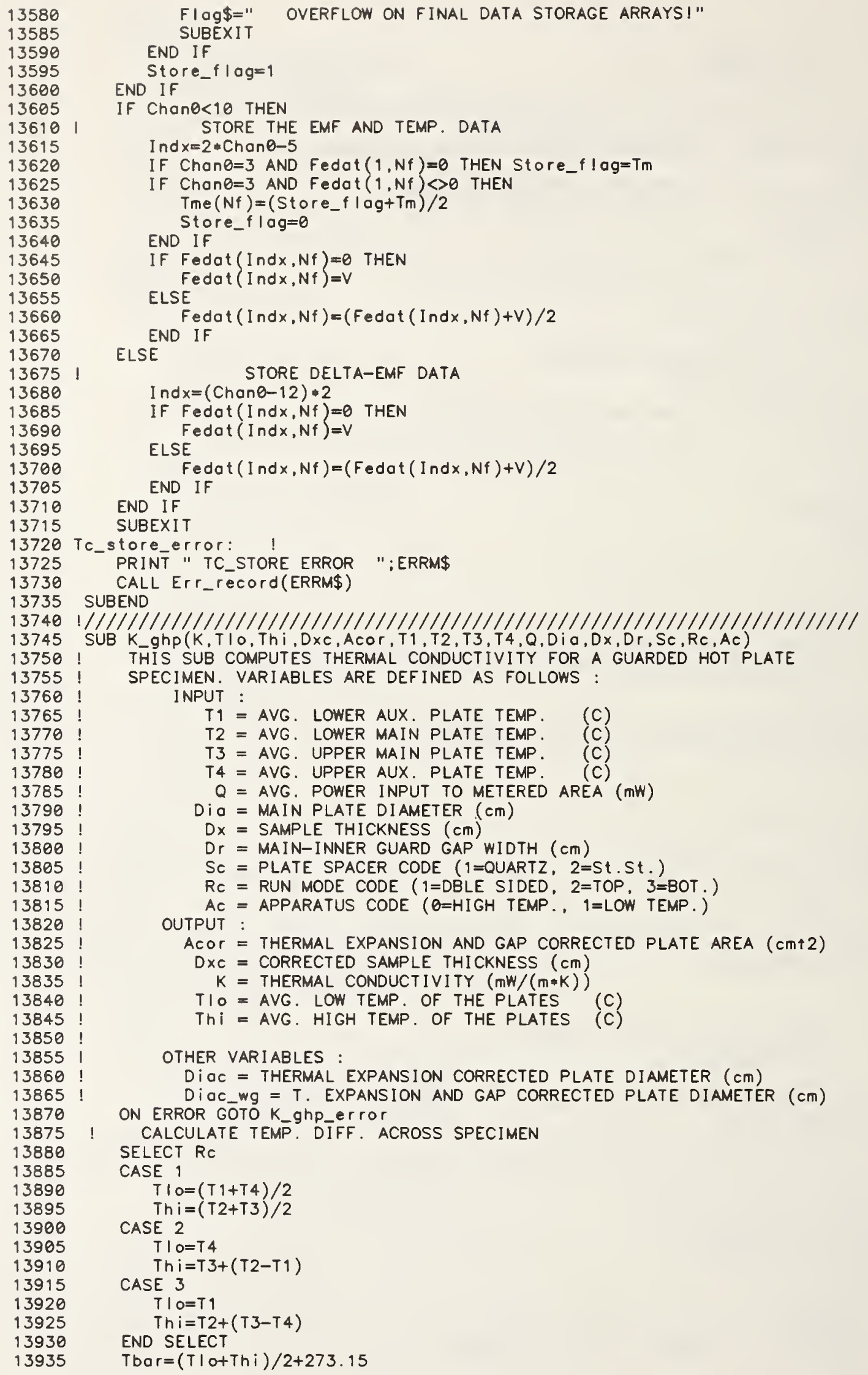


1 ALUMINA THERMAL EXPANSION CORRECTION ON DIAMETER OF THE MAIN PLATE D i O $=$ D i $0 *(1+7.5 E-6 *(T P-20))$ AREA CORRECTION FOR GAP

Dioc_wg $=2 * D_{r} *(1+7.5 E-6 *(T p-28))+D i o C$ $A p=P I *(D$ ioc $+2 / 4)$

$A g \circ p=P I *\left(D i o C_{-} w g \uparrow 2 / 4\right)-A p$

$A C O R=A p+A g O P / \overline{2}$

DIA. OF THE PLATE + GAP

! AREA OF THE PLATE

! AREA OF THE GAP

! CORRECTED AREA

1 THERMA

\section{CASE 1} $D \times c=D x *(1+1.7 E-5 *(T b a r-20))$

CASE 2

CASE ELSE $D \times C=D x$

END SELECT

IT MAY BE NECESSARY TO CORRECT FOR PLATE SAG IN THE SINGLE SIDE RUNS. DXC IS LARGER FOR HEAT FLOW UP AND SMALLER FOR HEAT FLOW DOWN. NOT KNOWN AT THIS TIME - NOT NECESSARY FOR RIGID SPECIMENS.

$K=100 \cdot 0 \cdot D \times C /($ Acor*Del $t)$

$$
\text { CALCULATE THERMAL CONDUCTIVITY }
$$

SUBEXIT

K_ghp_error:

$\mathrm{K}=-1$

DISP " CALCULATION ERROR ";ERRM\$

SUBEND

CALL Err_record(ERRM\$)

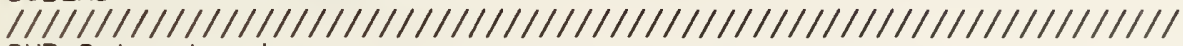

SUB Set_pnt_colc

THIS SUB RECALCULATES SETPOINTS FOR THE CONTROL LOOPS. THE VALUES OF TEMP. IN THE 'Set temp' ARRAY ARE USED AS TEMP. SETPOINTS.

com /Ctr1/Coto (*), Cset (*), CntrI_vIim(*), Loop_label\$(*), Cstr\$(*), Mhvmox

COM /Mc5/Op_mode (*), Htemp (*), Ltemp (*), Ht_mode (*), File_num (*), Set_temp (*)

COM /Rn/Run

COM /Rtd_corr/ Tcorr_rtd,Rtd_adj_flog, Sp_corr(*)

ON ERROR GOTO SP_err

1 CALC SETPOINTS (IN OHMS)

FOR $I=2$ TO 5 NEXT I

$$
\text { Cset }(I, 1)=\text { FNOhms_rtd }\left(I,\left(S_{\text {Set_temp }}(I)-S_{\text {S }} \operatorname{corr}(I)\right)\right)
$$

I CALC IG SETPOINT (IN VOLTS)

Cset $(1,1)=$ Set_t $\operatorname{emp}(1) / 1 . E+6$

If Htemp(Run) $<>S e t_{\text {_t }} \operatorname{emp}(5)$ THEN Htemp(Run) $=$ Set_temp (5)

Lowe st $=$ Set_t emp (3)

If Set_temp (4)<Lowest THEN Lowest=Set_temp (4)

If Lowest $<$ Ltemp(Run) THEN Ltemp(Run)=Lowest SUBEXIT

Sp_err:

PRINT " ERROR IN SUB 'SET_PNT_CALC' : "\&ERRM\$

SUBEND

CALL Err_record(ERRM\$)

\section{I///////////////////////////////////////////////////////////////////////////}

SUB Write_io (Instr, Cnd\$)

! THIS SUB OUTPUTS COMMANDS TO INSTRUMENTS ON THE HPIB BUS

$\mathrm{COM} / \mathrm{FI} / \mathrm{Flog} \$$

COM /Instr/ Mh181, Jr1181, Mh195, Top195,Bop195, I g195

COM /Jrlchan/Chan, Tchan,Dvm_comd\$, Defoult_chan

COM /Reod1/ Io_error,Bod_instr(*),Bod_read_time\$(*)

Error=0

ON ERROR GOTO Write_err

ON TIMEOUT 7,1. GOTO Wrt_time_err

FOR Is is=1 TO 2

OUTPUT Inst $r ;$ Cmd\$

If Inst $r<723$ THEN ENTER Inst $r$;Dummy

NEXT I s is

IF Inst $r=J r \mid 181$ THEN DVm_cmmd $\$=C m d \$$

OFF TIMEOUT

SUBEXIT

Wrt_time_err

Error=Errorti 


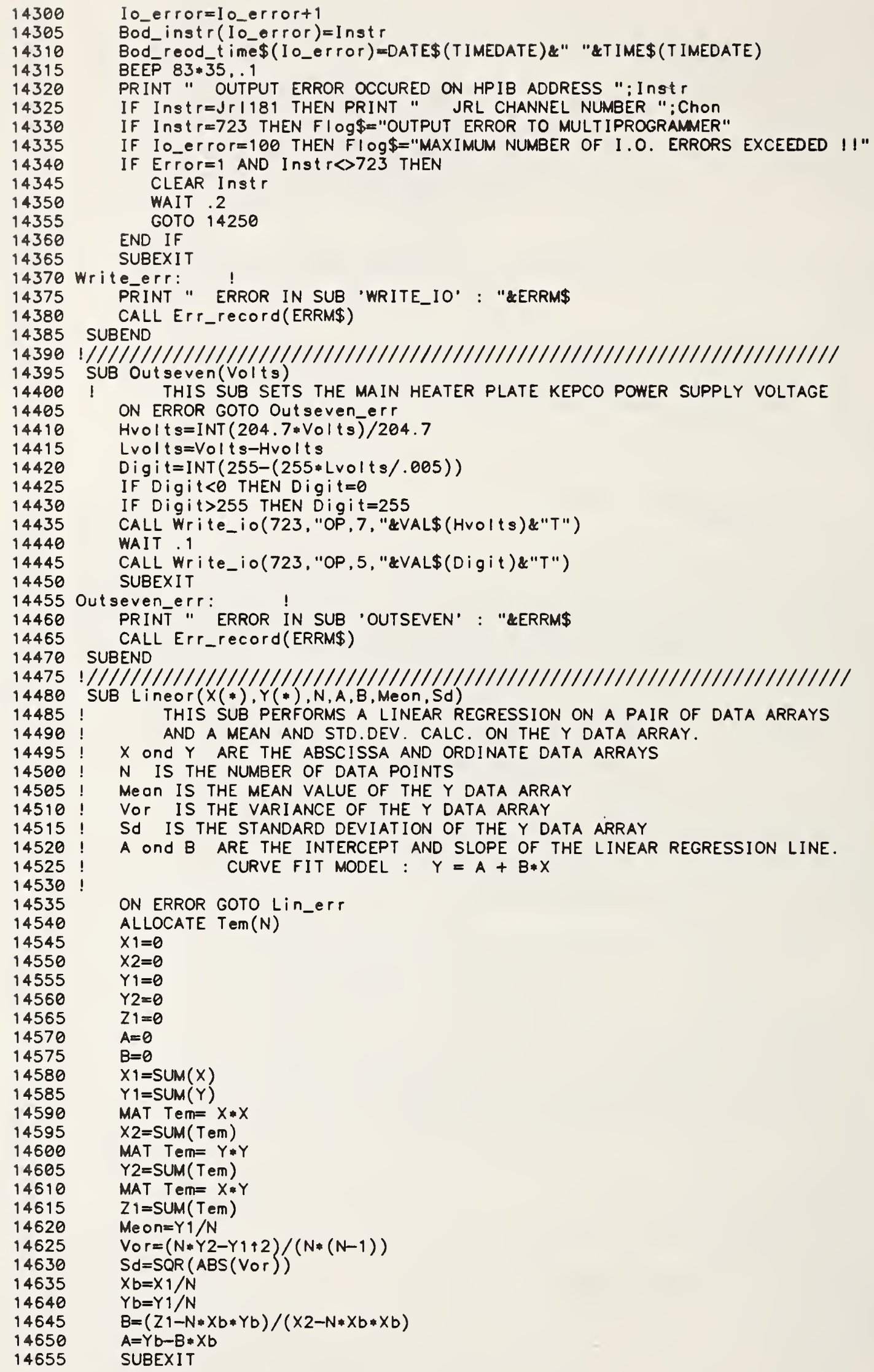




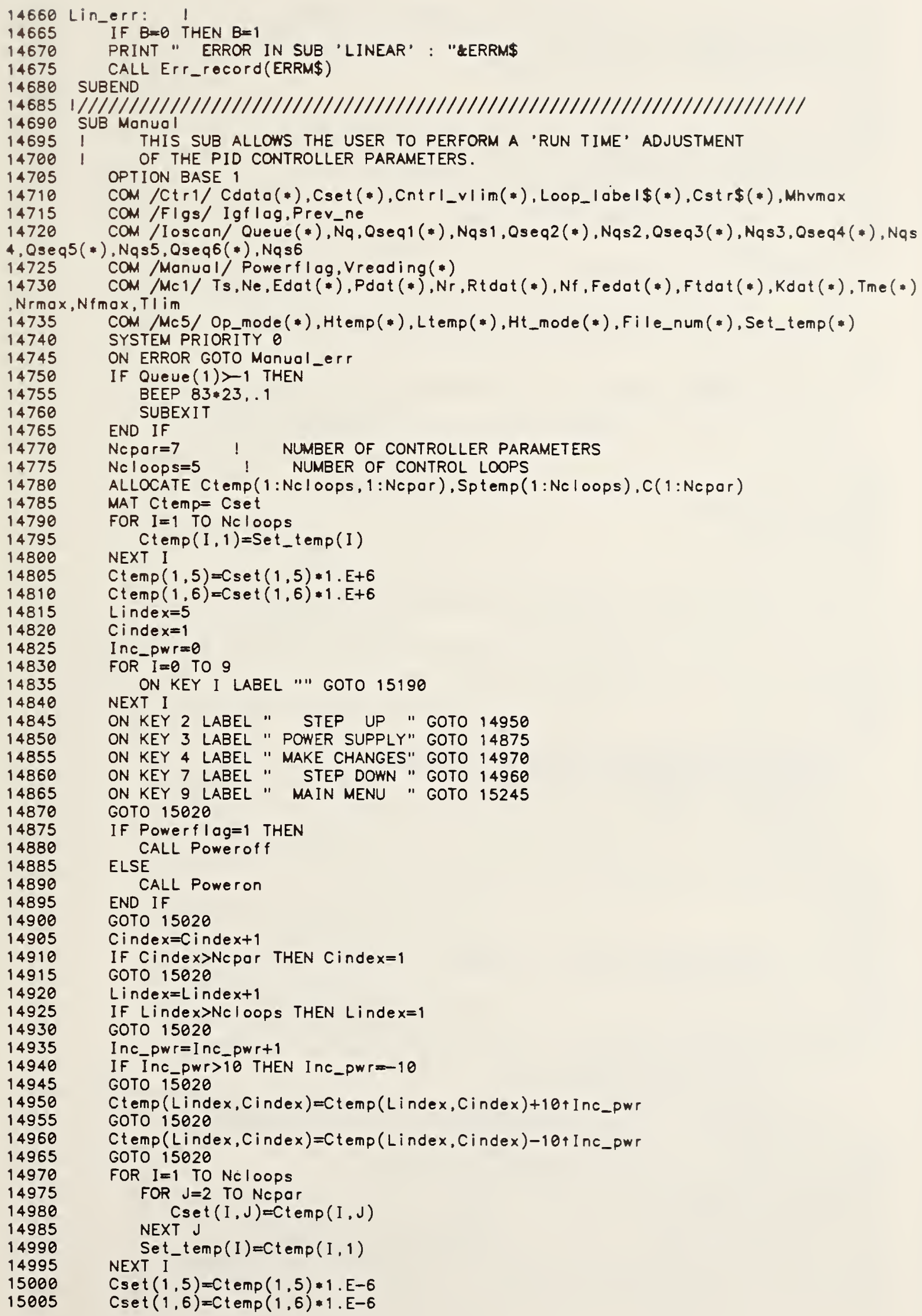




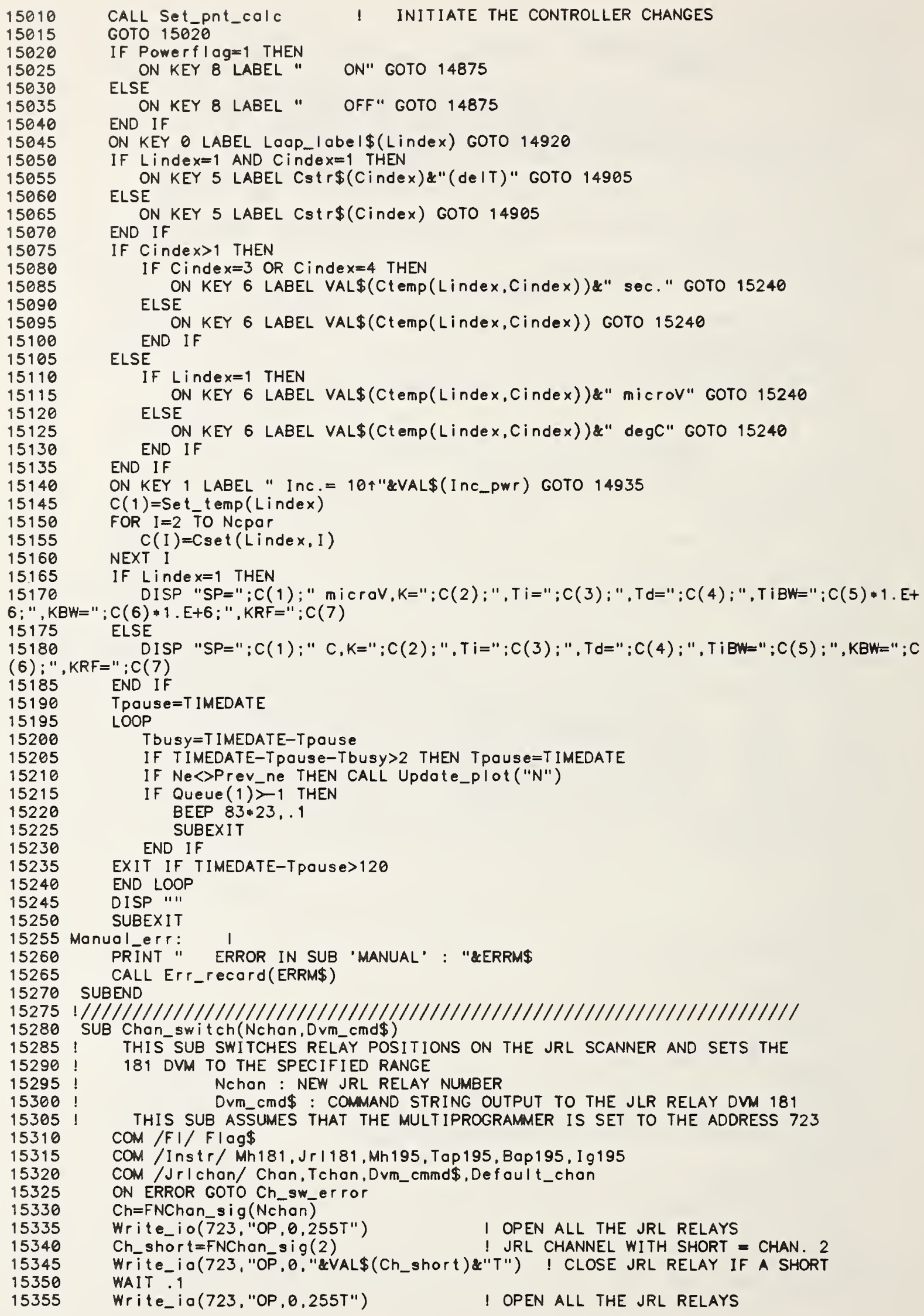


Nrmax, 15675

15680

15685

15690

15695

15700

15705

15710

IF Dvm_cmo\$ $\triangle$ Dvm_cmmd\$ THEN CALL Write_io( $J$ r I 181, Dvm_cmd\$)

Write_io(723, "OP,0, "\&VAL\$(Ch)\&"T") I CLOSE THE REQUESTED JRL RELAY

Chan $=$ Nchan

TChon=TIMEDATE

SUBEXIT

Ch_sw_error: I

PRINT "ERROR IN CHANNEL_SWITCH SUB"

SUEEN $/ / / / / / / / / / / / / / / / / / / / / / / / / / / / / / / / / / / / / / / / / / / / / / / / / / / / / / / / / / / / / / / /$

IF FIOg\$="OK" THEN FIOg $\$="$ CHANNEL SWITCH SUB ERROR"

SUB Read_old_doto

1 THIS SUB READS IN THE SETUP PARAMETERS FOR A PREVIOUS RUN

COM /Dt1/File_specs $\$(*), \operatorname{Mode} \$(*), \operatorname{Gas} \$(*)$

COM /Sb3/Fo(*). Tavg_interval

ON ERROR GOTO OId_dot_err

PRINT USING "e,3/"

PRINT " INPUT THE NAME OF THE FILE FROM WHICH YOU"

PRINT " WOULD LIKE TO READ A SET OF EXPERIMENTAL RUN PARAMETERS"

PRINT " TO BE USED WITH THIS RUN."

PRINT " PLACE THE DISK CONTAINING THAT FILE IN THE RIGHT DRIVE."

LINPUT " ENTER FILENAME.",FIn\$

IF $F \mid \cap \$=" "$ THEN GOTO 15465

ASSIGN $\odot$ I TO FIn\$

ENTER $\odot I ; F i l e \_s p e c s \$(*), F d(*)$

ASSIGN $\odot I$ TO *

SUBEXIT

old_dat_err:

PRINTT USING "e,5/"

PRINT " ERROR IN OLD DATA READ ATTEMPT"

PRINT" "; ERRM\$

Ans\$=""

LINPUT " DO YOU WANT TO TRY AGAIN? (Y/N)", Ans\$

IF Ans $\$=" Y "$ THEN GOTO 15435

SUBEXIT

\section{SUBEND}

$1 / / / / / / / / / / / / / / / / / / / / / / / / / / / / / / / / / / / / / / / / / / / / / / / / / / / / / / / / / / / / / / / / / / / / / 1$

SUB Time set

THIS SUBROUTINE SETS THE SYSTEM DATE AND TIME LOOP

PRINT USING " $\theta, 5 /$ "

PRINT "THE CURRENT TIME SETTING IS ",DATE\$(TIMEDATE),TIME\$(TIMEDATE)

Ans\$="N"

INPUT "IS THIS TIME VALUE APPROPRIATE $(Y / N)$ ?", AnS\$

IF AnS\$="Y" THEN SUBEXIT

PRINT USING " $0,10 / "$

PRINT "INPUT THE DATE IN THE FOLLOWING FORMAT :"

PRINT

PRINT " " ";DATE\$(TIMEDATE);" "

St $r$ \$ $\$=D A T E \$$ ( $T$ IMEDATE)

INPUT " DAY MONTH YEAR ",St $1 \$$

IF LEN(Str $1 \$$ ) $<10$ THEN GOTO 15585

PRINT USING "๑, 10/,60A"; "INPUT THE TIME IN 24 HOUR FORMAT :"

St $r 2 \$=$ TIME $\$$ ( $T$ IMEDATE)

INPUT " HOURS:MINUTES ",St $2 \$$

IF LEN(St $r 2 \$)<4$ THEN GOTO 15620

SET TIMEDATE DATE (St $r 1 \$)+\operatorname{TIME}($ St $r 2 \$)$

SUBEND

END LOOP

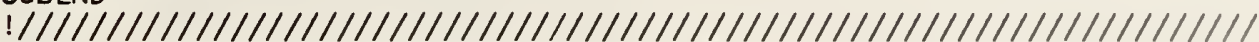

SUB Plot_prep(X1, X2,Xinc, Y1,Y2,Yinc, Xt it $\$, Y t i t \$)$

! THIS SUB CALCULATES THE NECESSARY GRAPHICS LIMITS

$\operatorname{COM} / \mathrm{Mcl} / \mathrm{Ts}, \mathrm{Ne}, \operatorname{Edat}(*), \mathrm{Pdot}(*), \mathrm{Nr}, \mathrm{Rtdat}(\cdot), \mathrm{Nf}, \mathrm{Fedat}(*), \mathrm{Ftdat}(*), \mathrm{Kdat}(\cdot), T$ me (*)

, Nfmax, TI im

COM /Gry/Plot view,Plot type,Pindex

COM /Mc5/ Op_mode (*).Htemp (*), Ltemp (*),Ht_mode (*), File_num (*), Set_temp (*)

COM Mc6/ Ntm, Ntr, NtP, Ntz

$\mathrm{COM} / \mathrm{Sb} 1 / \mathrm{TO}, \mathrm{Td} \theta$

THIS SUB SETS PARAMETERS FOR THE CRT PLOTTER

ALLOCATE G\$[20]

ON ERROR GOTO PIOt_prep_error

CALL G_l abel (G\$,Plot_type,Pindex) 
$x t i t \$=" T$ IME (MINUTES)"

If Plot_typex3 THEN

ELSE Yt it\$=G\$\&" (WATTS)"

15730

15735

15740

15745

15750

15755

15760

15765

15770

15775

15780

15785

15790

15795

15800

15805

15810

15815

15820

15825

15830

15835

15840

15845

15850

15855

15860

15865

15870

15875

15880

15885

15890

15895

15900

15905

15910

15915

15920

15925

15930

15935

15940

15945

15950

15955

15960

15965

15970

15975

15980

15985

15990

15995

16000

16065

16010

16015

16020

16025

16030

16035

16040

16045

16050

16055

16060

16065

16070

Yt it\$=G\$\&" TEMP. (C)"

If Plot_type=2 THEN Ytit\$="CORRECTED "\&G\$\&" TEMP. (C)"

IF Plot_type=1 AND Pindex=1 THEN Ytit\$nG\$" EMF (microv)" END IF

IF Plot_type=5 THEN Y $\mathrm{it} \$=G \$ \& "(\mathrm{~mW} /(\mathrm{m} * \mathrm{~K}))^{\prime \prime}$

1 DEF INE DEFAULT $Y$-AXIS VALUES FOR TEMP. BASED ON MAIN PLATE TEMP.

$Y 1=0$

$Y 2=0$

$Y m=S e t \_t \operatorname{emp}(5)$

$Y$ inc $=Y m / 5$

Yinc=INT (Yinc/10)*10

IF $Y$ inc=0 THEN Yinc=10

REPEAT

$Y 2=Y 2+Y$ inc

UNTIL Y2>YinctYm

SELECT Plot_type

CASE 1 ! FULL SCALE $Y$ AXIS DEFAULT VALUES FOR GAP tc

If $P$ inde $x=1 \cdot$ THEN

$Y 1=-500$

$Y 2=500$

END IF

$Y$ inc $=100$

CASE 2 ! FULL SCALE Y_AXIS DEFAULT VALUES FOR tC TEMPS.

Y $1=Y 2-5 * Y$ in

CASE 3 ! FULL SCALE Y-AXIS DEFAULT VALUES FOR MAIN HEATER POWER $Y 2=100$

Y i $c=10$

CASE 4

$Y 1=18$

$Y 2=30$

$Y$ inc $=2$

CASE 5

$Y 1=0$

$Y 2=100$

$Y$ in $\mathrm{C}=10$

CASE ELSE

END SELECT

Xronge $=1800 ! 30$ MIN. RANGE

$x 1=0$

$X$ inc $=300$

Foct $=I N T(($ ( $s * N e) / X$ ronge $)+1)$

IF (Foct $* X$ ronge $-\mathrm{Ts} * \mathrm{Ne})<.2 * X$ ronge THEN Foct $=\mathrm{Fact}+1$

$X 2=X r o n g e * F o c t$

IF Plot_type=2 OR Plot_type=5 THEN

$X 1 p+\overline{2}=I N T(T d \theta / X i n c)=X i n c$

$X 1=X 1 p+2$

Foct $=($ INT $((T s * N e-X 1 p t 2) / X$ ronge $)+1)$

IF (Foct $* X$ ronge $-T s * N e+T d \theta)<.2 * X$ ronge THEN Foct=Foct +1

$X 2=X 1+F$ oct $\# X$ ronge

END IF

If Plot_view>0 OR $N f>2$ THEN I X-AXIS MODIFY \& $Y$-AXIS AUTO SCALE IF Plot_view=0 THEN $X$ inc $=X$ inc*Foct

ELSE

Xronge $=X$ ronge $*(2 \uparrow(P$ lot_view-1) $)$ ।

$X$ inc $=X i n c *\left(2 \uparrow\left(P \mid \circ t_{-} v i\right.\right.$ ew-1) $)$

$X 1=\times 2-x$ ronge

IF $\times 1<\theta$ THEN

$\times 1=0$

$X 2=x 1+x$ ronge

END IF

IF ( $P \mid \circ t_{-} t y p e=2$ OR $P \mid \circ t_{-} t y p e=5$ ) AND $x 1<\times 1 p t 2$ THEN

$X 1=X 1 p+2$

$X 2=X 1+X$ ronge

END IF

WHILE Ne*Ts<X1+.8*Xrange I SHOW $80 \%$ OF THE DATA IN LAST WINDOW $X 1=X 1-X$ inc

END WHILE 


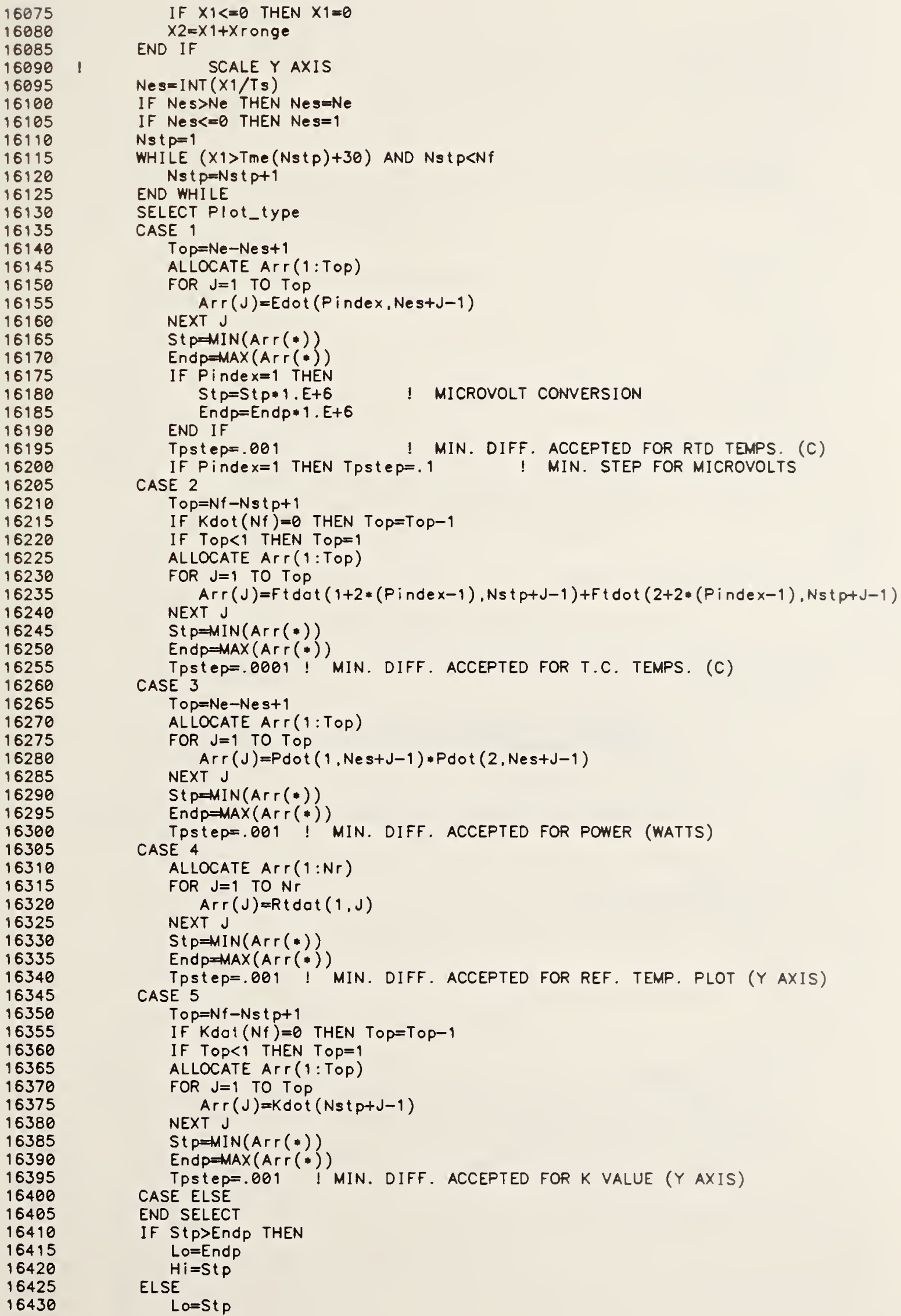




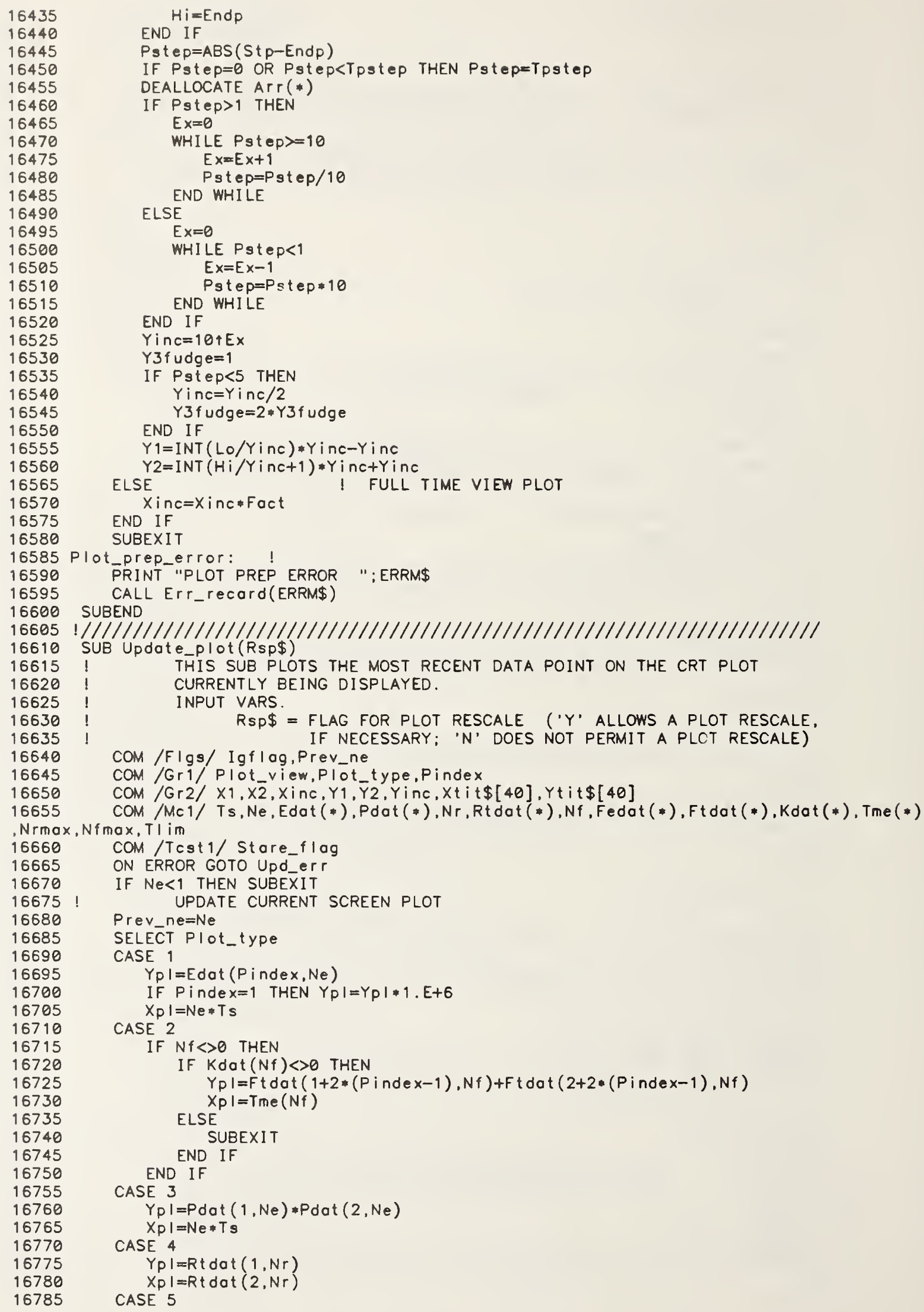


16798

16795

16880

16885

16810

16815

16820

16825

16830

16835

16840

N CALL

16845

16850

16855

$1686 e$

16865

16870

16875

16880

16885

16898

16895

16982

16985

16918

16915

16928

I 6925

16930

16935

16940

16945

16950

16955

16968

16955

i 6970

16975

16982

16985

16998

16995

17080

17085

17810

17895

17028

17225

17232

$17 e 35$

17248

17245

17052

i7es5

17050

17855

17872

17875

17080

17885

17890

17895

17180

17185

17110

17915

17128

17125

17130

17135

17148

IF $N: O \theta$ THEN

If $\operatorname{kdot}\left(N^{f}\right) O E$ THEN

$Y_{p} \mid=K o c t(N f)$

ELSE

$X P \mid=\operatorname{Tme}(N f)$

END I

SUBEXIT

END IF

CASE ELSE

END SELECT

IF RSPS="Y" AND (YPI>Y2 OR YPI<Y OR XPI $\left(X 1+\left(X_{2}-X_{1}\right)=1 . \theta\right)$ ) AND StOPE_f $\mid C g=8$ THE

Rescole_plot (XPI, YPI)

IF ( $P$ |Ot type=2 OR $P \mid C:$ type=5) THEN

IF $N f=1$ THEN WOVE XPT, YP

IF $N f>1$ THEN

$$
\text { END IF }
$$

$$
\text { IF TIME (Ní) OO THEN PLOT XPI,YPI }
$$

ELSE

PLOT XPI, YO

END IF

SUBEXIT

Upe_ert:

PRINT "PLOTTING ERROR IN SUB" UPDATE_PLOT" : "LERRNS

CALL Err_reCOTE(ERRNS)

SUBEND

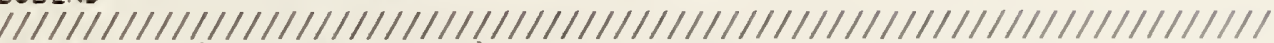

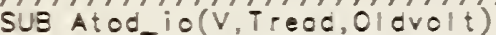

$!$ THIS SUE TAKES AND RETURNS AN AVERAGED A/O READING. THE VOLTAGE

1 READING RETURNED FRON THIS SUE IS THE OUTER GUARD RTD VOLTAGE.

CON/Reool/Io_ertor,Bod_instr(*),Boo_reod_times(*)

Car/Sol/ $T E$, T $\mathrm{CE}$

CON/FI/ Flegs

ON TINEOUT $7, .9$ GOTO RecC_it_ertor

ON ERROR GOTO ReOd_it_eTrOT2

$\mathrm{Vt}=\mathrm{e}$

FOR $I=1$ TO 28

OUTPUT 723;"IP, $2 T^{\prime \prime}$

ENTER 723ei;V

$V t=V t \div V$

NEXT I

$\mathrm{V}=\mathrm{V}: / 28$

$\mathrm{V}=\mathrm{V} / \mathrm{ie}$

CALCULATE AVERIGE VALUE

Treod=TINEDATE-TE

SCALE THE MULTIFROGRAMER OUTPUT

OFF TINEOUT

SUBEXIT

Reod_it_error:

io_etrorilo_etrotid

Bod_instr( Io_etror) $=723$

CLEAR 723

BCi_reci_ine\$(IO_ertor)=DATES(TINEDATE)\&" "\&TINES(TIMEDATE)

BEEF $83=\overline{3} 5, .9$

IF IO_etror=102 THEN FlOg\$="MAXINUN NUMEER OF IO ERRORS EXCEEDED !!"

$V=01$ divolit

Treci=TINEDATE-TE

Reod_it_ertor2:

CALL Err_recoro(ERRMS)

PRINT " ERROR IN 'AIOd_iO' SUB : "LERRNS

SUBEND

BEEF $83.35, .1$

! $/ / / / / / / / / / / / / / / / / / / / / / / / / / / / / / / / / / / / / / / / / / / / / / / / / / / / / / / / / / / / / / / /$

SUB DCtc-reoc

! THIS SUB TAKES JRL CHANNEL NUNEERS FRON THE QUUUE( ( ) ARRAY.

INCREMENTS THE QUEUE(*) ARRAY, THEN DIRECTS THE JRL RELAY TO

SHITCH TO THAT CHANNEL. AFTER A DESIGNATED WAITING PERIOO. A

VOLTAGE READING IS TAKEN AND STORED IN THE APPROORIATE ARRAY

STORAGE LOCATION.

VARIABLES :

Settle_time = TIME (SEC) BETHEEN THE CHANNEL SWITCH AND RENDING

COW/Asjloc2/Lest_reoding(*)

CON/OrI/ Bod_curr

con / Dr2/Rtdi_hist $(1: 18)$ 
COM / FId/ Disp_flag

17150 COM/Ioscan/ Queve(

4,Oseq5 (*), Nq95, Oseq6(*), Nqs6

17155 COM/Htr2/ New_htrcur

17160 COM/FIgs/Igflog,Prev_ne

17165 COM /Instr/Mh181,Jr1181,Mh195, Top195,Bop195, Ig195

17170 COM /Jrlchan/Chan, Tchan,Dvm_cmmd\$, Default chan

17175

Nrmax, Nfmax, Tl im

17180

17185

17190

17195

17200

17205

17210

17215

17220

17225

17230

17235

17240

17245

17250

17255

17260

17265

17270

17275

17280

17285

17290

17295

17300

17305

17310

17315

17320

17325

17330

17335

17340

17345

17350

17355

17360

17365

17370

17375

17380

17385

17390

17395

17400

17405

17410

17415

17420

17425

17430

17435

17440

17445

17450

17455

17460

17465

17470

17475

17480

17485

17490

$\operatorname{CoM} / \mathrm{Mc} 1 / \mathrm{Ts}_{3}, \mathrm{Ne}, \mathrm{Edat}(*), \operatorname{Pdat}(*), \mathrm{Nr}, \mathrm{Rtdat}(*), \mathrm{Nf}, \mathrm{Fedat}(*), \mathrm{Ftdat}(*), \operatorname{Kdat}(*), T m e(*)$

$\mathrm{COM} / \mathrm{Mc} 2 /$ Heater_sres

$\mathrm{COM} / \mathrm{Mc3} / \mathrm{Rtdpwr}$ sres

$\mathrm{COM} / \mathrm{Rn} / \mathrm{Run}$

$\operatorname{COM} / \mathrm{Sb} 1 / \mathrm{TO}, \mathrm{Td \theta}$

$\mathrm{COM} / \mathrm{Sb} 2 / \mathrm{I}_{-}$rtd, Tref, Emf_ref

$\mathrm{COM} / \mathrm{Sb} 3 / \mathrm{Fo}(*)$. Tovg_interval

COM /Sdisp/Screen_prnt

COM /Water/ Now, Cwater(*)

COM /Zeros/Zjrl181_200,Zjrl181_20.Zgop195,Zhistory(*)

ON KBD GOSUB Nothing2

ON KEY O LABEL "" GOSUB Nothing2

ON KEY 5 LABEL "' GOSUB Nothing2

ON ERROR GOTO Data_read_er

DISP " JRL OVM READING IN PROGRESS ... DON'T TOUCH ANY KEYS!!" Set $t$ le_time=5 ! DVM SETTLING TIME (SECONDS)

Disp_f I og=TIMEOATE+Se $t \mathrm{t} l e_{-} t$ ime-9

Nchan=Queve (1)

If (Nchan>2 AND Nchan<7) OR (Nchan>12 AND Nchan<17) THEN

ELSE

CALL Chan_switch(Nchan, "R2B1X")

END IF

CALL Chan_switch (Nchan, "R3B1X")

! UPDATE THE QUEUE

FOR I $=1$ TO $\mathrm{Nq}-1$

Queve (I ) Queve $(I+1)$

NEXT I

Queve $(\mathrm{Nq})=-1$

REPEAT

IF Ne<>Prev_ne THEN

CALL Updote_plot ("N")

Tint e rupt=TIMEDATE

END IF

UNTIL TIMEDATE-Tchan>Set $t$ le_t ime

VIast=Last_reading(Chan)

If Chan $=19$ THEN

SYSTEM PRIORITY 15

WAIT 2-(TIMEDATE-Tinterupt)

END IF

If (Nchan>2 AND Nchan<7) OR (Nchan>12 AND Nchan<17) THEN

CALL Read_io(V,Tmr, Jr|181, "R2B1X", VIost)

ELSE

CALL Read_io(V,Tmr,JrI181, "R3B1X",VIast)

END IF

IF Chan $=8$ THEN

END IF

CALL Read_io(Vg, Tt, Ig195, "ROX", Last_reading(Chan))

Last_reading(Chan) $=V$

Chan日=Chan

STORE THE 181 READING IN THE APPROPRIATE PLACE

SELECT Chane

CASE 1

CALL Ref_rtd(V,Tmr)

CASE 2 ! CORRECT JRL DVM ZEROS

Zhistory $(1,2)=Z$ history $(1,1)$

Zjrl181_200=Zjrl181_200+V

Zhistory $(1,1)=Z$ ir I 1 $\overline{8} 1200$

CALL Chan_switch (Nchon, "R2B1X")

REPEAT

UNTIL TIMEDATE-Tchon SSet $t$ le_t $\mathrm{ime}$

CALLReod_io(V,Tmr, Jr|181, "R2B1X",0)

Zhistory $(2,2)=Z$ history $(2,1)$

$Z$ jrl181_20=Zjr|181_20+V

Zhistory $(2,1)=Z$ j r I 181_20 
Laxcur $r=.00001 /(1+$ INT $(($ TIMEDATE-T0 $) /(6 \theta * 50)))$

17505 IF TIMEDATE-T0<60.50 THEN Loxcur $r=.0001$

17510 If Rtdi_hist (1)=0 THEN Rtdi_hist (1)=I_rtd

17515 If (ABS(Rtdi_hist (1) -V/Rtdpwr_sres)<.0000001) OR (TIMEDATE-TO<60*150 AND ABS

(I_rtd-V/Rtdpwr_sres) <Laxcurr) THEN

$17520 \quad$ FOR Joy=9 TO I STEP -1

$17525 \quad$ Rtdi_hist (Jayt1) =Rtdi_hist (Jay)

$17530 \quad$ NEXT Joy

$17535 \quad$ Rtdi_hist (1)=V/Rtdpwr_sres

17540

17545

17550

17555

17560

17565

17570

If ((TIMEDATE-TO>60*120) OR Run>1) AND Rtdi_hist (10) $<>\theta$ THEN

ELSE

$$
I_{-} r t d=\left(S U M\left(R t d i \_h i s t\right)\right) / 10
$$

END IF

I_td=Rtdi_hist (1)

17575

If Screen_prnt THEN PRINT " RTD CURRENT = "i I_rtd

17580

- rtd

$\overline{1} 7585$

Bod_curr $=B O d_{-}$curr +1

PRINT " BAD RTD CURRENT READING! V/R=";V/Rtdpwr_sres;" , OLD I_rtd="; I

OLD I_rtd ="\&VAL $\left.\$\left(I_{-} r t \bar{d}\right)\right)$

17590

IF Screen_prnt THEN OUTPUT 701;" BAD RTD CURRENT READING! I_RTD="; I_rtd;

". $V / R=", V / R t d p w r$ sres

$17595 \quad$ BEEP $83, .2$

17600

17605

IF Bod_curr $>3$ THEN

17610

17615

17620

17625

17630

17635

17640

17645

17650

17655

17660

17665

17670

17675

17680

17685

17690

17695

17700

17705

17710

17715

17720

17725

17730

17735

17740

17745

17750

17755

17760

17765

17770

17775

17780

17785

17790

17795

17800

17805

17810

17815

17820

17825

IF $\bar{V} / R t d p w r$ sres>.002 OR V/Rtdpwr_sres<.0001 THEN ELSE FIOg\$=" RTD CURRENT POWER SUPPLY PROBLEM (FLUKE)"

FOR JaY=9 TO 1 STEP -1

Rtdi_hist (Joy+1)=Rtdi_hist (Joy)

NEXT Joy

Rtdi_hist (1)=V/Rtdpwr_sres

I_rtd=Rtdi_hist (1)

IF Rtdi_hist $(10)<>$ THEN I_rtd=SUM(Rtdi_hist) $/ 1 \theta$

ND IF

Bod_cur $r=0$

END IF

CASE 19

$\operatorname{Pdot}(1, \mathrm{Ne})=\mathrm{V} / \mathrm{Heoter}$ sres

New_ht rcur=1

CASE 3 TO 6,13 TO 16

IF $T d \theta=0$ THEN

ELSE

CALL Rtd_tune (Chano,V)

END IF

CASE 7

$F d(20)=V \quad$ ! TOP IG

CASE 8

If I $g f \mid a g=1$ THEN

Fd $(19)=V$

Zhistory $(3,2)=Z$ history $(3,1)$

ELSE

Zhistory $(3,1)=Z$ gap $195+(\mathrm{Vg}-\mathrm{V})$

Zhistory $(3,2)=$ Zhistory $(3,1)$

Zgop 195=Zgop 195+(Vg-V)

END IF

Zhistory $(3,1)=$ Zgap 195

CASE 9

$F d(18)=V$

CASE 11

$\mathrm{NCw}=\mathrm{NCw}+1$

Cwoter $(1$, Ncw $)=($ INT $(($ FNT emp_tc $(V)) * 1000)) /$.1000 .

Cwoter $(2, \mathrm{Ncw})=1.0$ INT $(\mathrm{Tmr} / \overline{6} \theta)$

CASE ELSE

END SELECT

SUBEXIT

17830

BEEP $83 * 23, .1$

RETURN 
17835 Doto_reod_err: I

17840 PRINT" " ERROR IN THE SUB 'DATA_READ'"

17845 PRINT ERRM\$

17850 CALL Err_record(ERRM\$)

17855 BEEP $83 * 25, .1$

17860 SUBEND

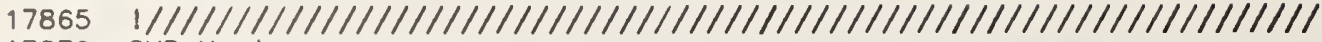

17870 SUB K_stor

17875 I THIS SUB COMPUTES THE RUNTIME VALUES OF T.C. TEMPERATURES (PHASE 2)

17880 I AND THERMAL CONDUCTIVITY USED IN PLOTTING AND STAT. ANALYSIS.

17885

- Nrmax, Nfmax, TI im

$17890 \quad$ COM /Sb2/ I_rtd, Tref, Emf_ref

$17895 \mathrm{COM} / \mathrm{Sb} / \mathrm{Fd}($ ). Tovg_intérval

17900 ON ERROR GOTO K_stor_err

17905

17910

17915

17920

17925

17930

17935

17940

17945

17950

17955

17960

17965

17970

17975

17980

17985

17990

17995

18000

18005

18010

18015

18020

18025

18038

18035

18040

18045

18050

18055

18060

18065

18070

18075

18080

18085

18090

18095

18100

18105

18110

18115

18120

18125

18130

18135

Nrmax
18140

18145

18150

18155

18160

18165

18170

18175

18180

! RECOMPUTE THE PLATE TEMP. USING AVG. REF. BLOCK TEMP.

Avg_tref $=(\operatorname{Rtdot}(1, \mathrm{Nr})+\operatorname{Rtdot}(1, \mathrm{Nr}-1)) / 2$

Emf_ref=FNEmf_tc (Avg_tref, 1)

FOR $I=1$ TO 7 STEP 2

$F t \operatorname{dat}(I, N f)=F N T$ emp_tc $(F \operatorname{dot}(I, N f))$

$F t \operatorname{dat}(I+1, N f)=F N T$ emp_tc $(F \operatorname{dat}(I, N f)-F \operatorname{dat}(I+1, N f) / 9)-F \operatorname{dat}(I, N f)$

1 NOTE: THE DeIto T (STORED IN Ftdat) IS COMPUTED ABOVE BASED ON

1) 9 ARMS OF THE STAR THERMOCOUPLE

2) A POSITIVE STAR tC SIGNAL CORRESPONDS TO

3) DeItOT IS DEFINED AS THE DIFFERENCE : AVERAGE PLATE TEMP. - CENTER PLATE TEMP.

NEXT

! ASSIGN VARIABLES USED IN THE SUB CALL FOR $k$ CALC. $\mathrm{Ntme}=\operatorname{INT}($ Tme $(\mathrm{Nf}) / \mathrm{Ts})$

$Q=P \operatorname{dat}(1, N$ tme $) * P d a t(2, N$ tme $) * 1000$

$T 1=F t \operatorname{dot}(7, N f)+F t \operatorname{dot}(B, N f)$

$T 2=F t \operatorname{dot}(5, N f)+F t \operatorname{dot}(6, N f)$

$T 3=F t \operatorname{dat}(3, N f)+F t \operatorname{dot}(4, N f)$

$T 4=F t \operatorname{dat}(1, N f)+F t \operatorname{dat}(2, N f)$

CONVERTED TO MILLIWATTS

! B.A.P. TEMP. (CORRECTED)

I B.M.P. TEMP. (CORRECTED)

! T.M.P. TEMP. (CORRECTED)

Di $a=F d(8) * 100$

T.A.P. TEMP. (CORRECTED)

$D x=F d(3) * 100$

$\operatorname{Dr}=\mathrm{Fd}(21) * 100$.

$\mathrm{Sc}=\mathrm{Fd}(22)$

$\mathrm{RC}=\mathrm{Fd}(15)$

PLATE SPACER CODE

CALL K_gho(K,TIO,Thi,DXc, Acor, T1, T2, T3, T4, Q, Di O, DX, Dr, Sc, Rc, O)

$K d a t(N \bar{f})=K$

SUBEXIT

K_stor_ert:

PRINT " ERROR IN 'K STOR' SUB"

CALL Err_record(ERRM\$)

BEEP $83 \neq \overline{3}, .1$

SUBEND

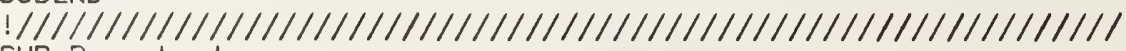

SUB Run_abort

! THIS SUB SETS THE RUN ABORT VARIABLES

$\mathrm{COM} / \mathrm{FI} / \mathrm{FlOg} \$$

CALL Power of $f$

FI Og $\$=" R U N$ ABORTED"

SUBEND

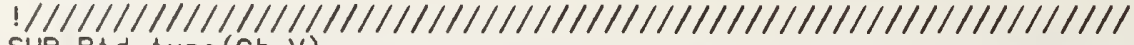

SUB Rtd_tune ( $\mathrm{Ch}, \mathrm{V})$

$! \quad$ THIS SUBROUTINE ADJUSTS A SETPOINT OFFSET THAT CALIBRATES

THE RTD TEMPERATURE SETTING TO THE TC READING FOR EACH PLATE.

COM /Conv_dat/RO(*), Alpha(*), Delta(*)

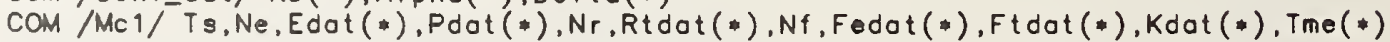
Nfmax.TIim

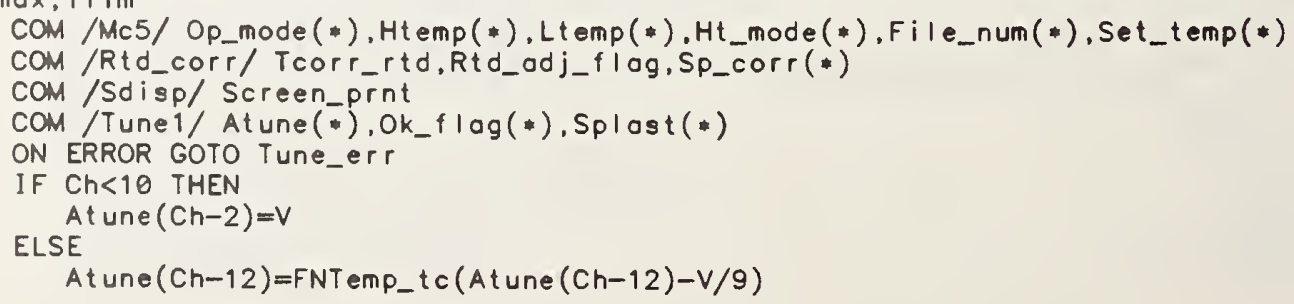




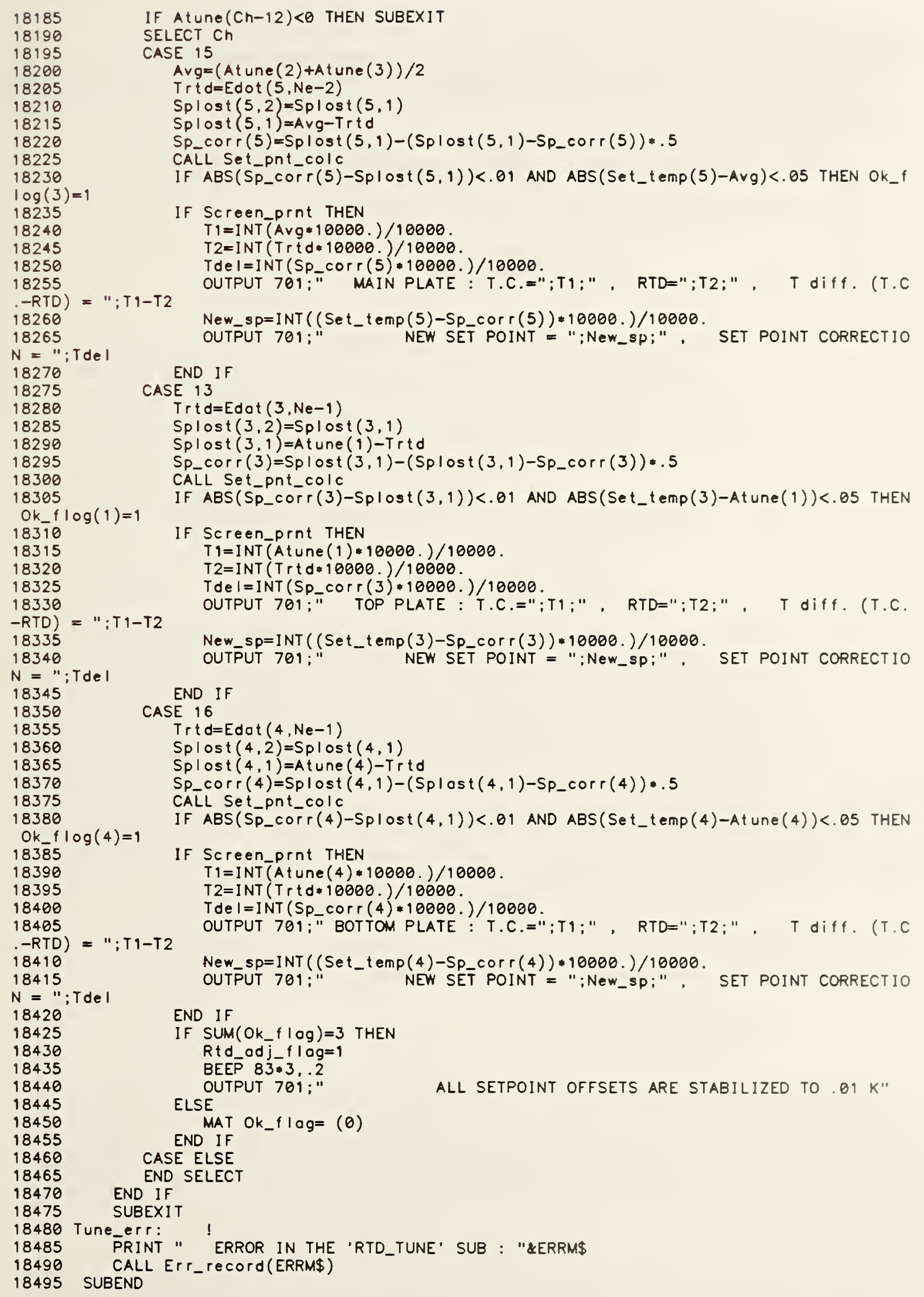


$1 / / / / / / / / / / / / / / / / / / / / / / / / / / / / / / / / / / / / / / / / / / / / / / / / / / / / / / / / /$

18505 SUB Err-record (M\$)

185101 THIS SUB RECORDS ALL NON-I.O. ERRORS IN THE STRING ARRAY 'RUN_ERRORS\$'

$18515 \mathrm{COM} / \mathrm{FI} / \mathrm{Flag} \$$

18520

18525

18530

18535

18540

18545

18550

18555

18560

18565

18570

18575

COM /Run_err/Rterr,Run_errors $\$(*), E r r \_m a x$

ON ERROR GOTO Err_err

Rterrmentert+1

IF Rterr $>$ Err_max THEN

Flag $\$="$ THE MAXIMUM NUMBER OF PROGRAM ERRORS HAS BEEN EXCEEDED I!" ELSE

Run_errors $\$($ Rterr) $=M \$$

END IF

SUBEXIT

Err_err:

Flog $\$="$ ERROR IN 'Err_record' SUB "\&ERRM\$

SUBEND 
Appendix B: A Thermocouple Device for Determination of Average Surface Temperature*

J. G. Hust and David R. Smith

Chemical Engineering Science Division

National Bureau of Standards

Boulder, Colorado

Abstract

A thermocouple-based device for the measurement of average surface temperature is described. The device requires the measurement of only two emfs and yields the average temperature over the entire surface instrumented with the device. It consists of a single (normal) thermocouple and a thermopile-like element which performs the averaging. A particular use of the device is described to illustrate its utility.

Key words: average temperature; thermocouple; thermopile; thermal properties.

\section{INTRODUCTION}

The determination of thermal properties of materials frequently requires the measurement of the average temperature of a surface. This is usually done by placing more than one temperature sensor on the surface and averaging the resultant temperatures. The number of such sensors is usually small to simplify wiring and reduce cost and complexity of instrumentation. As a result, the average temperature obtained is often based on an inadequate sampling of the surface. Depending on the degree of temperature nonuniformity, the error in such measurements may be a significant contribution to the total error involved in thermal property determinations. For example, the determination of surface temperatures for thermal conductivity measurements using guarded hot plate or heat flow meter apparatus can be significantly affected by such errors.

The device described here has only three leads but is capable of providing a much more accurate average temperature of the surface than that obtained with two thermocouples.

\section{PHYSICAL DESCRIPTION}

The device is illustrated in Figure 1. It consists of a normal thermocouple of alloys $A$ and $B$ that measures the temperature of point 0 of the surface. At that point, a third wire consisting of a series of alternating thermocouple elements ( $A, B, A \ldots B$ ) (similar to a thermopile) is attached. The points of connection between the alternating thermocouple elements are labeled $1,2,3, \ldots$

* Contribution of the National Bureau of Standards, not subject to copyrlght in the U.S. 
In this example, we have chosen 18 points for illustration, but the number can be any even number. The wire exits the surface from the last point, forming with the original thermocouple a set of three measurement leads. From wires $A_{1}$ and $B$ one obtains the temperature of point 0 . From wires $A_{1}$ and $A_{2}$ one obtains a measure of the average difference in temperature between the even-numbered points and the odd-numbered points. By combining the two results one obtains a measure of the average temperature of the surface.

\section{MATHEMATICAL DESCRIPTION}

The emf, $e\left(T_{r}, T_{0}\right)$, produced by a single thermocouple at temperature, $T_{0}$, with respect to a reference temperature, $T_{r}$, can be expressed by eq. (1)

$$
e\left(T_{r}, T_{0}\right)=\int_{T_{r}}^{T_{0}} S_{A} d T+\int_{T_{0}}^{T_{r}} S_{B} d T=\int_{T_{r}}^{T_{0}} S_{A B} d T
$$

where $S_{A}$ is the thermopower of wire $A, S_{B}$ is the thermopower of wire $B$, and $S_{A B}=S_{A}-S_{B}$. See reference [1]. The emf $e_{p}$ produced by the thermopile-like elements can thus be written as

$$
e_{p}\left(T_{0}, T_{18}\right)=\int_{T_{0}}^{T_{1}} S_{A} d T+\int_{T_{1}}^{T_{2}} S_{B} d T+\ldots \ldots+\int_{T_{16}}^{T_{17}} S_{A} d T+\int_{T_{1} 7}^{T_{18}} S_{B} d T
$$

where it is assumed that $\mathrm{T}_{0}=\mathrm{T}_{1} 8$ because of their physical proximity, and thus the emf from the wires $A_{1}$ and $A_{2}$ (of the same material) between the surface and reference temperature is zero. If, in addition, we assume that the thermopowers are nearly constant over the temperature range of the surface, we can approximate

$$
e_{p}\left(T_{0}, T_{18}\right)=S_{A}\left(T_{1}-T_{0}\right)+S_{B}\left(T_{2}-T_{1}\right)+\ldots+S_{A}\left(T_{17}-T_{16}\right)+S_{B}\left(T_{18}-T_{17}\right)
$$

This, using $\mathrm{T}_{0}=\mathrm{T}_{18}$, yields

$$
e_{p}\left(T_{0}, T_{18}\right)=S_{A B}\left(\sum_{j=1}^{9} T_{2 j-1}-\sum_{j=1}^{9} T_{2 j}\right)
$$


This can be rewritten as

$$
e_{p}\left(T_{0}, T_{18}\right) /\left(9 S_{A B}\right)=\bar{T}_{\text {odd }}-\bar{T}_{\text {even }}
$$

yielding the average temperature difference of the odd-numbered points with respect to the even-numbered points. If the even-numbered points are placed in proximity to each other, we can assume that their average temperature is the same as $T_{0}$ and can write

$$
\bar{T}=T_{0}+e_{p}\left(T_{0}, T_{18}\right) /\left(9 S_{A B}\right),
$$

where $\bar{T}$ is the average temperature of the surface as indicated by the odd-numbered points.

\section{EXPERIMENTAL VERIFICATION}

A high-temperature guarded-hot-plate thermal conductivity apparatus that uses this device was recently completed at the National Bureau of Standards, Boulder, Colorado [2]. The utility of this device is clearly demonstrated from an analysis of surface temperature difference measurements used in the calculation of thermal conductivity near ambient temperature as a function of axial temperature difference across the specimens. Measurements were performed both in the double-sided and single-sided mode of operation [2]. The axial temperature differences through the specimens ranged from those typically used in a guarded-hot-plate apparatus, approximately $20^{\circ} \mathrm{C}$, to very small differences, ${ }^{\circ} \mathrm{C}$. The purpose of these measurements is to detect the existence of systematic errors in the determination of the axial temperature difference through the specimens. The presence of such systematic errors, if they are not linearly dependent on axial temperature difference, will be exhibited by an increasingly larger error in thermal conductivity as the axial temperature difference approaches zero.

Figure 2 shows the results of our double-sided mode [2] thermal conductivity measurements on a pair of insulation specimens. In addition, we have included the results that were calculated from the temperatures of the plates as determined by the single thermocouple at point 0 . As can be seen, the temperature-averaging device produces thermal conductivities that are much less dependent on axial temperature difference. This indicates that the measurement technique using a single thermocouple has a significantly larger bias due to radial temperature variations. 
Figures 3 and 4 show the same type of results for the single-sided mode of operation in which the top and bottom specimens were measured separately. Aga in the thermal conductivity results are less dependent on axial temperature difference when average surface temperatures are used.

\section{REFERENCES:}

[1] Manual on the Use of Thermocouples in Temperature Measurement, ASTM STP 470B, (ASTM, Philadelphia, PA, 1981) p. 4

[2] Hust, J. G.; Filla, B. James; Hurley, J. A. and Smith, David R.; An Automated High Temperature Guarded-Hot-Plate Apparatus for Measuring Thermal Conductivity of Insulation Between 300 and $800 \mathrm{~K}$, to be published as an NBSIR. 
List of Figures.

Figure 1. A thermocouple-based device for the determination of average surface temperature. Leads $A_{1}$, and $A_{2}$ are of the same material as $A$ in the thermocouple.

Figure 2. Thermal conductivity of an insulating specimen versus temperature difference as determined by the average surface temperatures (circles) and the single thermocouple on each surface (squares) for the double-sided mode of operation.

Figure 3. Thermal conductivity of an insulating specimen versus temperature difference as determined by the average surface temperature (circles) and the single thermocouple on each surface (squares) for the upper specimen in the single-sided mode of operation.

Figure 4. Thermal conductivity of an insulating specimen versus temperature difference as determined by the average surface temperature (circles) and the single thermocouple on each surface (squares) for the lower specimen in the single-sided mode of operation. 


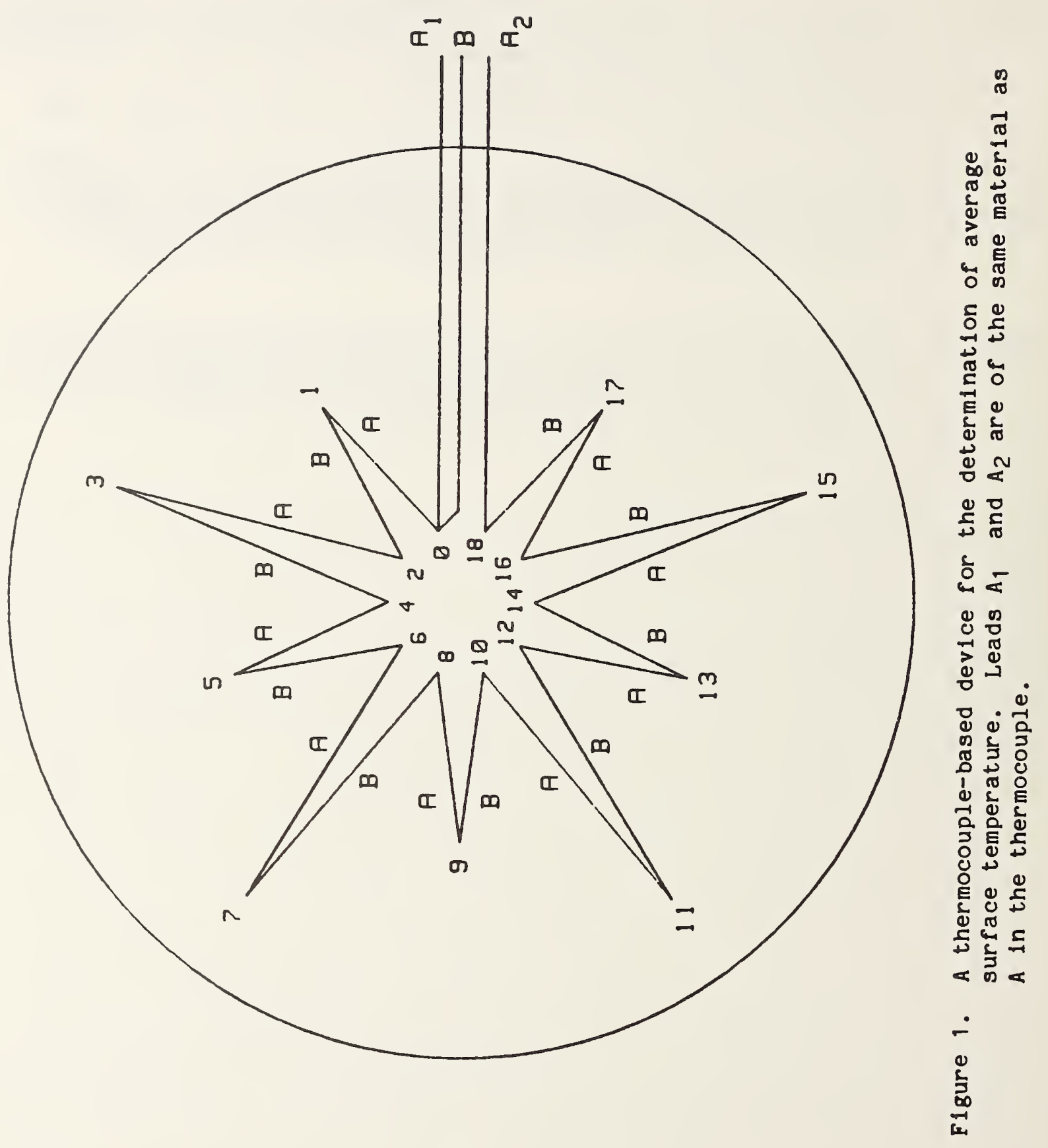




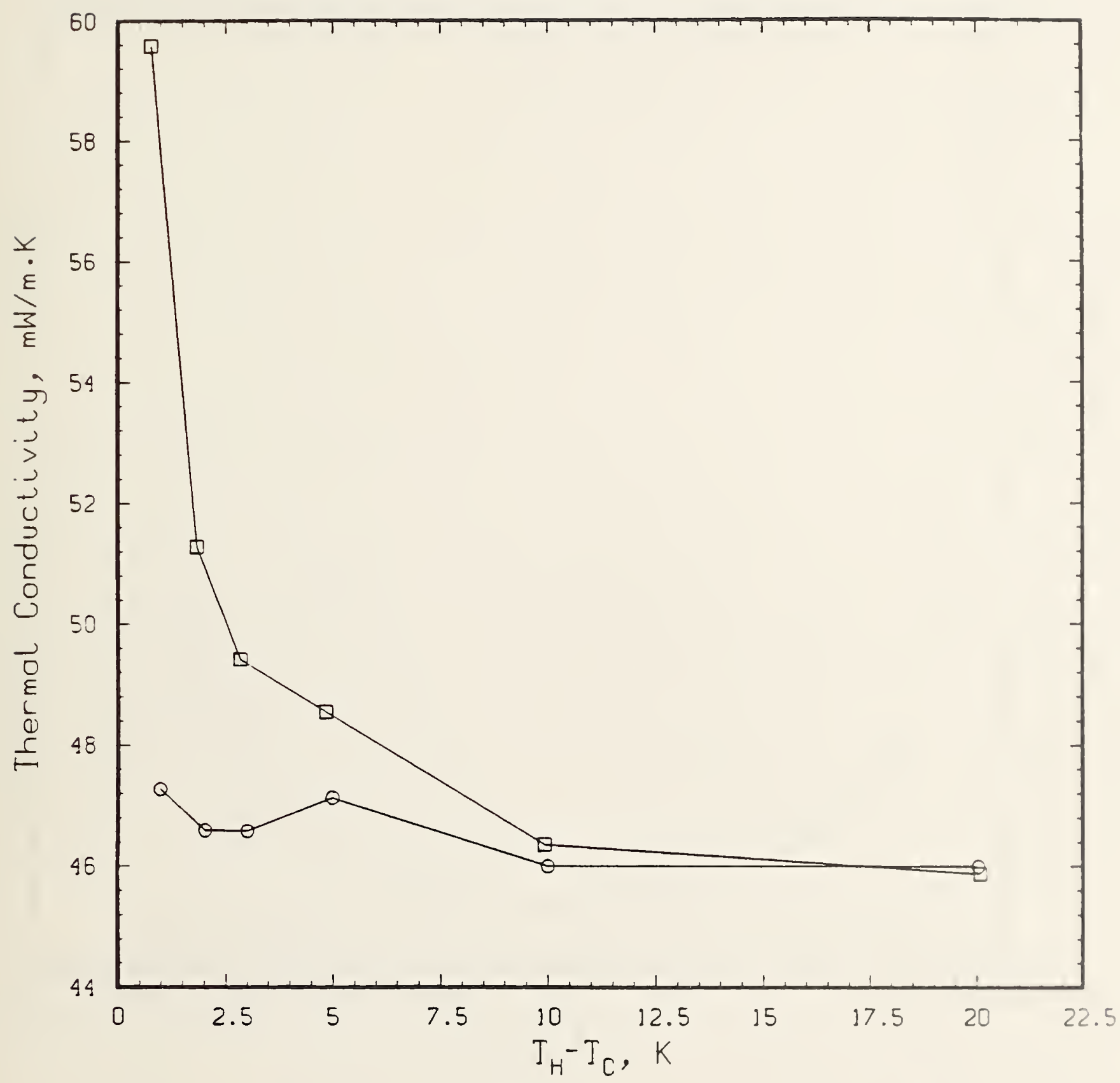

Figure 2. Thermal conductivity of an insulating specimen versus temperature difference as determined by the average surface temperatures (circles) and the single thermocouple on each surface (squares) for the double-sided mode of operation. 


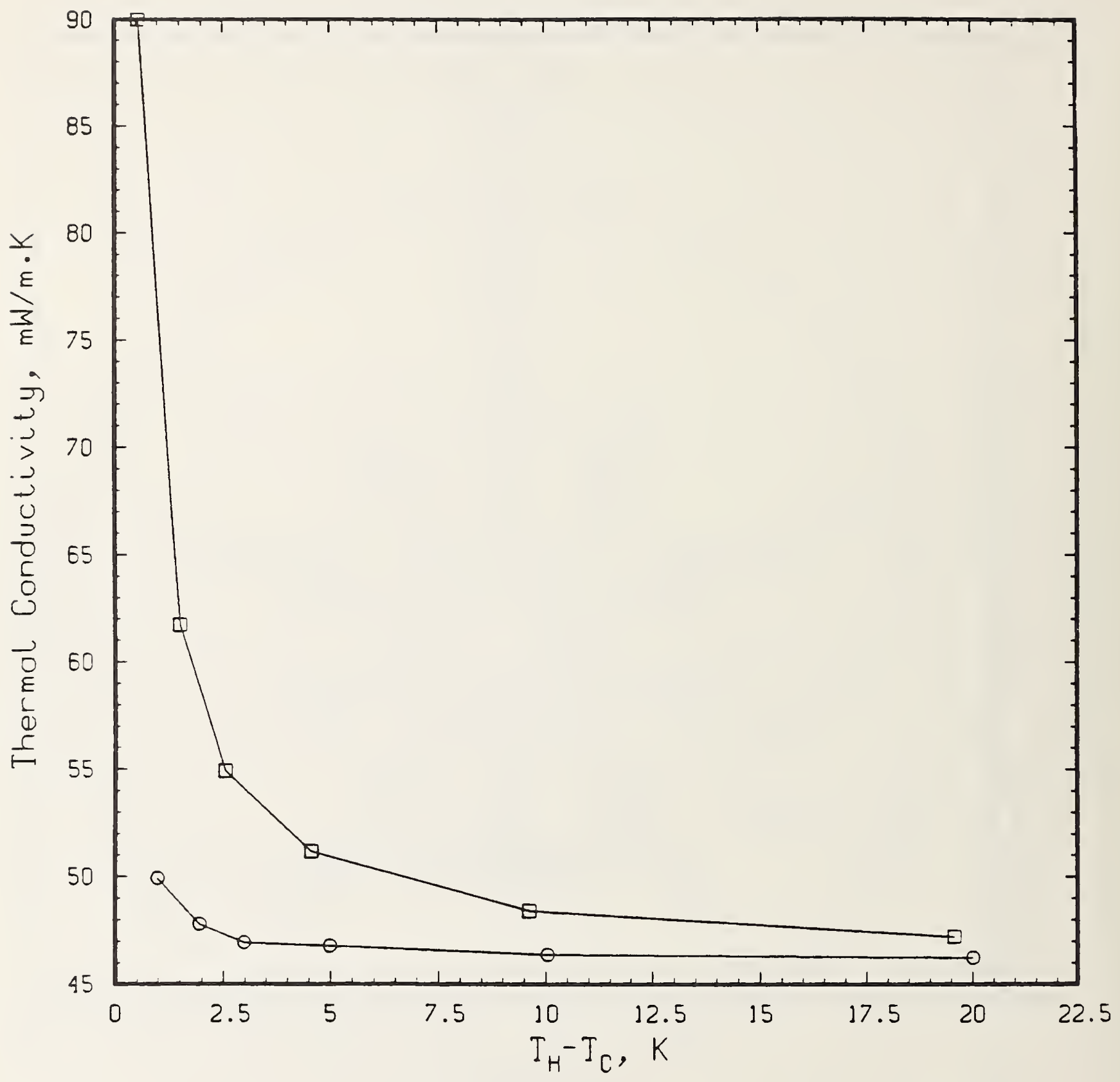

Figure 3. Thermal conductivity of an insulating specimen versus temperature difference as determined by the average surface temperature (circles) and the single thermocouple on each surface (squares) for the upper specimen in the single-sided mode of operation. 


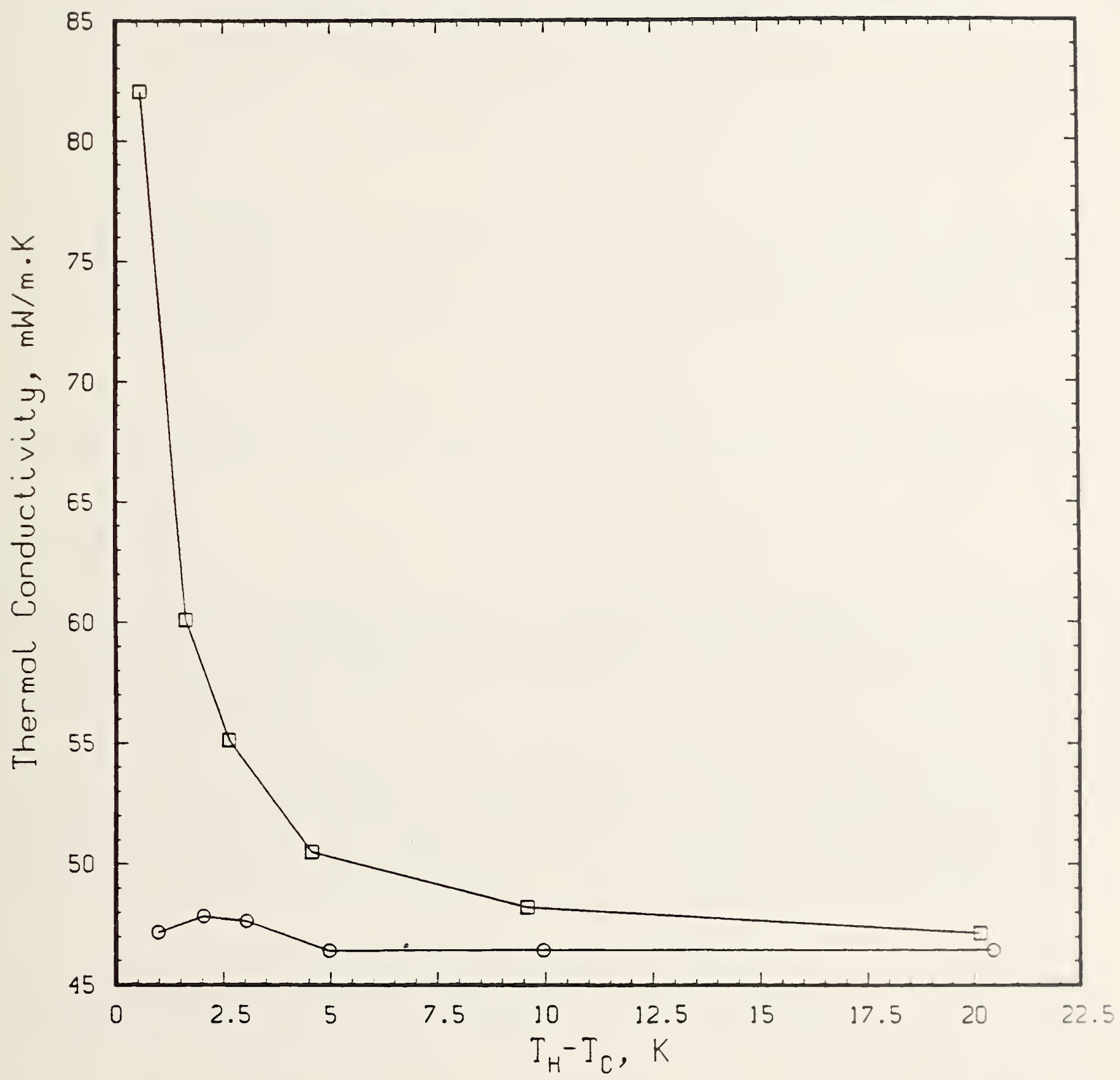

Figure 4. Thermal conductivity of an insulating specimen versus temperature difference as determined by the average surface temperature (circles) and the single thermocouple on each surface (squares) for the lower specimen in the single-sided mode of operation. 

Appendix C: A Modified Digital PID Temperature Controller

for Thermal Properties Measurements*

Jerome G. Hust, B. James Filla, and David R. Smith

Chemical Engineering Science Division

National Bureau of Standards

Boulder, Colorado

\section{Abstract}

A modified digital PID temperature controller for thermal properties measurements is described. Data are presented to illustrate the approach to equilibrium and the degree of stability at equilibrium. The controller is being used to control the heating elements of a high temperature guarded hot plate to within approximately $10 \mathrm{mK}$.

Key words: derivative control, digital computer control, integral control, proportional control, thermal properties, temperature controller, digital PID controller.

\section{INTRODUCTION}

Thermal properties testing often requires a high degree of temperature stability over long periods of time to achieve accurate results. For example, steady-state thermal conductivity guarded-hot-plate and heat-flow-meter apparatus require stabilities in the $10 \mathrm{mK}$ range to produce accuracies on the order of one percent.

In the past these stabilities were obtained either by waiting long periods of time with constant power input or with analog controllers. With the advent of computerized automation, digital controllers were introduced. Digital computer controllers allow considerably more flexibility in the design of controller logic, because software can be used to perform complicated functions that are virtually impossible to accomplish with hardware.

This paper describes a proportional-integral-derivative (PID) controller that is being used to control the temperature of the heating elements in a recently completed high temperature guarded-hot-plate apparatus [1] at the National Bureau of Standards, Boulder, Colorado.

* Contribution of the National Bureau of Standards, not subject to copyright in the U.S. 
GENERAL

The basic equation for a PID controller is

$$
m=m_{0}+K\left(e+\frac{1}{\tau_{I}} \int_{0}^{t} e d t+\tau_{D} d e / d t\right)
$$

where $e$ is the controller input error signal, $m$ is the controller output signal, $m_{0}$ is the controller bias, $t$ is $t i m e, K$ is the proportional gain, $T$ is the integrator time constant, and $\tau_{D}$ is the differentiator time constant. The latter three parameters are usually considered to be constants set by the operator to optimize the controller operation for a specific application.

In a digital computer control system the input error signal is sampled at discrete times rather than continuously as in an analog system. To accommodate discretely sampled error signals eq (1) is replaced by the approximation,

$$
m_{i}=K\left(e_{i}+\frac{1}{\tau_{I}} \sum_{j=1}^{i} t_{c} e_{j}+\tau_{D}\left(e_{i}-e_{i-1}\right) / t_{c}\right)
$$

where $t_{c}$ is the time between sampled error signals and the subscript i denotes the current reading.

In addition, the operation of the controller can be improved by making the control parameters dependent on the magnitude of the input error signal. For example, with respect to the proportional gain, it is desirable to have a high value of gain when the error signal is large and a smaller value of gain near the set point. This allows a rapid approach to equilibrium with robust control. Alternatively, the proportional control becomes more quiescent near the setpoint, stabilizing the controlled output variable, $\mathrm{m}$. This feature is especially important on control loops where both the error signal fluctuation and the controller output fluctuation must be minimized.

An approach opposite to that used for proportional gain adjustment is taken with respect to the integral gain adjustment, where integral gain is defined as $1 / \tau I$. If a fixed integral gain adjustment, optimized near the setpoint, is used in a digital controller it will work well near the setpoint. However, a large positive setpoint change will result in a large error signal and rapid growth of the integrator sum. This reset windup can cause severe setpoint overshoot and oscillation. The adverse effects of reset windup can be minimized if integral gain is very small for large values of $e_{i}$. As the setpoint is approached, the value of integral gain is increased until it reaches an optimum value. This run-time adjustment of control parameters results in controller operation based primarily on proportional control when $e_{i}$ is large and on integral control when $e_{i}$ is small. 
The time required to achieve system stability can be reduced through the addition of derivative control so long as the error signal is relatively free of noise. Using this criterion, one can argue that derivative gain should be zero when $e_{i}$ is within the noise band of the system and adjusted to some optimized value when the error signal is sufficiently larger than the nolse band. This allows the derivative control to operate normally when the system is approaching equilibrium, but prevents it from magnifying noise in the error signal during steady-state operation at the setpoint. As with each of the other modifications, this allows the controller to operate with optimum parameter settings both during the approach and at achievement of system equilibrium. In a software-based control system such behavior is easily incorporated into the control logic. These concepts, when incorporated into eq (2), result in eq (3),

$$
m_{i}=K K_{p} e_{i}+\sum_{j=1}^{i} t_{c} e_{j} K K_{I} / \tau_{I}+K K_{D} \tau_{D}\left(e_{i}-e_{i-1}\right) / t_{c}
$$

The digital controller used in the NBS guarded hot plate is based on eq (3) with the following functional forms for $K_{P}, K_{I}$ and $K_{D}$ :

$$
\begin{aligned}
& K_{p}=\left(1-\left(1-K_{p 1}\right) \exp \left(-\left(e i / S_{p 1}\right)^{2}\right)\right)\left(1-\left(1-K_{p 2}\right) \exp \left(-\left(e_{i} / S_{p 2}\right)^{2}\right)\right) \\
& K_{I}=\exp \left(-\left(e_{i} / S_{I}\right)^{2}\right) \\
& \left.K_{D}=-\left(1-\exp \left(-e_{i} / S_{D}\right)^{2}\right)\right)
\end{aligned}
$$

where $K_{P 1} K_{P 2}, S_{P 1}, S_{P 2}, S_{I}$, and $S_{D}$ are constants, along with $K$, $\tau_{I}$, and $T_{D}$, to be determined by optimizing the controller operation.

These functional forms are illustrated in Figure 1.

\section{OPTIMIZATION OF THE PARAMETERS}

The optimization procedure for a control system involving a large number of parameters can be frustrating unless a systematic approach is used. The following approach has been found to simplify the optimization task: 
A. Using proportional control only, with $\mathrm{K}_{\mathrm{P}}$ set equal to unity, find

1. the maximum value of $K, K_{m i n}$, that produces no overshoot in the controlled variable. Also determine the stable value of the error signal, $e_{0}$, at this gain.

2. the value of $\mathrm{K}, \mathrm{K}_{\mathrm{max}}$, that produces constant amplitude oscillations. Also determine the period of these oscillations, $\tau_{p}$.

3. the standard deviation of the error signal, $\sigma_{n}$, at stability without feedback control other than a bias to maintain stability.

B. Acceptable adjustment of the PID control can be obtained as follows:

1. Set $S_{p 2}$ and $S_{D}$ equal to four times the standard deviation $\sigma_{n}$, and $S_{I}$ to $2 e_{0}$.

2. Set $K$ to $K_{m a x} / 2, K_{P 1}$ to $K_{m i n} / K$, and $K_{P 2}$ to 0.95 .

3. Set $\tau_{I}$ to $1.2 \tau P$.

4. Set $\tau_{D}$ to produce an acceptable rate of change of the controlled variable at the maximum error signal.

5. Set $S_{p} 1$ such that the approach to the setpoint is as rapid as possible while maintaining acceptable overshoot.

\section{RESULTS}

To illustrate the characteristics of the modified digital controller, results are presented as obtained from the bottom auxiliary heater of the NBS high temperature guarded-hot-plate apparatus. This plate is constructed of alumina with a thickness of $2.5 \mathrm{~cm}$, a diameter of $25.4 \mathrm{~cm}$, and a total mass of $3.2 \mathrm{~kg}$. The heater element is powered by a programmable 275 watt direct current power supply. The control sensor, mounted on the outer edge of the heater plate, is a platinum resistance thermometer with an ice point resistance of 100 ohms. The thermometer current ranges from 0.5 to $1.5 \mathrm{milliamp}$ depending on the set point temperature. The sensor voltage and current are determined with a $51 / 2$ digit DVM.

Figure 2 shows the initial approach to the setpoint, $356.15 \mathrm{~K}$, for a large initial offset signal. Note the rapid approach to equilibrium without significant oscillation on the scale of this graph. Figure 3 shows the control band as final equilibrium conditions are approached. 
Automation of the apparatus using this control algorithm has eliminated the need for time-intensive operator interaction with the instrument. Concurrently, system control is achieved that equals or exceeds the most sensitive manual operation presently obtainable with this apparatus. Because of the high degree of adaptability and the resulting robust yet delicate control obtained with this algorithm we feel that it could be quite useful in a variety of digital computer control applications.

\section{REFERENCES}

1. Hust, Jerome G.; Filla, B. James; Hurley, James A.; and Smith, David R., An automated High Temperature Guarded-Hot-Plate Apparatus for Measuring Thermal Conductivity of Insulation Between 300 and $800 \mathrm{~K}$, to be published as a National Bureau of Standards Report. 


\section{List of Figures}

Figure 1. Graphical representation of the functional forms $K_{p}, K_{I}$ and $K_{D}$.

Figure 2. Typleal initial approach to equilibrium after a step setpoint change for the bottom auxiliary plate of the NBS high temperature guarded hot plate apparatus.

Figure 3. Typlcal deviations from the set point following the initial approach to equilibrium for the bottom auxiliary plate. 


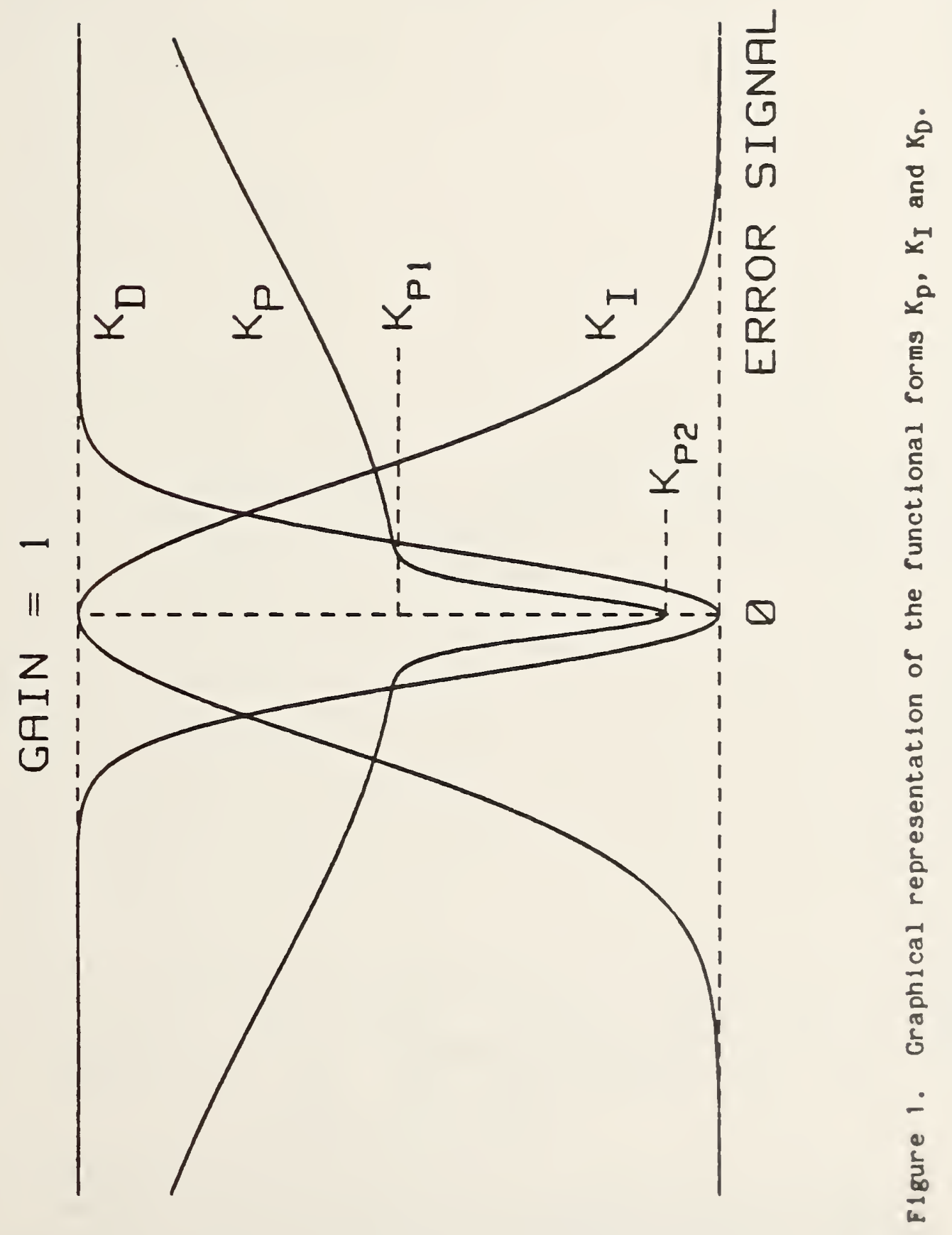




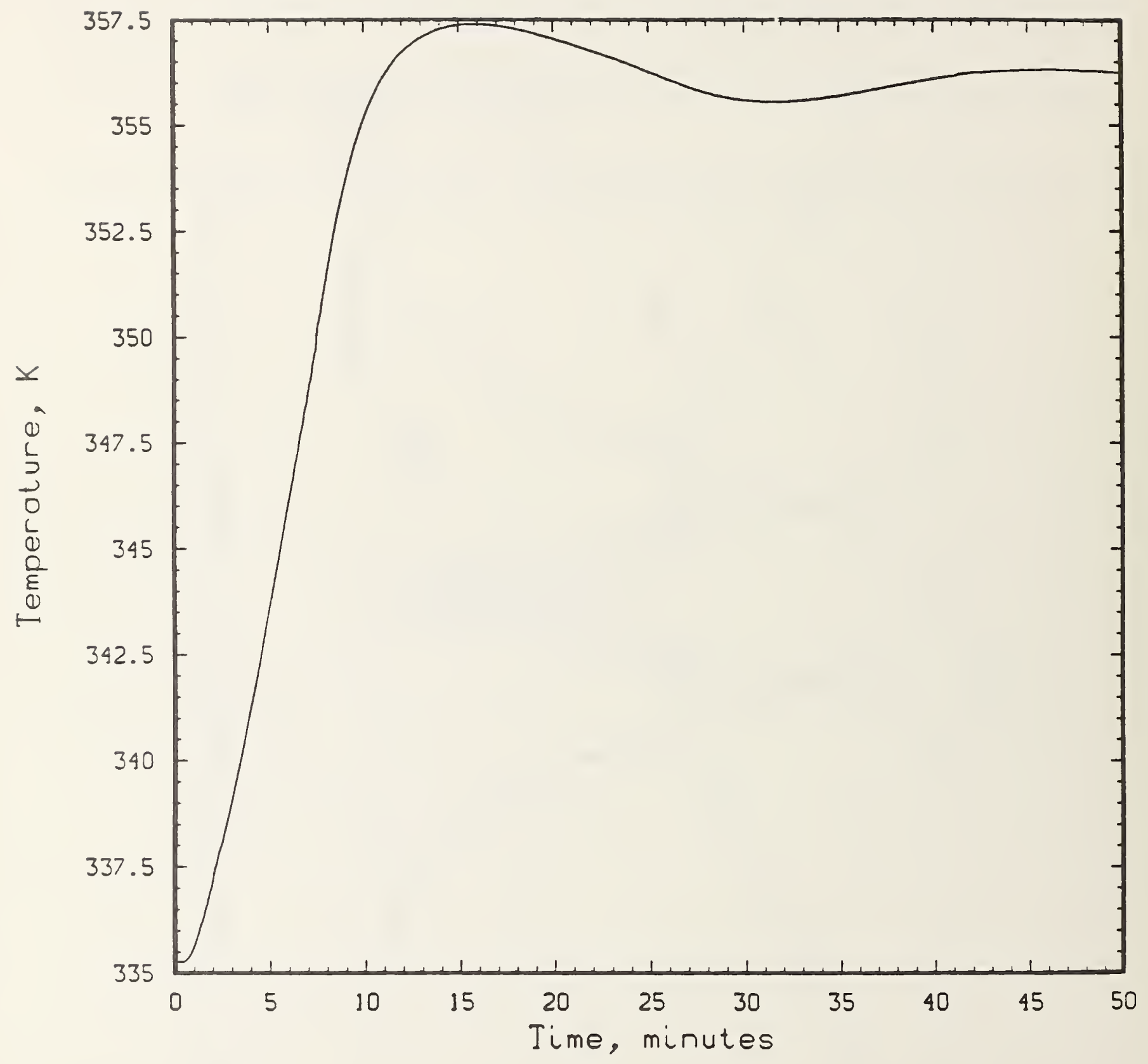

Figure 2. Typical initial approach to equilibrium after a step setpoint change for the bottom auxiliary plate of the NBS high temperature guarded hot plate apparatus. 


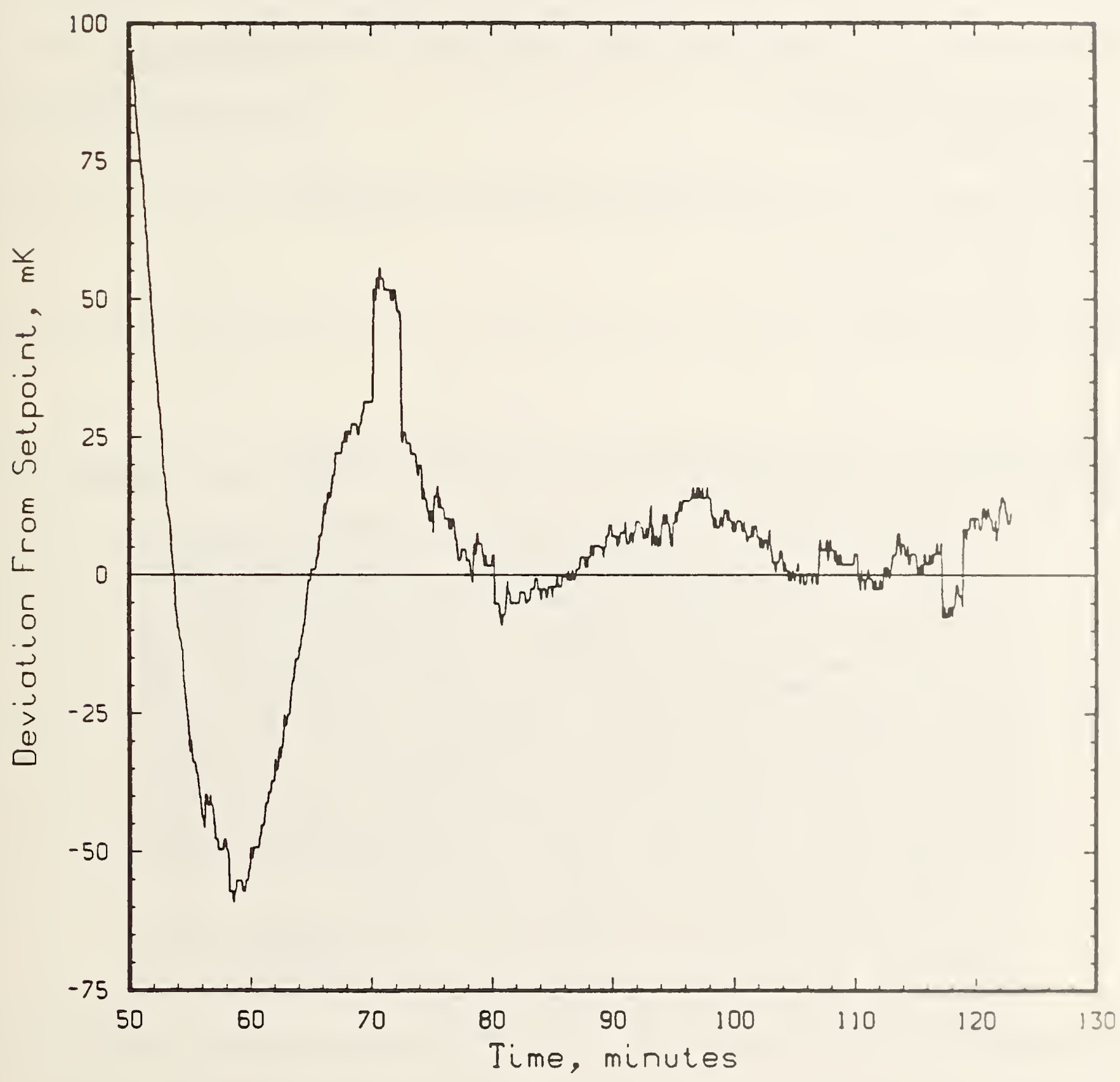

Figure 3. Typical deviations from the set point rollowing the lnitlal approach to equilibrium for the bottom auxiliary plate. 
SHEET (See instructions)

4. TITLE AND SUBTITLE

AN AUTOMATED HIGH-TEMPERATURE GUARDED-HOT-PLATE APPARATUS FOR MEASURING APPARENT THERMAL CONDUCTIVITY

5. AUTHOR(S)

Jerome G. Hust, B. James Filla, James A. Hurley, and David R. Smith

6. PERFORMING ORGANIZATION (If joint or other than NBS, see instructions)

NATIONAL BUREAU OF STANDARDS

DEPARTMENT OF COMMERCE

WASHINGTON, D.C. 20234

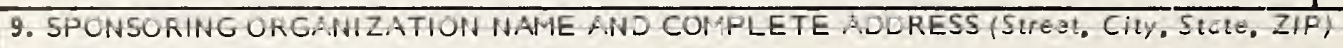

Department of Energy

Oak Ridge Operations

P.O. Box E

Oak Ridge, TN 37831

10. SUPPLEMENTARY NOTES

Document describes a computer program; SF-185, FIPS Software Summary, is attached.

11. ABSTRACT (A 200-word or less factual summary of most significant information. If document includes a significant bibliography or literature survey, mention it here)

An automated guarded-hot-plate apparatus was designed and built to meet the requirements of ASTM Standard Test Method C-177 for measuring the thermal conductance of thermal insulation. Apparent thermal conductivity has been measured with this apparatus in the range from 40 to $100 \mathrm{~mW} /(\mathrm{m} . \mathrm{K})$ at mean temperatures from 300 to $750 \mathrm{~K}$, in environments of air and helium, at pressures ranging from atmospheric pressure to roughing-pump vacuum. The apparatus is controlled by a desk-top computer. A thermocouple device of novel design more accurately senses the average temperature over the surface of each heater plate. An improved algorithm for the control sequence leads to more stable heater powers and specimen temperatures. Initially it brings the system rapidly to a temperature setpoint with minimal overshoot. It also permits highly sensitive control of the plate temperatures in later phases of the measurement sequence when thermal stability of the specimen boundaries is very important in measuring the thermal conductivity with high precision. This algorithm has enhanced the performance of both the high-temperature and the low-temperature guarded-hot-plate apparatus at this laboratory. The apparatus can be operated at either constant hot-plate temperature or constant heater power.

overall uncertainties of apparent thermal conductivities at atmospheric pressure are $2 \%$ at $300 \mathrm{~K}$ and $5 \%$ at $750 \mathrm{~K}$ when measuring conductivities in the range from 40 to $100 \mathrm{~mW} /(\mathrm{m} . \mathrm{K})$. The apparatus will be valuable in development of new Standard Reference Materials of low conductivity and for higher temperature ranges, and is being used in comparative interlaboratory measurement programs.

12. KEY WORDS (Six to twelve entries; alphabetical order; capitalize only proper names; and separate key words by semicolons) automated control system; guarded-hot-plate apparatus; high temperature; meantemperature sensor; thermal conductivity; thermal insulation; thermocouple device

13. AVAILABILITY

Unlimited

For Official Distribution. Do Not Release to NTIS

Order From Superintendent of Documents, U.S. Government Printing Office, Washington, D.C. 20402.

14. NO. OF PRINTED PAGES

134

15. Price

X] Order From National Technical Information Service (NTIS), Springfield, VA. 2216I 

